\title{
Utility reforms and performance of the urban water sector in Africa
}

Citation for published version (APA):

Mbuvi, D. (2012). Utility reforms and performance of the urban water sector in Africa. [Doctoral Thesis, Maastricht University]. Maastricht University. https://doi.org/10.26481/dis.20121019dm

Document status and date:

Published: 01/01/2012

DOI:

10.26481/dis.20121019dm

Document Version:

Publisher's PDF, also known as Version of record

\section{Please check the document version of this publication:}

- A submitted manuscript is the version of the article upon submission and before peer-review. There can be important differences between the submitted version and the official published version of record.

People interested in the research are advised to contact the author for the final version of the publication, or visit the DOI to the publisher's website.

- The final author version and the galley proof are versions of the publication after peer review.

- The final published version features the final layout of the paper including the volume, issue and page numbers.

Link to publication

\footnotetext{
General rights rights.

- You may freely distribute the URL identifying the publication in the public portal. please follow below link for the End User Agreement:

www.umlib.nl/taverne-license

Take down policy

If you believe that this document breaches copyright please contact us at:

repository@maastrichtuniversity.nl

providing details and we will investigate your claim.
}

Copyright and moral rights for the publications made accessible in the public portal are retained by the authors and/or other copyright owners and it is a condition of accessing publications that users recognise and abide by the legal requirements associated with these

- Users may download and print one copy of any publication from the public portal for the purpose of private study or research.

- You may not further distribute the material or use it for any profit-making activity or commercial gain

If the publication is distributed under the terms of Article $25 \mathrm{fa}$ of the Dutch Copyright Act, indicated by the "Taverne" license above, 


\title{
Utility reforms and performance of the urban water sector in Africa
}

\author{
Dissertation \\ to obtain the degree of Doctor at Maastricht University, \\ on the authority of the Rector Magnificus Prof. dr. L.L.G. Soete and \\ in accordance with the decision of the Board of Deans, \\ to be defended in public on Friday 19 October 2012.
}

By

Dorcas Mbuvi 


\title{
Supervisor:
}

Prof. dr. Pierre Mohnen

Co-Supervisors (in alphabetical order):

Dr. Klaas Schwartz (UNESCO-IHE, the Netherlands)

Prof. dr. Sergio Perelman (Liège University, Belgium)

\author{
Assessment Committee: \\ Prof. dr. Bertrand Candelon (chairman) \\ Dr. David Saal (Aston University, United Kingdom) \\ Dr. Jaap W.B. Bos \\ Dr. Jan Hoffer (Vitens Evides International)
}

ISBN 9789086662760

Copyright (C) Dorcas Mbuvi, 2012

All rights reserved. No part of this publication may be reproduced, stored in a retrieval system, or transmitted in any form, or by any means, electronic, mechanical, photocopying, recording or otherwise, without the prior permission in writing, from the author.

Publisher: Boekenplan, Maastricht, the Netherlands 


\section{Acknowledgments}

My dream of owning a house seemed tenable this summer after I visited a colleague in the Czech Republic. Not only did she design her home but she built it manually and largely, on her own. I couldn't help thinking though of what I will go through to become a home owner. Building one's home is exciting but challenging. An aspiring home owner needs to make lasting innovative decisions on what, how, where and when to build. S/he needs to identify, collaborate and maintain (non)professional links with several stakeholders. My PhD journey, interestingly, paralleled this process.

Like my colleague, I developed different sketches of my preferred home proposals in line with the municipality (gemeente)'s building codes and safety regulations. Prof. dr. Chris de Neubourg, Dr. Mindel van de Laar and Dr. Franziska Gassmann, thank you very much for your review and approval of the final building plan and more so, for your ensuing intellectual support. Ad, AnaMaria, Annemarie, Anouk, Danny, Erik, Eveline, Floortje, Herman, Howard, Janneke, KCIS management, Lutz, Marc, Mieke, Susan, Wilma and the entire MGSoG and UNU-Merit management, I would like to heartily thank you for making this planning and construction process, possible.

The quality of this process and all subsequent developments was assured, but not without the constant oversight by my creative and objective architects. I am deeply indebted to Prof. dr. Pierre Mohnen, Prof. dr. Sergio Perelman and Dr. Klaas Schwartz for your inspiring criticism, advice and guidance through the entire process. You taught me how to scholarly handle complex building challenges and introduced me to the world of political economy and productivity research. Thank you for introducing me to other inspiring home owners and encouraging me to join related networks. I would like to profoundly thank my co-authors Dr. Kristof de Witte and Achraf Tarsim. I learned a lot from our fruitful discussions and your valuable feedback. I am very grateful for the insightful comments I received from various conference, summer school, seminar and research tutorial participants.

During the construction process, one needs to identify and liaise with reliable quantity surveyors, engineers and material suppliers, etc. I am very grateful to the National Water \& Sewerage Corporation management and team for their valuable support through the months that I visited Uganda in 2008 and 2009; and for allowing me access the entire Service Areas' (urban water utilities') operational information. Thank you Dr. William Muhairwe, Dr. Silver Mugisha, Mahmood Lutaaya, David Isingoma, Peter Twesigye, Beat Nabacwa and Dr. Martin Kalibbala, among others. Thank you Stephen Baryahirwa (UBoS) and Chris Azuba (DWD) for your priceless help.

My profound gratitude goes to the National Water Supply and Sanitation Council in Zambia for facilitating my entire data collection exercise in Zambia in 2009. Thank you Kelvin Chitumbo, Mugeni Mulenga, Peter Mutale, Rose Tembo, Josephine Goma, Dr. Simone Klawitter and many more (....). I would like to thank my key informants in both Uganda and Zambia for their willingness and time to meet and make an in-depth interview with me.

For the best outcome, an aspiring home owner needs to make time to consult and exchange notes with colleagues, friends, etc. Ajay, Alejandro, Andrea, Bianca, Biniam, Britta, Carlos, Daniel, Filbert, Florian, Francesca, François, George, Geranda, Giorgio, Hibret, Ibrahim, Ilire, Iman, Irina, Jennifer, Jessie, Jinjin, Jocelyn, Joe, Julieta, Kristine, Kwaku, Luciana, Margaret, Marina, Marion, Martin, Mahmut, Melissa, Metka, Mumbi, Omar, Oxana, Ozge, Pascal, Paula, Patricia, Peter, Renée, Robert, Ruediger, Sachin, Samyukta, Sepideh, Shuan, Tatevik, Zina, Zipporah and 
many more..., I am very grateful for the interesting talks, discussions and laughs we had! I really enjoyed your company during the $\mathrm{PhD}$ academy events and birthday parties among other functions. I am very grateful for the joyful moments I shared with my cohort-members; Sonila, Lenka, Cheng, Siu Hing, Kwan and Nyasha. For the few times we spent together over dinners or during the writing camp in Italy, you managed to temporarily wipe away my construction troubles. For that and many more.., I say thank you.

A home builder hopes for a stress-free construction period and especially, to enjoy visiting the construction site. The office was always fun to come to, thanks to Nevena, Sonila, Cheng, Hamton, Guney, Richard, Eleni and Yesuf. We joked a lot, exercised together in the gym and motivated each other in diverse ways. I'll treasure the moments we shared in our common construction site. Notably, I am indebted to Prof. dr. Luc Soete and Prof. dr. Bart Verspagen for the great and inspiring working environment. I am very grateful to my housemates (overtime); Britta, Eline, Franzi, Katerina, Kitty, Luisa, Nadja, Neri and Oana. You kept a smile on my face each time we spent in the house.

After construction, the final product needs inspection and approval by the constructor, architect(s) and the municipality. Thereafter, different permits are issued including the Certificate of Occupation. I am grateful to my assessment committee chair and members for their critical review, suggestions and approval of my finished home. I am thankful to the various anonymous journal and book chapter referees for their critical evaluation and suggestions that helped improve the quality of the different leased (and yet-to be leased) studios. I am deeply grateful to the MGSoG's facilitation of my construction project.

Similar to my Czech colleague, doubts, worries and fears during the construction journey, were inescapable. Dad, mom, my dear sisters and brothers; mere words cannot explicitly describe what you mean to me. You stood by and encouraged me through the journey. Nasema asante saana. To my entire family, thank you for walking with me. Grand-pa and ma, your constant care and love were my strength. This dissertation is a dedication to you, my invaluable family. To God almighty, asante saana kwa yote uliyonitendea! 


\section{Contents}

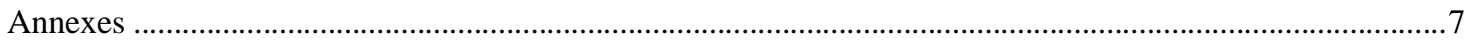

Figures

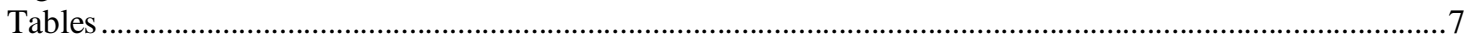

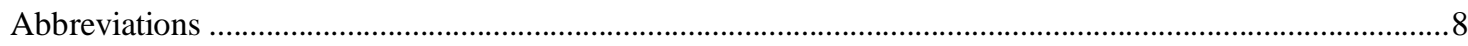

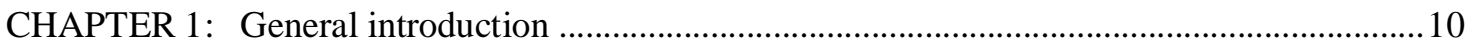

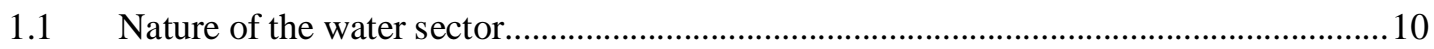

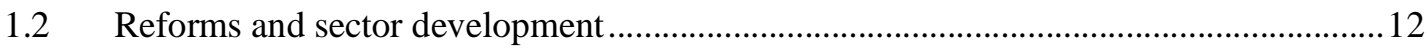

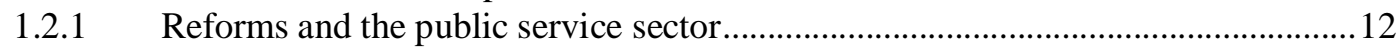

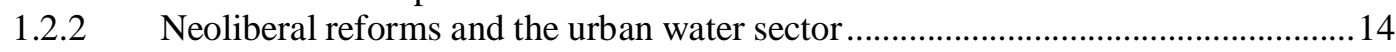

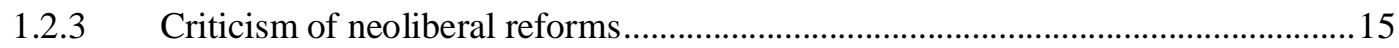

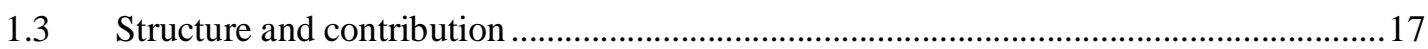

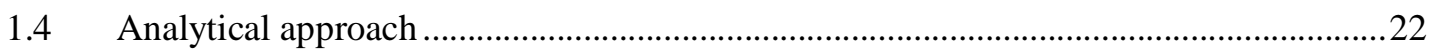

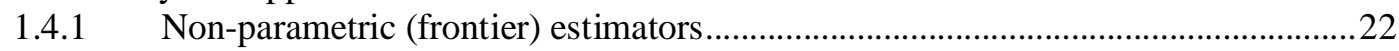

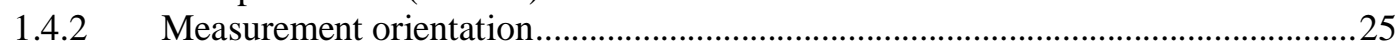

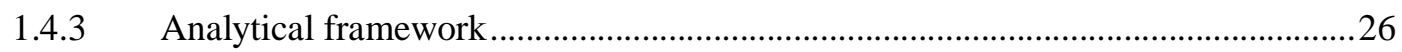

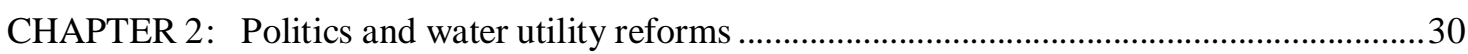

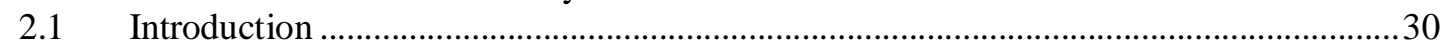

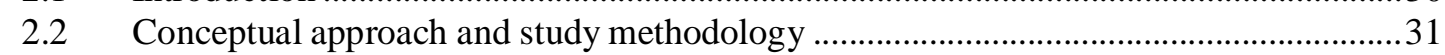

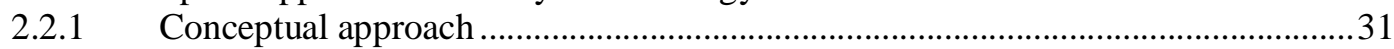

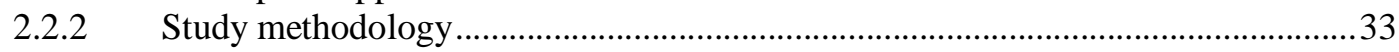

2.3 Global water politics: From infrastructure to institutions ...............................................34

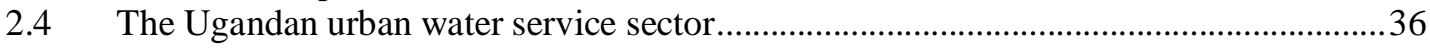

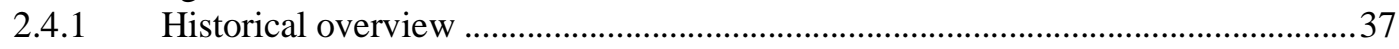

2.4.2 Increased demands for quality water supply services .............................................39

2.5 Politics in the Ugandan urban water sector: Nature and implications.............................41

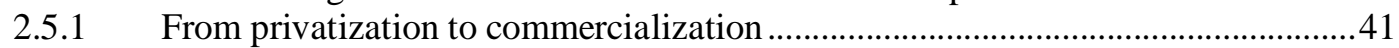

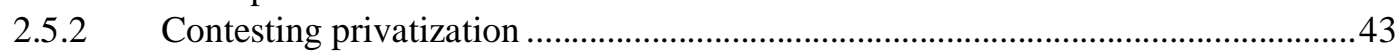

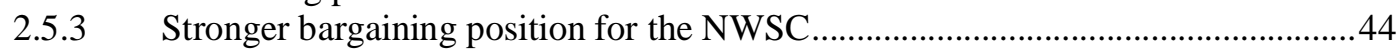

2.6 Global politics in shaping national reform trajectories...................................................46

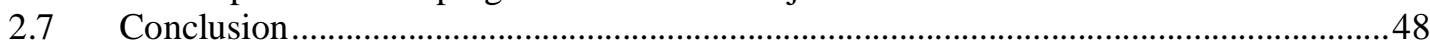

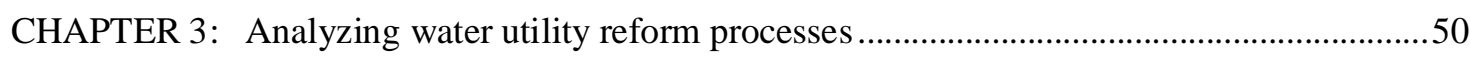

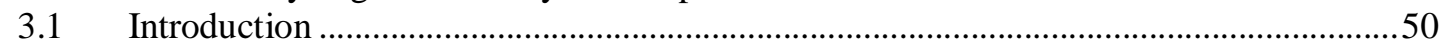

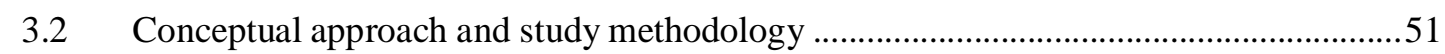

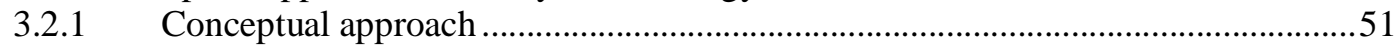

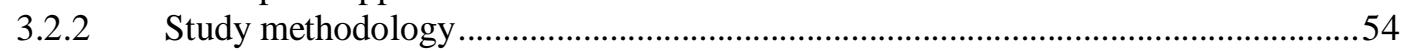

3.3 Governance shifts in the Zambian urban water services sector .........................................55

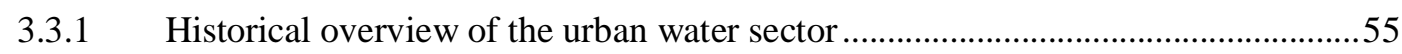

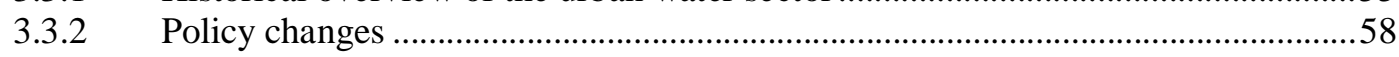

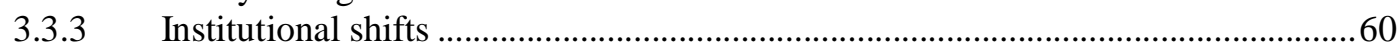

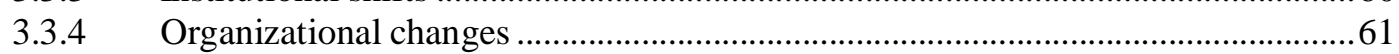

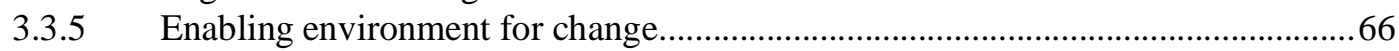

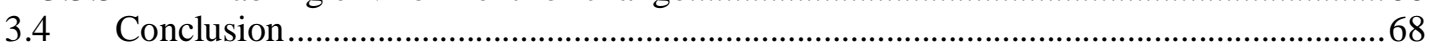

CHAPTER 4: Managerial ownership and urban water utilities efficiency …………....................... 70

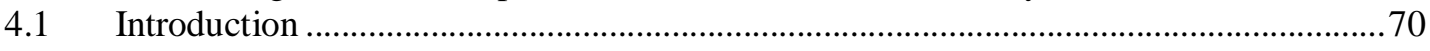

4.2 Managerial ownership and water utilities performance ………..................................... 73 


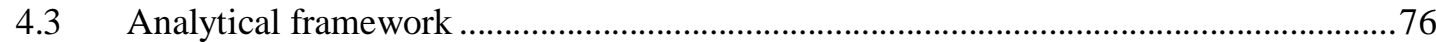

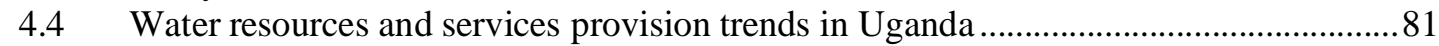

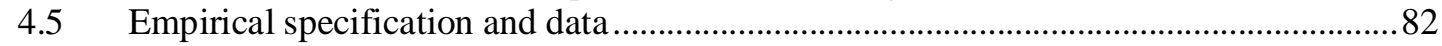

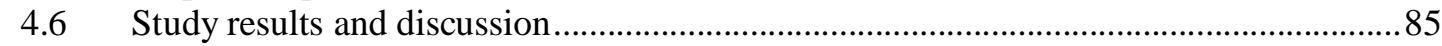

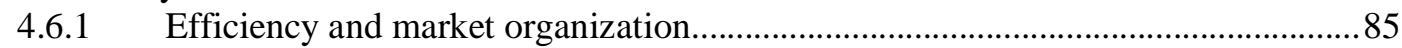

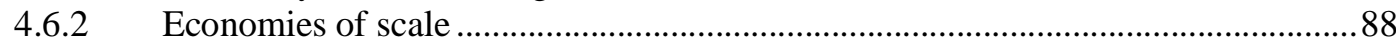

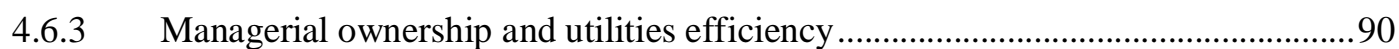

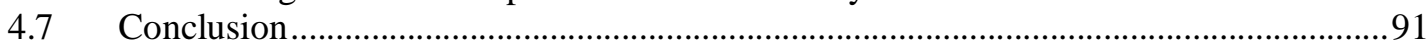

CHAPTER 5: Productivity and productivity determinants in urban water supply ..........................95

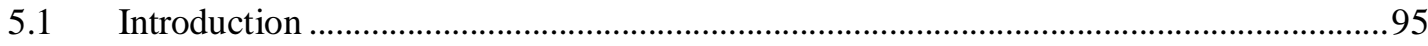

5.2 Productivity and productivity change assessment …….................................................98

5.2.1 Productivity assessment ………………..............................................................98

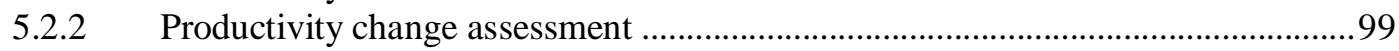

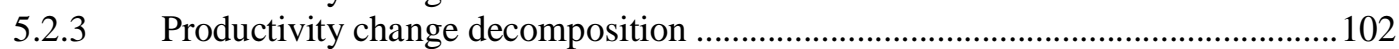

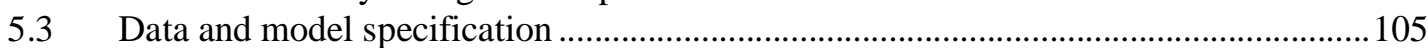

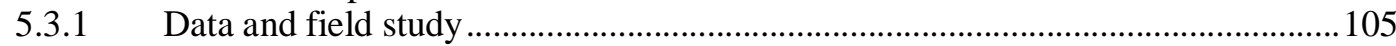

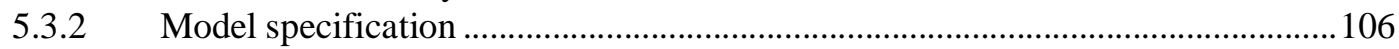

5.4 Performance changes in the Ugandan and Zambian urban water sectors ......................111

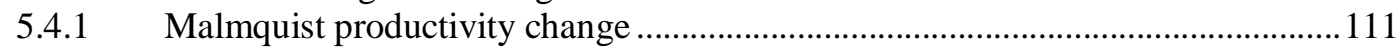

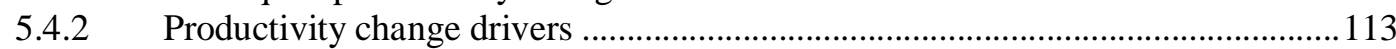

5.4.3 Urban water utilities productivity and effectiveness ............................................117

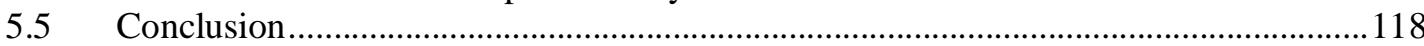

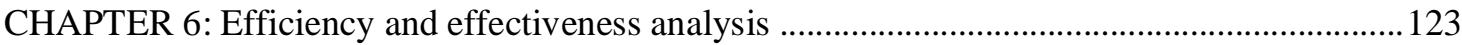

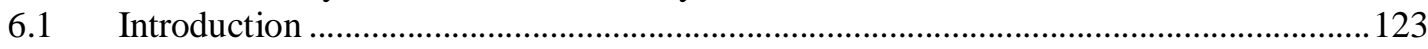

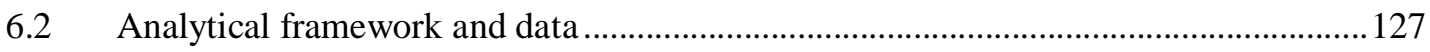

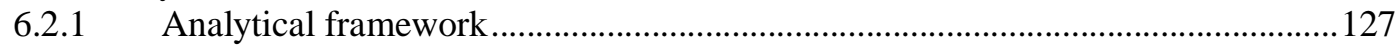

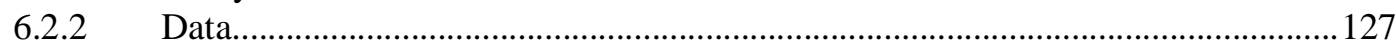

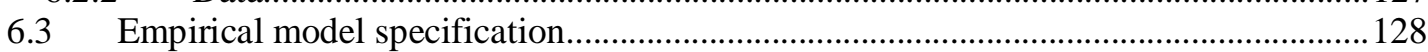

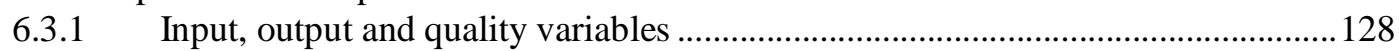

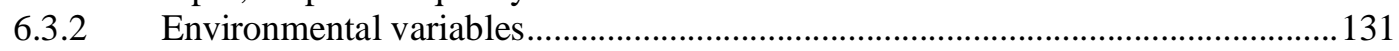

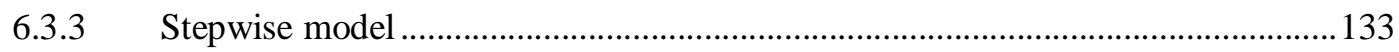

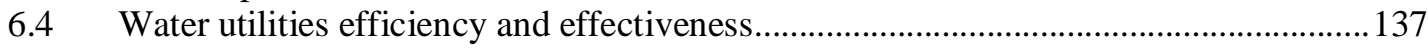

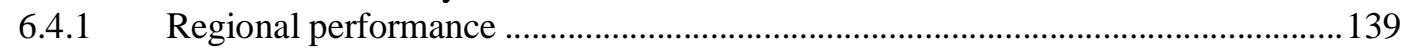

6.4.2 Explaining utility performance differences......................................................... 140

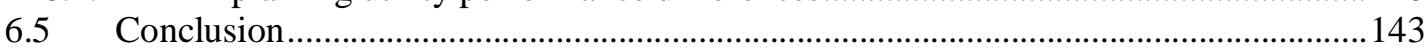

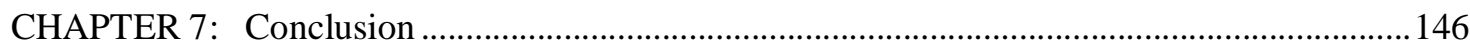

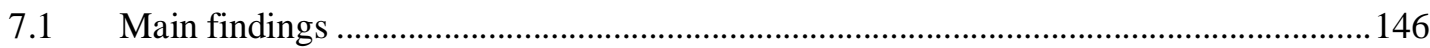

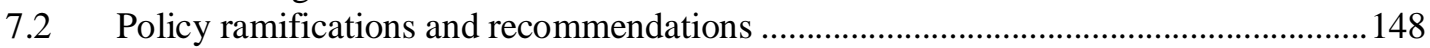

7.3 Study limitations and avenues of further research .......................................................... 150

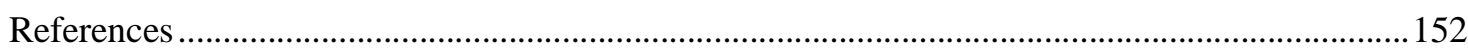




\begin{abstract}
Annexes
Annex 4.1: Earlier studies on the role of ownership on urban water supply utilities efficiency..94

Annex 5.1: Technical efficiency estimates ............................................................................. 121

Annex 5.2: Metering efficiency, technical efficiency and biennial productivity growth ........... 122

Annex 5.3: Water losses, technical efficiency and productivity growth...................................122

Annex 5.4: Network density, technical efficiency and productivity growth ............................122

Annex 5.5: Urban water services coverage and productivity growth ...................................... 122

Annex 6.1: Quality variables used in urban water distribution efficiency studies ..................... 145
\end{abstract}

\title{
Figures
}

Figure 3.1: An illustration of governance structures' interdependence .......................................54

Figure 4.1: An illustration of the metafrontier technique* ...................................................8 80

Figure 5.1: Biennial Malmquist productivity index framework .............................................. 101

Figure 5.2: Metering efficiency and urban WUs productivity ............................................. 115

Figure 5.3: Water losses and urban WUs productivity .......................................................... 116

Figure 5.4: Network density and urban WUs productivity .................................................... 116

Figure 5.5: Service coverage and urban WUs productivity .................................................... 117

Figure 5.6: Urban WUs catch-up rates............................................................................... 118

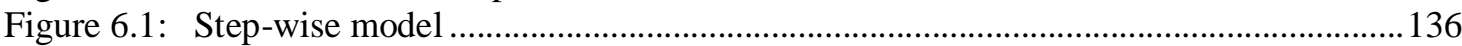

Figure 6.2: Urban water utilities performance - stepwise analytical framework ..................... 137

\section{Tables}

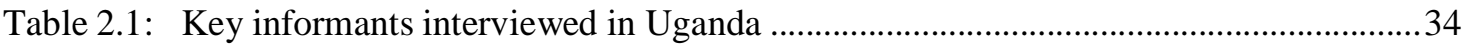

Table 2.2: NWSC Performance, 1998 - 2010 .....................................................................45

Table 3.1: Key informants interviewed in Zambia................................................................55

Table 3.2: Water service providers in Zambia, 1997 - 2009 .....................................................64

Table 3.3: Urban water sector performance in Zambia, 2002 - 2010 ......................................65

Table 3.4: Shifts in policies, institutions and organizations in the Zambian urban water ............66

Table 4.1: Input, output and environmental variables summary statistic ...................................85

Table 4.2: Bias-corrected technical efficiency estimates (DEA VRS) * ...................................87

Table 4.3: Yearly bias-corrected technical efficiency estimates * ..............................................8 88

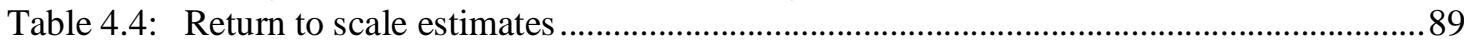

Table 4.5: Efficiency determinants...............................................................................91

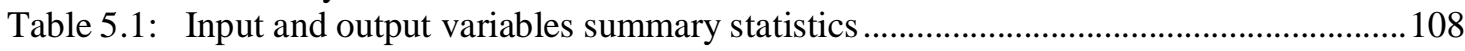

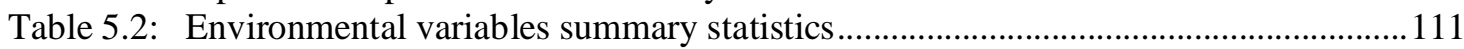

Table 5.3: Biennial Malmquist productivity index and components ........................................ 113

Table 5.4: Exogenous variable categorization......................................................................... 114

Table 6.1: African urban water utilities summary statistics, 2006 .........................................129

Table 6.2: Utilities technical efficiency, effectiveness and potential input capacity estimates.. 139

Table 6.3: Mean performance estimates per region .............................................................. 140

Table 6.4: Technical efficiency determinants................................................................... 142

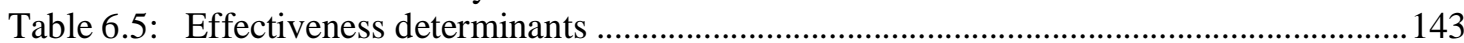




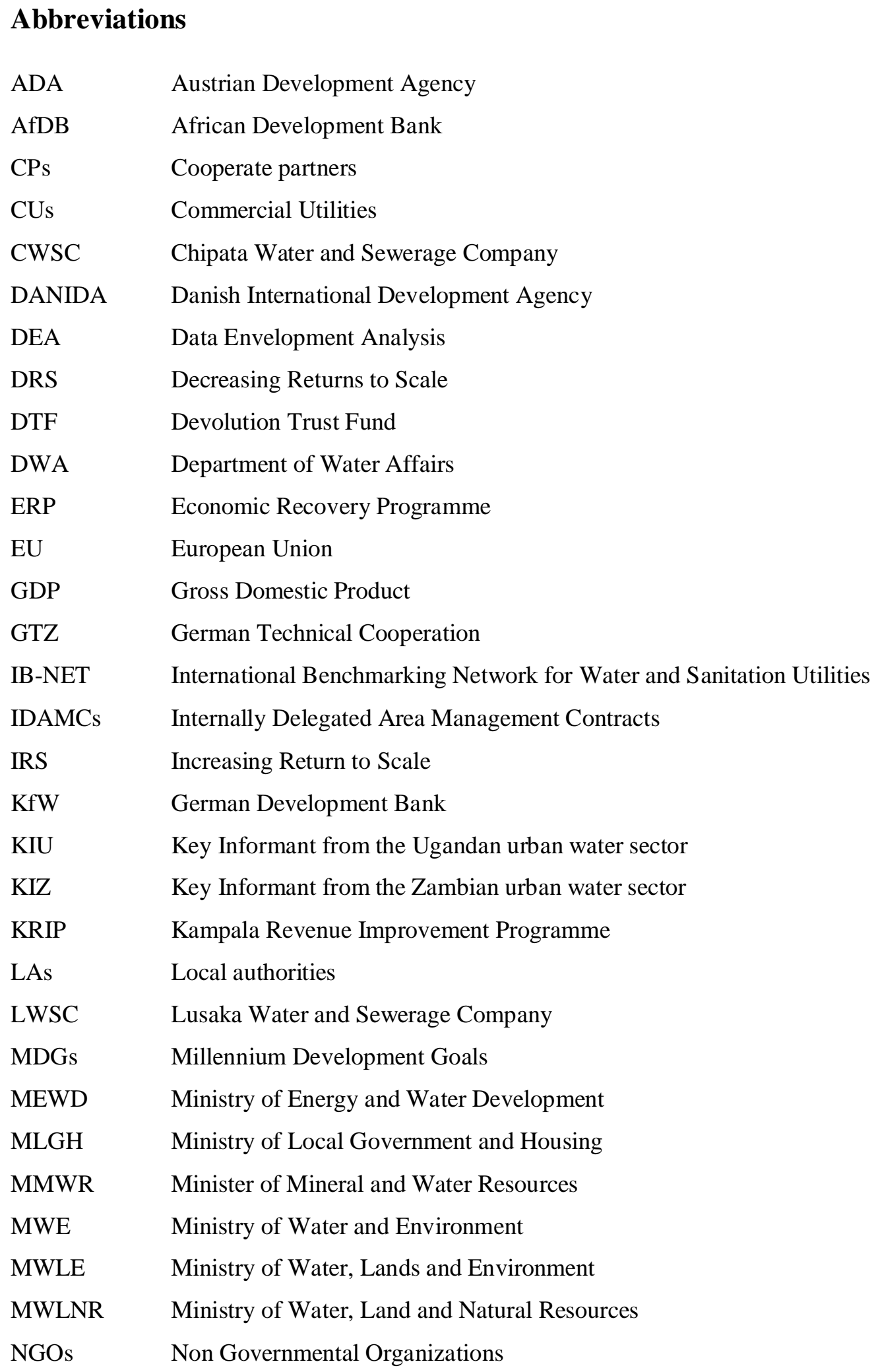




$\begin{array}{ll}\text { NIRS } & \text { Non Increasing Returns to Scale } \\ \text { NWASCO } & \text { National Water Supply and Sanitation Council } \\ \text { NWSC } & \text { National Water and Sewerage Corporation } \\ \text { PCU } & \text { (Inter-ministerial) Programme Coordination Unit } \\ \text { PSP } & \text { Private Sector Participation } \\ \text { PtIs } & \text { Part-time Inspectors } \\ \text { SAPs } & \text { Structural Adjustment Programmes } \\ \text { SLG\&A } & \text { Service level guarantees and agreements } \\ \text { UN } & \text { United Nations } \\ \text { UNICEF } & \text { United Nations Children's Fund } \\ \text { US\$ } & \text { American dollar } \\ \text { UWASNET } & \text { Uganda Water and Sanitation NGO Network } \\ \text { VRS } & \text { Variable Returns to Scale } \\ \text { WASAZA } & \text { Water and Sanitation Association of Zambia } \\ \text { WSDG } & \text { Water Sector Development Group } \\ \text { WSP-WB } & \text { Water and Sanitation Programme of the World Bank } \\ \text { WUs } & \text { Water Utilities } \\ \text { WWGs } & \text { Water Watch Groups }\end{array}$




\section{CHAPTER 1: General introduction}

\subsection{Nature of the water sector}

The water sector encompasses the main water uses for ecological and socio-economic development. The sector explores, abstracts, distributes, regulates and manages water resources - for use in ecosystem services' sustenance, waste disposal, human consumption and in production (agriculture, energy, transport, manufacturing, tourism, etc). At the domestic level, water consumption in sufficient quantity and quality is a basic human right (United Nations, 2010) indispensable for a healthy and productive life. ${ }^{1}$

The water sector is unique in a number of ways. First, water resources are finite and transverse territorial boundaries. They are hardly confined to particular hydro-geological spaces. Their allocation given their centrality to human life, use and sustainability is thus, susceptible to politics among diverse stakeholders (Savenije, 2002). Moreover, their valuation is tied to the incurred extraction, conveyance and disposal costs that vary from one region to another (Kessides, 2004).

Second, large storage dams, treatment plants and network mains are used to convey, often against gravity, piped water services to connected customers (Savenije, 2002). To establish these systems, utility managers have to incur lump-sum capital investments, upfront (Kessides, 2004). These investments however, face long-term recovery periods of about 10-15 years (for plant and machinery), 20-30 years (for buildings) and 50-60 years to recover costs incurred in dam construction and land acquisitions (Twort et al., 2000). By implication, utility managers can not rely only on the existing customers to fully recover the costs, but also, future demand. Besides, it is not easy to relocate or reuse installed water supply assets for other functions (Blanc, 2008). This makes the industry, especially in developing countries, unattractive to private entrepreneurs who seek immediate returns on investments (Prasad, 2008; Swyngedouw, 2009).

\footnotetext{
${ }^{1}$ To sustain human life, the World Health Organization recommends the daily use of 25 liters of water per capita (Kessides, 2004).
} 
Third, two-thirds of water supply costs are tied to network pipe-installations (Abbott et al., 2011). ${ }^{2}$ This makes it costly to duplicate systems and open the industry to product (and to some extent, entry) competition. The low value added in water distribution makes it impractical to rely on centralized distribution systems (Savenije, 2002; Nauges and van den Berg, 2007). The latter are common for example, in electricity provision where decentralized transmission systems are more expensive (Savenije, 2002). In the water sector, decentralized systems are commonly organized around regional or municipal monopolies (Prasad, 2007).

Fourth, water supply is largely an economic service or a private good whose consumption depends on customers' abilities to pay (see Nickson, 1999). Moreover, this prevents possible free-rider behaviors. On the other hand, governments incur high opportunity costs for such exclusivity in service provision (Savenije, 2002). This makes safe water supply, especially in low income regions, a merit good or service for which universal coverage by governments is necessary in order to mitigate costs due to negative externalities such as the overexploitation or pollution of underground reserves by nonstate or individual providers (Kessides, 2004). ${ }^{3}$

Provision of merit goods (water, sanitation, security, health care and basic education, etc) is however prone to X-inefficiencies (Santhakumar, 1998). Owing to information asymmetries between governments and citizens among other problems, governments can impose specific consumption levels against public will - e.g., use of far-located water taps, schools and health centers. Such arrangements can thus mask non-optimal solutions and decisions by governments (Walsh, 1995). These traits, among others, have continually sparked debates around the sector's development, organization and regulation, as well as, shaped policy strategies across different countries, globally.

\footnotetext{
${ }^{2}$ For an historical technological overview of the water sector since the early $19^{\text {th }}$ century and its subsequent NorthSouth transfer, see Braadbaart (2009), Abbott et al. (2011) and Angelakis et al. (2012).

${ }^{3}$ For an extensive discussion on merit goods and services, see Schwartz (2006) and Schouten (2009).
} 


\subsection{Reforms and sector development}

\subsubsection{Reforms and the public service sector}

Reforms are a product of both desirable and feasible ideas or models of change that are designed through complex multi-leveled networks and applied at varied speeds and extents across sectors and countries (Pollitt and Bouckaert, 2002). Change is triggered, among other aspects, by complexity, skills advancement, environmental threats (or opportunities) and chance incidents (Rusaw, 2001).

First, as organizational structures become complex, devolved multi-leveled governance is preferred to ease activities' coordination and communication. Second, advancements in organizational aptitude (human, technological and financial) can create opportunities based on which different models of change can be realized. Third, environmental threats (e.g., climate change) and opportunities (e.g., globalization) can pressure, facilitate and maintain change. Fourth, chance incidents or crises can expose deficiencies in systems that subsequently provoke change.

In the process of change, organizational structures and processes are transformed or reengineered with an aim of getting more outcomes with fewer resources (Pollitt and Bouckaert, 2002). This however, comes at a cost in overcoming resistant forces from interest or ignorant groups such as labor unions (Mwanza, 2001). Resistance may arise when new ideas contradict or detract existing sector developments (Pollitt and Bouckaert, 2002). In other cases, proposed changes can entail colossal capital investments or encounter time-delays in amending or establishing supportive legislative frameworks. On the other hand, policy makers can agree on the need to change but not how and to what extent to change (Pollitt and Bouckaert, 2002).

Since the 1970s, public sector delivery processes and structures have faced distinct paradigm shifts denoted variedly as "post-bureaucratic", "managerialism", "new public management", "market-based public administration", "entrepreneurial government" and "new public policy" (Lynn, 1998; Manning, 2001). These neoliberal ideologies form part of the models of change that were advanced as an alternative to the classical Weberian 
public sector decision making model, since the 1940s (Lane, 2000). These paradigm shifts occurred first in the western countries with the exception of Germany, Greece, Japan and Spain; and latter by the early $21^{\text {st }}$ century, in Africa, South America and South Asia (Hood, 1995; Ferlie and Steane, 2002).

Before the 1940s, centralized public bureaus and enterprises invested in, owned and regulated key basic service infrastructure including energy, health, postal, security, transport, water and sewerage services (Hood, 1995; Manning, 2001; Ferlie and Steane, 2002; Laking and Norman, 2007). The intention was to crowd-out private sector monopolies and spearhead efficient and equitable socio-economic development (Lane, 2000).

By the mid $20^{\text {th }}$ century however (Lane, 2000; Frant, 1998), public choice proponents accused the traditional public bureaucrats of rational choice tendencies based on selfinterests' pursuit. Public bureaus were blamed for over-appropriation of sector budgets in ways that would assure economic rents to the bureaucrats rather than the public/customers. Since it was not in their interest to cut costs devoid also, of competitive pressures, public enterprises suffered X-inefficiencies/slacks. Principal-agent adherents pointed to the possible rent-seeking activities of regulated monopolies that would seek favorable regulation of entry, tariffs and standards in favor of certain products from nonautonomous public regulators. Given information asymmetries between public enterprises (agent) and the government/ministry (principal), agents were able to extract monopoly profits. Moreover, principals indirectly paid-off all related transaction costs incurred by the agents.

The neoliberal agenda (Durant, 2001; Feldheim, 2001) seeks to first, bust and downsize bureaucracies or Weberian governance frameworks. This strategy assumes that individuals are rational self-interested decision makers whose motives to work are driven by economic goals. As such, contracts should be used to seal economic relations between workers and their employers. To avoid public choice problems among politicians, contracts have been advanced on the other hand, to assure a closer match between 
customer demands and public servants' interests (Frant, 1998; Lynn, 1998). Second, devolve rather than centralize responsibilities to local authorities, private or nongovernmental organizations. Unlike public managers that (Liou, 2001: 513) "have legally based purposes, operate by vast system of rules and regulations and serve clientele who have rights and privileges set in legislation rather than market-driven interests", it is easier as noted by Liou, for non-public managers to command and effect change among lower echelons.

Third, deregulate public service sectors in attempts to reduce costs and user prices; and increase firms' entry, merger, acquisitions and innovativeness. Fourth, expose public service sectors to (quasi)competition and fifth, focus on results rather than procedures. For more information on how these neoliberalistic strategies have been defined and implemented divergently across varied sectors globally, see Hood (1991: 1995), Osborne and Gaebler (1992), Lane (1994), OECD (1995), Borins (1997), Burki and Perry (1998), Kernaghan (2000), Manning (2001), Ferlie and Steane (2002), Parker and Saal (2003), Pollitt (2003).

\subsubsection{Neoliberal reforms and the urban water sector}

In the urban water sector, different accounts of the neoliberal reforms exist (see Walsh, 1995; Sheshinski and Lòpez-Calva, 2003; Harvey, 2005; England and Ward, 2007; Nauges and van den Berg, 2007; Prasad, 2007). For an overview of the origins and nature of these neoliberal reforms, see Harvey (2005) and England and Ward (2007) among other authors.

In Africa, since the late 1980s, "there (was) is little prospect for improvement unless the water supply and sanitation sector (engaged) engages in broad institutional reforms with the aim of increasing financial autonomy and providing greater transparency" (Mwanza, 2001:3). The sector faced operational deficiencies, political meddling and regulatory difficulties that necessitated urgent remediation (Mwanza, 2001, see also Chapters 2 and $3)$. 
To address these problems, different neoliberalistic policies were proposed and advanced variedly across water sectors in the continent (Nickson, 1999; Larbi, 2001; Kessides, 2004; Estache, 2005; Van Dijk, 2006; Baietti et al., 2006; Nyarko, 2007; Schwartz, 2008).

First, there was a move to corporatize state-owned utilities with a preference for lean and autonomous organizational forms that were legally separated from the state and managed by visible managers. Notwithstanding their intrinsic social missions, these corporatized entities were founded on (or expected to operate under) clear commercial objectives and bound by specific corporate laws. Second, there have been attempts to employ mutually voluntary, incentive-based and time-bound contracts. These have been used to inject competition - through bids or benchmarking and assure efficient, transparent and accountable service delivery.

Third, the use of contracts has made it easy to engage private entrepreneurs in the sector. Privatization among other approaches ${ }^{4}$ has been advanced in attempts to boost innovation, technical capacities and fiscal austerity in the water sector. Closely linked to this move is the attempt to fourthly, decentralize decision making and service provision mandates to local governments/municipalities. This has been seen as a way to devolve resources, increase systems' flexibility and grow a customer-centered service. Fifth, independent regulation or regulation by contracts has been adopted as a way to protect both customers and service providers. Sixth, policy making has been retained in the hands of the government or the department/ministry responsible for water resources development.

\subsubsection{Criticism of neoliberal reforms}

While meaningful, neoliberal agendas have widely been criticized. First, downsizing efforts have been blamed for the loss of jobs and tied social security benefits, family or

\footnotetext{
${ }^{4}$ See Schouten (2009) for a detailed analysis of these private sector participation developments and shifts in the water sector since the $1990 \mathrm{~s}$.
} 
community fragmentation, insecurity, low-self esteem, depression and mistrust of public service sectors and organizations (Feldheim, 2001; Hood 1995). Whereas retrenchment exercises have prioritized firms' economic interests, they have ignored other noneconomic and non-concrete rewards that motivate employees to engage in paid work such as self satisfaction linked to affective, self sacrifice and normative motives (Feldheim, 2001).

Second and especially when dealing with (naturally) non-competitive sectors such as the water supply, both public and non-public providers are susceptible to rent seeking behaviors, predominant with monopolies (Savoie, 1995; Castro and Heller, 2009). Besides, the inconsistent empirical evidence on the superiority of private over public enterprises in these non-competitive environments (see also section 4.2) does not explicitly support market over non-market solutions to public failure. Indeed, the invisible hand of markets does not always result in optimal resource allocation (Jreisat, 2001).

Third, neoliberal policies especially in the water and sanitation sector "did not emerge from an analysis of the particular problems and requirements of these services, but have rather been imposed on the sector in the course of the process of economic globalization" (Castro and Heller, 2009:24). Similar views have been made by Schouten (2009) who notes that neoliberal policies have not been based on scientific evidence but a set of beliefs. That is, lean is better than overstretched government departments, more business is better, market mechanisms bring change and private sector participation results in cheap, faster and long term private capital and management expertise.

For a continent that is presently challenged by mounting urbanization and climate variability pressures (UNICEF and WHO, 2011) however, neoliberal ideals have certainly broadened the managerial choices available to water sector stakeholders in Africa. These have been instrumental in the water sector's efforts to meet increasing demands for safe, reliable and sustainable services. 
This thesis restricts itself to the urban water supply sector in Africa. We define safe (potable, quality, etc) water coverage to entail mainly, piped water supplies within 200 meters from observed customer meters (MWLE, 2006: 2007). This is because, unlike non-piped sources, quality standards for most piped water systems are guaranteed by a centralized entity at the national or sector level.

\subsection{Structure and contribution}

Drawing from the above discussion, urban water sectors, like any enterprise, are susceptible to dynamic change. To explain this phenomenon, it is worthwhile to examine how and why reforms - from their introduction to implementation, are unpredictable. Besides, policy makers need to understand the potential implications of such unpredictability on reform processes (extent, pace, etc) and outcomes.

Chapter 2 examines the nature and influence of two overriding 'water politics' domains in shaping neoliberalist utility reforms since the mid 1990s. Using the case of the Ugandan urban water sector, the chapter discusses how actors at the global water politics and at the politics of water policy, i.e., at the sovereign national level, interacted and transformed reform paths in the sector. We conclude that utility reforms are inherently political in nature. This political process is most pronounced when organizational changes, as part of the reforms' implementation plan, are demanded. As the reforms unfold, the bargaining power and influence of involved actors change. This in turn results in changing reform trajectories.

The use of 'multi-level politics' in analyzing reform processes provides useful insights on potential reform dynamics. These mask however, the underlying governance structures and shifts that respectively, influence and characterize restructuring processes. We provide in Chapter 3 a framework for analyzing governance shifts in the water sector. We identify four mutually dependent governance structures that practitioners and academics can use to further analyze reform processes in the water sector. We argue that policies, institutions, organizations and infrastructure or resources matter in discerning multi-layered governance shifts, given reforms. Indeed and given the existing 
infrastructure (technology, resources, etc), policies, institutions and organizations interact constantly across global, inter-state, national and local water politics' domains.

This interaction is translated and manifested in both major and minor governance shifts. Major shifts engender changes in policies, institutions, organizations or actual infrastructure (resources or technological choices) that trigger innovativeness in the form of new structures or increased diversity, in other governance structures. This can be exemplified by the creation of a regulatory agency that follows the enactment of an Act of Parliament. Minor shifts embody changes in one of the governance structures that may not lead to changes in other elements.

In other words, while Chapter 2 analyses the political processes in the reforms' introduction and implementation, Chapter 3 looks at how these neoliberal reforms have changed existing governance structures in recipient countries. In particular, we focus on the predominant governance structures' mix at given periods of time for the Zambian urban water sector. We concentrate on the neoliberalistic reforms that were advanced in the sector between 1993 and 2010. The chapter concludes that, over time, the momentum of involving private sector organizations in the provision of water services in Zambia has diminished. However, private sector institutions have increasingly been incorporated in 'public' service provision modalities.

On the other hand, the continued advancement of these organizational and institutional governance structures across the urban water sector urge for performance assessments in the sector. This is urgent for the developing countries and Africa in particular that have in the past, received limited empirical attention. Some rare exceptions are studies based on data provided by supra-national organizations such as the World Bank - through its International Benchmarking Network for Water and Sanitation Utilities (IB-NET), ${ }^{5}$ or similar regional initiatives such as the South East Asian Water Utilities Network benchmarking program. ${ }^{6}$

\footnotetext{
${ }^{5}$ The project is implemented in partnership with the World Bank and the Water and Sanitation Program. It is funded by the Department for International Development of the United Kingdom, see http://www.ib-net.org.

${ }^{6} \mathrm{See} \mathrm{http://www.seawun.org/benchmarking.}$
} 
We focus on the role of organizational shifts in service provision on urban water utilities (hereafter, WUs) performance. To provide services following the reforms, governments can abstract, treat and distribute potable water through a department within or a public company owned by, the ministry of water or the local government. In this case, the department or the public company is dependent on the government for infrastructure financing and regulation. The government sets and enforces services' user fees and other output-quality standards.

Second, governments can unbundle services production (raw water abstraction, treatment and storage) from distribution and delegate the latter to public companies or private operators. In the former case, a public-public partnership is constituted in which the government owns the assets, approves tariffs and regulates the public company's operations at arms-length. The public company manages established assets and is free to externally source additional funds besides public subsidization. Regarding the latter case, a public-private partnership is arranged between the government and a private operator. Asset ownership remains the mandate of the government but tariff setting and operations' funding are a priori provided (and continuously renegotiated) in the contract.

Thirdly, water production and distribution mandates can be delegated to a private operator through a (non)renewable license to operate. This limits government's role in assets ownership, financing and tariff setting to operations' (i.e., service level, quality, etc) regulation. The latter can be arranged formally in the form of an independent agency/department or informally within the ministry.

Both public-public and public-private partnership arrangements typify the case of the Ugandan urban water sector, discussed in Chapter 4. To assess their role on the sector's performance, we first examine the technical efficiency differences between both utilitygroups. Secondly, we use diverse utility-specific exogenous factors to explain the differences. We further examine to what extent utilities could improve their efficiency by optimizing their scales of operation. Performance is considered in light of the key urban 
water sector objectives that are to universally increase qualitative water coverage and subsequently, enhance utilities revenue.

We rely on a two-staged bias-corrected metafrontier based on the data envelopment analysis (hereafter, DEA) estimators. We find the public-private compared to the publicpublic owned utilities less technical output-efficient. The kind of managerial ownership adopted by WUs in Uganda positively and significantly influences subsequent utilities' efficiency. However, public-public owned utilities operate largely under decreasing returns to scale while the average public-private owned utility operates under an increasing return to scale region. While there is no consensus in literature on the preferable optimal operation sizes for urban WUs (Carvalho et al., 2012), we find diseconomies of scale to happen after service coverage of about 29,868 customers.

Besides knowledge on utilities technical performance and given present efforts towards the Millennium Development Goals (here after, MDGs) attainment by 2015, it is imperative to explore and understand potential productivity dynamics among WUs in Africa. More so, it is central for utility managers, regulators and other interested policy makers to ascertain and explain diverse productivity determinants. The latter provide useful insights on what, why and how productivity at the sector or WU levels could be improved, given the reforms.

Chapter 5 examines and explains the productivity of two urban water sectors in Africa: Uganda and Zambia (i.e., for WUs under public ownership). Since the mid 1990s as discussed in Chapters 2 and 3, ideologically comparable water sector reforms were introduced in both sectors. While both restructuring processes differ in their implementation and outcomes, analogous neoliberalistic reform strategies were advanced in both countries. These were in attempts to not only increase WUs' efficiency, but also, their effectiveness (i.e., total productivity).

Inter-temporal productivity trends and their drivers are examined by a bootstrapped biennial Malmquist productivity measure. We find, given the reforms, that utilities' 
technical inefficiency decreased over time. Zambian utilities are found to be more efficient but at the expense of high water losses. Urban WUs in Uganda experience a large productivity growth, thanks to increased catch-up rates. A negative correlation is observed between investments in urban water distribution and productivity growth.

Chapter 5 provides interesting insights on utilities productivity growth due to technical change, technological efficiency change and scale changes. The chapter however, does not identify which productivity changes are due to effectiveness besides efficiency increases. Yet, urban WUs, as with any other firm, ought to operate both efficiently and effectively. In the case of Africa where universal safe water coverage remains a major challenge (WSP-WB, 2009), the need for effectiveness without resources wastage (efficiency) is evident. Chapter 6 provides a step-wise approach for evaluating WUs' efficiency and effectiveness. Taking the case of urban WUs in Africa, we estimate in a first step, utilities' technical efficiency. In a second step, we examine utilities' effectiveness in meeting existing customer demands for drinking water services within their licensed service areas.

The difference between (in)efficiency and (in)effectiveness is decomposed in a third step. To ascertain and explain the extents to which utilities utilize available resources to achieve complete effectiveness, we take the ratio of utilities' effectiveness to technical efficiency. We refer to this ratio as utilities' 'potential input capacity' (PIC). PIC values equal to unit imply exact resource allocation. PIC values of more than one denote excess use of existing resources due to inefficiency problems. To attain 100 percent effectiveness, related utilities do not need extra inputs but efficiency improvement. PIC values of less than one on the other hand, reflect resources deficiency. Related utilities are efficient but unable to attain complete effectiveness that demand additional input use. A final step explores country specific (e.g., income per capita), sector specific (e.g., regulation) and utility specific (e.g., density economies) inefficiency and ineffectiveness determinants. These steps are described in detail in section 6.3.3. 
We find WUs to suffer technical inefficiency rather than ineffectiveness challenges. This finding is consistent across the varied African regions (East, West, South, etc). By implication, these utilities do not need extra inputs to entirely extend services in their operational areas, but the efficient use of their available resources (capital, labor, etc). To increase utilities technical efficiency and effectiveness levels nonetheless, countries' economic advancement is significant.

\subsection{Analytical approach}

This section introduces the non-parametric approach that is used in Chapters 4 to 6 . The qualitative approach employed in Chapters 2 and 3 is detailed in sections 2.2.2 and 3.2.2.

\subsubsection{Non-parametric (frontier) estimators}

In assessing urban WUs' performance, binary (partial productivity) ratios of output to input are often used. Binary ratios are preferred as they are easy to measure and to understand (see Smith, 1990). Nonetheless, they face a number of limitations that hinder full performance assessments (Bogetoft and Otto, 2011). First, binary measures compare different utilities against a single indicator while ignoring other equally important and/or competing indicators. Second, they do not take into account any heterogeneity across utilities and compare firms assuming constant returns to scale. By construction, smallscaled utilities appear less productive than the large-scaled utilities on variables with scale economies (and vice versa for variables with diseconomies of scale). Besides, due to Fox's paradox, lower values for all considered binary combinations do not necessarily imply low total productivity for a specific utility since utility managers can as well utilize sub-processes that have relatively higher productiveness than others (Bogetoft and Otto, 2011).

Multidimensional frontier techniques provide an endogenously weighted approach where an entity is compared to a best practice. To estimate the production technology (or frontier of the best practice observations), two benchmarking approaches are presented in literature. Both require information on utilities' input and output variables. A frontier is 
then fitted on top of these data points and a measure of (technical) inefficiency is taken as the distance between the estimated frontier and the specific data points or observed utilities (Coelli et al., 2003). Nonetheless, both methods face different advantages and disadvantages. Econometric frontier models define a priori functional form on the sampled data (e.g., Cobb-Douglas, Translog, Fourier), have a well established statistical inferencing framework and it is easy to incorporate environmental or discretionary variables into the models (Fried et al., 2008). The former property in particular is however problematic as the functional form or the direction in which inputs are converted into outputs, is often unknown.

On the other hand, even though researchers can test and reject models in which chosen input or output vectors have the wrong sign - relative to those that are predicted by economic theory, a wrong (functional form) specification could lead to biased results (Yatchew, 1998). Non-parametric models such as DEA (used in this thesis) do not assume a functional form on the data, are flexible and easy to compute through linear programming techniques. They are nonetheless, deterministic ${ }^{7}$ in nature (Charnes et al., 1978; Banker, 1984).

DEA is a data-oriented linear programming technique for summarizing performance, in the form of indices, among complex ${ }^{8}$ utilities (Cooper et al., 2011). The technique defines a production technology that embodies a piecewise convex surface that envelopes all sample utilities. Performance is thus measured relative to this production technology, referred also, to as the best-practice frontier. Dissimilar to econometric techniques that rely on the central predispositions of observed data, DEA estimators are further preferred for their ability to reveal more insightful data relations that are otherwise masked (Cooper et al., 2011). Practitioners and academics can easily use estimated indices to assess utility performance and regulate or set different quality, quantity and price-related targets.

DEA measures and especially, those that allow production technologies to exhibit varying returns to scale were first introduced by Banker et al. (1984). Banker et al.

\footnotetext{
${ }^{7}$ Assume observed data is free of noise or measurement errors.

${ }^{8}$ Use multiple inputs to produce multiple outputs.
} 
modified - by imposing a variable returns to scale (here after, VRS) constraint, Charnes et al. (1978)'s conical hull estimators ${ }^{9}$ that assumed constant returns to scale (CRS) technologies. This made it possible to assess performance across varied service sectors (such as banking, education, transport and water industries) that are not only complex but exhibit also, diverse market sizes.

To overcome the deterministic nature of DEA, Chapters 4 to 6 apply a DEA approach that is based on a double-bootstrap procedure (Simar and Wilson, 2007). Whilst the bootstrap procedure suffers a number of limitations especially with small samples, it "currently offers the only sensible approach to inference" deterministic DEA estimators (Simar and Wilson, 2011: 250). To generate data and subsequently estimate smooth production technologies in this double bootstrap environment, different assumptions arise (see Cooper et al., 2011 and the references therein). First, the production technology is assumed to be convex (i.e., the frontier consists of convex combinations of observed input-output combinations), bounded and closed for all input and output vectors in specific identically, independently and randomly selected samples.

Related to this assumption is that of 'no free lunches'. That is, non-negative and freely disposable inputs are at least needed to produce some freely disposable outputs. Free disposability means that an output can still be produced with even more inputs or; for the same level of inputs, less outputs can be produced. These assumptions, among other properties, have widely been developed in literature (see Fried et al., 2008; Simar and Wilson, 2007: 2011) and assure consistent DEA estimators.

Besides, the double-bootstrap procedure helps us to reduce the influence of noise in data (Kneip et al., 2003). Noise can arise from measurement errors, typological mistakes or in the form of outlying or atypical observations. The bias due to noise in this stochastic nonparametric environment is computed by taking the difference between the efficiency estimates based on the 'true' unobserved variables and those based on the 'biased' observed variables (Emrouznejad and De Witte, 2010; see also Daraio and Simar, 2007).

\footnotetext{
${ }^{9}$ These estimators stemmed on Farrell (1957)'s efficiency analyses.
} 
This is estimated within the first bootstrap procedure that defines also, specific production technologies for observed utilities.

Implicitly, the double bootstrap procedure assumes a separability condition between the production inputs and outputs space (in the first bootstrap procedure) and the environmental variables space (in the second bootstrap procedure) such that the latter does not influence the shape of the technology frontier but the mean and variance of the inefficiency process. To this end, the procedure first smoothes the irregularly bounded densities of observed input and output vectors and second the technology frontier. Both (first and second) bootstrap procedures are outlined in detail in Simar and Wilson (2007 and elaborated further in Simar and Wilson 2011). They yield consistent inference parameters (confidence intervals, standard errors, etc) of the approximated estimators (Kneip et al., 2008).

To avoid extra computational difficulties inherent especially in small samples, such as, the curse of dimensionality problem (slow convergence rates with increases in input and output vectors, see Simar and Wilson, 2011), production variables in Chapters 4 to 6 are kept at minimum relative to the observed WUs. Indeed, our analyses satisfy the rule of thumb of Banker et al. (1989, see also Paradi et al., 2004) in addressing degrees of freedom problems. ${ }^{10}$ Assuming $n$ and $m$ to be the number of input and output vectors used in an analysis, the sample size $(s)$ should satisfy $s \geq \max [n \times m ; 3(n+m)]$.

\subsubsection{Measurement orientation}

We assume that urban WUs strive to maximize their outputs with given inputs. Moreover, given the prevailing need to halve by 2015 the number of persons without access to sustainable safe water systems, it is likely that African WUs prioritize outputs' expansion. As such, we adopt an output-maximization objective for the analyses in Chapters 4 to 6 . This is contrary to most productivity analyses for WUs in the development countries where service coverage deficits are not an issue. Then the problem revolves around costs

\footnotetext{
${ }^{10}$ The degrees of freedom increase with the number of observations (i.e., WUs) and decrease with the number of input and output variables used.
} 
minimization rather than services expansion. For an overview of these input-oriented (where resources are radially minimized given certain output units), other non-oriented (where both input and output vectors are simultenously and non-radially reduced and maximized) or multiplicative (non-dimensional) models, see Cooper et al. (2007: 2011).

\subsubsection{Analytical framework}

Mostly, WUs have no control over their operational scales except through acquisitions that have to be approved by a government institute. Utilities operate within predefined licensed jurisdictions and as such, there scale of operation is given. Consequently, with the existence of multi-scaled utilities across the African urban water sector, Chapters 4 to 6 assume VRS. As such, utilities' inefficiency can be explained by the prearranged scales that are not a fault of the utilities.

In a first step, DEA estimators are used to estimate the reference unobserved true production technology. For observed utilities, DEA assumes a production technology which transforms non-negative $M$ x 1 inputs ( $x$ ) into $S$ x 1 output ( $y$ ) vectors (Coelli et al., 2005). The production technology set $(T)$ for $N$ WUs $(i=1,2,3, \ldots, N)$ can be defined as:

$$
T=\left\{\left(x_{i}, y_{i}\right): x_{i}>0 ; y_{i}>0 ; x \text { can produce } y\right\}
$$

$T$ is unobserved but can be estimated $(\hat{T})$ by the DEA estimators (Simar and Wilson, 2011). An output distance function (equation 1.2) defined on an equivalently denoted (as the production technology set $T$ ) output set $\left\{\mathrm{P}\left(x_{\mathrm{i}}\right)\right\}^{11}$ is used to estimate $\mathrm{WU}_{\mathrm{i}}$ 's technical $\operatorname{efficiency}\left(\hat{\theta}=\hat{T} E_{i}\right) .^{12}$

$$
D_{o}\left(x_{i}, y_{i}\right)=\min \left\{\theta>0:\left(x_{i}, y_{i} / \hat{\theta}\right) \in P\left(x_{i}\right)\right\}
$$

\footnotetext{
${ }^{11}$ Algebraically expressed as $P\left(x_{i}\right)=\left\{y_{i}: x\right.$ can produce $\left.y\right\}=y_{i}:\left(x_{i}, y_{i}\right) \in T . P\left(x_{i}\right)$ denotes the set of all output vectors $(y)$ that can be produced by use of a given input $(\mathrm{x})$ vector.

${ }^{12}$ And $\mathrm{WU}_{\mathrm{i}}$ 's effectiveness as is the case in chapter 6.
} 
$D_{o}\left(x_{i}, y_{i}\right)$ represents the maximal radial expansion of specific outputs given existing resources. Utilities are technically output efficient $(\hat{\theta}=1)$ or effective (as discussed in Chapter 6), if they operate on or along the estimated technology $(\hat{T})$ and technically output inefficient $(\hat{\theta}<1)$ or ineffective, if they operate below $\hat{T}$. The distance $\hat{\theta}$ estimates the output shortfall reflected by the euclidean distance to the boundary of the production frontier from $\mathrm{WU}_{i}$, in a direction parallel to the output axes and orthogonal to the input axes (Daraio and Simar, 2007). ${ }^{13}$

DEA-VRS considers the following optimization problem that is solved for each of the $N$ utilities $(i=1,2,3 \ldots N)$ in $T$ periods $(t=1,2,3 \ldots T)$ :

$$
\begin{array}{cc}
\max _{\phi_{i}, \lambda_{i}} \theta_{i} & \\
\text { Constraints: } & \theta_{i} y_{i}-Y \lambda_{i} \leq 0, \\
& X \lambda_{i}-x_{i} \leq 0, \\
& \lambda_{i} \geq 0 ; \sum \lambda_{i}=1
\end{array}
$$

Where $\theta_{i}$ is a scalar variable that approximates $\mathrm{WU}_{i}$ 's technical efficiency $\left(1 / \theta_{i}\right) . y_{i}$ is the output vector for $\mathrm{WU}_{i}$ while $Y$ is the output matrix for all $N$ WUs in a given time period. $\lambda_{i}$ represents the non-negative weights while $X$ is the input quantities' vector for all $N$ WUs. $x_{i}$ is the input quantities' vector for $\mathrm{WU}_{i}$ while $\sum \lambda_{i}=1$ imposes VRS to the linear program. $1 / \theta_{i}$ gives the output-oriented technical efficiency estimates for observed WUs relative to their specific best practice technology.

While this section described the conventional DEA optimization framework, we adopted Simar and Wilson (2007)'s double bootstrap algorithm that builds on this DEA model.

\footnotetext{
${ }^{13}$ Besides these output distance function measures, other approaches including the use of hyperbolic or directional distance functions, are possible (see Cooper et al., 2011).
} 
Sections 4.5, 5.3.2 and 6.3.1 detail how different inputs and output variables were chosen and employed throughout the thesis.

\subsection{Conclusion}

To sum up this chapter, the urban water sector in most developing countries and Africa in particular has experienced different transformations with the onset of the neoliberal ideologies. Sector policy makers (and all interested stakeholders) need to understand the nature of these transformations, their influence on the existing governance structures and their role in utilities' performance improvement. This thesis attempts to diagnose and provide valuable insights to these complex issues.

To examine different angles of the reform processes, Chapter 2 looks at the politics that preceded and followed the reforms' initiation. Here, we rely on the Ugandan urban water sector, whose reform process has been highly profiled internationally since the early 2000 (see Section 2.6). Due to the political nature of the process, we find its outcomes to constitute a number of compromises among various stakeholders.

Chapter 3 examines the nature of these compromises. In particular, the chapter analyzes how the emphasis on neoliberal reform strategies influenced sectors' policies, institutions and organizations. Since comparable developments as discussed in Chapter 2 are visible in other African countries such as Ghana, Kenya, Mozambique, Namibia and Tanzania, another case study, that is, the Zambian urban water sector, is preferred. Nonetheless, similar conceptual frameworks (as outlined in Chapters 2 and 3) can be used to analyze analogous reform processes in other sectors (in Uganda, Zambia, etc) and urban water sectors across the African continent.

Common to the neoliberal reforms (as evidenced in Chapters 2 and 3) is the increased emphasis on performance improvement (cost-recovery, target achievement, efficiency increases, etc). The role of these reform elements in improving WUs' performance is variedly explored in Chapters 4 to 6 . Here, performance scores and their determinants are 
estimated and decomposed. For broader analyses of the issues, operational data from varied case studies is used. Chapter 4 focuses on the Ugandan urban water sector. Here, performance across the public-public owned and public-private owned urban WUs is discussed.

Chapter 5 compares the productivity of the public-public owned urban WUs in Uganda with that of the Zambian urban WUs. The latter utilities are also public-owned. Chapter 6 relies on a larger representative dataset of urban WUs in 21 African countries. Here, efficiency and effectiveness estimates across the utilities are estimated and decomposed. For multi-dimensional insights on utilities' performance, different modelling approaches are employed in each of these chapters (see Sections 4.3, 5.2 and 6.2 to 6.3). 


\section{CHAPTER 2: Politics and water utility reforms ${ }^{14}$}

\subsection{Introduction}

Globally over the past decades, the public sector has increasingly been subject to reforms. These changes to state structures and dynamics have increased in pace and scope more than previously experienced (Thynne, 2000). The water supply and sanitation sector has not been an exception to this proliferation of public sector reforms. In particular, the onset of neoliberalism and its emphasis on altering market-state relations has had tremendous impact in the water services sector. "Private institutions" (Bakker, 2002), "market organized production" (Swyngedouw, 2004) and "private sector ethos" (Smith, 2004) have become increasingly important in the water services sector. At the same time, these reforms though visible in many countries, have neither spread as a unitary coherent concept nor have their pursuit led to homogeneous outcomes.

Two main reasons appear to explain these heterogeneous outcomes. Firstly, neoliberal reforms that have swept through the global water services sector essentially represent broad strategic concepts that have been primarily crafted at the international policy spheres for reorganizing institutional patterns at the national water service sectors, rather than a clearly defined end-state. Secondly, neoliberalism is "path-dependent" and “contextually specific" (Brenner and Theodore, 2002:349; see also Peck, 2004).

In this chapter, we examine the politics of public utility reforms by examining the reform process of the Ugandan urban water service sector. During this reform process, some elements of a neoliberal reform agenda were ingrained in the sector while other reform aspects were strongly resisted by a coalition of key sector stakeholders. The neoliberal reform agenda that was introduced across most public sectors in the 1990s, reasserts "an old neoclassical economic argument that society functions better under a market logic than any other logic, especially a state-command one" (Purcell, 2008:13, see also sections 1.2.2 and 1.2.3). In order to stimulate economic growth and innovativeness in

\footnotetext{
${ }^{14}$ This chapter is adapted from "The politics of utility reform: A case study of the Ugandan water sector" that is already accepted for publication in Public Money and Management journal (with Klaas Schwartz).
} 
competitive sectors, market institutions are advocated for an efficient allocation of inputs and production of outputs. For a natural monopoly like the water supply sector, neoliberal reforms have been characterized by the transfer of service production and provision rights from the public to private actors and the incorporation of market institutions within the public domain.

We illustrate that the particular manifestation of these reforms in Uganda is the outcome of a protracted political process involving organizations and actors operating at different 'politics' levels. We highlight the importance of the interaction between the national urban WU and international financing agencies and the impact this interaction has had on the respective bargaining positions of the actors.

The case of Uganda is interesting for two reasons. Firstly, important institutional elements associated with neoliberalism have been incorporated within the sector since the early 2000. These elements include a strong emphasis on service provision by an autonomous organization, increased importance of cost-recovery and efficiency gains and the introduction of more business-oriented performance management strategies. Secondly, the case highlights clear shifts in the direction of reforms as the bargaining position of different actors and organizations changed over time. At the onset of the reforms in the late 1990s for instance, the government's intention was to strengthen the private sector's role in urban water provision (MWLE, 1999: 20). Despite these initial intentions however, complete private sector participation never fully materialized especially, across large towns in Uganda. Instead, reforms across the Ugandan urban water sector took the form of commercialization of the existing national public WU.

\subsection{Conceptual approach and study methodology}

\subsubsection{Conceptual approach}

To analyze the reform processes that unfolded between 1997 and 2009 in the Ugandan urban water sector, we employ the "water politics" conceptual framework (Mollinga, 2008). This framework is based on the premise that water management is inherently 
political in nature. It identifies a typology of "water politics" that stretches across four domains. Across these domains, social power relations converge, mediate and shape water management processes in and across states. The four domains comprise the (i) global water politics, (ii) inter-state hydropolitics, (iii) politics of water policy, and (iv) everyday politics.

While the four domains are largely differentiated, they are nonetheless, strongly interlinked and interact with one another. In our analysis, we focus particularly on two of these domains identified by Mollinga (2008). That is the global politics and the politics of policy at the sovereign states' level. Of importance to note is that Mollinga developed this framework to analyze politics in water resources management. In the context of urban water supply, as is our case, the domain of inter-state hydropolitics becomes less relevant as it is unlikely that water distribution systems transcend national borders. More so, this chapter does not explore the everyday politics that characterize daily social power relations at the local community levels.

Global water politics refers to water discourse, policy and tentative regulation at the international level. Actors in this political arena constitute organizations and institutions that are internationally active in the water services sector. They include among others, development banks, some national governments, UN agencies, international interest groups, international NGOs, international water management and supply companies, practitioners and academics. ${ }^{15}$ They form a "network of water policy elites" (Conca, 2006) that discusses and at times advocates policy prescriptions for reforms in the water services sector. Often anecdotes and success-stories ('best-practices') of successful providers are used to promote specific policy prescriptions (see for example ADB, 2007; Schaub-Jones, 2008; Solo, 2003).

The politics of policy on the other hand, concerns the policy processes regarding water supply services within sovereign states. Sector policies, programs and projects are "negotiated and re-negotiated in all phases, stages and at all levels, and are often

\footnotetext{
${ }^{15}$ It should be noted that in addition to these global actors, global social movements such as the social justice or antiprivatization lobby groups among others, operate also within this global domain.
} 
transformed on their way from formulation to implementation" (Mollinga, 2008:12). These transformation paths depend on one hand, on the existing sector priority areas and on the other hand, on veiled interests by external stakeholders.

The arena of global politics and that of the politics of policy are strongly interconnected. Ideas and policy prescriptions emanating from the global level are translated into national water policies or programs. Similarly, national water organizations influence the discussions and negotiations that occur at the global politics level. For a detailed overview of the four 'water politics' domains, see Mollinga (2008 and the references therein).

\subsubsection{Study methodology}

We use both primary and secondary data sources to explain the neoliberalization processes across the Ugandan urban water sector. First, qualitative in-depth interviews with the key stakeholders engaged in the Ugandan urban water supply development were carried out in September 2009 (see Table 2.1). Unlike other qualitative data collection techniques including focus groups, in-depth interviews offer detailed and clear understanding of complex or delicate phenomena as experienced by experts (Legard et al., 2003). We used both semi-structured and closed interview guides to interview the chosen key informants (referenced henceforth as KIU). Appendix 1 provides a sample of the interview guide used in Uganda.

Expert interviews lend themselves to a number of biases. For instance, they comprise the subjective opinions, perceptions or stories by the chosen interviewees. For the case at hand, we purposely selected informants to include all experts with first hand information on the urban water sector reforms and the sector. For this, we chose the key decision makers across all stakeholders in the Ugandan urban water sector. To assure the validity of and add-onto the collected interview information, we triangulated the interviewees' opinions with the related annual sector reports and other sector or organizational publications. Moreover, we compared these opinions with different perceptions acquired via informal discussions with other sector actors. 
Table 2.1: Key informants interviewed in Uganda

Organization

Number of respondents

1. National Water and Sewerage Corporation ${ }^{\partial}$

5

2. Kampala Water and Sewerage Company ${ }^{\text {K }}$

3. Ministry of Water and Environment ${ }^{\beta}$

4. Ministry of Local Government and Housing ${ }^{\lambda}$

5. CPs: ADA, AfDB, EU, GTZ, UNICEF, WSP-WB ${ }^{¥}$

6. NGOs: UWASNET, Water Aid ${ }^{\hbar}$

7. Association of Private Water Operators ${ }^{\mathrm{d}}$

8. Private Consultant, water and energy development*

TOTAL

CPs: Cooperate partners, ADA: Austrian Development Agency, AfDB: African Development Bank, EU: European Union, GTZ: German Technical Cooperation, UNICEF: United Nations Children's Fund, WSP-WB: Water and Sanitation Programme of the World Bank, NGOs: Non-governmental organizations, UWASNET: Uganda Water and Sanitation NGO Network.

${ }^{\partial}$ Chief managers in charge of commercial, corporate, customer care, engineering, legal, planning and development affairs.

Ж Managers in charge of corporate management, customer care, marketing, sewerage services and urban poor issues among others.

${ }^{\beta}$ Commissioners in charge of liaison; reforms; rural, urban and small towns' water development and water for development.

$\lambda$ Principal inspector of operations.

${ }^{¥}$ Infrastructure specialists, programme officers, technical advisors and water and sanitation specialists.

${ }^{5}$ Programme officers in charge of advocacy, communication and policy affairs.

${ }^{\circledR}$ Chair and programmes coordinator.

* The former director of the Privatization Unit under the Ministry of Finance and Planning.

Prior to providing an historical overview of the Ugandan urban water supply sector in section 2.4, we first discuss how global politics transformed reform trajectories across the global urban water sector since the late 1970s. Section 2.5 investigates in particular, how global water politics interplayed with institutions and stakeholders at the politics of policy level in Uganda. The nature and implications of this interaction are moreover, explored. Section 2.6 provides an encompassing discussion of how global politics shaped reform trajectories especially in Uganda while section 2.7 concludes the chapter.

\subsection{Global water politics: From infrastructure to institutions}

This section highlights how global politics transformed reform trajectories across the global urban water sector since the late 1970s. We focus on the African continent whose efforts of attaining affordable, sustainable and universal potable water coverage have long been challenged (AfDB, 2010; WSP-WB, 2009). Besides service coverage deficits of about 35 percent (WSP-WB, 2009), utilities across the continent suffer multifaceted technical problems reflected for instance, in high water losses (Mwanza, 2005). In addition, utilities face chronic financial difficulties as a result of low metering rates, low 
user tariffs and unreliable consumer records that constrain billing and revenue collection practices (Mwanza, 2005; World Bank, 1994).

On the other hand, advanced policy reforms emanating largely from the global sphere and aimed at addressing these challenges have transformed considerably over the past decades. Prior to the 1990s, reforms in the water services sector had a strong focus on infrastructure development. Guided by the persistent infrastructural ideal of providing universal and standardized services to everyone worldwide, the predominant approach to expanding access for unserved populations lay in the construction of sufficient hardware to provide services and transfer technical know-how to WUs (Gleick, 2003). This infrastructure focus became increasingly challenged particularly, after the disappointing results of the International Drinking Water Decade (1981/1990). The Decade adhered to the exceptionally ambitious target of providing potable water and improved sanitation services for all. The outcome of the Decade was however, disappointing. At the end of the decade, as many people still lacked access to safe drinking water and sanitation services as when the Decade began (Economist, 1994).

As a reaction to the unsatisfactory results of the International Drinking Water Decade, a new reform agenda became prevalent. Rather than having a primary focus on infrastructure, the new global consensus argued that institutions matter. Subsequently, reforms that focused on institutional build-up and strengthening were propagated across the African water sectors. Rather than viewing resource and infrastructure shortages as the main obstacles in improving service provision, impediments were increasingly presented as being 'institutional' in nature. Spiller and Savedoff (1999:2) for example, argue that;

"the nature of the sector, coupled with a nation's political institutions, [...] together create incentives for government-owners of public utilities to behave opportunistically, for the service providers to operate inefficiently, and for the consumers to withhold support to the sector. As such, the water 
services sector under these circumstances has a tendency toward a low-level equilibrium from which it is difficult to escape".

In addressing these institutional obstacles, reforms largely reflected the prevailing neoliberal restructuring ideology in other public service sectors such as education, energy, health, telecommunication and transport (see Harvey, 2005). Privatization and commercialization were promulgated as the future of the water supply industry (Idelovitch and Ringskog, 1995; Nickson, 1997; Panayatou, 1997; World Bank, 1997; Spiller and Savedoff, 1999; Franceys, 2008). Privatization can be defined as the organizational change in ownership (from public to private) and management (from nearcomplete public control of water-supply functions to the involvement of the private sector) (Bakker, 2002). A fundamental element of this approach was the takeover of state-owned utilities by private organizations.

Advocacy for (complete or near complete) private sector involvement was based on a number of arguments. First of all, private sector involvement was believed to increase utilities efficiency as service providers were meant to operate under profit motives guided by clearly defined performance contracts. Secondly with private sector involvement, regulation was separated from actual service provision thus, addressing the poachergamekeeper problem. ${ }^{16}$ Thirdly, experience from privatization projects in England and Wales "played a major role in convincing policy makers worldwide, that private financing of urban WUs could be viable" (Marin, 2009:19; Franceys, 2008). Subsequently, private operators were viewed as a potential source of investmentfinancing required to improve services.

\subsection{The Ugandan urban water service sector}

In this section, we provide an historical overview of the Ugandan urban water service sector. We in particular, highlight the overriding reasons that lend the sector to

\footnotetext{
${ }^{16}$ The poacher-gamekeeper problem concerns the concentration of regulatory and operational functions within the same public sector entity. This results in weak or dysfunctional regulation, accountability and transparency of concerned service providers (Foster, 1996).
} 
restructuring by the end of the 1990s. Henceforth, we rely largely on the findings of the key-informant interviews (see section 2.2.2).

\subsubsection{Historical overview}

Following independence in 1962, nation building was the topmost priority of the Ugandan government (Hope and Chikulo, 2000). As part of this drive, existing public infrastructure was extended and maintained through investment subsidies. ${ }^{17}$ Population growth rate was minimal and most urban households enjoyed piped water services. ${ }^{18}$ Economic mismanagement during the Idi Amin Dada's presidency and severe political turmoil following that presidency led to skilled workers and investors fleeing the country. As a result, export revenues declined and public infrastructure including water supply systems, deteriorated. ${ }^{19}$ By the mid-1980s, Uganda was nearly a 'failed state' (World Bank, 2009). ${ }^{20}$

In 1972, the National Water and Sewerage Corporation (hereafter, NWSC) was established by decree 34 as a parastatal owned fully by the Ugandan government. This followed recommendations of a study on 'how to corporatize utilities' funded by the African Development Bank. ${ }^{21}$ A Board of Directors was appointed by the Minister of Mineral and Water Resources (hereafter, MMWR) ${ }^{22}$ consisting largely of political appointees. The Board appointed a Managing Director and oversaw the corporation's activities. ${ }^{23}$ It constituted the link between NWSC and the MMWR. Some Board members were housed within the NWSC building and hence, were indistinguishable from the corporation's management. This meant that "when a board member requested for a

\footnotetext{
${ }^{17} \mathrm{KIU} 8,9$.

${ }^{18}$ For more information on how the piped water and sewerage systems evolved in Uganda before the 1950s, see Nilsson (2006).

${ }^{19}$ KIU 13, 17, 19.

${ }^{20}$ According to KIU 13 and 17, Uganda was a "dead state".

${ }^{21}$ KIU 3, 4. As noted in Muhairwe (2009), the study was moreover, undertaken in collaboration with the World Bank and the World Health Organization.

${ }^{22}$ The MMWR transformed into the Ministry of Water, Lands and Environment in the early 1990s and later to the Ministry of Water and Environment in 2007.

${ }^{23}$ KIU 9.
} 
corporation's vehicle (among other assets for official or personal use), s/he was given a vehicle, yet such was neither provided and budgeted for, nor accounted for". ${ }^{4}$

NWSC provided water and sewerage services to the urban towns of Kampala, Entebbe and Jinja. ${ }^{25}$ The MMWR through water departments on the other hand, provided water and sewerage services to the rest towns outside NWSC's mandate. The ministry designed, reinforced and regulated the sectors' policies and programs. ${ }^{26}$ This conflict of interests within the Ministry meant that NWSC had very little incentive to improve performance. Resultantly, "pipes extension and maintenance works took long to finalize or never ended (as) the investor and implementer self-supervised herself". ${ }^{27}$ Regulatory frameworks related to water service coverage, quality, user fees and performance management were absent. ${ }^{28}$ The MMWR ended-up "doing nothing" ${ }^{29}$ in terms of providing reliable services and regulating sector operations.

Recruitment, promotion and dismissal of staff in the ministry were based on self-defined criteria highly prone to political manipulation. ${ }^{30}$ Water departments essentially became "analogous to political-family businesses". ${ }^{31}$ Moreover, financial support from the government to the water departments was minimal, insufficient or often delayed. ${ }^{32}$ Consequently, newly established but far-located (i.e., away from Kampala the capital city) districts hardly attracted and/or retained skilled personnel. As noted by KI 14, "no one was willing to work from the remote towns that for the most, lacked basic amenities like passable roads, decent housing, electricity ... and so forth".

Service expansion was politically-driven and mostly in return for political favors. ${ }^{33}$ Priority was first to the government organizations, ministers and permanent secretaries'

\footnotetext{
${ }^{24}$ KIU 1.

${ }^{25} \mathrm{KIU} 1,4,27$.

${ }^{26} \mathrm{KIU} 1,2,3,7,8,9,10,11,12,13,15,16,17,18,20,23,26,27$.

${ }^{27}$ KIU 17.

${ }^{28}$ KIU 8, 9, 10, 15, 16, 18, 19, 20, 21, 23, 26, 25, 27.

${ }^{29}$ KIU 27 . Illustratively, no operational records were kept also by NWSC in this era. The existing few were manually stored and haphazardly maintained (KIU 23, 27).

${ }^{30}$ KIU $9,10$.

${ }^{31} \mathrm{KIU}$ 1, echoed also by KIU 10, 14.

${ }^{32} \mathrm{KIU} 15$.

${ }^{33} \mathrm{KIU} 1$ - e.g., in return for appointments to different positions in the Ministry.
} 
residents and other senior government functionaries. ${ }^{34}$ These three customer types usually either never paid their water bills at all, or on time. Politically-driven network extension and maintenance operations were often costly and counter-productive as they entailed mains extension to the city fringes where most government officials resided. Given that most households lived within cities; such main's extension works were only accessible to a few households (located along the extended networks) depending on their abilities to pay. ${ }^{35}$

\subsubsection{Increased demands for quality water supply services}

By the early 1980s, only 7 (out of 37) urban towns had functional, though poorlymanaged, piped water systems. Service coverage stood at a mere 18 per cent. ${ }^{36}$ During the end of the International Drinking Water Decade, multiple externally funded multisectoral and non-state actors saturated the sector with isolated, non-coordinated and nonregulated water supply projects. ${ }^{37}$ These projects prioritized infrastructure development. ${ }^{38}$ Through a World Bank loan guaranteed by the MMWR, for example, the 'Seven town's water supply project' was instituted in $1987 .{ }^{39}$ The project expanded water production infrastructure across Kampala, Entebbe, Jinja, Mbale, Masaka, Mbarara and Tororo. ${ }^{40}$

A follow-up 'second water project' funded by the World Bank, Austrian government and the European Union extended water works and distribution lines across the seven towns between 1990 and 1999. ${ }^{41}$ The projects were successful, as long as funding was sufficient. When funding ended with the projects expiration, the schemes quickly became non-functional. ${ }^{42}$ Local communities were in most cases hardly familiar with the

\footnotetext{
${ }^{34} \mathrm{KIU} 1,3,6,7$.

${ }^{35}$ KIU 6.

${ }^{36} \mathrm{KIU} 16$.

${ }^{37} \mathrm{KIU} 9,10,14,16,24$.

${ }^{38} \mathrm{KIU} 13,16,18,20,24,25,27$.

${ }^{39} \mathrm{KIU} 4,15,16$

${ }^{40}$ After the project's termination, further development and management mandates of water schemes in Mbale, Masaka, Mbarara and Tororo were transferred to NWSC.

${ }^{41}$ KIU 4. Each financier signed a bilateral foreign aid arrangement with the government (through the ministry). Financial facilitation was largely supply-oriented and based on "take it or leave it" principles.

${ }^{42}$ KIU 20, 21, 27.
} 
schemes' operations. ${ }^{43}$ In response, most affected communities sought other alternative water sources whose quality and reliability was hardly guaranteed.

Despite the investments, revenue collection stagnated. ${ }^{44}$ By the end of the 1990s, NWSC debts amounted to more than US\$5 53 million (Muhairwe, 2009). The national utility was "broke and did not have anything. (The utility) had to simply borrow money to pay (its) staff ${ }^{46}$ Moreover, NWSC management was found incompetent, non-transparent and corrupt. ${ }^{47}$ Staff productivity was estimated at 36 staff per 1000 connections against Africa's best practice of less than 10 employees per 1000 connections (Muhairwe, 2009). Each NWSC employee and her/his immediate family were entitled to free medical care by the corporation. In most cases, however, employees' extended family members and friends benefited also from the free health care policy (Muhairwe, 2009: 339). The corporations' operating costs (related to energy, personnel, transport, security expenses, etc) resulted in monthly deficits of about 384 million Ugandan Shillings ${ }^{48}$ (Muhairwe, 2009). Direct investments into infrastructural projects through NWSC "were similar to sinking 100 million dollars into a company that does not operate meaningfully". 49

The World Bank in particular, redefined its investment strategy from direct infrastructural development and capacity building, to the facilitation of the Water Sector Reforms Study in June 1999. ${ }^{50}$ Plans for the study had started in September 1997 but, faced severe resistance until mid 1999. To assert its seriousness in launching the study, the World Bank warned that "if you (the MMWR) do not do the study this time, we will not give you any money both for investment and capacity building". 51

\footnotetext{
${ }^{43} \mathrm{KIU} 4,10,20$.

${ }^{44} \mathrm{KIU} 1,2,3,6,7,9,10,11,13,15,19$.

${ }^{45}$ American dollar.

${ }^{46} \mathrm{KIU} 23$.

${ }^{47} \mathrm{KIU} 10,13,15,24,26$. For instance as noted by KIU 6, some staff colluded with customers to underestimate their water consumption bills.

${ }^{48}$ About US\$ 354, 571; 1997 equivalent (http://www.oanda.com/currency/historical-rates).

${ }^{49}$ KIU 23 and confirmed by KIU 3.

${ }^{50} \mathrm{KIU} 15,23$

${ }^{51}$ KIU 15, who was involved in the World Bank facilitated Water Sector Reforms Study that commenced in June 1999.
} 


\subsection{Politics in the Ugandan urban water sector: Nature and implications}

This section describes how global water politics interplayed with institutions and stakeholders at the politics of policy level in Uganda. The nature and implications of this interaction are examined.

\subsubsection{From privatization to commercialization}

As part of the Economic Recovery Programme (hereafter, ERP), the World Bank pressured for the privatization of the public sector in Uganda (Kuteesa et al., 2010). This ERP essentially emulated Structural Adjustment Programmes (henceforth, SAPs) implemented elsewhere, globally. SAPs austerity measures were conditioned on loans granted to most transition and low income countries and advanced as the only macroeconomic and human development strategy by the World Bank and the International Monetary Fund. ${ }^{52}$ During this time, the World Bank acted as a global knowledge broker that mediated, performed and championed exemplary policy models often as the one and only solution (cf. Rap, 2006). In Uganda “...privatization was advanced as the only best way of running urban water services provision". 53

The Ugandan urban water sector conformed to the World Bank's pressures through the Ministry of Finance. ${ }^{54}$ In 1997, NWSC was enlisted for full privatization by the Privatization unit of the Ministry of Finance as provided by the Public Enterprises Privatization and Divestiture (PEPD) statute. ${ }^{55}$ In the same year, the Local Government Act Cap 243 (RoU, 2008) and the Water Act Cap 152 (RoU, 1997) were enacted. These Acts allowed for service provision decentralization and private sector participation, respectively.

The Water Sector Reform Study facilitated by the World Bank proposed the procurement of a single lease contract for the then 33 largest towns and a management contract for the remaining small towns overseen by the Water and Sanitation Development Agency

\footnotetext{
${ }^{52}$ For an overview of the nature and effects of SAPs, see SAPRIN, 2004 (and the references therein).

${ }^{53}$ KIU 1 .

${ }^{54} \mathrm{KIU} 17,18,25$.

${ }^{55} \mathrm{KIU}$ 4, 12, 15, 20.
} 
(MWLE, 2001). Other proposed privatization options included the (i) formation of an Urban Water Alliance under a management contract to provide water supply services to all 78 urban towns under an Alliance Board oversight, (ii) procurement of a single lease for all 78 urban towns, and the (iii) procurement of a single concession contract for the 3 largest urban towns (Kampala, Entebbe and Jinja) and other private operators for the rest towns, under management contracts (MWLE, 2001).

To advance its intended reforms, the World Bank sponsored several senior urban water sector employees to attend trainings, workshops and conferences related to infrastructure and public service privatization (Muhairwe, 2009). These activities were mainly targeted at preparing the sector for increased private sector involvement. In addition, the World Bank facilitated a study tour of key sector stakeholders, including top ministerial functionaries, as part of the Water Sector Reform Study to Ghana, Côte d'Ivoire and Senegal. These countries represented cases where private sector involvement was already in existence or was being pursued. ${ }^{56}$

Between 1998 and 2001, the World Bank facilitated the procurement of the first international private operator for the city of Kampala. ${ }^{57}$ A German engineering company, H.P. Gauff Engineers, was contracted on a 3-year management contract to run the Kampala Revenue Improvement Programme (hereafter, KRIP) (NWSC, 2003). While KRIP contract excluded water production and sewerage services provision, it was meant to comparatively distinguish private from public sector performance (NWSC, 2001). More so and "given that Kampala was NWSC's cash cow ${ }^{58}$, successful performance of the private operator would eventually lead to (justify) similar contracts across the rest urban towns". ${ }^{59}$ This initial contract with an international private operator was largely seen as a "transition to full-fledged privatization" (Muhairwe, 2009:12) but did not yield much success. ${ }^{60}$ Following the end of the contract, a second international private

\footnotetext{
${ }^{56} \mathrm{KIU} 15,27$.

${ }^{57}$ KIU 3, 5, 10, 13, 18, 27.

${ }^{58}$ With the highest active customers and generating about 70 per cent of NWSC's total revenue (Muhairwe, 2009).

${ }^{59} \mathrm{KIU} 9$ and also noted by KIU 10.

${ }^{60} \mathrm{KIU} 3,5,10,13,18,27$. For a detailed discussion of how and why this privatization pilot failed, see Muhairwe, 2009.
} 
operator, ONDEO Services, was contracted between 2002 and 2004 (NWSC, 2003). This contract was again facilitated by the World Bank but was also, not very successful. ${ }^{61}$

\subsubsection{Contesting privatization}

As a minimum requirement, all reforms require rules and legal frameworks to guide and sustain them (Patashnik, 2008). The enactment of supporting legislation however, is not a guarantee for successful (non-disputable) reforms implementation. In the case of Uganda, legal frameworks that allowed for privatization were easily accepted and implemented. Related organizational reforms were nonetheless, much more problematic and contested. ${ }^{62}$ Organizational changes that would logically ensue from privatization were particularly opposed by the new NWSC's Management Board that was instituted in 1998. ${ }^{63}$ The Board resisted the Water Sector Reform Study's recommendation to privatize NWSC arguing that the World Bank's push to privatize the national utility, packaged in numerous conditionalities, was "irritating and humiliating" (Muhairwe, 2009: 259). ${ }^{64}$ Officials within NWSC preferred "home-grown alternatives" to the "misleading ready-made solutions" by the World Bank (Muhairwe, 2009: 178, 280-282).

Having witnessed the privatization of other state owned enterprises including the Uganda Commercial Bank, Uganda Grain Millers and the Uganda Posts and Telecommunication Corporation, NWSC privatization "for ordinary employees meant in practice, the loss of jobs - the only source of income and means of livelihood, and the premature termination of careers" (Muhairwe, 2009: 333). ${ }^{65}$ Moreover, privatization was seen to compromise the corporation's autonomy in decision making. External financiers, especially those who advanced privatization, were perceived as presumptuous, overbearing, intrusive and selfservicing (Muhairwe, 2009). NWSC preferred to self-regulate its operations with minimal

\footnotetext{
${ }^{61} \mathrm{KIU}$ 3, 5, 10, 13, 18, 27. See also Muhairwe, 2009 and NWSC, 2003.

${ }^{62} \mathrm{KIU} 1,5,8,11,12,13,15,23,26,27$.

${ }^{63} \mathrm{KIU} 1,9,12$.

${ }^{64}$ Moreover, as noted by KIU 15 who also took part in the study tour that was part of the Water Sector Reform Study, privatizing Ugandan's urban water industry through concessionary arrangements was not an option following a similar failed pursuit for Accra city in Ghana. Similar observations were noted by KIU 10 and KIU 23.

${ }^{65}$ Similar observations were made by KIU 3, 9, 10, 11 .
} 
or no interference from international financiers, Ministry of Finance and the Ministry of Water, Lands and Environment (hereafter, MWLE). ${ }^{66}$

In order to resist privatization, NWSC's top management developed a broad coalition of stakeholders. The management sought support of the corporation's Board of Directors, its Service Area managers, its staff, the media and the Uganda Public Employee Union. ${ }^{67}$ Moreover, although the Ministry of Finance and the MWLE (through the Directorate of Water Development) officially supported the Water Sector Reform Study recommendations, ${ }^{68}$ some officials within the government preferred sector commercialization under public ownership. These influential senior government officials provided crucial support for NWSC's efforts to resist privatization.

\subsubsection{Stronger bargaining position for the NWSC}

The home-grown alternatives preferred by NWSC, came in the form of commercialization. Commercialization entails changes in water supply institutions with the application of private sector culture that emphasizes efficiency, effectiveness, competition and economic equity advancements (Bakker, 2002). Smith (2004) refers to this commercialization phase as the second wave of neoliberalization. WUs remained government-owned, but were organized as autonomous corporations according to private sector principles and management practices.

In 1999, the 100-day programme was rolled-out by the new NWSC management. ${ }^{69}$ The programme aimed at improving water and sewerage services production, increasing potable water distribution, strengthening revenue collection and costumer care improvement (NWSC management, 1999). As noted by then Managing Director of NWSC, the "100-Day programme was meant to serve as a beacon of performance

${ }^{66} \mathrm{KIU} 12,13$.

${ }^{67}$ KIU 1.

${ }^{68} \mathrm{KIU} 12,13,14,15,16,17,20$.

${ }^{69}$ Confirmed also by KIU 15 . 
measure that must be maintained to ensure the viability of NWSC irrespective of the looming privatization" (Muhairwe, 2009: 31). ${ }^{70}$

More so, NWSC instituted Area Performance Contracts that were later substituted with the Internally Delegated Area Management Contracts (hereafter, IDAMCs). ${ }^{71}$ IDAMCs are internal management contracts (between NWSC the Head Office and the Area service providers that constitute all gazetted large urban towns) that emulate the management contracts of the Office of Water in England and Wales (Muhairwe, 2009). The IDAMCs introduced decentralized autonomous service provision, performance-based management and competition through benchmarking.

Best performers based on prior set targets are quarterly rewarded with bonuses, cash prizes, trophies and promotions; but chronic poor performers, for more than 3 consecutive months, are demoted or laid off. ${ }^{72}$ In implementing these reforms, NWSC, "used the shadow of privatization to spur staff productivity" (Muhairwe, 2009: 259, see also Table 2.2). Internal reforms that introduced private sector institutions and practices that under other circumstances would have been difficult to implement, became feasible under the looming privatization. Introduction of these efficiency-oriented reforms improved the performance of the national utility (see Table 2.2).

Table 2.2: NWSC Performance, 1998 - 2010

\begin{tabular}{|c|c|c|c|}
\hline Indicator & 1998 & 2004 & $2010^{k}$ \\
\hline Unaccounted-for-water (as a percentage of the total water produced) & $49 \%$ & $37.6 \%^{\lambda}$ & $33.3 \%$ \\
\hline Staff productivity (total staff per 1000 connections) & $36^{\ddagger}$ & $10^{\lambda}$ & 6 \\
\hline Service coverage & $48 \%{ }^{\delta}$ & $65 \%^{\lambda}$ & $74 \%$ \\
\hline Connections (total active water supply accounts) & $34,272^{¥}$ & $100,475^{\lambda}$ & 246,459 \\
\hline Collection efficiency & $71 \%^{¥}$ & $98 \%{ }^{\circledR}$ & $100 \%$ \\
\hline
\end{tabular}

Source: NWSC management, 1999 (¥); NWSC, 2003 ( ); Mugisha, 2008 ( $\delta$ ); NWSC, $2004(\lambda)$, NWSC, 2009a (®) and NWSC, $2010(\not)$

Service coverage: Total population served with piped water supplies within NWSC's service area.

Collection efficiency: Percentage of the revenue collected from billed water/expected revenue from all billed water.

\footnotetext{
${ }^{70}$ Analogous programmes were initiated by the Dar es salaam Water and Sewerage Corporation (after the exit of City Water private operator in 2005) and the Lusaka Water and Sewerage Company between November 2005 and February 2006. The nature, successes and failures of these 100-days change programmes (including the NWSC's 100 programme) are discussed in Schouten and Buyi (2010).

${ }^{71} \mathrm{KIU}$ 5, 8, 10, 11, 13, 16, 18, 20, 21, 24.

${ }^{72} \mathrm{KIU} 1,4,5,6$.
} 


\subsection{Global politics in shaping national reform trajectories}

This section discusses how global politics shaped national urban water sector reform paths especially, in Uganda. We draw from the fact that the context in which water sector reforms were implemented globally had changed considerably by 2003 . First of all, the threat of privatization had diminished by 2003 as the privatization policy had lost momentum internationally. Various high-profile privatization projects were cancelled, faced technical or financial difficulties (Prasad, 2008).

In 2000, the concession contract in Cochabamba, Bolivia, was terminated following a period of unrest described as the "Water War" (Perreault, 2006:150). ${ }^{73}$ Other highlypublicized urban water contracts, such as those in Manila and Jakarta, faced substantial operational challenges (Jensen, 2005; Braadbaart, 2007; Prasad, 2008). Besides costs incurred prior to or during these privatization periods, affected countries faced an additional "burden of paying compensation to private companies that (had) failed to deliver but (were) entitled by contract to receive such payments" (Castro, 2009:28).

Not only did international organizations become more hesitant to promote privatization but the private sector itself also, appeared less interested in fostering water projects in developing countries (see Jimenez and Perez-Foguet, 2009 for an overview of international private sector investments in the water sector between 1995 and 2004). As noted by the Chairman and CEO (Chief Executive Officer) of SAUR International, these concessionary or full divestiture arrangements were based on unrealistic convictions that the private sector has unlimited funds and is able to engage in good business whereby "water pays for water" (Talbot, 2002:20). More over, there were attempts to apply costly European standards in developing countries yet, providers were not able to recover related investment costs solely, from service users. Faced with such limitations, investors sought "other potentially more remunerative markets" (Talbot, 2002:18).

\footnotetext{
${ }^{73}$ Analogous cancellations occurred in Argentina (Tucumán), Atlanta, Brazil, Cape Verde, Chad, Mali (Bamako), Senegal (Conakry) and Tanzania (Dar es Salam) $\rightarrow$ see Zanetta (2001: 525), Auriol and Blanc (2009: 213) and Twort et al. (2000).
} 
In exemplifying this shift for instance, one of the leading international private operators, SUEZ (now SUEZ Environment), indicated that it would only "concentrate on the soundest markets that provided the most recurrent revenues starting with the FrancoBelgium domestic market and including the European Union and North America" (SUEZ, 2003:2). The Action Plan continued to explain that "exposure to emerging countries, as measured by the capital employed, was expected to be reduced by close to one third" (SUEZ, 2003:2).

In other words, the international private sector was becoming less willing to be involved in providing services in developing countries. At the same time, the World Bank, which had been one of the strongest promoters of private sector involvement, found itself confronted with disappointing levels of lending to the water supply and sanitation sector. Lending decreased by more than two-thirds between 1996 and 2002 (World Bank, 2005).

The strong decline in lending to the water supply and sanitation sector by the World Bank (through loans and guarantees by the International Bank for Reconstruction and Development and the International Development Agency), led to a policy shift in the Bank. Roughly speaking from 2003 onwards, the World Bank set to engage itself again with public sector WUs (Baietti et al., 2006; Prasad, 2008). In 're-engaging' itself with public service providers, for example, the World Bank implicitly acknowledged that the promise of large-scale private sector involvement as it was envisioned in the early 1990s did not live up to expectations. By 2003, the "privatization decade" (Franceys, 2008) roughly came to an end.

At the same time, the bargaining position of NWSC was strengthened between 2000 and 2004 as a result of the impressive performance improvements highlighted for example in Table 2.2. These performance improvements propelled NWSC's reputation, globally. ${ }^{74}$ Increasingly, the national utility was presented at international water fora as a successful reformer. Along with this exposure came the international recognition for the utility, which further boosted its bargaining position in the reform process. Also within Uganda

\footnotetext{
${ }^{74}$ Noted also by KIU 4.
} 
the reputation of NWSC grew. NWSC was seen as the most capable organization to manage rehabilitated water systems. Between 2001 and 2006, eight additional towns were transferred to the service area of NWSC by the MWLE (Nabakiibi and Schwartz, 2009).

One of the most important consequences of gaining international recognition was that NWSC was able to capture the attention of alternative external financiers. This greatly reduced its dependency on the World Bank and the accompanying policy prescriptions and further strengthened its bargaining position. These external financiers, such as the German Development Bank (KfW) and the European Union, replaced the World Bank as the dominant external financier. These financiers placed less emphasis on NWSC's privatization, as long as the process of commercialization was continued. ${ }^{75}$ For NWSC, this conditionality was easily accepted, - as commercialization was very much in line with the prevailing organizational strategy and interests of the utility. Commercialization with its emphasis on financially autonomous agencies meant that, as long as performance would remain in line with sector expectations, NWSC would have considerable autonomy to make decisions.

\subsection{Conclusion}

Using the case of the Ugandan urban water sector, this chapter divulged that decisionmaking regarding the direction of public utility reforms is a highly political process involving actors operating at multiple levels. At the global level, the World Bank, adhering to its global policy of promoting private sector involvement, strongly pushed for the privatization of the urban water industry in Uganda. As the reform process continued, however, the respective bargaining positions of different actors started to change. Internationally, privatization as a reform policy started to lose momentum as large-scale contracts collapsed or faced operational difficulties. Increasingly, the international private companies became hesitant to embark on new privatization initiatives.

\footnotetext{
${ }^{75}$ Analogues observations were made by KIU 13, 14, 15, 18, 19, 21, 23, 25, 27.
} 
While legal frameworks that allowed for privatization were easily adopted, related organizational reforms were strongly resisted. A coalition incorporating the NWSC's management board, senior officials in the Ugandan government ministries and the media opposed organizational reforms associated with privatization. The NWSC further strengthened its bargaining position by displaying remarkable performance improvements which captured the attention of the international water community. The ensuing access to funds from alternative external financiers meant that dependency on the World Bank loans diminished. Using its strengthened bargaining position, the NWSC managed to shift the direction of the initial organizational reforms from complete privatization to sector commercialization that was more in line with the utility's interests.

What we learn from this chapter is that, reform processes in urban water supply are inherently political in nature. As power relations among actors at both global and national policy levels transform overtime and space, initial reform strategies mold and reshape in line with the interests of the most hegemonic actor - at either or both policy levels. Organizational changes that entail the loss of control/power by incumbent (public utility) managers are largely contested than the crafting or amendment of existing legislative and institutional frameworks.

Chapter 3 extends this investigation to examine what these mean for policies, institutions and organizations at the national sector level. While similar developments are observed for the Zambian urban water case (discussed in Chapter 3), we use a different conceptual approach to analyze the process. This helps us to provide a comprehensive understanding of the neoliberal reform process (i.e., from two African urban water sectors). 


\section{CHAPTER 3: Analyzing water utility reform processes ${ }^{76}$}

\subsection{Introduction}

The global water sector, as discussed in Section 2.3, has experienced multileveled governance shifts since the 1980s. Following the disappointing outcomes of the International Drinking Water Decade, global focus in dealing with urban water sector challenges shifted from an infrastructural to an institutional outlook. The latter, drawing from the then prevailing neoliberalistic ideology, was advanced to entail increased private sector participation (hereafter, PSP) in the production and provision of water services. Conversely however, initial PSP exercises faced different operational challenges as discussed in Section 2.6.

Various reasons explain why it was difficult to establish functioning PSP especially, across the developing countries. First, high transaction costs undermined the successful operationalization of these projects (Hall and Lobina, 2005). These transaction costs manifested in legal, consulting and other financial expenditures incurred in PSPs' establishment, risk management and in the establishment of regulatory structures. Second, the design of the first PSPs contracts in the early 1990s was conceptually flawed (Braadbaart, 2005). These flaws resulted into failed tenders and the suspension of contract negotiations. Besides, awarded contracts had to be renegotiated shortly after they became effective.

Thirdly, designed PSP projects lacked matching regulatory structures prior, during and after their design (Parker and Kirkpatrick, 2005; Prasad, 2006). This followed the inadequate institutional capacities of the receiving sectors. Fourthly, contracted international water companies were largely profit-seeking and risk avoiding (Lobina and Hall, 2003). This behavior went against the main tenet of the water services sector in most developing countries - where water provision is considered not only an economic service but a social good with environmental benefits.

\footnotetext{
${ }^{76}$ A modified version of this chapter is available as: Kemerink, J., Mbuvi, D., and Schwartz, K. (2012). Governance shifts in the water services sector: A case study of the Zambian water services sector. In Katko, T., Juuti, P., and Schwartz, K. Water services management and governance: Lessons for a sustainable future, IWA Publishing.
} 
While the water privatization decade ended by 2003, this did not imply that the water services sector in developing countries and Africa in particular, returned to the service provision modalities of the decades before the onset of private sector involvement. Service provision remained public, but utilities were increasingly expected to operate in line with private sector management practices and principles (shifts to sector commercialization).

These sector transformations motivate the current chapter's inquiry in analyzing reform processes. We provide a framework for analyzing governance shifts in the water sector (see Section 3.2.1). We use the case of the Zambian urban water sector and focus on the neoliberalistic reform processes that characterized the sector between 1993 and 2010. We find that, although the momentum of involving private sector organizations in the provision of water services in Zambia may have diminished over time, private sector institutions have increasingly been incorporated in 'public' service provision modalities.

Prior to discussing the main governance shifts across the Zambian urban water sector in section 3.3, the following section discusses the conceptual approach and methodology employed by the study. Section 3.4 concludes the chapter.

\subsection{Conceptual approach and study methodology}

\subsubsection{Conceptual approach}

In analyzing reform processes, this chapter distinguishes four mutually dependent governance structures. That is; policies, institutions, organizations and (existing) infrastructure or resources. Scott (2001) and Hage and Meeus (2006) define institutions as the agglomeration of rules, laws, routines, practices and habits that prescribe and regulate the behavior of markets (economic dimension), states (political science) and organizations, associations or individuals (sociological dimension). These institutions can either be imposed on actors or translated to fit within the local polity conditions (Campbell, 2006). Relying on game theory, Aoki (2001:10) characterizes institutions as 
self-sustaining systems of shared beliefs - about salient ways in which 'the game is repeatedly played' or the 'rules of the game' are repeatedly played.

Furubotn and Richter (2005) define institutions as a set of formal and informal rules, including their enforcement arrangements. Rational actors acting for the public interest can consciously create these rules and their enforcement mechanisms or they can occur spontaneously. Furubotn and Richter institutional outlook borrows strongly from the new institutional economics that sees 'institutions' as devices for reducing transaction costs that in turn, have cascading influences on entities' performance. Transaction costs increase with uncertainty, delayed or uncoordinated decision making among actors. As costs increase, so does the performance (economic, political, social) of related actors' decrease. These studies bunch-up the 'rules of the game' with their enforcement arrangements and structures. Following Aoki (2001) however, it is not the semantics of words that matter, but how they are conceptualized in explaining specific phenomena. We treat these aspects separately.

We understand institutions in a sociological sense in that they comprise the social arrangements that shape, regulate and reproduce human behavior across time and space. These social arrangements may be formal in nature but can also be informal. At any given time and location, multiple institutions may co-exist (and possibly conflict) at the same time. Similar to earlier literature on the other hand, we see policies as the rules of the game that define and limit choices. Policies may be explicit - such as the Zambian National Water Policy of 1994 . More so, they can be implicit or largely symbolic in nature.

Hage and Meeus (2006) define organizations as the formal structures that are intentionally established for explicit purposes. Besides these formal structures, Furubotn and Richter (2005) broach the informal organizations that are spontaneously created by invisible hands (e.g., markets) for particular purposes. For the case at hand that relates specifically to the water services sector, we refer to these formal and informal structures as actors. We thus understand organizations to constitute those stakeholders that are 
formally ascribed with the responsibility of providing services, developing policies and/or regulating the sector. They comprise of ministries, departments, asset holding agencies, regulators and utilities among others. Besides, we understand organizations to concern other actors that influence decision-making processes in the sector such as, nongovernmental entities.

Policies, institutions and organizations continually interact given existing infrastructure (technology, resources, etc) and stretch across a polity continuum. See Figure 3.1. Similar to Mollinga (2008, explained earlier in Section 2.2.1), we distinguish the polity range. Analogous to chapter 2, we focus on shifts in governance structures (spheres) at the global and national water policy levels. Shifts in governance spheres can manifest as either major or minor. Major shifts embody changes in either organizations, policies, institutions or the actual infrastructure, resources or technological choices that result into subsequent changes in another (or other) governance structure(s). Minor shifts reflect changes in one of the governance structures that may not lead to changes in other elements. Given this interaction, reform processes can be analyzed in terms of the prevailing mix of organizations, policies, institutions or actual infrastructure (resources or technological choices) that predominate the water services sector at a given time and space. 
Figure 3.1: An illustration of governance structures' interdependence

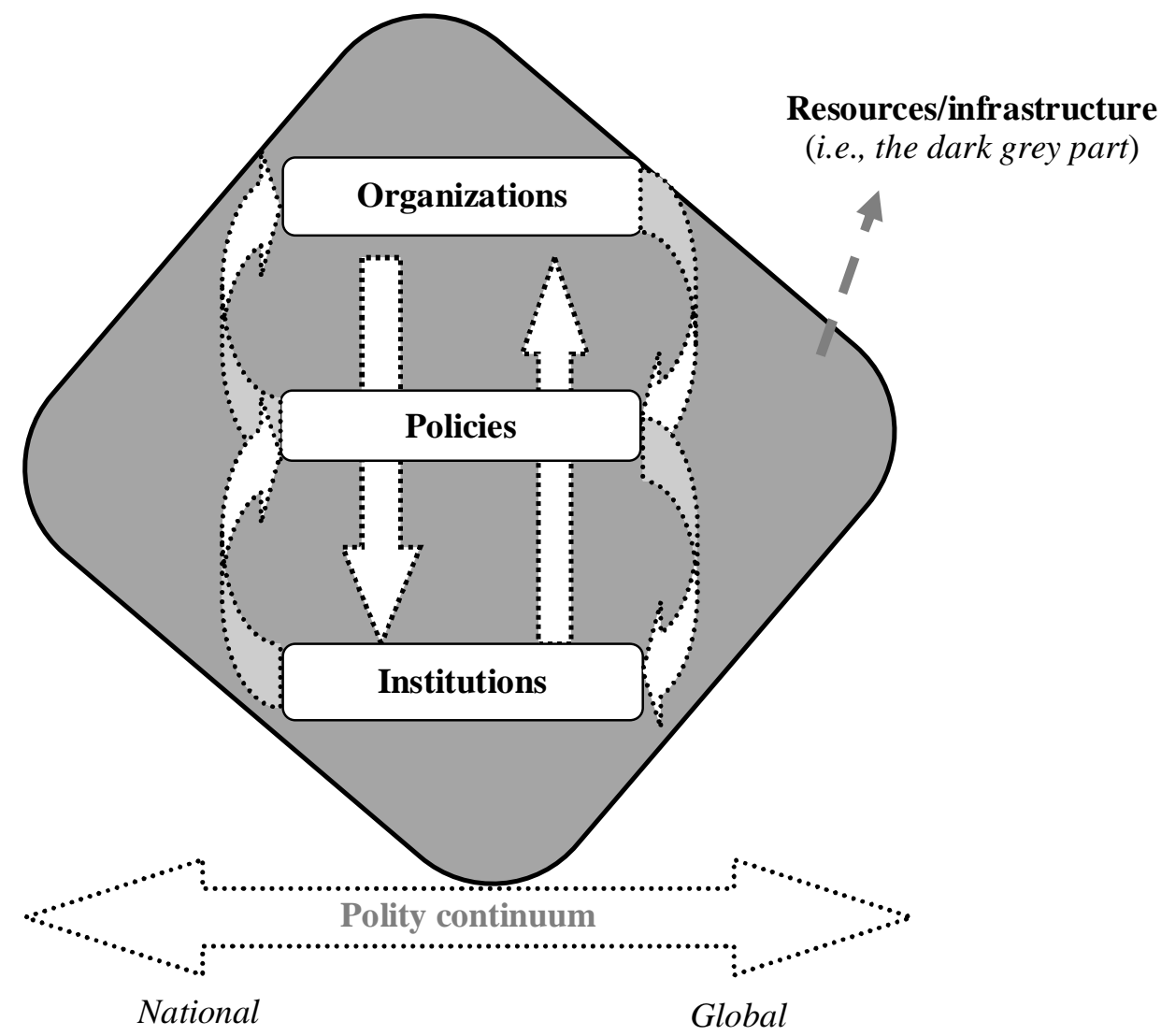

Source: Authors illustration

\subsubsection{Study methodology}

To explain governance shifts in the Zambian urban water sector, this chapter, similar to chapter 2 (see section 2.2.2), relies on both primary and secondary data sources. The former constitutes data gathered through in-depth face-to-face interviews with key urban water sector stakeholders across Zambia in August 2009. 27 key informants were interviewed (see Table 3.1) by use of both semi-structured and closed interview guides. ${ }^{77}$ Key informants (referenced hereafter as KIZ) presumed to possess significant first hand information on the sectors' developments since and before the country's independence, were preferred. We added to and verified this interview data with related information

\footnotetext{
${ }^{77}$ These were similar to the guide provided in Appendix 1.
} 
from archival sector reports and other relevant publications availed online or by the different interviewed stakeholders.

Table 3.1: Key informants interviewed in Zambia

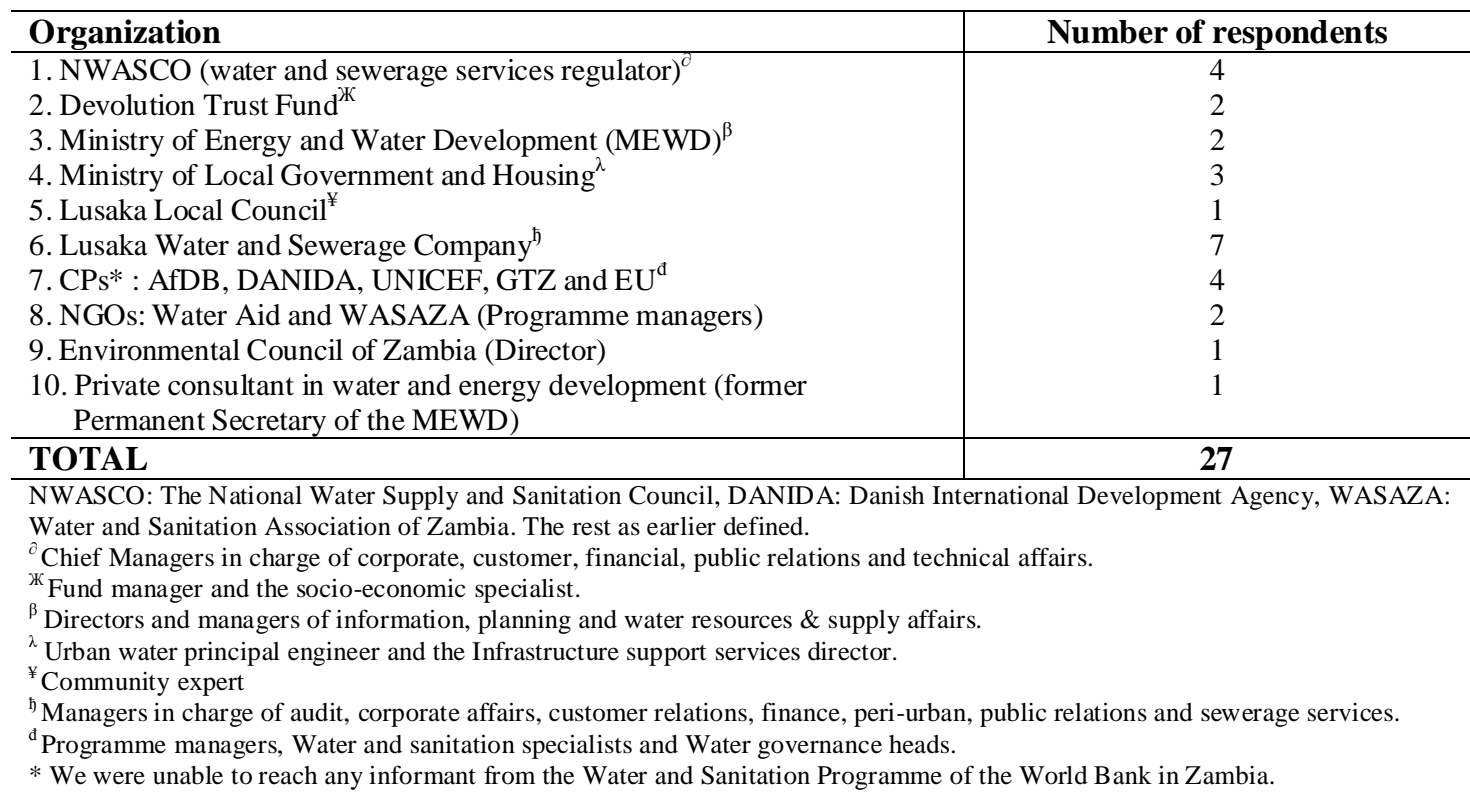

\subsection{Governance shifts in the Zambian urban water services sector}

We first provide an historical overview of the Zambian urban water services sector. Subsequently, we discuss the governance shifts that took place in the sector. We examine how policy changes interplayed with subsequent organizational and institutional transformations given the existing resources (infrastructure) in the sector.

\subsubsection{Historical overview of the urban water sector}

Demand increases with the rise of new developmental sites (breweries, abattoirs, bakeries, residential estates, etc) in the late 1960s challenged the socialist government that was at the same period, experiencing severe fiscal crises. Real gross domestic product (hereafter, GDP) growth declined from 7.1 (1970) and 2.5 (1975) percent to 0.1 percent in 1980 (Barry, 1990). Global oil prices increased as national earnings, largely 
from copper exports, declined. Investments as a percentage of the GDP declined from 29 (1970) and 18 (1980) percent to 10 percent in 1988 (Barry, 1990, see also Cocq, 2005). Resultantly, subsidies to public services including water supply, shrunk (Barry, 1990; GoZ, 2006). ${ }^{78}$

The Department of Water Affairs (hereafter, DWA) under the Ministry of Water, Land and Natural Resources (hereafter, MWLNR) developed water resources, built water supply infrastructure (rural and urban), supplied water and provided sewerage services to district townships as well as, designed and enforced sector legislation. A water board established in 1946 regulated (only surface) water resource abstraction. Water and sewerage service provision including user tariffs, services quality and systems functionability was unregulated. ${ }^{79}$ Water departments (alike other public offices) became unattractive to skilled personnel. ${ }^{80}$

To bridge the gap in water provision, other line ministries including the Ministries of Works, Health, Education and Local government and housing provided water supply services to government institutions, hospital employees, schools and the rest district townships through local authorities. Private organizations (including mining and other manufacturing companies) provided water and sewerage services to their employees (NWASCO, 2002). Non-governmental operators (local community groups, international organizations, etc) provided water and sewerage services in the form of projects or water trusts. ${ }^{81}$ Formal urban areas were firstly prioritized while "attention to the non-planned peri-urban regions was only after (or as a response to) water borne and water related disease outbreaks". ${ }^{82}$ By nature, this multiplicity in water services provision resulted in activities duplication, information asymmetries and piecemeal projects that relied on erratic funds. ${ }^{83}$

\footnotetext{
${ }^{78}$ Similar observations were made by KIZ 1, 9, 13, 27.

${ }^{79} \mathrm{KIZ} 5,20$.

${ }^{80}$ As investments to the sector became negligible, skilled personnel attraction and retention became a challenge - noted KIZ 1,2, 27.

${ }^{81} \mathrm{KIZ} 10$.

${ }^{82}$ KIZ 15, similar observations by KIZ 2, 3, 7, 10, 12, 15, 16, 17, 20, 27.

${ }^{83} \mathrm{KIZ}$ 4, 5, 10, 13, 27.
} 
Water supply at the district townships was part of the overall public service provision mandate of the local authorities as provided in the Local Government Act Cap 281 (GoZ, 1991). ${ }^{84}$ Local authorities conjointly provided water and sewerage services with other council services including urban planning and drainage, road development, street lighting, education, cemetery, health, fire fighting, rural water supply, housing and solid waste disposal. Revenue from these services was banked in a common account from where allocations to the different departments (based on perceived needs) were made. Being among the few revenue-generating utility services, accrued water and sewerage service revenue (i) subsidized other council services and (ii) was used for other personnel costs such as, to remunerate council members' allowances. Fewer (or no) funds were (re)invested in water mains extension and maintenance (Opio-Lukone, 2003, Cocq, 2005)..$^{85}$

Local authorities/councils owned most of the urban residential houses. Own-council tenants hardly paid their utility bills as they owned the houses and provided all relatedutility services. Utility services' user fees were incorporated in the monthly housing rent. This aggregation concealed the true economic value of clean piped water supply and constrained any efforts to monitor and control wasteful water consumption. Moreover, "if a property was disconnected for non-payment, its occupants alternatively drew water from their neighbors who hardly felt the pinch of such extra usage since billing was based on a fixed monthly assessment". ${ }^{86}$

It was a challenge for the water departments to identify and confront water-bill defaulters. First, regulatory capacities within the departments and DWA lacked. ${ }^{87}$ Secondly, related perpetrators constituted sensitive government institutions (hospitals, police barracks, etc) or officials (ministers, city mayors and their allies). "If a government department (or official's residence) was disconnected for non-payment, we (DWA management) would

\footnotetext{
${ }^{84}$ KIZ 27.

${ }^{85} \mathrm{KIZ} 12,20$.

${ }^{86}$ KIZ 6 and echoed by KIZ 27.

${ }^{87}$ KIZ 18, 20, 26.

${ }^{88}$ KIZ 27.
} 
get phone calls from allover to reconnect the disconnected premises without discourse". 89 This continued until the late President Levy Mwanawasa "strongly instructed the controlling officers in the government (ministers, etc) to promptly settle their departmental and residential municipal water bills from their centrally allocated ministerial utility allowances". ${ }^{90}$ Through the then Secretary to the treasury, the late President instructed DWA in writing to "treat all government officials as the rest customers and disconnect them if they defaulted their water consumption bills". 91

\subsubsection{Policy changes}

Soon after the International Drinking Water Supply and Sanitation Decade (1981/1990), the first multi-party government was elected in Zambia. Providing water services remained a challenge to the new government. Lusaka province where the country's capital city is located, received for example, less than 2 hours of daily water supply (Nyumbu et al., 1997). More than 60 percent of the distributed water was lost through illegal connections. About 72 percent of the then formally connected customers in Lusaka province were discontent with the services reliability, sufficiency and quality (Nyumbu et al., 1997). ${ }^{92}$ As noted by KIZ 20, it was impossible to maintain constant water supplies as demand outstripped existing supply schemes' capacities.

With the support of, respectively, GTZ (German Technical Cooperation) and KfW (German Development Bank), Lusaka and Chipata local authorities transformed their water schemes into water and sewerage companies in 1989 and $1992 .{ }^{93}$ These commercial utilities were purposely established as pilots in experimenting whether and how local authorities could cost-effectively provide universal and affordable quality water supply services and ultimately, increase revenues. However, elected water board

\footnotetext{
${ }^{89} \mathrm{KIZ} 6$.

${ }^{90} \mathrm{KIZ} 6,10,25$.

${ }^{91} \mathrm{KIZ} 6$.

${ }^{92}$ Such dissatisfaction was not unique for Lusaka inhabitants but also among other customers nationally as noted by KIZ 3, 4, 5, 7, 10, 13, 15, 17.

${ }^{93}$ KIZ 16.
} 
members to the newly established companies were mainly political appointees (e.g., city mayor or other council members). ${ }^{94}$

These political appointees were hardly familiar with the operation and management of WUs. It was hard to hold the board members accountable. Routine maintenance was neglected to the detriment of the few existing water production and supply systems. Sector subsidization was likened to "putting money into a hole" $"$. At the same time the economic downturn that characterized the country since the $1970 \mathrm{~s}^{96}$ meant that the Zambian government had few funds to invest in the water services sector. Between 1990 and 1995, budget allocation for investments in the water service sector dropped from US\$ 4.3 million to US\$ 0.9 million (Nyumbu et al., 1997).

Further reforms were initiated shortly after the establishment of the pilot utilities in Lusaka and Chipata provinces. Consensus existed between the various stakeholders in the Zambian urban water sector that the causes of poor performance could be backtracked to the sector's legislative, institutional and organizational 'weaknesses' (Chanda, 2000). In addressing these weaknesses, additional reforms were initiated in 1993. These latter reforms correlated with other neoliberal restructuring programmes introduced in Zambia under the auspices of the World Bank (Cocq 2005, Opio-Lukone, 2003). ${ }^{97}$

These restructuring programmes reflected strongly, the PSP focus of the World Bank (GoZ, 2006). By 1994 the government of Zambia adopted the National Water Policy and the Institutional Framework for Water Supply and Sanitation. These were designed by the Water Sector Development Group (hereafter, WSDG) under the oversight of the Interministerial Programme Coordination Unit (hereafter, PCU) established by the Cabinet (Nyumbu et al., 1997). In steering sector restructuring, the documents provided for the ${ }^{98}$ :

\footnotetext{
${ }^{94} \mathrm{KIZ}$ 13, 20, 27.

${ }^{95} \mathrm{KIZ} 20$.

${ }^{96}$ Per capita income fell from US\$ 752 in 1965 to US\$ 351 in 2002 (Dagdeviren 2008:103).

${ }^{97}$ Analogous observations were made by KIZ 2, 24, 25.

${ }^{98}$ Noted also by KIZ 1, 2, 3, 4, 5, 7, 8, 9, 10, 12, 13, 14, 16, 18, 20, 23, 25, 26, 27.
} 
- Isolation of water resources development from water supply and sanitation provision

- Separation of regulatory and executive functions from water resource development and services provision

○ Devolution of water supply mandates to local authorities and private enterprises

○ Full cost recovery - in the long run

- Human resource development - for effective institutions

- Use of appropriate technologies that are suitable to and informed by local conditions, and

- Increased sector prioritization by the government - reflected in improved budgetary allocations.

To provide a legal basis for the reform's implementation, the WSDG prepared the first legal draft by 1995 . Following a period of consultation, the revised draft was submitted to the Ministry of Legal Affairs. Over a period of 18 months, the proposed legislation was discussed by the Ministries of Local Government, Energy and Water Development. By November 1997, the parliament enacted the Water Supply and Sanitation Act (WUP, 2001).

\subsubsection{Institutional shifts}

Based on the policy principles set forth in the National Water Policy, private sector institutions (emphasizes on the economic value of potable water provision, performance management, quasi-competition, etc), were introduced in the water services sector. These institutions were fundamentally advanced to allow the sector attain full cost recovery by 2010 and ultimately, universal urban water services coverage (NWASCO, 2005:13, see also Dagdeviren, 2008). User fees were readjusted in attempts to achieve full-cost recovery.

In 2005 , the national water regulator approved nationally, tariff adjustment proposals ranging from 20 to 50 percent increases in user tariffs (NWASCO, 2005). To stimulate 
efficiency, the national regulator introduced quasi-competition through benchmarking (based on one-dimensional measures - refer to Section 1.4.1). Over these benchmarking exercises, utilities' performance is assessed and published annually in comparative sector reports. These 'internal competition' exercises motivate previous-poorly performing utilities to outperform their peers and/or perform as the benchmark/best-practice utilities (NWASCO, 2005).

Based on the sector principles as provided by the National water policy, arm's-length utilities' operation - i.e., by the government was advanced. Given Zambia's inability to sustain water services sector subsidization, 'agencification' of service providers was pursued. ${ }^{99}$ Agencification refers to "the conversion of government-departments that previously operated in a hierarchical chain [...] into semi-autonomous [agencies]" (van Donge 2002: 315). These utilities, operating at arm's length of the government, would be expected to reap the efficiency gains associated with private sector organizations. NWASCO, for example, argues that organizing utilities as autonomous agencies "gives more promise to the achievement of cost recovery leading to more sustainable provision of services" (NWASCO, 2006:6).

\subsubsection{Organizational changes}

Policies implemented by the mid 1990s (see section 3.3.2) influenced the organizational setup of the Zambian urban water services sector. A key element of the National Water Policy is that it called for the isolation and dedication of water resources development, services provision and sector regulation functions to separate entities. Water resources development included all activities linked to raw water mapping and abstraction for agricultural, municipal and industrial use. Water services provision entailed operations associated with the (i) development of raw water pumping, storage, treatment, distribution and waste water disposal infrastructure, (ii) systems maintenance and (iii) the overall water supply management. Regulatory functions included tasks such as 'service

\footnotetext{
${ }^{99} \mathrm{KIZ} 10$.
} 
areas' delineation, tariffs approval, standards design and enforcement as well as, service providers' licensing.

First, as provided by the 1997 Water Supply and Sanitation Act, an independent regulatory agency - the National Water Supply and Sanitation Council (hereafter, NWASCO) was established in $2000 .{ }^{100}$ The design and implementation of this regulatory structure was mainly informed by the 'British-regulatory' framework (Foster, 1996). Its organizational structure however, built on the existing PCU organs, in that, the PCU became the regulator. NWASCO's board reports to the Zambian parliament through the Ministry of Energy and Water Development (hereafter, MEWD). ${ }^{101}$

In its capacity ${ }^{102}$, NWASCO licenses service providers and regulates user tariffs and quality standards. The regulator is responsible for advising the government, licensed service providers and customers on matters related to services provision and management. This is for instance, accomplished through the Water Watch Groups (hereafter, WWGs), Part-time Inspectors (hereafter, PtIs) and desk officers. WWGs and PtIs were respectively established in 2002 and 2005 as volunteer customer groups and inspectors. They support NWASCO's local regulatory activities including service provider's supervision and customer care (NWASCO, 2009: 2010a: 2011). PtIs do not form part of the centralized NWASCO's full-time personnel and thus allow for a decentralized regulatory outreach. By 2010, NWASCO engaged 9 WWGs and 17 PtIs (NWASCO, 2010b). Desk officers are assigned among NWASCO's full-time staff to each licensed service provider for close regular performance monitoring and assessment.

NWASCO arbitrates disputes among sector stakeholders. Dissatisfied actors can nonetheless seek redress from the Minister of MEWD and/or the high court of appeal. ${ }^{103}$ The regulator in collaboration with other actors such as the Environmental Council of Zambia designs and enforces other health and environmentally-related guidelines. It

${ }^{100} \mathrm{KIZ} 2,5,6,23$. Alternatively, government departments can regulate the sector, but as noted by KIZ 5, 6, 9, 25 and 27 , these departments lack oversight boards and hence prone to political meddling and corruption.

${ }^{101}$ KIZ 5, 13, 23.

${ }^{102}$ KIZ 2, 5, 6, 7, 12, 20, 24, 27.

${ }^{103} \mathrm{KIZ} 1$. 
hedges service provision activities against likely political capture possible especially, with the unpredictable government reshuffles. ${ }^{104}$ To surmount probable regulatory capture, the regulator is largely financed by the (public) service providers. The latter contribute 2 percent of their turnover in the form of license fees. In 2003 when the contribution by the licensees was 1 percent of their turnover, license fees comprised 72 percent of NWASCO's budget. The remaining 18 percent was financed by the government and other external financiers (NWASCO, 2004a).

Second, the actual service providers changed. As part of the new organizational framework, water supply and sanitation responsibilities were devolved to Local authorities (city, municipal and district councils). This act provided local authorities with a number of options for organizing service delivery in their locality (GoZ, 1997). Local authorities could ${ }^{105}$ :

- Provide services through a section or department within the Local authority

○ Establish Commercial Utilities (hereafter, CUs). In this scenario, a local authority could establish a government-owned company (either on its own or jointly with other local authorities) and transfer responsibilities for providing services to this government-owned company.

- Involve the private sector in providing services through management, lease, concession or build-operate and transfer contractual arrangements. Over the same period, a study by the English private operator Severn Trent (financed by the World Bank) examined the possibility of involving the private sector in service provision in Zambia. The study, using the case of Lusaka city, concluded that involving private operators by way of lease contracts was the most preferred reform strategy. After heated discussions on the study's recommendations, however, the proposal was shelved-off (Cocq, 2005). ${ }^{106}$

\footnotetext{
${ }^{104}$ These are exemplified by the erratic appointments of (i) ministers in the ministries of Local government and housing and Energy \& water development and (ii) board members - some of whom are unfamiliar with the ministerial operations (KIZ 5, 10, 20, 22).

${ }^{105}$ Also pointed out by KIZ 1, 2, 3, 4, 5, 7, 10, 12, 14, 16, 23.

${ }^{106}$ Moreover, attempts to involve a French private operator to improve water services provision at the Copper Belt region in the mid-1990s by the World Bank, were not successful (KIZ 2, 7, 9, 12, 20, 23). While the private operator only managed the existing infrastructure, user fees increased over the time of the contract (KIZ 16).
} 
Eventually, the sector opted for the creation of government-owned regional CUs that would however, operate as private companies under the Zambian Law and according to commercial principles. The preference for CUs is strongly linked to the adherence of the private sector institutions described in section 3.3.3 and in particular, targeting the attainment of full cost-recovery. ${ }^{107}$ Table 3.2 provides an overview of water service providers in Zambia since the 1970s.

Table 3.2: Water service providers in Zambia, 1997 - 2009

\begin{tabular}{lccc}
\hline Provider & Before $\mathbf{1 9 9 7}$ & $\mathbf{2 0 0 4}$ & $\mathbf{2 0 0 9}$ \\
\hline Central government & 46 & 0 & 0 \\
Local authorities & 29 & 23 & 0 \\
Commercial utilities & 2 & 51 & 11 \\
Private schemes* & 7 & 10 & 6 \\
TOTAL & $\mathbf{8 4}$ & $\mathbf{8 4}$ & $\mathbf{1 7}$ \\
\hline
\end{tabular}

Sources: NWASCO, 2004a: 2010a.

*Constitute companies such as the Zambia Sugar PLC, Chilanga Cement, ZESCO, Konkola Copper Mines (KCM-Nampundwe), etc that supply water services to their employees as a fringe benefit (2010a).

First, as evident in Table 3.2, service provision by the central or local governments has faded out since the early 2000. Reliance on CUs has become the dominant organizational mode for organizing services provision in the Zambian urban water sector. Secondly and in efforts to maximize potential scale economics, larger regional operators (CUs) have been established solely or conjointly by Local authorities. ${ }^{108}$ In 2000, six CUs (Kafubu, Mulonga, Nkana, North-Western, Southern and Western) were established by the PCU through the WSFG. In 2003, 2006 and 2009, three more CUs (Chambeshi, Lukanga and Luapula) were established, respectively. Chipata Water and Sewerage Company transformed into the Eastern Water and Sewerage Company after extra service areas besides Chipata town were delegated by NWASCO to the utility (NWASCO, 2011).

As at 2009, the total number of service providers across the urban regions decreased from 84 providers to 17 organizations. Richards et al. (2008) highlight the importance of CUs as a tool to pursue commercialization, especially, if they operate at optimal scales. By mandating CUs to provide services across multiple municipalities, the regulator/sector

${ }^{107} \mathrm{KIZ} 2,6,7,8,12,13,17,20,25,24$.

${ }^{108}$ KIZ 2. 
can "enable the realization of synergies and economies of scale and thus improve prospects for commercial viability" (Richards et al., 2008:20).

CUs are regulated by NWASCO through ten-year renewable licenses. In these licenses, specific CU's Service level guarantees and agreements (henceforth, SLG\&A) are defined. These SLG\&A define each CU's services quality, continuity, coverage, reliability, costefficiency, functionability and customer care targets (NWASCO, 2004a). Since 2008, the best performing CUs relative to these priori defined SLG\&A are periodically rewarded through the Regulation by Incentive program (NWASCO, 2009).

By 2010, CUs served 75 percent of the total urban population within licensed service areas in Zambia (see Table 3.3). This corresponded to about 4 million customers (NWASCO, 2010a). Moreover, this is equivalent to about 3 and 25 percent increase in coverage compared to service coverage levels in 2006 and 2002, respectively (see Table 3.3). Over the same time, CUs have reduced their water losses and improved their metering and collection efficiencies among other key efficiency indicators.

Table 3.3: Urban water sector performance in Zambia, 2002 - 2010

\begin{tabular}{lrrr}
\hline Indicator & $\mathbf{2 0 0 2}$ & $\mathbf{2 0 0 6}$ & $\mathbf{2 0 1 0}$ \\
\hline Service coverage & $60 \%$ & $73 \%$ & $75 \%$ \\
Total connections & 182,600 & 213,053 & 293,796 \\
Metering ratio (metered/total connections) & $21 \%$ & $39 \%$ & $55 \%$ \\
Water losses (unaccounted for water) & $51 \%$ & $48 \%$ & $45 \%$ \\
Collection efficiency & $60 \%$ & $77 \%$ & $86 \%$ \\
Staff per 1,000 connections & 12 & 11 & 11 \\
\hline
\end{tabular}

Sources: NWASCO, 2002: 2006: 2010a.

Service coverage: Served population/total urban population in licensed service areas.

Third, as part of the reforms, water resource development functions have been delegated to the MEWD. ${ }^{109}$ Besides, the MEWD is responsible for the overarching water policy making. The physical planning of water supply and sanitation services is the mandate of the Ministry of Local Government and Housing (MLGH) through the Department of Infrastructure Support Services (ZWP, 2008). Evidently, the organizational setup of the

${ }^{109} \mathrm{KIZ} 6,16$. 
Zambian urban water sector is/has been strongly associated with the policies and institutions designed - following the reforms, to guide the sector. These developments are chronologically summarized in Table 3.4. Governance structures established prior to the reforms (as at 1993) are compared with those instituted at the onset or during the implementation of the neoliberal reforms.

Table 3.4: Shifts in policies, institutions and organizations in the Zambian urban water sector

\begin{tabular}{|c|c|c|}
\hline Governance structure & Established as at 1993 & Established by 2010 \\
\hline Policies & $\begin{array}{l}\text { - Local Government Act Cap } 281 \\
\text { (1991). }\end{array}$ & $\begin{array}{l}\text { - National Water Policy (1994, revised in } \\
\text { 2010). } \\
\text { - Water Supply and Sanitation Act (1997). }\end{array}$ \\
\hline Institutions & $\begin{array}{l}\text { - Non autonomous supply and } \\
\text { regulatory agencies. } \\
\text { - Inexistent performance } \\
\text { management and benchmarking } \\
\text { practices. } \\
\text { - No (full) cost recovery. } \\
\text { - Self regulation. }\end{array}$ & $\begin{array}{l}\text { - Autonomous agencies (2000). } \\
\text { - Performance management through SLG\&A } \\
\text { (2001). } \\
\text { - Benchmarking by use of partial indicators } \\
\quad(2002) \text {. } \\
\text { - Quasi-competition (2002). } \\
\text { - Incentive regulation (2008). } \\
\text { - (Full) cost-recovery (2008). }\end{array}$ \\
\hline Organizations & $\begin{array}{l}\text { - Water boards as surface water } \\
\text { abstraction regulators (1946). } \\
\text { - DWA under MWLNR as water } \\
\text { service developer and supplier } \\
\text { across district townships. } \\
\text { - LAs as water service providers } \\
\text { across municipal/city councils. } \\
\text { - Other multi providers as water } \\
\text { service providers especially, } \\
\text { where DWA and LAs' services } \\
\text { lacked. } \\
\text { - Lusaka LA transformed into } \\
\text { LWSC (1989). } \\
\text { - Chipata LA transformed into } \\
\text { CWSC (1992). }\end{array}$ & $\begin{array}{l}\text { - Inter-ministerial PCU (by 1995). } \\
\text { - Water sector development group (by 1995). } \\
\text { - NWASCO as an independent regulator } \\
\text { (2000). } \\
\text { - MEWD \& MLGH mandates separated } \\
\text { (2000). } \\
\text { - Public commercial utilities (2000). } \\
\text { - Water watch groups (2002). } \\
\text { - Devolution trust fund (2003). } \\
\text { - Part-time inspectors (2005). } \\
\text { - Desk officers (2007). }\end{array}$ \\
\hline
\end{tabular}

DWA: Department of water affairs, MWLNR: Ministry of water, land and natural resources (changed into the MEWD in 1992), LAs: Local authorities, Multi providers: Other ministries such as the ministry of local government and housing, private companies, local and international organizations, LWSC: Lusaka water and sewerage company, CWSC: Chipata water and sewerage company, SLG\&A: Service level guarantees \& agreements, PCU: Programme coordination unit, MEWD: Ministry of energy and water development.

\subsubsection{Enabling environment for change}

Governance shifts at the policy, institutional and organizational spheres since the 1990s in Zambia have been supported and made possible by the availability of technical, financial and political support at both global and national polity levels. First, in executing 
its responsibilities towards increased sector commercialization, the WSFG received both technical and financial support from the Germany $\left(\mathrm{GTZ}^{110}\right.$ and KfW) and Norwegian ${ }^{111}$ governments. ${ }^{112}$ Technical support was in the form of institutional development and capacity building programmes, among other aspects.

GTZ among other partners has been a "faithful partner to the Zambian water sector since the early 1990s. Compared to the World Bank, the Germany corporate partners literally maintain their technical assistant officers on the ground. ${ }^{113}$ "The World Bank gives you (CU) a loan, workshop and two tones of analytical work followed by the signing of the terms of reference". ${ }^{114}$ The German partners have physically maintained their technical staff in the form of 'management advisors', etc., within the MEWD, MLGH and in some CUs including the Eastern Water and Sewerage Company.

Secondly, the Germany government facilitated the transformation of the Inter-ministerial PCU into an independent regulator (NWASCO) in 2000. The Danish International Development Agency with support of the GTZ (until 2010) supports NWSCO's benchmarking exercises through the "Regulation by Incentive" program (NWASCO, 2010a: 2011). Thirdly in 2003, the Germany government pioneered the establishment of the Devolution Trust Fund (hereafter, DTF). Initially, DTF was instigated to facilitate the establishment and development of regional CUs in Zambia. ${ }^{115}$

Overtime and with the support of other external financiers (Danish government, the European Union, etc), the fund has primarily being used to subsidize water supply and sanitation service provision projects across the peri-urban areas (NWASCO, 2010a: 2011). ${ }^{116}$ These projects are funded from the 'general fund' portfolio of DTF through established regional CUs. On the other hand, CUs' performance improvement activities

\footnotetext{
${ }^{110}$ Since 2010, GTZ merged its activities globally with the German Development Service (DED) and the Capacity building International (Inwent) to form the Deutsche Gesellschaft für Internationale Zusammenarbeit (GIZ) organization.

${ }_{111}$ Through the Norwegian Agency for Development Co-operation.

${ }^{112} \mathrm{KIZ} 4,13,20,27$.

${ }^{113}$ KIZ 23

${ }^{114} \mathrm{KI} 22$

115 These developments are further summarized in Table 3.4.

${ }^{116}$ KIZ 13 .
} 
(including, meter installations) are funded from the "performance enhancement revolving fund' portfolio of DTF. CUs obtain these latter funds in the form of loans (NWASCO, 2010a: 2011).

Fourthly, the water sector reform processes have benefited from increased internal technical capacity building. ${ }^{117}$ Since 2000 , urban water sector employees in Zambia have attained advanced training in water engineering, infrastructure development, utility regulation and management among other water-related courses from both national and international professional institutions supported by the Dutch, Danish and Germany governments, among others (NWASCO, 2006: 2010a: 2010b).

\subsection{Conclusion}

This chapter provided a four-tier framework for analyzing reform processes. In explaining neoliberalistic reform developments in the Zambian urban water sector, we distinguished four mutually dependent governance structures. At any given time after the introduction of the reforms, resultant organizational arrangements are found to mold on the established policies and institutions, given the prevailing infrastructure or resources at the national and global levels.

Considering the Zambian urban water sector case, we draw a few lessons. First, under pressure from international financing agencies, policies in support of PSP were advanced in the 1990s. While these policies often called for the creation of private organizations to provide water services, actual full PSP (privatization) was postponed and ultimately suspended owing to the lack of support at the national water policy levels. PSP at national policy and legal framework discourses faced limited (or no) objection, but the actual replacement of public-owned WUs with privately-owned providers was strongly opposed.

${ }^{117}$ KIZ 13, 20. 
Secondly, the incorporation of private sector institutions in the sector continued with minimal opposition. Presently, the Zambian urban water sector is characterized by its endeavor to (i) increase utilities efficiency through quasi-competition induced for instance by the annual benchmarking exercises, (ii) achieve full cost-recovery in the long-run and eventually, (iii) attain complete effectiveness - that is, universal services coverage. Moreover, established utilities are regulated by an independent regulator as provided by the Water Supply and Sanitation Act. Thirdly, the inclusion of these private sector institutions was strongly promoted and supported by the existing resources (technical, financial, political, etc) and technology. These 'enabling environmental elements' have been supported by actors at both global and national policy domains.

Fourthly, it is important to note that the urban water sector reforms implemented in Zambia in the past two decades are not specific to Zambia but mirror those introduced in other African countries such as Uganda, Namibia, Kenya and Mozambique. As such, an analogous conceptual framework can adaptively be used to characterize, explain and understand reform processes in, but not limited to the urban water sectors in these African countries. Chapter four explores the role of these governance shifts on urban WUs' performance. 


\section{CHAPTER 4: Managerial ownership and urban water utilities efficiency ${ }^{118}$}

\subsection{Introduction}

Given marginal investment realities across urban water sectors in most developing countries, the call for utilities' operational efficiency advancement seems indisputably central. This is elemental, especially for Sub-Saharan Africa, Southern Asia and SouthEast Asia regions that experience unrivaled demands for qualitative water supplies. Among other factors, these regions face demographic e.g., high urbanization rates and varying geo-climatic challenges that threaten their raw water quantities and quality (UNICEF and WHO, 2011).

To surmount WUs' inefficiency, the Ugandan government like most African countries, embarked on diverse organizational and institutional water sector reforms in the late 1990s (MWLE, 2001). Chapter 2 characterizes these reforms in detail. Following the neoliberalistic urban water sector reforms, service provision mandates for gazetted large and small urban towns were delegated to two agencies. The NWSC was responsible for the former towns while services provision for the small urban towns was the task of local governments (MWLE, 2001).

Both NWSC and the local governments sign a renewable three year performance contract with the government - that is, the Ministry of Water and Environment (hereafter, MWE). Secondly, they own the respective water distribution assets on behalf of the government. Thirdly, they engage self-procured WUs through renewable three-year management contracts, to supply water on their behalf across towns under their mandate (MWLE, 2001). Compared to long-term contractual arrangements, short term management contracts assure regular competitive bidding. The latter is decisive for utilities' operational efficiency improvement (Seppala et al., 2001). Although susceptible however, to adverse selection problems - where parties hide useful information ex-ante

\footnotetext{
${ }^{118}$ An earlier version of this chapter is available as: Mbuvi, D., and Tarsim, A. Managerial ownership and urban water utilities efficiency in Uganda, UNU-MERIT Working Paper 2011-036. We are indebted to the participants of the XI European Workshop on Efficiency and Productivity Analysis (EWEPA2009) conference for insightful remarks on an earlier version of this paper.
} 
(e.g., actual infrastructure state, market size), short term management contracts are less vulnerable to post-contractual renegotiations predominant in long-term contractual pacts. Long-term contracts are prone to moral hazard problems related to unobserved or hidden contingencies that translate in high transaction costs to governments or regulators (Lane, 2000; Estache and Wren-Lewis, 2009).

WUs under NWSC's oversight are publicly owned. WUs under the local governments are privately owned as provided by the Local Government Act, Cap 243 (RoU, 2008). The MWE regulates and provides technical support to all urban WUs in Uganda (MWLE, 2008). Regulation is tied to the a priori defined partial performance indicators as provided in the respective management contracts.

In attempts to advance utilities operational efficiency given inherent resource limitations, it is worthwhile to examine the impact of these organizational forms on WU's performance. Normally, traditional production frontier models (parametric or nonparametric) are used to link actual produced outputs to optimal production levels defined by the best-practice frontier (Fried et al., 2008). This is often the case when observed firms or group of firms are homogenous in nature. Urban WU-groups in Uganda are however heterogeneous with respect to their managerial ownership and scale of operation. By implication, operational efficiency differences across both WU-groups depend on these structural differences, among other factors.

We use the metafrontier technique based on DEA estimators (Rao et al., 2003; O'Donnell et al., 2007). The metafrontier approach is preferred for two main reasons. First, it permits us to capture specific utilities' technical efficiency relative to each WU-group's frontier. This is achieved by computing each WU's distance to the specific WU-group's frontier. Secondly, it allows us to estimate and explain technological differences/gaps between both WU-groups while taking into account between WU-groups' heterogeneity. Here, we assess specific WU-group frontier's distance to the best-practice technology available across the urban water supply sector in Uganda - i.e., as defined by the metafrontier. 
Despite their advantages over econometric frontier techniques (see Section 1.4.1), twostage approaches (where WUs' efficiency is computed in a first stage and then regressed on several external factors in a second stage) face several statistical limitations like the serial correlation of estimated values in both stages. This is a problem especially, in finite samples that can result in incorrect and misleading estimates. To overcome these limitations, we use the two-stage double bootstrap truncated regression technique (Simar and Wilson, 2007). The technique (i) allows us to mitigate the deterministic nature of the metafrontier technique and (ii) enables consistent inferencing while controlling for likely noise-impacts in the data (see also, Section 1.4.1). This enables us to examine whether WUs' efficiency is different across both WU-groups in Uganda and whether other utility and sector specific environmental factors explain differences in efficiency between the groups.

As evident in Annex 4.1, few efficiency assessments exist for urban water sectors in Africa. This is mainly due to data inexistency or/and inconsistency problems (Parker and Kirkpatrick, 2005; see also Sheshinski and Lòpez-Calva, 2003; Kun et al., 2007 and Walter et al., 2009 for other regions). We rely on self-collected operational data from both urban WU-groups in Uganda between 2005 and 2007. Since the late 1990s when the MWE initiated reforms across the Ugandan urban water sector, limited performance analyses that incorporate the sector's complexity - in terms of multiple-input use and multi-output production, exist. Available annual performance assessment reports use partial rather than multidimensional performance indicators such as, the share of people with or without access to safe water systems (see for e.g., MWLE, 2006: 2007: 2008).

We understand managerial ownership to constitute or follow from the transfer by the government of service provision mandates through management contracts. The study findings are of interest to a wide range of stakeholders including utility managers, sector regulators, academics and other decision makers in Uganda, Africa and the developing countries in general. They provide useful insights on the role of organizational changes on utilities' efficiency advancement. 
The following section discusses the role of managerial ownership on WUs' performance. Section 4.3 develops the analytical framework while section 4.4 characterizes trends in water resources and water services provision in Uganda. The empirical methodology and data used for the study are defined in section 4.5. Sections 4.6 and 4.7 discuss the study's results and conclusion.

\subsection{Managerial ownership and water utilities performance}

Common to the 1990 reform programmes that were rolled out across public network utilities such as electricity, gas, telecommunications and water supply is the change in the ownership of assets and/or service provision rights (Seppala et al., 2001; Parker and Kirkpatrick, 2005; Boubakri et al., 2008). In Africa, countries such as Cote d'Ivoire, Gabon, Mozambique and Senegal have engaged private organizations to abstract, treat and distribute water services (see Section 6.1). In other countries such as Uganda - for the small towns, private operators have only been involved in services provision. For the majority African countries including Eritrea, Namibia and Zambia, water supply - from abstraction to waste water disposal, is the mandate of the government (Mbuvi et al., 2012).

Theoretically, public and privately-owned utilities differ in a number of ways that influence their operational efficiency. Governments through tax payers own public WUs while private shareholders own private firms. By regulating input prices among other aspects, governments control public utilities' production and service delivery decisions. Public control guarantees or is meant to guarantee inclusive quality services provision for optimal social welfare. Public control is advanced, especially, for the urban water supply industry that is geographically monopolistic, characterized by high initial investment sunk costs and hardly competitive in nature (Waterson, 1988; Seppala et al., 2001; Joskow, 2007; Spronk, 2010; see also Section 1.1). Competition in the industry is limited by the non-detachability of water production and distribution networks within specific service areas. 
Government control and subsidization of public-owned utilities pose multiple implications. First, it entails superfluous cost overruns. This follows from, among others, weak budget oversights, conflicting trade union interests and low propensity to market take-over in case of bankruptcy (Boubakri et al., 2008; Marques, 2008a; Lin et al., 2009).

Second, public ownership lends itself to attenuated foresightedness and systems innovativeness (Tisdell and Hartley, 2008). Structurally, public utility property rights are designed in a way that they can not be transferred (or their expected returns capitalized) by their owners, i.e., the citizens (Crain and Zardkoohi, 1978). At the same time, it is very costly for individual citizens to monitor public managers' activities. Besides, as noted by public choice theorists, public utility managers do not necessarily act for the public interest, but their self or for the benefit of their appointing authorities'. This weakens public planning, operations efficiency and activity specialization (Byrnes, 1985; Vining and Boardman, 1992).

Private utility managers face persistent pursuit for profits with limited multi-tasking and free-riding problems (Seppala et al., 2001; Anwandter and Ozuna, 2002). This, coupled with hardly politicized shareholder performance monitoring, results in high allocation efficiency, innovativeness and responsiveness to consumer demands ${ }^{119}$ (Tisdell and Hartley, 2008; Spronk, 2010). Besides, multiple hybrid ownership arrangements i.e., between public and private actors, exist in urban water supply. These range from simple operational (service, lease, concession, etc) contracts to build (own, operate and transfer) arrangements. For a detailed review, see Idelovitch and Ringskog (1995) and Twort et al. (2000). ${ }^{120}$ Hybrid modes differ in the contractual duration and in the manner in which associated mandates (decision making, capital investments and revenue allocation, etc) and risks are allocated. As earlier broached, this chapter focuses on two hybrid organizational forms; public-public and public-private, under management contracts.

\footnotetext{
${ }^{119}$ Especially in competitive industries or sectors.

${ }^{120}$ Other privatization options involving either formal or informal contracts between public and private (including volunteers, not-for profit organizations) actors are discussed by Johnston and Seidenstat (2001).
} 
Empirical literature is inconclusive on the role of ownership on urban WUs' efficiency (see Annex 4.1). Compared to public-owned WUs, privately ${ }^{121}$ owned utilities have previously been found to be more cost effective, responsive to costumer demands, less corrupt, well governed and more likely to exploit scale, scope and costumer density economies (see Crain and Zardkoohi, 1978: 1980; Raffiee et al., 1993; Bhattacharyya et al., 1995; Estache and Rossi, 2002; Bitran and Valenzuela, 2003; Moreira et al., 2005; Andrés et al., 2008; Gassner et al., 2009; Picazo-Tadeo et al., 2009; Correia and Marques, 2011; Wang et al., 2011).

Private rather than public ownership is however characterized by low (or no) capital investments, ${ }^{122}$ operations-downsizing, high retail prices, exclusive service provision and high information asymmetries (Lynk, 1993; Bhattacharyya et al., 1994; Shaoul, 1997; García-Sánchez, 2006; Saal et al., 2007; Marques, 2008a; Souza et al., 2008; Ruester and Zschille, 2010). Drawing from a metaanalytic study, Bel et al. (2010) found no sufficient support for cost-savings with private production. They examined 27 econometric studies that analyzed cost differences in the production of water supply and solid waste collection services among privately and public-owned firms.

A few empirical studies nonetheless, found no significant difference between privately and public-owned urban WUs in both developed and developing countries (see Feigenbaum et al., 1983; Hausman et al., 1986; Byrnes et al., 1986; Teeples and Glyer, 1987; Lambert et al., 1993; Estache and Rossi, 2002; Saal and Parker, 2004; Kirkpatrick et al., 2006; Souza et al., 2007).

While earlier empirical literature does not provide a clear direction, such uncertainty reflects the continued relevance of the issue. Changes in urban WUs' ownership in Africa remain highly contested as countries implement (e.g. Cote d'Ivoire, Gambia, Ghana, Guinea, Kenya, Lesotho, Mozambique, Senegal, Uganda, Zambia) or initiate (e.g.,

\footnotetext{
${ }^{121}$ In addition to the completely privatized urban markets, we also considered markets under hybrid (public-private) governance structures.

${ }_{122}$ In some cases as noted by Davis (2005), private capital investments surpass pre-privatization investments but at levels below the target investments provided in the hybrid-contracts e.g., in Cancun, Mexico (1994) and Hamilton, Canada (1995). In other cases as was in the Conakry city of Senegal, post-privatization capital investments are mainly facilitated by international financing organizations such as the World Bank than the engaged private operators.
} 
Democratic Republic of Congo) neoliberalistic reform agendas in their urban water sectors (ECA, 2005; AMCW et al., 2006; Osumanu, 2008). This chapter provides new evidence on the role of service provision ownership on urban WUs' technical efficiency.

\subsection{Analytical framework}

DEA takes into account most service sectors' complexity - i.e., reflected in their multiinput and multi-output nature (see Section 1.4.1). For similar utilities, DEA estimates specific WU's efficiency in relation to a best-practice frontier (Fried et al., 2008). While the deterministic technique compares favourably with parametric approaches (Chalos and Cherian, 1995), it avoids a priori specification of the production function that is often unknown for most public service utilities. The metafrontier technique in particular, permits efficiency measurements across dissimilar utility-groups relative to an overarching best practice frontier (metafrontier).

Metafrontier is defined as the boundary of an unrestricted technology set that envelopes specific utility-groups' frontiers. This allows for the estimation of individual utilities' technical efficiency relative to the individual group's best-practice frontier i.e., defined by the group's observations. Second, it permits the estimation of specific group's technology gaps relative to the metafrontier - where the metafrontier reflects the overall available technology accessible across observed utility-groups. Technical efficiency denotes the ratio of the maximal achievable to the actually attained outputs given certain input mixes ${ }^{123}$ (Fried et al., 2008). Efficiency estimates provide useful insights that can inform performance improvement designs within and across utility-groups.

Both WU-groups observed in this chapter share similar water distribution technology. They distribute potable water through piped network systems (MWLE, 2006: 2007). Nonetheless, they differ in two main aspects that potentially influence their resource usage among other choices. First, they differ in their managerial ownership nature. Second, they operate under different scales. In 2006 for example, the public-public

\footnotetext{
${ }^{123}$ Or the ratio of the minimal inputs required to the actual inputs used given a certain output level, in the alternative resource-saving case.
} 
owned utilities provided piped water services to about 1,669,182 (out of a total of $2,384,546)$ customers within their licensed jurisdiction. The public-private owned utilities served on the other hand 451,823 (out of a total of 996,335) persons with piped water services within their service areas. In total, there existed 18 (public-public) and 71 (public-private) urban towns (utilities) with functional piped water systems in Uganda in 2006 (MWLE, 2006).

Since WU-groups' production technologies can potentially criss-cross or overlap (refer also to Table 4.1), the metafrontier is preferred as it envelopes both WU-group's frontier. This enables us to identify and explain likely gaps in technology between the specific WU-group's frontier and the metafrontier, among other aspects. Besides, smaller WUs or WU-groups can conceptually consolidate and increase their sizes. On the other hand, larger WUs or WU-groups can split-up and decrease their operation scales. In such cases where WU-groups can practically switch from one technology (production possibility set) to another, the metafrontier technique offers a better analytical approach in examining and understanding performance difference among such groups.

We use the managerial ownership dummy variable under VRS to capture unobserved structural differences due to dissimilarities in service provision ownership - i.e., fixed for each WU in a certain WU-group. A metatechnology set $\left(T_{M F}\right)$ is associated with technologically feasible input and output sets based on non-negative input $(x)$ and output (y) vectors of the dimension $M \times 1$ and $N \times 1$ respectively. $\left(T_{M F}\right)$ is specified as:

$$
T_{M F}=\{(x, y): x \geq 0 ; y \geq 0 ; x \text { can produce } y\}
$$

With minimal investment potentials, the call for WUs' cost minimization for a given output would seem much plausible. In the case of Uganda alike most African countries where universal piped water coverage is still a delusion, utilities' cost efficiency while vital, seems less urgent than utilities' output maximization with given resources 
(investments, etc). Additionally and partly due to the recently advanced performancebased regulation, it is unlikely in the short-term, for utilities to alter their input (capital, labour, etc) mixes and preset tariffs but their output mixes. The liberty to change output mixes given the prevailing resources, provides utilities with multiple opportunities in attaining a priori set performance targets with sufficient cost-recovery (Estache and Rossi, 2002).

We thus adopt an output oriented technological specification. To estimate technical efficiencies $\left(\theta^{M F}\right)$ across utility-groups, an output metadistance function $\left\{D_{M F}^{o}(x, y)\right\}$ is defined on the output set representing the metafrontier technology set as:

$$
D_{M F}^{o}(x, y)=\inf _{\theta_{M F}}\left\{\theta_{M F}>0:\left(y / \theta_{M F}\right) \in P_{M F}(x)\right\}
$$

Where $D_{M F}(x, y)$ is the maximal radial expansion of unit outputs given existing input resources. $P_{M F}(x)$ is the output set defined for any input vector as $P_{M F}(x)=\left\{y:(x, y) \in T_{M F}\right\}$ while, 'inf' stands for 'infimum'. 'Inf' allows for the possibility that a minimum may not exist $\rightarrow$ i.e., $\left(\theta_{M F}\right)=+\infty$ is possible (see Coelli et al., 2005).

In the absence of price information (input costs, output revenue) we use distance functions to define the multiple-input and multiple-output technology sets (Coelli and Perelman, 1999). In the output-oriented case, distance functions are non-decreasing in $y$, decreasing in $x$, linearly homogenous in $y$ and convex in $y$ (Coelli et al., 2005). Relative to the metafrontier, a given utility $(x, y)$ is technically efficient if the output metadistance function equals to one. This implies that $(x, y)$ is located on the outer boundary of the production possibility set. 
To further estimate individual WU's technical efficiency scores relative to each group's best-practice frontier, an $n^{\text {th }}$ group-specific technology set $\left(T_{G F}^{n}\right)$ is defined (equation 4.3) and represented in terms of its group-specific distance function (equation 4.4).

$$
\begin{aligned}
& T_{G F}^{n}=\{(x, y): x \geq 0 ; y \geq 0 ; x \text { can be used by WUs in group } n \text { to produce } y\} \\
& D_{G F}^{n}(x, y)=\inf _{\theta_{G F}^{n}}\left\{\theta_{G F}^{n}>0:\left(y / \theta_{G F}^{n}\right) \in P_{G F}^{n}(x)\right\}, n=1,2,3 \ldots N
\end{aligned}
$$

Where $P_{G F}^{n}(x)$ represents the group specific output set whose boundaries define the group frontier. $P_{G F}^{n}(x)=\left\{y:(x, y) \in T_{G F}^{n}\right\}, n=1,2,3 \ldots N . \mathrm{WU}_{i}$ is technically efficient relative to its group best-practice frontier if its group specific distance function is equal to one. The technical efficiency score $\left(T E_{G F_{i}}^{n}\right)$ of a given $\mathrm{WU}_{i}$ is thus computed as the distance relative to the group frontier $\left(T E_{G F_{i}}^{n}=D_{G F_{i}}^{n}\right)$.

Figure 4.1 provides an illustration of a convex metafrontier $A B C D E$ that envelopes utility-groups $A 2$ ' and $Q 1$ ' frontiers. ${ }^{124}$ The distance between the metafrontier $\left(D_{M F}^{N}\right.$, overarching dotted line) and either group's frontiers ( $\left.D_{G F}^{n}\right)$ provides a measure of the technology gap ratio $\left(\mathrm{D}_{\mathrm{MTR}}\right)$. The farther a specific group's average efficiency is to one, the farther (in terms of output production) to the maximum potential output given the technology available across the urban water sector, WUs within the specific group are.

\footnotetext{
${ }^{124}$ Note that, an adjusted representation can be made for cases with more than 2 utility-groups.
} 
Figure 4.1: Schematic illustration of the metafrontier technique*

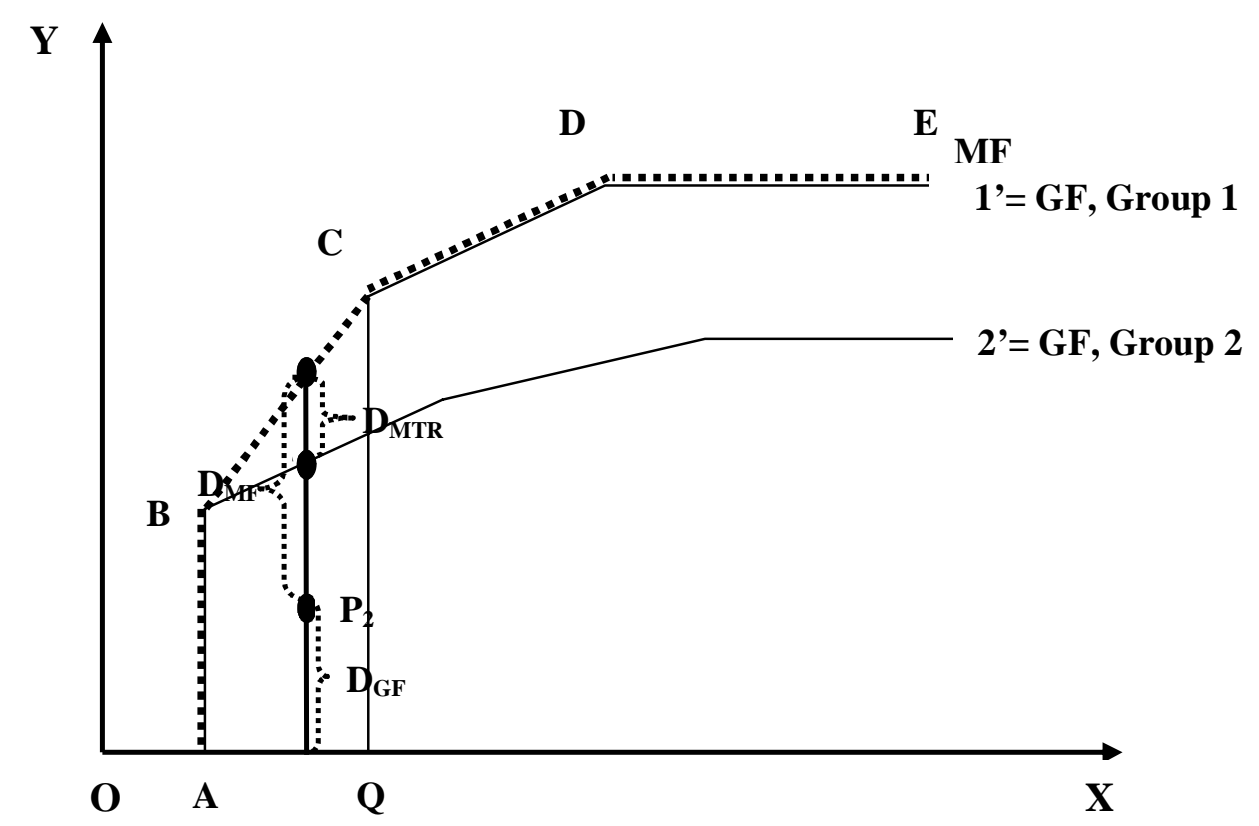

* For utilities producing unit output with unit input. An output orientation under VRS is assumed. Source: Authors illustration.

Technology gap $\left(\mathrm{D}_{\mathrm{MTR}}\right)$ measures the ratio of group- $n$ 's output relative to the potentially attainable output defined by the metafrontier, given observed input units. The technology gap for the public-private owned utility-group is for example computed as (O'Donnell et al., 2007):

$$
\operatorname{MTR}_{P p r}(x, y)=D_{M F}^{P p r}(x, y) / D_{G F}^{P p r}(x, y)
$$

We use the two stage double bootstrap DEA VRS technique to estimate both utilitygroups' production technologies and the metafrontier in the first stage. We further examine, in the second stage, the influence on the estimated efficiency scores of various exogenous variables. The metafrontier is computed by pooling all utility-groups' observations. DEA VRS solves a similar optimization problem as outlined in equation 1.3 . 


\subsection{Water resources and services provision trends in Uganda}

Uganda unlike many African countries is well endowed with adequate water resources. The country has a mean annual rainfall of 1300 millimetres (mm). This ranges from 100 $\mathrm{mm}$ in the semi-arid parts of Karamoja to $3000 \mathrm{~mm}$ in the Northeastern region of the country (UN-Water and WWAP, 2006). Renewable water resources are estimated at 66 $\mathrm{km}^{3}$ per year, nationally. By 2007, per capita annual internal renewable water resources were estimated at 1,412 cubic meters $\left(\mathrm{m}^{3} / \mathrm{inh} / \mathrm{y}\right)$. This endowment exceeds by far the internal renewable fresh water resources in some (30 percent) African countries with quantities below $1000 \mathrm{~m}^{3} / \mathrm{inh} / \mathrm{y}$ (AfDB, 2010). These countries include among others Algeria (342 m³/inh/y), Burkina Faso (906 m³/inh/y), Egypt $\left(24 \mathrm{~m}^{3} / \mathrm{inh} / \mathrm{y}\right)$, Libya (104 $\left.\mathrm{m}^{3} / \mathrm{inh} / \mathrm{y}\right)$, Kenya $\left(630 \mathrm{~m}^{3} / \mathrm{inh} / \mathrm{y}\right)$ and Tunisia $\left(418 \mathrm{~m}^{3} / \mathrm{inh} / \mathrm{y}\right)$. Levels below $1,700 \mathrm{~m}^{3} / \mathrm{inh} / \mathrm{y}, 1,000 \mathrm{~m}^{3} / \mathrm{inh} / \mathrm{y}$ and $500 \mathrm{~m}^{3} / \mathrm{inh} / \mathrm{y}$ denote respectively, water stressed, water scarce and absolute water scarce conditions (UNDP, 2006).

Prominent fresh water reservoirs in Africa including (i) the Nile basin - the longest in the world, (ii) rivers Ruizi, Katonga, Kafu, Mpologoma and Aswa, and (iii) lakes Kyoga, Albert, George, Edward and Victoria pass through or are found in Uganda (UN-Water and WWAP, 2006). Lake Victoria is the world's second largest freshwater lake and the main source of River Nile. Consequently, 82 percent of the land in Uganda is arable (UNWater and WWAP, 2006).

More than 40 percent of the urban population however lacked access to improved water supply systems by 2008 (MWLE, 2008). This was equivalent to about 1.7 million urban residents out a total of 4.4 million. This number is projected to rise with increased urbanization and population growth rates, among other factors. More so, sewerage service provision remains an enormous challenge constrained by low infrastructural development. By 2007, only 10 percent of the population living in the large urban towns had access to improved sewerage services (Mugisha, 2007). While improved sewerage service provision is equally indispensable for a healthy productive population, this chapter (and thesis) focuses only on improved water supply provision. 
Besides catchment-level institutions that protect fresh water reservoirs, WUs constitute a major actor in sustainable water resource and supply management. They invest - with public or private sector support, in infrastructural development, maintenance, services distribution and waste water disposal. Secondly, they guarantee water resources sustainability against inevitable water shortages owing to seasonal or highly contested surface and underground water catchments.

\subsection{Empirical specification and data}

We characterize water distribution technology across the Ugandan urban water sector in terms of one input; operational expenditures (OPEX) and two outputs; the volumetric amount of water sold and services coverage. The latter is defined by the number of customers served with piped water systems in WUs' service areas. Volumetric water sold rather than the total amount of water supplied from the production sites is preferred for two main reasons. First, for improved collection efficiencies with minimal (or no) water losses, WU managers have to employ more field staff and incur high network maintenance costs reflected in their operating expenses. In such cases, the amount of water sold reflects better the input requirement.

Secondly, to distribute water, utilities with higher water losses reflected also in reduced revenue collections could appear efficient due to their low input use (operating expenses). Hence, the amount of water sold provides a better output indicator that takes also into account, water losses (non-revenue water). To attain universal piped water service coverage for all urban customers in Uganda, WUs need to strengthen their revenue collection for reinvestments in systems' extension and maintenance.

In the short term and given marginal (or no) capital investments, utilities incur higher maintenance-related rather than capital-related expenditure. We therefore, use utilities' OPEX as the aggregate measure of the incurred physical inputs given prices. ${ }^{125}$ Since

\footnotetext{
${ }^{125}$ Essentially, costs on all inputs (including capital) or their equivalent quantity measures are required for comprehensive production function estimation. We were unable to access capital expenditure and key physical capital
} 
WUs in Uganda face similar input prices, OPEX reflects an aggregated cost-measure that is linked to network maintenance, labour and other materials' expenditure. More so, the use of OPEX allows us to capture other managerial malfunctions linked for example, to corrupt practices in resources utilization.

We use gross domestic product (GDP) price deflators to convert WUs' OPEX into constant-dollar GDP measures. Contrary to other price indices such as the Consumer Price Index, GDP price deflators are preferred as they take into account annual changes in countries' consumption and investment patterns. To explain efficiency differences between the two WU-groups, we first examine the influence of WUs' target population as a share of the total active water connections on utilities efficiency. Increased market capture is associated with declines in unserved customers within utilities service areas. This can result in either high or low WUs' efficiency. Efficiency decreases are likely if service connectivity operations entail higher input use. Secondly, we investigate the impact of WUs' managerial ownership structure on efficiency.

We rely on data from 27 urban WUs in Uganda; 10 public-public and 17 public-private owned. The sample represents more than 23 percent of the total urban WUs established in Uganda by 2007. Whereas the data is limited, it permits consistent technical efficiency estimation and comparison across both WU-groups between 2005 and 2007. Given the short analysis period, it is unlikely that major technological changes occurred across both utility-groups. Thus, we focus on utilities performance due to efficiency changes.

We obtained some operational data from the water sector's online annual reports. However, to cross-check the validity of gathered information and fill-in missing information gaps, a field visit to Uganda was necessary by the end of 2008. During the visit, we were allowed access to the internal management information systems of the Directorate of Water Development (of the MWE) and NWSC. Both information

proxies' (e.g., network length) data for the public-private WU-group in particular. Use of OPEX as the single input measure is nonetheless consistent with earlier studies in the water sector (see for example, Estache and Rossi, 2002). 
depositories capture and store centrally, operational information for the public-private and the public-public owned WUs.

Table 4.1 provides some summary statistics of the highlighted input, output and environmental variables between 2005 and 2007. Over the three years, the public-public owned urban WUs expensed about five million Ugandan shillings more than the publicprivate owned utilities. The public-public rather than the public-private owned utilities were thus able to advance piped water services to more customers. Coverage by the public-private (compared to the public-public) owned utilities was less by twenty six thousand customers.

Compared to the public-private owned WUs, the public-public utilities managed to penetrate better their urban water markets and meet much of their existing demand for quality water services. This is reflected in their lower share of target population per total water connections (see Table 4.1). The public-public owned WUs made more collections than their counterparts. Considering the former group, the average utility sold eleven thousand more cubic meters of water than the average public-private owned utility (see Table 4.1). 
Table 4.1: Input, output and environmental variables summary statistic

\begin{tabular}{|c|c|c|c|c|c|c|}
\hline & Group & WUs & Mean & St. Dev. & Minimum & Maximum \\
\hline \multicolumn{7}{|l|}{ Input variable } \\
\hline Operational & Public-public & 30 & 49054899 & 22114458 & 24076000 & 98396000 \\
\hline \multirow{2}{*}{ expenditures* } & Public-private & 51 & 43514117 & 26801008 & 7760589 & 155864768 \\
\hline & All & 81 & 45566258 & 25168687 & 7760589 & 155864768 \\
\hline \multicolumn{7}{|l|}{ Output variables ${ }^{126}$} \\
\hline \multirow{3}{*}{$\begin{array}{r}\text { Volumetric water sold } \\
\text { (cubic meters) }\end{array}$} & Public-public & 30 & 53131 & 27054 & 16346 & 119500 \\
\hline & Public-private & 51 & 42004 & 22509 & 12251 & 99224 \\
\hline & All & 81 & 46125 & 24723 & 12251 & 119500 \\
\hline \multirow{3}{*}{$\begin{array}{r}\text { Served population } \\
\text { with piped water } \\
\text { (persons) }\end{array}$} & Public-public & 30 & 38789 & 20704 & 9727 & 94669 \\
\hline & Public-private & 51 & 11820 & 4684 & 3144 & 27684 \\
\hline & All & 81 & 21809 & 18462 & 3144 & 94669 \\
\hline \multicolumn{7}{|c|}{ Environmental variables } \\
\hline \multirow{3}{*}{$\begin{array}{r}\text { Managerial ownership } \\
\text { (dummy variable) }\end{array}$} & Public-public & 30 & 1 & 0 & 1 & 1 \\
\hline & Public-private & 51 & 0 & 0 & 0 & 0 \\
\hline & All & 81 & 0.37 & 0.49 & 0 & 1 \\
\hline \multirow{3}{*}{$\begin{array}{r}\text { Target population over } \\
\text { total water connections } \\
\text { share }\end{array}$} & Public-public & 30 & 20.30 & 6.43 & 12.81 & 37.46 \\
\hline & Public-private & 51 & 57.99 & 50.30 & 14.26 & 316.95 \\
\hline & All & 81 & 44.03 & 43.95 & 12.81 & 316.95 \\
\hline
\end{tabular}

WUs: Urban water utilities.

\subsection{Study results and discussion}

\subsubsection{Efficiency and market organization}

In light of the 'service-expanding' objective of the Ugandan urban water sector like other similar sectors in most developing countries, technical inefficiency implies that utilities can potentially increase their output without changing their input levels relative to their respective group (for individual WUs) and meta-frontier (for WU-groups). Table 4.2 provides the bias-corrected technical efficiency estimates relative to the (i) specific group's best practice frontier and (ii) overall urban water distribution technology (defined by the metafrontier).

\footnotetext{
${ }^{126}$ The volumetric water sold variable across both WU-groups is higher than the corresponding served population (SerP) variable across both groups. Likely, the average utility across both groups sells high cubic meters of water per individual connections that are not shared by more than one household. On the other hand, it is likely that some water is sold to water tankers or other private vendors - whose customers do not end up into the SerP counts for both WUgroups. While we lack sufficient proof especially for the later observation, it is unlikely that either situation occurs differently across both WU-groups.
} 
The average public-public owned utility produced 78 percent of the potentially attainable output, given prevailing inputs, relative to the water distribution technology across the public-public owned utilities. This was 14 percent more than the average public-private owned utility when assessed relative to the public-private group's best-practice frontier for a given input level.

The technological gap with respect to the public-public owned group's frontier is estimated at 0.83 . This is higher than the public-private group's metatechnology ratio (of 0.74). By implication and given the group-specific inputs, the maximum output that could be produced by specific WUs from either group is 83 percent and 74 percent of the output that is possible if the technology as defined by the metafrontier is used (see Table 4.2). As such, the average public-public and public-private owned utilities can at maximum attain 5 and 10 percent more outputs (i.e., difference between their feasible and actual outputs) respectively, if the metatechnology is adopted. Moreover, the public-private, compared to the public-public owned utilities seem to operate under less favourable environments that are beyond the control of the related utility managers. ${ }^{127}$ We estimated the gaps, similarly to the metatechnology ratio defined in equation 4.5.

Technology gap differences across both WU-groups can be explained by the differently implemented regulatory frameworks in Uganda. While WUs in both groups sign performance contracts with the government (MWE), the public-public owned utilities self-regulate their operations, since the early 2000, through the NWSC (see Muhairwe, 2009). Such internal monitoring helps to improve the public-public owned utilities' technical efficiency. This is evidenced by their shorter technology gap (i.e., the difference between their actual produced outputs and what is feasible, as estimated by the metafrontier). Private management flexibilities among other traits traditionally predominant with the private sector were found insufficiently relevant in advancing performance among utilities structured along public-private partnerships.

\footnotetext{
${ }^{127}$ When compared to the public-public owned utilities, the public-private WUs incur as high operating costs in comparison to their ensuing outputs (see Table 4.1).
} 
Table 4.2: Bias-corrected technical efficiency estimates (DEA VRS)*

\begin{tabular}{|c|c|c|c|c|c|c|c|c|c|}
\hline \multirow[b]{2}{*}{ Group } & \multicolumn{3}{|c|}{ Group frontier } & \multicolumn{3}{|c|}{ Metafrontier } & \multicolumn{3}{|c|}{ Metatechnology ratio $(* *)$} \\
\hline & $\begin{array}{l}\text { Public- } \\
\text { public }\end{array}$ & $\begin{array}{l}\text { Public- } \\
\text { private }\end{array}$ & $A l l$ & $\begin{array}{l}\text { Public- } \\
\text { public }\end{array}$ & $\begin{array}{l}\text { Public- } \\
\text { private }\end{array}$ & $A l l$ & $\begin{array}{l}\text { Public- } \\
\text { public }\end{array}$ & $\begin{array}{l}\text { Public- } \\
\text { private }\end{array}$ & All \\
\hline WUs & 30 & 51 & 81 & 30 & 51 & 81 & 30 & 51 & 81 \\
\hline Mean & 0.781 & 0.638 & 0.732 & 0.648 & 0.465 & 0.586 & 0.829 & 0.736 & 0.797 \\
\hline Median & 0.718 & 0.616 & 0.650 & 0.586 & 0.416 & 0.496 & 0.790 & 0.759 & 0.783 \\
\hline Std. Dev. & 0.176 & 0.211 & 0.211 & 0.173 & 0.196 & 0.199 & 0.128 & 0.239 & 0.205 \\
\hline
\end{tabular}

Exploring utility efficiency estimates overtime provided further insightful trends. ${ }^{128}$ Public-public owned utilities produced 25, 21 and 20 percent less output relative to their respective group frontiers in 2005, 2006 and 2007 (see Table 4.3). The average publicprivate owned utility produced 35,41 and 34 percent less output (given existing inputs) relative to its respective group's water distribution technology in 2005, 2006 and 2007 (see Table 4.3).

Though the public-private compared to the public-public owned utilities were overall found less technical efficient, their metatechnology ratio declined overtime. If the metatechnology as estimated by the metafrontier was adopted given the yearly group's specific resources, the feasible output for the average public-private owned utility would increase overtime. That is, 0.66 (2005), to 0.78 (2006) and to 0.79 in 2007 . In reality however, the average public-private owned utility did not attain these outputs, but 0.65 (2005), 0.59 (2006) and 0.66 in 2007. Nonetheless, it should be noted that the MWE has also introduced performance-based regulation across the public-private owned utilities since mid 2000 (MWLE, 2006: 2007: 2008).

On the other hand, the gap between what is feasible (if the metatechnology is adopted) and what was actually produced (given the yearly group-specific resources) by the average public-public utility, declined overtime. That is, from 8 percent (2005) to 5 percent (2006) and to 3 percent in 2007 (see Table 4.3).

\footnotetext{
${ }^{128}$ We first estimated utilities' technical efficiency within each group and later, across the groups. To estimate the metafrontier for the latter exploration, both groups' data was pooled.
} 
Table 4.3: Yearly bias-corrected technical efficiency estimates*

\begin{tabular}{lclccc}
\hline Group & Period & & Group Frontier & Meta frontier & Metatechnology ratio** \\
\hline Public-public & 2005 & Mean & 0.751 & 0.620 & 0.826 \\
& & Median & 0.721 & 0.567 & 0.802 \\
& 2006 & Mean & 0.790 & 0.663 & 0.835 \\
& Median & 0.720 & 0.617 & 0.789 \\
& \multirow{2}{*}{2007} & Mean & 0.798 & 0.659 & 0.826 \\
& & Median & 0.711 & 0.607 & 0.797 \\
Public-private & & & & 0.656 \\
& \multirow{2}{*}{2005} & Mean & 0.651 & 0.426 & 0.643 \\
& \multirow{2}{*}{2006} & Median & 0.616 & 0.404 & 0.777 \\
& & Mean & 0.593 & 0.466 & 0.787 \\
& \multirow{2}{*}{2007} & Median & 0.602 & 0.486 & 0.794 \\
& & Median & 0.658 & 0.509 & 0.769 \\
\hline * Weighted by the total number of served population per utilities' licensed jurisdiction. & 0.479 &
\end{tabular}

** As earlier defined.

\subsubsection{Economies of scale}

To determine possible scale economies (or diseconomies) among WUs in Uganda, we compared WUs' VRS technical efficiency scores with those computed under NIRS (non increasing returns to scale). We computed NIRS by restricting the sum of weights in equation 1.3 to less than or equal to one $\left(\sum \lambda_{i t} \leq 1\right)$. Identical VRS and NIRS technical efficiency scores signify decreasing returns to scale (DRS) while dissimilar VRS and NIRS technical efficiency scores denote operation in an increasing return to scale (IRS) region (Krasachat, 2003).

Most public-public owned utilities were found to operate under a DRS region. The majority public-private owned WUs were however found to operate under an IRS region (see Table 4.4). 3 and 1 utilities were found to operate, overtime, under a DRS region for the public-public and the public-private owned WUs, respectively. 2 and 5 WUs were found to operate under an IRS region for the public-public and the public-private owned utilities. For the rest public-public owned; 2, 3 and 4 utilities operated under a DRS in 2005, 2006 and 2007. Nevertheless, 3 (2005), 2 (2006) and 1 (2007) utilities were found to operate under an IRS region. Considering the public-private owned WUs, 5, 6 and 9 
utilities were found to operate under an IRS region in 2005, 2006 and 2007. During the same period, 6, 5 and 2 WUs operated under a DRS region.

Table 4.4: Return to scale estimates

\begin{tabular}{lccclccc}
\hline \multicolumn{5}{c}{ Public-public owned water utilities } & \multicolumn{3}{c}{ Public-private owned water utilities } \\
\hline UTILITY & $\mathbf{2 0 0 5}$ & $\mathbf{2 0 0 6}$ & $\mathbf{2 0 0 7}$ & UTILITY & $\mathbf{2 0 0 5}$ & $\mathbf{2 0 0 6}$ & $\mathbf{2 0 0 7}$ \\
Arua & D & D & D & Adjumani & D & I & D \\
Bushenyi & I & I & I & Bugiri & D & I & I \\
FPortal & I & D & D & Busia & I & D & I \\
Kabale & I & D & D & Buwenge & I & I & I \\
Kasese & I & I & I & Kaliro & I & I & I \\
Lira & D & I & I & Kalisizo & D & D & D \\
Masaka & D & D & D & Kamuli & I & I & I \\
Mbale & I & D & D & Kapchorwa & I & I & I \\
Soroti & D & I & D & Kayunga & I & D & I \\
Tororo & D & D & D & Kiboga & I & I & D \\
& & & & Kitgum & I & D & I \\
& & & & Kumi & D & D & I \\
& & & & Luwero & D & I & I \\
& & & & Moyo & I & I & I \\
& & & & Rukasongola & D & I & I \\
& & & & Wobulenzi & I & I & I \\
\hline
\end{tabular}

I: increasing returns to scale, D: decreasing returns to scale.

In terms of the urban water market characterization, WUs operating under a DRS region have reached and exceeded their optimum water distribution capacity. That is, in terms of attaining optimal services provision with the existing resources. To accommodate potential growth in demand, these utilities could either split-up or prioritize individual rather than shared piped water connections. Given the positive correlation between household income (better education, etc) and increased willingness and ability to connect to individual water connections (see Larson et al., 2006), such would subsequently reinforce cross-subsidized services to low income customers.

WUs operating under an IRS region could on the other hand, merge with other utilities. This would certainly involve increased investments in infrastructure and human development among other aspects. Such would nonetheless, allow for increased effectiveness among WUs - in terms of water mains' expansion (to new customers) and 
maintenance (for existing customers) at affordable user rates. Besides, utilities could more so, exploit customer density economies and benefit from increased collections for re-investment.

Learning from a meta-regression analysis of 43 studies on scale and scope economies between public and privately-owned WUs, Carvalho et al. (2012) acknowledge that there is no consensus in literature on the preferable optimal operation sizes for urban WUs. They however note that, small compared to large WUs enjoy significant scale economies. In reality nonetheless, small-sized utilities rarely benefit from these economies of scale owing to their low output levels. Mizutani and Urakami, (2001) identified 766,000 as the optimal size of water consumption population in Japan. They examined 112 WUs in 1994 with a cost-function. Across both WU-groups in Uganda, diseconomies of scale happen after 29,868 customers have been served across utilities' service areas. This service coverage corresponds to about 53,551 cubic meters of delivered water. To identify utilities' optimal sizes, we computed the average of all firms operating under IRS and DRS regions for the three years (2005-2007).

\subsubsection{Managerial ownership and utilities efficiency}

To further explain performance disparities between both WU-groups, we explored in a second stage ${ }^{129}$ interlinkages between utilities' technical efficiency and their extents in market capture and structure (see Section 4.5). Increases in the share of target population over the total active water connections were associated with declined efficiency. This was however, not significant (see Table 4.5). Public-public managerial ownership was found to be significantly and positively linked to increased WUs' efficiency. Public-public rather than public-private organizational arrangement was linked to a 15 percent increase in utilities' efficiency.

\footnotetext{
${ }^{129}$ That is, similar to Simar and Wilson (2007).
} 
This positive outcome attests the inherent links between efficiency and effectiveness. Indeed, to achieve a priori specified performance targets, (strongly) regulated utilities are motivated to improve their technical efficiency. Across the public-public rather than the public-private owned utilities in Uganda, exemplary performance is quarterly rewarded with bonuses, cash prizes, trophies and staff promotions (Muhairwe, 2009). Poorly performing managers, for more than 3 consecutive months, are demoted or laid off.

\section{Table 4.5: Efficiency determinants}

\begin{tabular}{lccc} 
Dependent variable: Bias-corrected technical efficiency & estimates relative to the metafrontier \\
\hline & Parameter & Standard deviation & P-value \\
Constant $(\mathrm{N}=81)$ & 0.431 & 0.047 & $0.000^{(* * *)}$ \\
Managerial ownership (public-public $=1$ ) & 0.147 & 0.047 & $0.002^{(* * *)}$ \\
Share of target population over total water connections & -0.00009 & 0.001 & 0.895 \\
Sigma constant & 0.190 & 0.016 & $0.000^{(* * *)}$ \\
\hline
\end{tabular}

${ }^{(* * *)}$ statistically significant at all levels (10, 5 and 1 percent, respectively), N: observed sample size

\subsection{Conclusion}

In response to the late 1990s neoliberalistic urban water sector reforms, two managerial ownership structures emerged in Uganda; the public-public and the public-private. Using a two-stage double bootstrap truncated regression metafrontier technique; this chapter examined first, technical efficiency differences and technology gaps between these two heterogeneous urban WU-groups in Uganda. Secondly, we explored whether WUs' technical efficiency is significantly different across both WU-groups and whether other utility-specific environmental factors explain performance differences between the groups.

Relative to the accessible water distribution technology across both WU-groups, the public-public owned utilities produced more (78 percent) potentially attainable output given existing inputs. The public-private owned utilities produced much fewer outputs (64 percent) relative to the potentially attainable outputs given existing resources available to utilities within the group. This implies that, both WU-groups can potentially 
increase their output, given existing input resources by 22 (for the public-public) and 36 (for the public-private) percent, relative to their respective best-practice frontiers.

The public-public (compared to the public-private) group's frontier was found much closer to the overall urban water sector best practice frontier - defined by the metafrontier. Such declined technology gap can be as a result of the additional selfmonitoring of WUs under NWSC's mandate. Regular benchmarking for the public-public owned utilities creates and retains intra-group competition that transforms subsequently, in enhanced group performance. The public-public (than public-private) managerial ownership arrangement was found significantly and positively linked to increased WUs' technical efficiency.

Indeed under a public-public (than a public-private) arrangement, investments are more directly linked to service provision. Such facilitates water mains expansion (and maintenance) to new governmental, residential and industrial premises. Since procured private operators under the public-private arrangement only manage existing assets, it is unlikely that they invest in systems' expansion. Following Prasad (2008, see also conclusions by Swyngedouw, 2009), infrastructural investments in urban water supply, especially in the developing countries, are unattractive to private investors.

Studying urban WUs in China, Wang et al. (2011) found a negative correlation between (domestic) private sector participation and investments in fixed assets. Not only do the lumpy investments (in relation to market size) face more than 20 years recovery time; but it is socio-politically impossible for private operators to set their own cost-recovery tariffs. Under these constraints, lighter forms of public-private arrangements including the use of management contracts, will persist in the water supply industry for most developing countries (Davis, 2005).

Besides, the technology gap across the public-private owned utilities was found to decline overtime. Such decline is attributable to the increased performance-based regulation advanced across the utilities by the government. Such initiative, though not as 
advanced as the benchmarking exercises across the public-public owned utilities, can eventually help bridge performance gaps between both groups. Such is likely especially, for the utilities operating under an IRS region.

It is possible that other input (e.g., capital costs) and output (e.g., total active connections) variables define better both WU-groups' production technologies. More so, we acknowledge that other factors that are specific to either WU-groups or/and specific utilities (e.g., customer density, water losses, etc) influence both WU-groups' technical efficiency. Due to data limitations among other methodological constraints (degrees of freedom problems, etc) however, we only accounted for a few of these aspects in this chapter. Consideration of additional production and environmental variables in future follow-up analyses would certainly offer more insights.

Chapter 5 extents this study by comparatively looking at the overall productivity (and its determinants) of the public-public owned urban WUs in Uganda and those in Zambia. 
Annex 4.1: Earlier studies on the role of ownership on urban water supply utilities efficiency

\begin{tabular}{|c|c|c|c|c|}
\hline Author(s) & Data (period, place) & Technique & Variables & Significant (in)efficiency determinants \\
\hline \multicolumn{5}{|c|}{ Private rather than publicly-owned urban WUs are more (significantly) efficient } \\
\hline Crain \& Zardkoodi, 1978 & 112: 88 public, 24 private $(1970$, North America) & CD prod function & 3 inputs; 1 output & (High) OPEX especially, by public utilities \\
\hline Crain \& Zardkoohi, 1980 & 78 (1970, North America) & Multiple regression & 2 inputs; 1 output, $1 \mathrm{Z}$ & High labor costs \& less capital investments \\
\hline Raffiee et al., 1993 & 112: 238 public, 33 private (1989, North America) & $\mathrm{CD}$ cost function & 4 inputs; 1 output & Property rights attenuation in public utilities \\
\hline Estache \& Kouassi, 2002 & 21: 18 public, 3 private (1995-97, Africa) & CD prod function & 5 inputs; 1 output; $3 \mathrm{Z}$ & Corruption \& sector governance \\
\hline Bitran \& Valenzuela, 2003 & 13: 8 public, 5 private $(1998-2001$, Chile ) & Performance indicators & 2 inputs; 3 outputs; $1 \mathrm{Z}$ & Private equity, economies of scale \\
\hline Moreira et al., 2005 & 148: 135 public, 13 private (2002, Brazil ) & CD prod function & 2 inputs; 1 output & Capital and labor overuse \\
\hline Andrés et al., 2008 & 49 (15 years, 8 LA countries) & Econometric & 3 inputs; 3 outputs; $3 \mathrm{Z}$ & Water losses, service continuity and reliability \\
\hline Gassner et al., 2009 & 977: 836 public, 141 private $(1973-2005$, LA \& Cb) & Regression \& DD & 1 input; 5 outputs; $3 \mathrm{Z}$ & Labor productivity \& daily water supply hours \\
\hline Correia \& Marques, 2011 & 68: 14 public, 23 private, 31 SA (2004-05, Portugal) & Translog cost function & 4 inputs; 2 outputs; $5 \mathrm{Z}$ & Scale and scope economies \\
\hline Wang et al., 2011 & 35: 5 public, 30 private $(1998-2008$, China) & Regressions & 1 input; 2 outputs; $6 \mathrm{Z}$ & Per capita income \\
\hline \multicolumn{5}{|c|}{ Public rather than privately-owned urban WUs are more (significantly) efficient } \\
\hline Lynk, 1993 & 10 private (1979/80 to $1987 / 88$, United Kingdom) & Multiproduct cost function & 3 inputs; 3 outputs; $2 \mathrm{Z}$ & Joint service production \\
\hline Bhattacharyya et al., 1994 & 257: 225 public, 32 private (1992, North America ) & TGV cost function & 2 inputs; 1 output; $1 \mathrm{Z}$ & Excessive capitalization under rate of return regulation \\
\hline Shaoul, 1997 & 10 private (1985-1999, England and Wales) & Accounting techniques & 3 inputs; 3 outputs & Decreased technological change \\
\hline García-Sánchez, 2006 & 24: (1999, Spain) & DEA, tobit regression & 3 inputs; 3 outputs; $10 \mathrm{Z}$ & Population density \\
\hline Saal et al., 2007 & 10 private (1985-2000, England and Wales) & GPP index & 3 inputs; 4 outputs; $4 \mathrm{Z}$ & Undue operation scale, technical economic losses \\
\hline \multicolumn{5}{|c|}{ No significant efficiency difference between public and privately-owned urban WUs } \\
\hline Feigenbaum \& Teeples, 1983 & 319: 262 public, 57 private (1970, North America ) & Hedonic cost function & 4 inputs; 1 output; $5 \mathrm{Z}$ & High labor, energy and purchased water costs \\
\hline Hausman et al., 1986 & 64: 32 public, 32 private (1899, North America ) & Ordinary Least Squares & 7 inputs; 3 outputs & Rates of return \\
\hline Byrnes et al., 1986 & 127: 68 public, 59 private (1976, North America ) & Linear programming & 7 inputs; 1 output & Scale of operation \\
\hline Teeples \& Gyler, 1987 & 119: 67 public, 52 private (1980, North America ) & Dual cost function & 8 inputs; 1 output; $8 \mathrm{Z}$ & Model mis-specification \\
\hline Lambert et al., 1993 & 270: 238 public, 32 private ( North America ) & DEA & 4 inputs; 1 output & Capital, labor, energy and material overuse \\
\hline Estache \& Rossi, 2002 & 50: 30 public, 20 private (1995, Asia and Pacific) & $\mathrm{CD}$ cost function & 1 input; 3 outputs; $6 \mathrm{Z}$ & High labor costs but low service coverage rates. \\
\hline Saal \& Parker, 2004 & 10 private (1985-1999, England and Wales) & PIN, Translog cost function & 5 inputs; 1 output & High labor productivity growth \\
\hline Kirkpatrick et al., 2006 & 14, out of $110(2000$, Africa) & DEA, CD cost function & 3 inputs; 2 outputs; $7 \mathrm{Z}$ & Regulation, but not significant \\
\hline Souza et al., 2007 & 164: 149 public, 15 private $(2002$, Brazil) & Translog cost function & 2 inputs; 1 output; $4 \mathrm{Z}$ & Cost (in) efficiency \\
\hline
\end{tabular}

* i.e., for small-scaled utilities where privately-owned WUs are found to be more cost-efficient than the publicly-owned utilities.

Z's: Environmental variables, CD: Cobb-Douglas, Prod: Production, LA: Latin America, Cb: Caribbean, RE: Random effects, FE: Fixed effects, DD: Difference-in-difference based on the propensity score nearest-neighbour matching, SA: Semi autonomous, TGV: Translog generalized variable, PR: Provincial regulated water operators, OPEX: Operating costs, TFP: Total factor productivity, GPP: Generalized parametric productivity, PIN: Price index numbers. 


\section{CHAPTER 5: Productivity and productivity determinants in urban water supply $^{130}$}

\subsection{Introduction}

Due to the lack of reliable data, earlier literature has ignored urban WUs' productivity aspects for most developing countries. Previous literature largely focuses on developed countries (Ashton, 2000a; Garcia and Thomas, 2001; Coelli and Walding, 2005; Saal et al., 2007; Marques, 2008b; De Witte and Marques, 2011; Abbott and Cohen, 2009). Using a rich and self-collected dataset from Uganda and Zambia, we explore urban WUs' productivity changes since the mid 2000s. Although some data are available online from annual sector reports, field research was necessary to counteract inherent operational data challenges - such as inexistency, inconsistency or inaccuracy.

This chapter contributes to the literature in two aspects. First, it analyses urban water provision in Uganda and Zambia between 2007 and 2009. For detailed information on the specific reform processes across both sectors, see respectively, Chapters 2 and 3. Uganda and Zambia share comparable operational environments including relatively stable political and macro-economic environments (important for long-term planning), topography, weather conditions, urban population densities and increasing demands for quality and adequate water services delivery. The conclusions of this chapter do not only apply to the two countries however, but to other African countries that have implemented (or are in the process of implementing) organizational and institutional reforms.

As a second contribution, we focus on efficiency and effectiveness aspects of water supply and link them to WUs' productivity growths. In the prospect of an unserved urban population of about 35 percent (WSP-WB, 2009), the call for efficiency (or doing things right) seems less important. Many people would consider the main priority of WUs as

\footnotetext{
${ }^{130}$ This chapter is adapted from "Productivity and its determinants in the African urban water supply" submitted to the Data Envelopment Analysis Journal (with Kristof De Witte). We are grateful to the participants of the VI North American Productivity Workshop, the 15th African International Water Congress and Exhibition and three anonymous referees for insightful comments on an earlier version of this paper. We would like to thank the National Water Supply and Sanitation Council - the water supply and sewerage service regulator in Zambia and the National Water and Sewerage Corporation - the national urban water and sewerage service provider in Uganda, for allowing access to and use of the rich and quality-controlled datasets used in this chapter.
} 
providing services to all citizens, rather than providing such efficiently but to a few (urban and rich) customers. We examine these competing goals in section 5.4.2. We find that a trade-off between efficiency and effectiveness can exist in the short run. This is possible for example, if performance improvements (e.g., in terms of increased metering) entail large fixed costs. Given increasing demands amidst limited raw water resources, we nonetheless conclude that effectiveness (attaining actual targets) is as important as working efficiently (i.e., not wasting resources in the process of providing services) at least, in the long-run.

To assess WUs' productivity improvements over time, we apply an output-oriented Malmquist productivity index (MPI). The MPI was first introduced by Caves et al. (1982) after Malmquist (1953). Using a MPI, this paper goes beyond the usual partial (singlefactor or uni-dimensional) productivity measures that have been used as a monitoring device by most African urban water sector stakeholders (WSP-WB, 2009; Tynan and Kingdom, 2002). Partial indicators such as staff productivity, barely provide the true productivity. In contrast, they provide simple ratios of output to input variables for particular utilities (Fried et al., 2008; Coelli et al., 2005, see also Section 1.4.1).

Various variants of the MPI have been suggested (e.g., Grosskopf, 1993; Ray and Desli, 1997; Färe et al., 1998; Balk, 2001). Färe et al. (1994) decomposed the index under constant returns to scale (CRS) into productivity changes due to mutually exclusive technical and efficiency components. By adding a VRS constraint, the authors further decomposed the estimated efficiency changes into pure technical change and scale efficiency changes.

While it is important to measure WUs' productivity growth against VRS in order to distinguish productivity gains or losses due to scale effects (Grifell-Tatje and Lovell, 1995), VRS assumptions result into linear programming infeasibilities especially when more than one production period is observed (Shestalova, 2003; Pastor and Lovell, 2005). Under the service maximization (i.e., output-orientation) assumption, such infeasible utilities remain efficient but under arbitrary declined outputs. As such, they are not 
involved in the construction of the specific period's technology frontier (Tone, 2004). To address this problem, we follow the MPI of Pastor et al. (2011) that (i) allows utilities to experience either technical progress or regress and (ii) maintains earlier computed estimates, even when new additional analysis periods are added.

Pastor et al. (2011) use a biennial MPI framework that is inspired on DEA (see Section 1.4). We adapt the biennial MPI to a bootstrapped procedure (Simar and Wilson, 1998: 1999). The latter allows us to replicate the underlying sampling distribution and, as such, account for the noise in the data. Indeed, measurement errors are likely, given the inevitable incentives faced by WUs in most developing countries to modify or amplify their operational data towards their national MDGs attainment.

Despite its uniqueness, the data has two limitations. First, due to data constraints, the paper describes productivity changes across only two urban WU sectors in Africa. This hinders the control of country-specific exogenous factors (e.g., corruption, customer's wealth) that potentially influence utilities productivity overtime. Second, the analysis is over a limited time period of three years. Only after mid 2000, consistent operational information has been documented across both urban sectors. Consequently, we are unable to (i) draw causal links between the implemented reform strategies and the resultant productivity improvements, and (ii) draw strong economic policy recommendations based on the implemented reforms. Nevertheless, it is insightful to describe and explain observed productivity changes across urban WUs in Africa. Particularly as we link them to various utility-specific environmental factors and explore their correction with eventual utilities' effectiveness.

The remainder of the chapter is organized as follows. The subsequent section details the productivity growth conceptual and analytical framework. The data and the model applied for the analysis are described in section 5.3. Productivity growth estimates for both sectors are explored and explained in detail within section 5.4. A final section concludes the chapter. 


\subsection{Productivity and productivity change assessment}

\subsubsection{Productivity assessment}

Productivity can be considered as the ratio between produced products (or delivered services) and the used resources. In the literature, a major distinction has been made between partial and multifactor measures (see Section 1.4.1). Restricting inputs and outputs to uni-dimensional interpretations, however, can result in the misinterpretation of a specific firm's productivity. Multifactor indexes account for heterogeneous inputs to produce multiple outputs. This chapter concentrates on these multifactor measures.

Consider a set of $N$ inputs $x$ and $M$ outputs $y$ for $\mathrm{WU}_{i}$. To aggregate the inputs and outputs into a single productivity measure at time $t$, market prices (input costs and output revenue) are often used as weights. In the absence of explicit price information, implicit prices are used as shadow weights on each input and output. As such, each input is weighted by weight $a$ and each output by weight $b$ to obtain an aggregate productivity measure (index) delineated as:

$$
\text { Productivity index }=\frac{\sum_{i=1}^{M} b y^{t}}{\sum_{i=1}^{N} a x^{t}} ; \quad i=\mathrm{WU} 1,2,3 \ldots \ldots K
$$

To generate optimal weights (i.e., $a$ and $b$ ) that maximizes each WU's productivity, the DEA linear programming algorithm can be used (equation 5.2, see also Coelli et al., 2005). DEA generates endogenously, the implicit weights for all observed inputs and outputs.

$$
\begin{aligned}
& \max _{b, a}\left(b^{\prime} y_{i} / a^{\prime} x_{i}\right) \\
& \text { s.t } \quad\left(b^{\prime} y_{i} / a^{\prime} x_{i}\right) \leq 1 \\
& \quad b, a \geq 0 ; a^{\prime} x_{i}=1 ; \quad i=1,2,3 \ldots \ldots . K
\end{aligned}
$$


Where $a, b, y_{i}, x_{i}$, are as earlier defined and $a^{\prime} x_{i}=1$ allows for the estimation of finite optimal weight solutions.

\subsubsection{Productivity change assessment}

Productivity change assessment explores changes in productivity over time. Various productivity growth models have been outlined (e.g., in Färe et al., 2011; Fried et al., 2008; Sherman and Zhu, 2006; Coelli et al., 2005 and references therein). We apply the biennial MPI (Pastor et al., 2011). The latter is convenient in the current setting as, first, it avoids infeasible solutions, which are likely in an intertemporal analysis. Second, it maintains previously computed productivity estimates when additional time periods are considered. Third, it captures utility productivity changes due to either technical progress or regress. ${ }^{131}$ Finally and alike most MPIs, it does neither require explicit price information (on observed inputs and outputs), nor prior information on the production function of or the relationship between observed inputs and outputs.

By use of distance functions, ${ }^{132}$ biennial MPI estimates the radial distance of the observed output and input vectors for $\mathrm{WU}_{i}$ in periods $t$ (first analysis period) and $t+1$ (subsequent analysis period) relative to a biennial technology $\left(\mathrm{T}^{\mathrm{B}}\right)$ that is made up of the convex hull of both period $t$ and $t+1$ technologies (i.e., $\mathrm{T}^{\mathrm{t}}$ and $\mathrm{T}^{\mathrm{t}+1}$ technologies, respectively). Assuming a $\mathrm{WU}_{i}$ with different sets of $N$ inputs $x$ and $M$ outputs $y$ in periods $t$ and $t+1$; its biennial technology $\left(\mathrm{T}^{\mathrm{B}}\right)$ would comprise the product of both period's technologies. Period $t\left(\mathrm{~T}^{\mathrm{t}}\right)$ and $t+1\left(\mathrm{~T}^{\mathrm{t}+1}\right)$ technologies can respectively be defined as:

$$
T^{t}=\left\{(x, y) \in \mathfrak{R}_{+}^{N+M} \mid x \leq \sum_{i=1}^{K} \lambda_{i}^{t} x_{i}^{t} \cdot y \geq \sum_{i=1}^{K} \lambda_{i}^{t} y_{i}^{t} ; \lambda_{i}^{t} \geq 0 ; i=1,2,3 \ldots . K\right\}
$$

\footnotetext{
${ }^{131}$ Pastor et al. (2011) point to the non-circularity/non-transitivity of the biennial MPI. We follow Fried et al. (2008) in that we assume the circularity property to be of less importance in the present case.

${ }^{132}$ To aggregate multi-input and output variables in productivity measurement, distance functions do not require market price information (for observed inputs and outputs) as is the case for some price-number indexes such as Laspeyres, Paasche, Fisher, Bennet-Bowley and Tòrnqvist. This permits productivity measurement for most public sectors especially in the developing countries, for whose explicit price information is often missing or hard to compute (see Fried et al., 2008).
} 


$$
T^{t+1}=\left\{(x, y) \in \mathfrak{R}_{+}^{N+M} \mid x \leq \sum_{i=1}^{K} \lambda_{i}^{t+1} x_{i}^{t+1} \cdot y \geq \sum_{i=1}^{K} \lambda_{i}^{t+1} y_{i}^{t+1} ; \lambda_{i}^{t+1} \geq 0 ; i=1,2,3 \ldots . K\right\}
$$

where $\mathfrak{R}_{+}^{N+M}$ represents $\mathrm{WU}_{i}$ 's input and output vectors and $\lambda_{i}^{t} \geq 0$ imposes a CRS technology. Under VRS assumptions, this CRS constraint is relaxed to $\sum_{i=1}^{K} \lambda_{i}^{t}=1$. In case of a two-period analysis, biennial MPI technology is analogous to a metafrontier technology that envelopes all observations in two consecutive analysis periods (Pastor and Lovell, 2005). In the event of more than two analyses periods, a series of $t-1$ (number of time periods - 1) overlapping biennial technologies exist for each pair-wise comparison of adjacent periods (Pastor et al., 2011).

Based on the $\mathrm{T}^{\mathrm{B}}$ (biennial technology), biennial output distance functions can thus be defined assuming either CRS or VRS. Output distance functions specify the maximal proportional expansion of output (services) vectors, given constant input vectors. Input distance functions on the other hand, indicate the maximal proportional contraction of input (resources) vectors, given unit output vectors. In the VRS case for $\mathrm{WU}_{i}$, this can be illustrated as:

$$
D_{o v}^{B}\left(x_{i,} y_{i}\right)=\min \left\{\theta>0 \mid\left(x_{i,} y_{i} / \hat{\theta}\right) \in T_{o v}^{B}\right\}
$$

where $D_{o v}^{B}\left(x_{i}, y_{i}\right)$ represents the maximal radial expansion of $\mathrm{WU}_{i}$ 's productivity given existing resources and relative to the biennial VRS (best-practice) technology $\left(T_{o v}^{B}\right)$. Given the biennial output distance functions, the biennial VRS MPI estimator can be defined as:

$$
\operatorname{MPI}_{o v}^{B}\left(x_{i}^{t}, y_{i}^{t}, x_{i}^{t+1}, y_{i}^{t+1}\right)=\frac{D_{o v}^{B}\left(x_{i}^{t+1}, y_{i}^{t+1}\right)}{D_{o v}^{B}\left(x_{i}^{t}, y_{i}^{t}\right)}
$$


Where the numerator and the denominator represent, respectively, the radial distance of $\mathrm{WU}_{i}$ in period $t+1$ and $t$ relative to the biennial technology. The biennial CRS MPI measure $\left(M P I_{o c}^{B}\right)$ is analogously denoted by replacing subscripts $v$ (VRS) by $c$ (CRS). Since both $t+1$ and $t$ technologies are included in the biennial technology, estimating the geometric mean of both technologies, as is the case in Färe et al. (1994), is no longer necessary in the present MPI measurement. Assuming an output orientation, Figure 5.1 illustrates the biennial MPI framework, with given inputs, between periods $t$ and $t+1$.

\section{Figure 5.1: Biennial Malmquist productivity index framework}

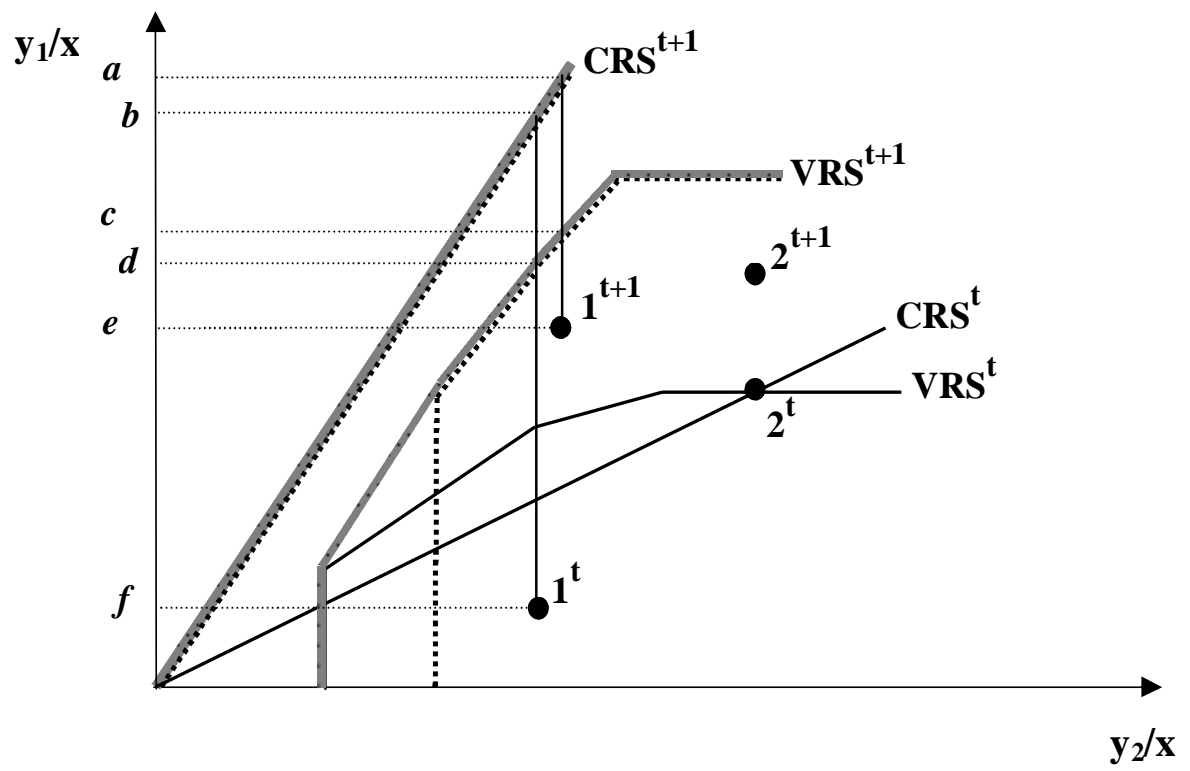

Source: Authors illustration.

Consider utilities 1 and 2 observed in both periods $t$ and $t+1$. Both CRS and VRS biennial technologies ( $T_{o c}^{B}$ and $T_{o v}^{B}$, respectively) are defined in grey lines. The corresponding period $t+1$ and $t$ technologies are respectively denoted in dotted and plain lines. Following equation 5.6, the biennial VRS MPI ( $\left.M P I_{o v}^{B}\right)$ measure of utility 1 can be defined as $e / c^{*} d / f$; and the biennial CRS MPI ( $\left.M P I_{o c}^{B}\right)$ measure as $e / a^{*} b / f$. Where $c, d, a$ and $b$ are all located on the grey lines. Biennial MPI outcome values can either be 
smaller, equal or larger than one. This indicates respectively for $\mathrm{WU}_{i}$, deteriorating, constant and improving productivity between periods $t$ and $t+1$ relative to the biennial VRS (best-practice) or CRS (benchmark) technology and given certain input resources.

\subsubsection{Productivity change decomposition}

The biennial MPI framework allows us to decompose estimated productivity improvements over time, into several productivity drivers including technical change (TC or frontier shift), technical efficiency change (TEC) and scale change (SC). The frontier shift (TC) denotes utilities' innovative ability (inability) to produce more (or less) with a given vector of input units in period $t+1$ compared to the levels feasible in the base period (period $t$ ) relative to the biennial technology. Based on the $\mathrm{WU}_{i}$ 's choice of input and output combinations, its technical change with respect to the best practice (VRS) biennial technology can be denoted as:

$$
\begin{aligned}
T C_{o v}^{B}\left(x^{t}, y^{t}, x^{t+1}, y^{t+1}\right) & =\frac{d_{o v}^{B}\left(x^{t+1}, y^{t+1}\right)}{d_{o v}^{B}\left(x^{t}, y^{t}\right)} / \frac{d_{o v}^{t+1}\left(x^{t+1}, y^{t+1}\right)}{d_{o v}^{t}\left(x^{t}, y^{t}\right)} \\
& =\frac{d_{o v}^{B}\left(x^{t+1}, y^{t+1}\right)}{d_{o v}^{B}\left(x^{t}, y^{t}\right)} \cdot \frac{d_{o v}^{t}\left(x^{t}, y^{t}\right)}{d_{o v}^{t+1}\left(x^{t+1}, y^{t+1}\right)}
\end{aligned}
$$

Where subscripts $o$ and $v$ denote, respectively, output orientation and VRS assumptions. $T C_{o v}^{B}$ values of more than one denote technological progress in period $t+1$ compared to period $t$. In other words, it indicates that the best practice technology in period $t+1$ along the ray denoted by $\left(x^{t+1}, y^{t+1}\right)$ is closer to the biennial best practice frontier than is the best practice technology in period $t$ along the ray defined by $\left(x^{t}, y^{t}\right)$. On the contrary, $T C_{o v}^{B}$ values of less than one indicate technological regress (decline) in period $t+1$ compared to period $t$. 
Technical efficiency change (TEC) estimates the distance shift of produced outputs in relation to the maximum potential outputs attainable. It is measured by the extent to which a WU can radially expand its observed output vector to operate on or closer to the best practice frontier. TEC (also called catch-up, learning or diffusion) is represented by:

$$
\operatorname{TEC}_{o v}^{B}\left(x^{t}, y^{t}, x^{t+1}, y^{t+1}\right)=\frac{d_{o v}^{t+1}\left(x^{t+1}, y^{t+1}\right)}{d_{o v}^{t}\left(x^{t}, y^{t}\right)}
$$

With $T E C_{o v}^{B}$ being the technical efficiency change measure under a VRS outputorientation. $T E C_{o v}^{B}$ values of less than, equal or more than one imply decreased, constant and increased efficiency change in period $t+1$ in relation to the base period $t$.

Relaxing the CRS benchmark technology to assume VRS, ${ }^{133}$ biennial MPI scores can further be decomposed into scale change (SC). SC measures the deviation resulting from the adoption of VRS technology in relation to the underlying CRS technology. It reflects a movement towards the technologically optimal scale of operation given the biennial technology. SC components are defined as:

$$
\begin{aligned}
S C_{o}^{B} & =M P I_{o c}^{B} / M P I_{o v}^{B} \\
& =\frac{D_{o c}^{B}\left(x_{i}^{t+1}, y_{i}^{t+1}\right)}{D_{o c}^{B}\left(x_{i}^{t}, y_{i}^{t}\right)} / \frac{D_{o v}^{B}\left(x_{i}^{t+1}, y_{i}^{t+1}\right)}{D_{o v}^{B}\left(x_{i}^{t}, y_{i}^{t}\right)}=\frac{D_{o c}^{B}\left(x_{i}^{t+1}, y_{i}^{t+1}\right)}{D_{o c}^{B}\left(x_{i}^{t}, y_{i}^{t}\right)} \cdot \frac{D_{o v}^{B}\left(x_{i}^{t}, y_{i}^{t}\right)}{D_{o v}^{B}\left(x_{i}^{t+1}, y_{i}^{t+1}\right)}
\end{aligned}
$$

Where $S C_{o}^{B}$ is the scale change measure. $o c$ indicates an output-orientation under CRS. $S C_{o}^{B}$ values of more than, equal or less than one imply, respectively, increased, constant or decreased scale effects between period $t+1$ and period $t$.

\footnotetext{
${ }^{133}$ VRS permits efficiency increment and decline with respect to firm sizes. Assuming CRS implies that firms are able to linearly scale up or down their input and/or output variables without increasing or decreasing their efficiency. In section 5, we use Wilson (2010)'s R routine that allows us to estimate a bootstrapped biennial Malmquist VRS model.
} 
Overall, CRS biennial MPI measure is a product of the VRS biennial MPI measure (product of technical change and technical efficiency change) and scale change effects. That is:

$$
\begin{aligned}
& M P I I_{o c}^{B}=M P I_{o v}^{B}, S C_{o}^{B} \\
& =\frac{d_{O V}^{t+1}\left(x^{t+1}, y^{t+1}\right)}{d_{o v}^{t}\left(x^{t}, y^{t}\right)} \cdot \frac{d_{O V}^{B}\left(x^{t+1}, y^{t+1}\right)}{d_{O V}^{B}\left(x^{t}, y^{t}\right)} \cdot \frac{d_{O V}^{t}\left(x^{t}, y^{t}\right)}{d_{O V}^{t+1}\left(x^{t+1}, y^{t+1}\right)} \cdot S C_{O}^{B} \\
& =\frac{d_{O V}^{t+1}\left(x^{t+1}, y^{t+1}\right)}{d_{O v}^{t}\left(x^{t}, y^{t}\right)} \cdot \frac{d_{O V}^{B}\left(x^{t+1}, y^{t+1}\right)}{d_{O V}^{B}\left(x^{t}, y^{t}\right)} \cdot \frac{d_{o v}^{t}\left(x^{t}, y^{t}\right)}{d_{O V}^{t+1}\left(x^{t+1}, y^{t+1}\right)} \cdot \frac{D_{O C}^{B}\left(x_{i}^{t+1}, y_{i}^{t+1}\right)}{D_{O C}^{B}\left(x_{i}^{t}, y_{i}^{t}\right)} \cdot \frac{D_{O V}^{B}\left(x_{i}^{t}, y_{i}^{t}\right)}{D_{O V}^{B}\left(x_{i}^{t+1}, y_{i}^{t+1}\right)}
\end{aligned}
$$

Where the first, second and last components represent $\mathrm{WU}_{i}$ 's technical efficiency change, technical change and scale change components.

To estimate the $M P I_{o c}^{B}$ (or $M P I_{o v}^{B}$ ) measures, distance functions $(d)$ need to be revealed. Following earlier literature, we estimate the distance functions $(d)$ by use of the nonparametric DEA technique (see Section 1.4.1). As a major drawback, the original DEA models are deterministic in that they do not assume noise or measurement errors, which might be present in the data (see Section 5.3.1). Simar and Wilson $(1998,1999)$ suggest using bootstrap resampling procedures to avoid this shortcoming. The bootstrap algorithm approximates the unknown sampling distribution of the DEA estimator by simulating its data generation process given a certain statistical model (see also Section 1.4).

As a major advantage, the bootstrap reveals information on the bias, standard deviation and the bootstrap confidence interval bounds of the DEA estimators (for a detailed discussion, see Simar and Wilson, 1999). We estimate the technical change $\left(\mathrm{TC}_{\mathrm{vr}}\right)$, technical efficiency change $\left(\mathrm{TEC}_{\mathrm{vrs}}\right)$ and scale change $(\mathrm{SC})$ effects by relying on the distance functions estimated by use of a bootstrapped DEA. 


\subsection{Data and model specification}

\subsubsection{Data and field study}

Walter et al. (2009) point to the absence of reliable data as a key factor limiting quantitative productivity analyses in the water sector. This is particularly relevant for most developing economies where consistent water and sanitation data are missing owing partly to fragmented service delivery and, partly to the inherent inconsistencies in data (with frequent sector restructuring). Consequently, for most countries, only decentralized and non-harmonized databases exist (Marques, 2008b; Corton and Berg, 2009).

For our analysis, we first obtained utilities' operational data from the annual sector reports available online via NWASCO (in Zambia)'s and the NWSC (in Uganda)'s websites. Second, to cross-check the validity and fill-in any missing information, a field visit to both agencies between September and November 2009 was arranged. Both agencies have a central computerized information management system that captures, documents and stores all existing WUs' operational information. During the visits, we were allowed access to this detailed information. Moreover, related sector publications from the Ministries concerned with water supply development (the MWE in Uganda and the MLGH in Zambia) were used for the study.

By 2009, there were 10 urban WUs in Zambia ${ }^{134}$ and 23 in Uganda (i.e., public-public owned). As consistent data was unavailable for years prior to 2007 (especially for the Zambian WUs), we considered 2007 as our base year. After removing ${ }^{135}$ outliers and observations with incomplete data, we analyzed a total of 23 urban WUs (9 Zambian and 14 Ugandan) for the periods between 2007 and 2009. ${ }^{136}$ The sample represents 90 and 61 percent of the total urban WUs (i.e., under public managerial ownership) in Zambia and Uganda, and about $178 * 10^{6}$ and $1.2 * 10^{5}$ volumetric amounts of drinking water in 2009 , respectively.

\footnotetext{
${ }^{134}$ These are commonly referred to as commercial utilities (refer to Table 3.2). The $11^{\text {th }}$ utility as shown in the Table was established by the end of 2009 and became functional by early 2010 (NWASCO, 2010a).

${ }^{135}$ In addition to dropping utilities with missing data, we omitted observations with extreme ratios (between considered inputs and outputs). For other approaches in detecting and dealing with outliers, see Emrouznejad and De Witte (2010: 1577).

${ }^{136}$ While three years are not enough for an extensive productivity trends' exploration, we provide insightful productivity differences among both WU-groups, given our data limitations.
} 


\subsubsection{Model specification}

The input and output variables applied in the analysis are in line with previous literature (e.g., Marques, 2008b; Corton and Berg, 2009; Ashton, 2000a; Saal et al., 2007; Coelli and Walding, 2005). Following Marques (2008b), the input and output values are better expressed in quantities rather than in monetary values, especially in cross-country analyses. The former do not (i) require any a priori updating that is prone to inevitable distortions resulting from different cost accounting approaches across sectors, (ii) depend on the prevailing water tariffs - that could influence subsequent water sales and, (iii) demand prior monetary conversion. Similarly, Coelli and Walding (2005) argue against $a$ priori monetary conversion into real measures. The authors show that the search for an appropriate and specific price deflator apart from the normally used Consumer Price Index is challenging (especially with the unavailability of comparable data) and could be misleading.

To proxy labor and capital, we use the number of employees and network length (in meters) as input variables. ${ }^{137}$ Zambian utilities encounter higher labor and capital expenditures than their Ugandan counterparts. This is particularly exemplified by their higher employee count and water mains (network) length. Over the three years, the average Zambian utility employs more than seven times the total staff engaged by the average Ugandan utility (see Table 5.1). Employee count is found to increase overtime by 6.4 percent i.e., from 265 in 2007 to 282 in 2009.

This is higher than the Ugandan utilities whose employee count is found to increase by 5.7 percent. The utility with the highest (and lowest) number of employees engages 782 (and 65) persons in Zambia but 92 (and 18) persons in Uganda by 2009. Moreover, Zambian WUs are found to extend their water supply network by more than nine-fold the Ugandan WUs' mains length, overtime. By 2009, the utility with the least (and most) mains is found to establish about 138,000 (and 8,572,000) meters of network in Zambia and about 63,000 (and 390,000) meters of network in Uganda (see Table 5.1).

\footnotetext{
${ }^{137}$ This is contrary to Chapter 4 where owing to data limitations, especially for the public-private owned WU-group, aggregate operating costs were used to proxy utilities inputs.
} 
Water coverage (i.e., the number of served population within specific WUs' licensed jurisdiction) represents the main output. It captures both equity aspects in water service delivery as well as potential utilities' effectiveness trends (as higher water coverage is required for national MDG's attainment). Table 5.1 indicates that more people have access to piped water supply systems for the Zambian than the Ugandan WUs. Zambian WUs supply more than six-fold the population served with piped water systems in Uganda. They (Zambian WUs) serve on average about 360,000 persons while the Ugandan utilities serve about 57,000 customers within their licensed jurisdictions (i.e., between 2007 and 2009).

In relation to their total target population within their licensed jurisdictions, the Zambian utilities serve about 71 percent of their total licensed population while the Ugandan utilities serve on average about 69 percent of their total target population. The WU with the most (and least) coverage is found to serve about 89 (and 57) percent of its total target population in Zambia but 83 (and 46) percent in Uganda (i.e., by 2009, see Table 5.1). Looking at this particular uni-dimensional measure, Zambian utilities are found to be more effective in terms of their licensed-market penetration (customer coverage) than the Ugandan WUs.

Moreover, they have higher water coverage per total network length (about 66 percent) than their Ugandan counterparts who serve about 46 percent of their costumers per mains length. Per employee, Zambian utilities serve fewer (about 1196) customers than urban WUs in Uganda that serve about 1716 customers per staff. In addition to being more effective, Zambian urban WUs are moreover found (in this uni-dimensional perspective) more efficient in their labor and capital resources usage. Evidently, Zambian utilities operate at higher scales. In the subsequent section (5.4), we examine in a multidimensional perspective, how and to what extent, their productivity growths are due to scale changes among other aspects. We compare these results with the findings from the Ugandan WUs. 
Robustness tests with other output variables (including WUs volumetric water sold) delivered very similar outcomes. ${ }^{138}$ To avoid any degrees of freedom (and related dimensionality) problems as discussed in Section 1.4.1, we limited our input and output variables to three.

Table 5.1: Input and output variables summary statistics

\begin{tabular}{|c|c|c|c|c|c|c|c|}
\hline Output variable & Country & Year & WUs & Mean & STDev & Maximum & Minimum \\
\hline \multirow[t]{6}{*}{ Water coverage* } & Uganda & 2007 & 14 & 56,571 & 38,158 & 136,525 & 11,835 \\
\hline & & 2008 & 14 & 52,987 & 38,243 & 152,624 & 12,313 \\
\hline & & 2009 & 14 & 62,650 & 47,526 & 199,883 & 13,440 \\
\hline & Zambia & 2007 & 9 & 349,521 & 364,589 & $1,039,138$ & 53,006 \\
\hline & & 2008 & 9 & 356,776 & 338,593 & $1,105,242$ & 63,429 \\
\hline & & 2009 & 9 & 374,182 & 350,656 & $1,168,390$ & 76,268 \\
\hline \multicolumn{8}{|l|}{ Input variables } \\
\hline \multirow{6}{*}{$\begin{array}{l}\text { Total network length } \\
\text { (in meters) }\end{array}$} & Uganda & 2007 & 14 & 124,526 & 53,878 & 270,530 & 64,430 \\
\hline & & 2008 & 14 & 128,636 & 54,790 & 276,530 & 64,430 \\
\hline & & 2009 & 14 & 138,066 & 81,820 & 390,171 & 63,412 \\
\hline & Zambia & 2007 & 9 & $1,094,893$ & $1,980,164$ & $6,321,610$ & 127,000 \\
\hline & & 2008 & 9 & $1,248,981$ & $2,198,947$ & $7,040,670$ & 127,000 \\
\hline & & 2009 & 9 & $1,488,926$ & $2,681,554$ & $8,572,500$ & 138,137 \\
\hline \multirow{6}{*}{$\begin{array}{l}\text { Total number of } \\
\text { employees }\end{array}$} & Uganda & 2007 & 14 & 35 & 19 & 80 & 19 \\
\hline & & 2008 & 14 & 37 & 21 & 81 & 16 \\
\hline & & 2009 & 14 & 37 & 22 & 92 & 18 \\
\hline & Zambia & 2007 & 9 & 265 & 219 & 627 & 66 \\
\hline & & 2008 & 9 & 265 & 179 & 627 & 69 \\
\hline & & 2009 & 9 & 282 & 220 & 782 & 65 \\
\hline \multirow{7}{*}{$\begin{array}{l}\text { Partial indicators } \\
\text { Water coverage/Total } \\
\text { target population }\end{array}$} & & & & & & & \\
\hline & Uganda & 2007 & 14 & 0.682 & 0.151 & 0.901 & 0.378 \\
\hline & & 2008 & 14 & 0.678 & 0.119 & 0.820 & 0.430 \\
\hline & & 2009 & 14 & 0.721 & 0.107 & 0.826 & 0.463 \\
\hline & Zambia & 2007 & 9 & 0.688 & 0.195 & 0.920 & 0.387 \\
\hline & & 2008 & 9 & 0.707 & 0.143 & 0.880 & 0.501 \\
\hline & & 2009 & 9 & 0.743 & 0.129 & 0.889 & 0.572 \\
\hline \multirow{6}{*}{$\begin{array}{l}\text { Water coverage/Number } \\
\text { of staff }\end{array}$} & Uganda & 2007 & 14 & 1,804 & 1,390 & 5,251 & 592 \\
\hline & & 2008 & 14 & 1,573 & 1,021 & 4,154 & 616 \\
\hline & & 2009 & 14 & 1,772 & 1,004 & 4,482 & 747 \\
\hline & Zambia & 2007 & 9 & 1,162 & 420 & 1,715 & 597 \\
\hline & & 2008 & 9 & 1,198 & 416 & 1,763 & 672 \\
\hline & & 2009 & 9 & 1,229 & 309 & 1,596 & 756 \\
\hline \multirow{6}{*}{$\begin{array}{l}\text { Water coverage/Total } \\
\text { network length }\end{array}$} & Uganda & 2007 & 14 & 0.489 & 0.400 & 1.631 & 0.184 \\
\hline & & 2008 & 14 & 0.419 & 0.296 & 1.312 & 0.191 \\
\hline & & 2009 & 14 & 0.469 & 0.291 & 1.289 & 0.198 \\
\hline & Zambia & 2007 & 9 & 0.879 & 1.292 & 4.234 & 0.034 \\
\hline & & 2008 & 9 & 0.568 & 0.373 & 1.262 & 0.051 \\
\hline & & 2009 & 9 & 0.517 & 0.319 & 1.046 & 0.044 \\
\hline
\end{tabular}

* Population served with potable piped water supplies within each WUs' licensed jurisdiction. STDev: Standard deviation.

${ }^{138}$ The findings are available upon request. 
As discussed in Section 5.1, productivity can be influenced by background variables beyond the control of WU managers. To distinguish the main productivity drivers, we examine the influence of four control variables in a second stage. In particular, we link utilities productivity growth with the proportion of metered connections, non-revenue water, unserved population and network density.

Metering share is a proxy of service delivery quality. Indeed, increased metering - that is, the proportion of connections with operational meters over the total connections reflects (i) relatively accurate and consistent water consumption billing, (ii) eased identification and rectification of illegalities (including leakages and meter recordings manipulation) at the customer connection points and ultimately, (iii) increased collections. In addition, improved metering permits better water conservation controls by both WU managers and service users. Most water connections are metered (about 97 percent) for WUs in Uganda than in Zambia (where only about 55 percent of established water connections are metered) i.e., in 2009. Nonetheless, the share of metering as a proposition of all established connections across both urban water sectors is found to increase from 2007 to 2009 (see Table 5.2)

Water losses are a serious issue for many developed countries as they indicate underinvestment in infrastructure. In developing countries, water losses represent also illegal water connections, leaks along distribution mains and meter reading inaccuracies. Water losses are measured in terms of the share of non revenue water. That is, the difference between water supplied and water billed to the total water supplied. ${ }^{139}$ High water losses compromise utilities returns per investment and eventually, their abilities to completely penetrate their licensed markets. In 2008 for example, the total revenue loss due to non revenue water for urban WUs in Zambia amounted to about 201 billion

\footnotetext{
${ }^{139}$ Aggregate measures are used since the data does not allow further differentiation into various types of losses; administrative, economic or physical. Nonetheless, it is likely that comparable water loss tendencies happen across Uganda and Zambia.
} 
Kwacha (about $43 \$$ million $^{140}$ ) compared to 187 billion Kwacha (about $40 \$$ million) lost in 2007 (NWASCO, 2008).

Water loss minimization means an increase in water sales in the long run but at a cost in the short run. As Corton and Berg (2009) note, utility managers, especially in most developing countries, find it more lucrative to expand water services to wealthier customers than rehabilitate destroyed or aged water works. Such laxity results in costly exclusion (cf. the increasing urbanization of safe water system's poverty following which increased illegal connections are inevitable). With the ongoing reform programs that advance increased quality services delivery for all customers (including the urban poor), WUs need to minimize water losses in the short term and improve sales in the long-run. For both cases, less water is lost overtime, see Table 5.2. Tynan and Kingdom (2002) and WSP-WB (2009) advance non-revenue water levels of about 23 and 25 percent as good practice for African WUs. This is by far lower than the levels obtained in Zambia (42 percent water losses).

Besides, the share of unserved population matters for effectiveness. 29 and 31 percent of the urban population in Zambia and Uganda respectively, is on average, unserved (see Table 5.2). Network density matters as well. It is defined as the share of water connections per network length (in meters). High network densities can be favorable as they result in many connections with minimal network expansion. In addition, they signal the likely existence of many commercial, institutional and industrial connections (Corton and Berg, 2009). Either high or low network densities are an important policy issue related to urban WUs' productivity. Zambian WUs have higher network densities than in Uganda. They are found to establish about 5 percent connections per unit mains length while the average Ugandan utility is found to make about 4 percent connections per established unit mains length (see Table 5.2).

\footnotetext{
${ }^{140}$ By January 2010, 1\$ (American dollar) was equivalent to about 4610 Zambian Kwacha and about 1945 Ugandan shillings (http://www.xe.com/ucc/).
} 
Table 5.2: Environmental variables summary statistics

\begin{tabular}{|c|c|c|c|c|c|c|c|}
\hline Variable & Country & Year & WUs & Mean & STDev & Maximum & Minimum \\
\hline \multirow[t]{6}{*}{ Metering share } & \multirow[t]{3}{*}{ Uganda } & 2007 & 14 & 0.933 & 0.070 & 0.987 & 0.738 \\
\hline & & 2008 & 14 & 0.930 & 0.089 & 0.998 & 0.709 \\
\hline & & 2009 & 14 & 0.965 & 0.059 & 1.000 & 0.803 \\
\hline & \multirow[t]{3}{*}{ Zambia } & 2007 & 9 & 0.457 & 0.372 & 1.000 & 0.027 \\
\hline & & 2008 & 9 & 0.505 & 0.344 & 1.000 & 0.076 \\
\hline & & 2009 & 9 & 0.549 & 0.316 & 1.000 & 0.103 \\
\hline \multirow[t]{6}{*}{ Non revenue water share } & \multirow{3}{*}{ Uganda } & 2007 & 14 & 0.180 & 0.107 & 0.448 & 0.002 \\
\hline & & 2008 & 14 & 0.169 & 0.072 & 0.290 & 0.074 \\
\hline & & 2009 & 14 & 0.155 & 0.054 & 0.255 & 0.094 \\
\hline & \multirow[t]{3}{*}{ Zambia } & 2007 & 9 & 0.453 & 0.100 & 0.581 & 0.307 \\
\hline & & 2008 & 9 & 0.419 & 0.076 & 0.532 & 0.296 \\
\hline & & 2009 & 9 & 0.398 & 0.057 & 0.507 & 0.308 \\
\hline \multirow[t]{6}{*}{ Network density } & \multirow[t]{3}{*}{ Uganda } & 2007 & 14 & 0.038 & 0.013 & 0.069 & 0.022 \\
\hline & & 2008 & 14 & 0.041 & 0.014 & 0.076 & 0.023 \\
\hline & & 2009 & 14 & 0.042 & 0.016 & 0.079 & 0.024 \\
\hline & \multirow[t]{3}{*}{ Zambia } & 2007 & 9 & 0.074 & 0.112 & 0.366 & 0.003 \\
\hline & & 2008 & 9 & 0.045 & 0.028 & 0.094 & 0.006 \\
\hline & & 2009 & 9 & 0.039 & 0.023 & 0.075 & 0.005 \\
\hline \multirow{6}{*}{$\begin{array}{l}\text { Share of unserved } \\
\text { population }\end{array}$} & \multirow[t]{3}{*}{ Uganda } & 2007 & 14 & 0.318 & 0.151 & 0.622 & 0.099 \\
\hline & & 2008 & 14 & 0.322 & 0.119 & 0.570 & 0.180 \\
\hline & & 2009 & 14 & 0.279 & 0.107 & 0.537 & 0.175 \\
\hline & \multirow[t]{3}{*}{ Zambia } & 2007 & 9 & 0.312 & 0.195 & 0.613 & 0.080 \\
\hline & & 2008 & 9 & 0.293 & 0.143 & 0.499 & 0.121 \\
\hline & & 2009 & 9 & 0.257 & 0.129 & 0.428 & 0.111 \\
\hline
\end{tabular}

\subsection{Performance changes in the Ugandan and Zambian urban water sectors}

\subsubsection{Malmquist productivity change}

Using the input and output variables described in Section 5.3.2, we estimate the multidimensional bootstrapped biennial MPI measures (see equation 5.10). The bootstrap procedure allows us to reduce the influence of bias arising from measurement errors. For presentational clarity, we only present the bias corrected weighted estimates. ${ }^{141}$ The cumulative biennial Malmquist productivity growth estimates are presented in Table 5.3

\footnotetext{
${ }^{141}$ Detailed estimates of the standard error, bias and confidence interval can be obtained upon request. All MPI estimates are weighted by the size of the utility. Output Farrell efficiency estimates (inverse of the output Shephard efficiency estimates) are reported.
} 
in the column denoted by $\mathrm{MPG}_{\mathrm{vrs}}$. We observe a clear difference in performance across urban WUs in Zambia and Uganda.

Looking at the technical efficiency estimates, most WUs operate inefficiently relative to each sector's VRS (best-practice) and CRS (benchmark) technology (see Table 5.3). Assuming VRS, WUs across both sectors can on average expand their output by 40.2 points given their existing resources (see Table 5.3). To operate on the best practice frontier and given their present input values, Ugandan utilities can potentially advance their service production by 53 percent and Zambian utilities by 37 percent. While Zambian utilities are found to be more technical efficient (i.e., under VRS assumptions) than their Ugandan counterparts, we observe a decline in technical inefficiency for most WUs across both sectors (see Annex 5.1).

Both sectors experienced an increased productivity change of about 7 percent between 2007 and 2009. Ugandan WUs are found to experience the highest productivity growth. They increased their productivity by 14 percent while their Zambian counterparts increased their productivity by only 4 percent (see Table 5.3). Thanks to the biennial MPI decomposition, one can decompose observed productivity changes across both urban water sectors into a number of underlying productivity drivers. This provides us with further additional insights.

First, consider the case of the Ugandan urban water sector. We observe (i) a catch-up of the firms lagging behind of about 38 percent due to increased efficiency changes, but (ii) a decrease in efficiency of the best practice firms of about 13 percent and (iii) a decline in scale changes of about 3 percent. As such, productivity growth increases are largely as a result of increased efficiency changes. Such productivity increases can be attributed to the increased investments that occurred across the urban water sector in the late 2008 when NWSC's long-term debt to both local and external financiers (totaling to about 154 billion Ugandan Shillings) was converted into equity (NWSC, 2008). ${ }^{142}$ Such conversion meant that much of the internally generated revenue could henceforth become reinvested

\footnotetext{
${ }^{142}$ Equivalent to $88,719,899 \$$ (based on 2008 conversion rates, http://www.oanda.com/currency/historical-rates)
} 
in expanding (and maintaining) potable water distribution infrastructure to new (and old) customers (NWSC, 2009b).

Second, consider the case of the Zambian urban water sector. In contrast to Uganda, we observe relatively lower positive productivity gains (of about 4 percent) between 2007 and 2009 (see Table 5.3). While lagging (inefficient) utilities experience increased efficiency changes of about 20 percent, the best practice firms are found to decrease their efficiency by 11 percent. Consequently, observed firms are found to encounter a decrease in scale changes of about 16 percent. Observed advances in productivity are mainly due to efficiency change increases.

Table 5.3: Biennial Malmquist productivity index and components

\begin{tabular}{|c|c|c|c|c|c|c|c|}
\hline Country* & WUs & $\mathrm{TE}_{\mathrm{vrs}}(\%)$ & $\mathrm{TE}_{\mathrm{crs}}(\%)$ & MPG $_{\mathrm{vrs}}$ & $\mathrm{TC}_{\mathrm{vrs}}{ }^{143}$ & TEC $_{\text {vrs }}$ & SC \\
\hline Uganda \& Zambia & 69 & 59.8 & 36.7 & 6.5 & -11.3 & 23.2 & -13.8 \\
\hline Uganda & 42 & 46.8 & 36.8 & 13.5 & -12.9 & 37.8 & -3.1 \\
\hline Zambia & 27 & 62.9 & 36.7 & 4.4 & -11.0 & 19.5 & -16.4 \\
\hline
\end{tabular}

\subsubsection{Productivity change drivers}

Literature counts various techniques by which the influence of exogenous variables on firms' productivity can be estimated (see for instance Fried et al., 2008). Due to data restrictions (in particular high degrees of freedom), the methodological options for a second stage (i.e., exploring what drives productivity estimates) are limited. In this chapter we limit the analysis to simple correlations (similar to, e.g., Aston, 2000a; Marques, 2008b). In our opinion, this yields in the current setting, the most reliable insights.

\footnotetext{
${ }^{143}$ Negative average technical change rates are likely in this non-sequential Malmquist environment where estimated utilities' efficiency frontiers can shift and especially decline in the second year, compared to the first year (such as Kabale and N.Western WUs in Annex 5.1).
} 
To examine the underlying relationships between the computed productivity growth estimates and observed utility-specific exogenous factors, we group all observed utilities across both sectors into groups of three (low, medium and high) based on their respective group-specific exogenous variable measure (see Table 5.4). For each group, we estimate the correlation between metering efficiency, water losses and network densities with observed productivity growth.

Table 5.4: Exogenous variable categorization*

\begin{tabular}{llcccc}
\hline Variable & Country & WUs & Low (\%) & Medium (\%) & High (\%) \\
\hline Metering efficiency & Uganda & 42 & $<85$ & $86-95$ & $>96$ \\
& Zambia & 27 & $<40$ & $41-60$ & $>61$ \\
\multirow{2}{*}{ Water losses } & Uganda & 42 & $<10$ & $11-23$ & $>24$ \\
\multirow{3}{*}{ Network density } & Zambia & 27 & $<35$ & $36-50$ & $>51$ \\
\multirow{3}{*}{ Unserved population } & Uganda & 42 & $<3$ & $3.1-4$ & $>4.1$ \\
& Zambia & 27 & $<1.9$ & $2-4.5$ & $>4.6$ \\
& Uganda & 42 & $<23$ & $24-30$ & $>31$ \\
& Zambia & 27 & $<16$ & $17-32$ & $>33$ \\
\hline
\end{tabular}

* Although each categorization is unique for each specific case, one can notice insightful trends between WUs' productivity growth and the four group-specific exogenous variables.

$\%$ : Percent

\subsubsection{Metering efficiency and utilities productivity}

Ugandan WUs have the highest metering efficiency (see Annex 5.2). Low metering is matched with (i) high technical efficiency as well as (ii) high productivity growth (see Annex 5.2). As WUs set-up more meters for established connections, their productivity declines (mainly in the short to medium-run, see Figure 5.2). 
Figure 5.2: Metering efficiency and urban WUs productivity

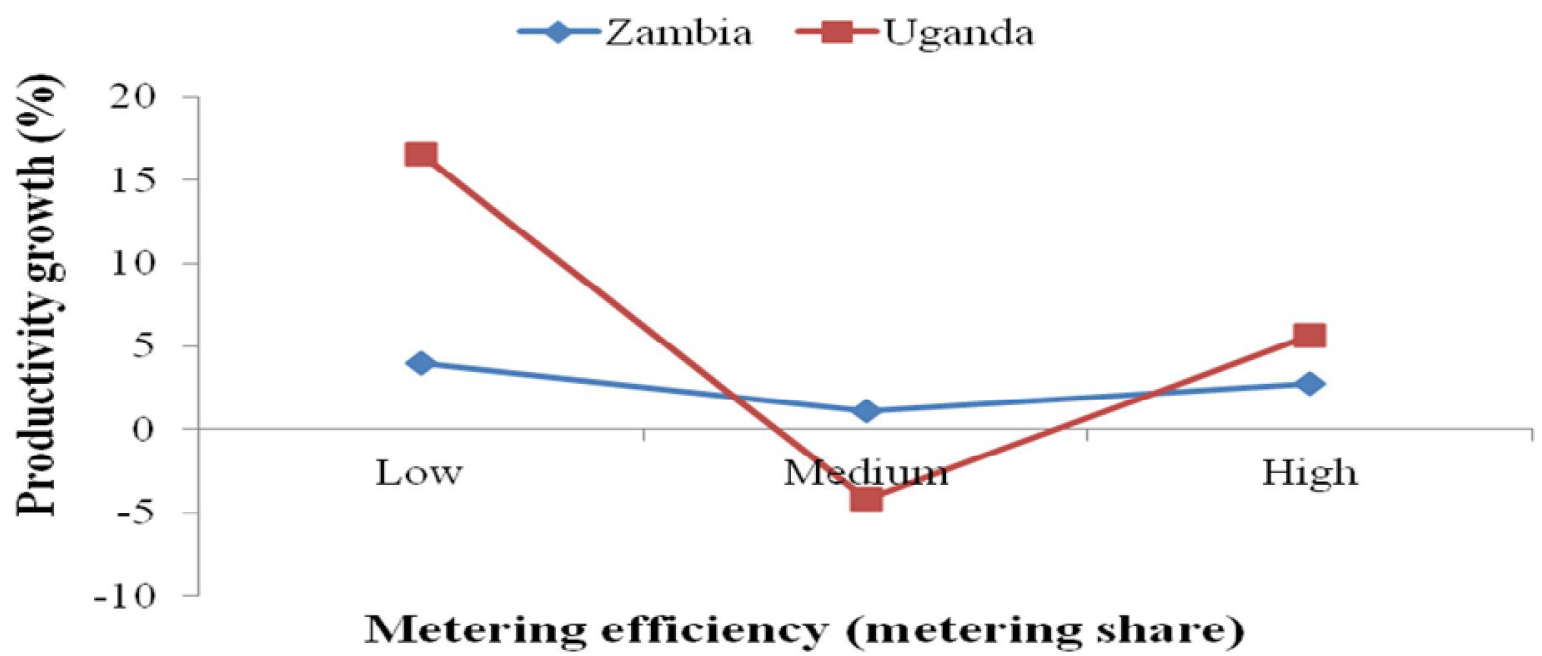

\subsubsection{Water losses and utilities productivity}

To understand the link between observed productivity growths and water losses, we analogously group each sector's utilities into three categories - that is, those with low, medium or high shares of non-revenue water, respectively. For both sectors, the lower the proportions of non-revenue water, the lower the technical efficiency (see Annex 5.3). Moreover and taking the case of the Ugandan utilities in particular, the more utilities invest (e.g., employ more staff, make more input purchases) in maintaining existing (or installing new) water distribution infrastructure, the more water loss problems are minimized but at the expense of less productivity gains especially, in the short-to medium term (see Figure 5.3). In the case of Zambia, as WUs increase their efficiency (thanks to higher water losses), their catch-up opportunities decline and consequently, encounter less productivity gains. 
Figure 5.3: Water losses and urban WUs productivity

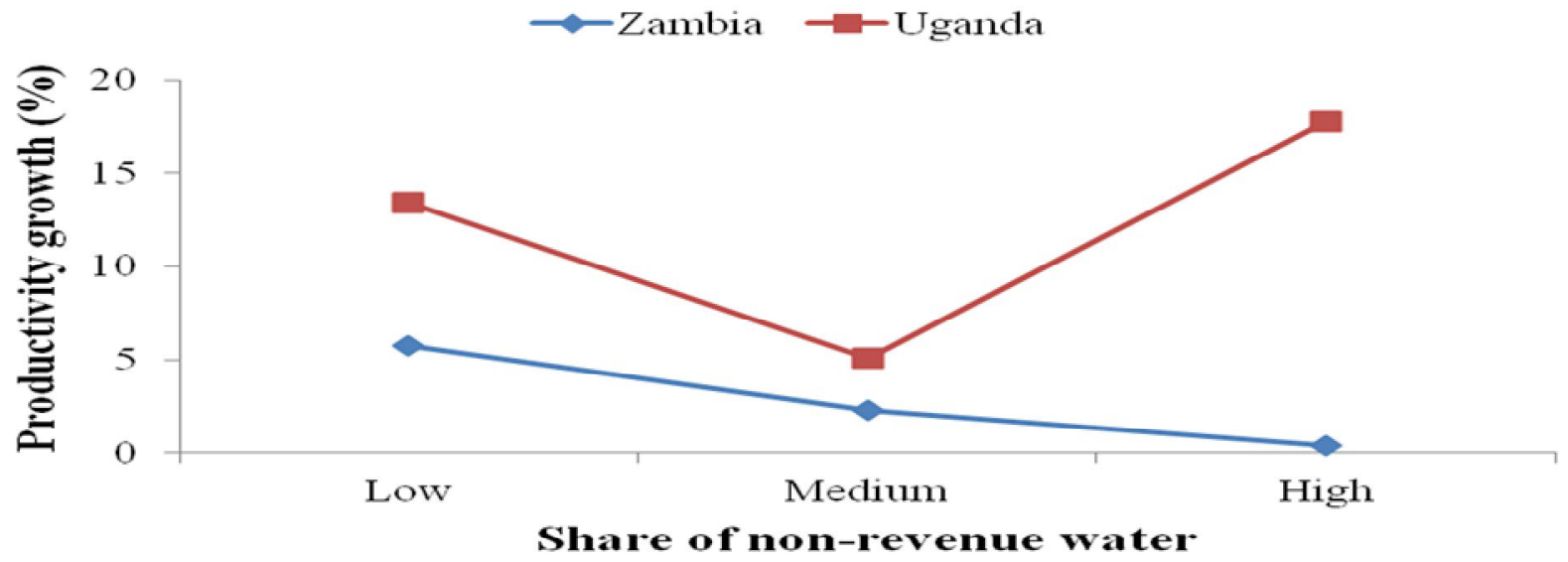

\subsubsection{Network density and utilities productivity}

High network densities are positively correlated with WUs technical efficiency. Hence, as utilities establish more connections per unit mains length, the more efficient they become (see Annex 5.4). Nonetheless, high network densities are found largely correlated with lower productivity gains across both utility-groups (see Figure 5.4).

Figure 5.4: Network density and urban WUs productivity

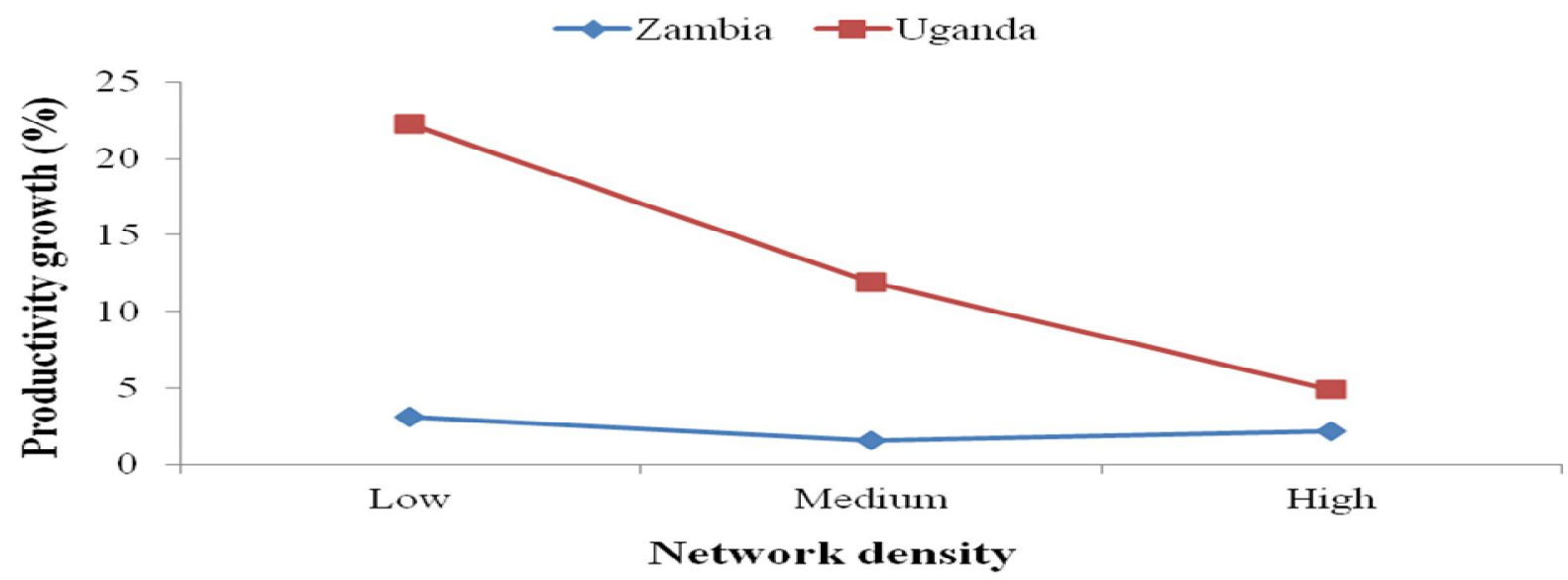




\subsubsection{Urban water utilities productivity and effectiveness}

\subsubsection{Service coverage and utilities productivity}

In addition to examining the productivity change determinants, we further explore the correlation between utilities effectiveness and resultant productivity changes. Again, we group observed utilities relative to their service coverage (served population as a share of the total target licensed population) proportions (see Annex 5.5). Increased piped water services coverage is associated with declined productivity gains in the short-run (see Figure 5.5). The latter suggests that, for complete effectiveness in the long-run, WU managers are likely to encounter temporal productivity losses due to increased resource use in, among others, establishing new connections per mains length, metering and mains' extension and maintenance.

Figure 5.5: Service coverage and urban WUs productivity

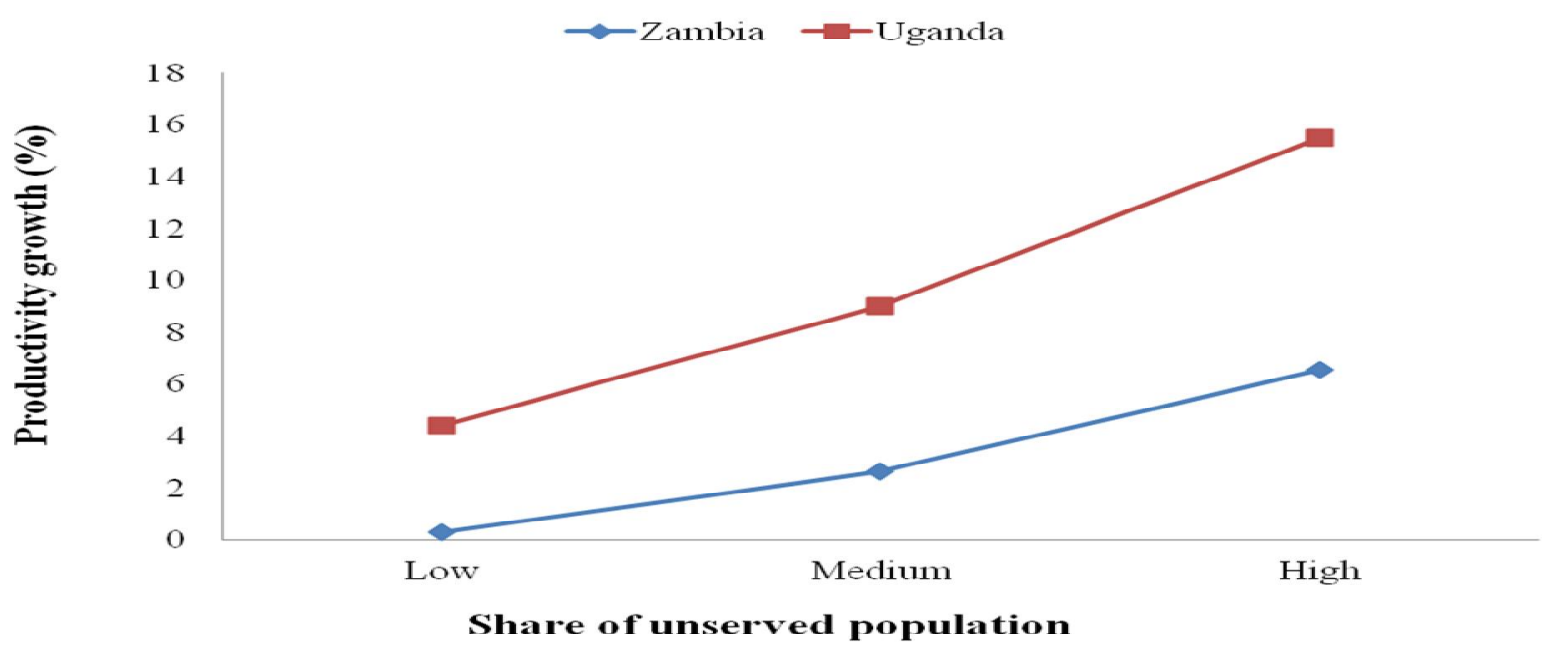

\subsubsection{Urban water utilities catch-up rates}

To understand how WUs increased (or decreased) their efficiency overtime, we group all utilities with respect to their initial technical efficiency in 2007. For both cases, utilities experience positive catch-up rates overtime (see Figure 5.6). In other words, utilities with the lowest technical efficiency scores in 2007 are found to improve their efficiency to 
operate on (or near to) the best practice frontier by the end of the analysis period in 2009 . Catch-up increases overtime are potentially linked to higher (increasing) utility effectiveness.

Figure 5.6: Urban WUs catch-up rates

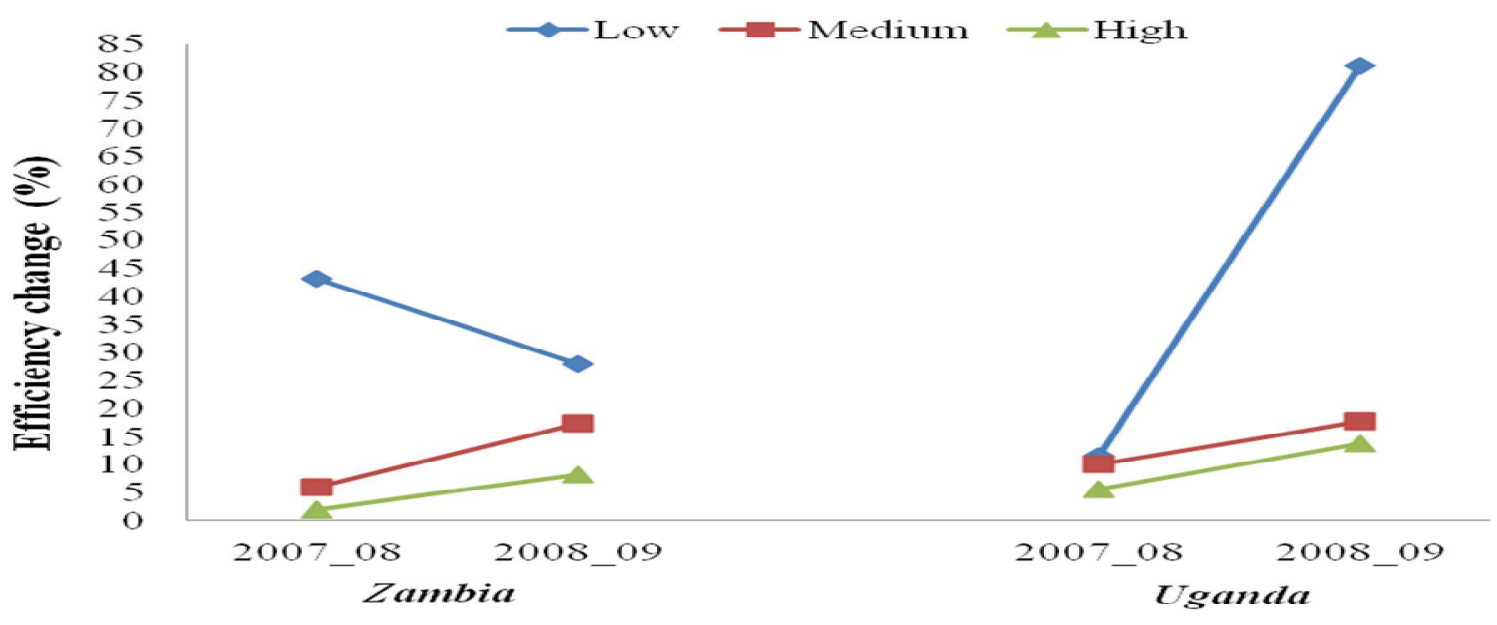

Techmical efficiency in 2007

\subsection{Conclusion}

Given growing urban populations, water providers in Africa face various challenges in their effort to extent and sustain access to safe water supplies. Given resource scarcity constraints, they face quality-related problems. This limits their efforts to expand (to new developmental and settlement areas) and sustain (for already existing customers) quality water distribution systems in a cost-effective manner. Increased access to quality water supply systems is among the MDGs for which the majority of the African nations have agreed to attain by 2015 .

This chapter discussed urban WUs' productivity and its determinants in Uganda and Zambia. Based on the one-dimensional estimates, Zambian utilities are more effective in terms of output expansion. They serve, on average, more customers as a proportion of their market share (entire urban population within their licensed jurisdiction). This is 
largely attributed to their higher network densities (connections per unit mains length). For both WU groups, water coverage (or customer base) is among the key performance indicators prioritized by the sector.

Each WU signs a management contract with the regulator (NWSC in Uganda and NWASCO in Zambia) in which various performance indicators are $a$ priori agreed upon by both parties. WUs' monitoring is thus based on these a priori designed performance targets. Nonetheless, most of the established connections for WUs in Zambia are not metered and consequently, suffer from higher water loss problems as compared to urban WUs in Uganda. Given our output-maximization study objective, the Zambian utilities are observed to be more technical efficient but at the expense of high non-revenue water owing partly, to limited connections' metering. Inefficiency for both WU-groups is found to decrease overtime.

To allow for a multi-dimensional interpretation, a bootstrapped biennial Malmquist productivity index (MPI) was estimated. The MPI decomposes WUs' productivity changes into (i) frontier shifts due to technical changes of the best practice observations, (ii) technical efficiency changes due to catch-up effects of the non-best practice observations and (iii) productivity changes, thanks to improvements in scale. Based on this multi-dimensional productivity growth estimates, WUs in Uganda and Zambia experience, on average, positive productivity gains. Given their lower initial efficiency levels, the Ugandan utilities exhibit a higher productivity growth by the end of the analysis period. Productivity gains for urban WUs in Zambia are largely affected by declined scale changes.

On productivity change determinants, we observe that high investments in urban water distribution correlate negatively with WUs' productivity. As utilities strengthen their metering efficiency and address their water loss problems, they lower their initial productivity. Nonetheless, we observe a positive correlation between network density and utilities productivity growth. To be effective (complete market penetration in the longrun), WU managers will likely face decreased productivity in the short-run but gain 
overtime from positive efficiency changes to eventually operate on (near to the) best practice effectiveness frontier. For more understanding on the links between efficiency and effectiveness, a step-wise decomposition framework is provided in Chapter 6. 
Annex 5.1: Technical efficiency estimates (Bias-corrected)

\begin{tabular}{|c|c|c|c|c|c|c|c|c|c|c|c|c|c|}
\hline \multirow[b]{3}{*}{ Water Utility } & \multicolumn{4}{|c|}{ UGANDA } & & & \multicolumn{7}{|c|}{ ZAMBIA } \\
\hline & \multicolumn{2}{|c|}{2007} & \multicolumn{2}{|c|}{2008} & \multicolumn{2}{|c|}{2009} & \multirow[b]{2}{*}{ Water Utility } & \multicolumn{2}{|c|}{2007} & \multicolumn{2}{|c|}{2008} & \multicolumn{2}{|c|}{2009} \\
\hline & TE_VRS & $T E \_C R S$ & TE_VRS & $T E \_C R S$ & TE_VRS & $T E \_C R S$ & & TE_VRS & $T E \_C R S$ & TE_VRS & $T E \_C R S$ & TE_VRS & $T E \_C R S$ \\
\hline ARUA & 0.254 & 0.251 & 0.279 & 0.254 & 0.297 & 0.291 & CHAMBESHI & 0.279 & 0.108 & 0.290 & 0.111 & 0.343 & 0.132 \\
\hline BUSHENYI & 0.147 & 0.094 & 0.153 & 0.098 & 0.174 & 0.123 & CHIPATA & 0.240 & 0.192 & 0.272 & 0.211 & 0.346 & 0.250 \\
\hline ENTEBBE & 0.203 & 0.133 & 0.200 & 0.138 & 0.225 & 0.178 & KAFUBU & 0.633 & 0.324 & 0.641 & 0.341 & 0.647 & 0.260 \\
\hline F.PORTAL & 0.356 & 0.290 & 0.360 & 0.294 & 0.213 & 0.220 & LUSAKA & 0.751 & 0.451 & 0.752 & 0.415 & 0.746 & 0.403 \\
\hline GULU & 0.762 & 0.837 & 0.630 & 0.673 & 0.708 & 0.730 & MULONGA & 0.503 & 0.206 & 0.530 & 0.202 & 0.525 & 0.200 \\
\hline JINJA & 0.505 & 0.250 & 0.620 & 0.306 & 0.753 & 0.365 & NKANA & 0.658 & 0.639 & 0.726 & 0.482 & 0.746 & 0.446 \\
\hline KABALE & 0.271 & 0.256 & 0.237 & 0.223 & 0.278 & 0.246 & N.WESTERN & 0.527 & 0.293 & 0.507 & 0.280 & 0.512 & 0.260 \\
\hline KASESE & 0.767 & 0.547 & 0.655 & 0.521 & 0.655 & 0.478 & SOUTHERN & 0.447 & 0.268 & 0.451 & 0.271 & 0.472 & 0.229 \\
\hline LIRA & 0.685 & 0.673 & 0.423 & 0.391 & 0.489 & 0.428 & WESTERN & 0.206 & 0.177 & 0.253 & 0.227 & 0.284 & 0.240 \\
\hline MASAKA & 0.278 & 0.203 & 0.294 & 0.220 & 0.334 & 0.264 & & & & & & & \\
\hline MBALE & 0.262 & 0.164 & 0.254 & 0.155 & 0.307 & 0.181 & & & & & & & \\
\hline MBARARA & 0.336 & 0.270 & 0.286 & 0.229 & 0.311 & 0.246 & & & & & & & \\
\hline SOROTI & 0.150 & 0.131 & 0.149 & 0.135 & 0.343 & 0.274 & & & & & & & \\
\hline TORORO & 0.150 & 0.155 & 0.130 & 0.120 & 0.228 & 0.210 & & & & & & & \\
\hline Mean (weighted) & 0.366 & 0.304 & 0.334 & 0.268 & 0.380 & 0.303 & & 0.472 & 0.295 & 0.491 & 0.282 & 0.514 & 0.269 \\
\hline
\end{tabular}


Annex 5.2: Metering efficiency, technical efficiency and productivity growth

\begin{tabular}{lccrrrrr}
\hline Country & WUs & Meter_Eff $(\%)$ & TE $_{\mathbf{v r s}} \mathbf{( \% )}$ & $\mathbf{M P G}_{\mathbf{v r s}}$ & $\mathbf{T C}_{\mathbf{v r s}}$ & TEC $_{\mathbf{v r s}}$ & $\mathbf{S C}$ \\
\hline Uganda & 42 & Low & 55 & 16.56 & -8.52 & 27.24 & -0.72 \\
& & Medium & 53 & -4.19 & -9.73 & 5.92 & -0.91 \\
& & High & 41 & 5.66 & -5.37 & 16.54 & -1.91 \\
\multirow{2}{*}{ Zambia } & & & & & & \\
& \multirow{2}{*}{27} & Low & 53 & 3.98 & -7.83 & 15.56 & -8.83 \\
& & Medium & 72 & 1.08 & -3.60 & 5.15 & -7.99 \\
& & High & 45 & 2.75 & -9.97 & 14.28 & -10.38 \\
\hline
\end{tabular}

Meter_Effic: Metering share. The rest as earlier defined.

Annex 5.3: Water losses, technical efficiency and productivity growth

\begin{tabular}{|c|c|c|c|c|c|c|c|}
\hline Country & WUs & Water losses (\%) & $\mathrm{TE}_{\mathrm{vrs}}(\%)$ & MPG $_{\mathrm{vrs}}$ & $\mathbf{T C} \mathbf{V r s}_{\mathrm{vrs}}$ & TEC $_{\text {vrs }}$ & SC \\
\hline \multirow[t]{3}{*}{ Uganda } & 42 & Low & 51 & 7.66 & -9.26 & 17.65 & -4.48 \\
\hline & & Medium & 41 & 2.72 & -7.49 & 15.75 & -0.70 \\
\hline & & High & 56 & 17.37 & -2.60 & 24.69 & -0.78 \\
\hline \multirow[t]{3}{*}{ Zambia } & 27 & Low & 58 & 5.76 & -7.73 & 14.61 & -5.31 \\
\hline & & Medium & 61 & 2.32 & -6.25 & 10.55 & -12.33 \\
\hline & & High & 68 & 0.43 & -3.05 & 3.58 & 4.69 \\
\hline
\end{tabular}

Water losses measured in terms of the share of non revenue water. The rest as earlier defined.

Annex 5.4: Network density, technical efficiency and productivity growth

\begin{tabular}{lccrrrrr}
\hline Country & WUs & Network density (\%) & TE $_{\mathbf{v r s}} \mathbf{( \% )}$ & $\mathbf{M P G}_{\mathbf{v r s}}$ & $\mathbf{T C}_{\mathbf{v r s}}$ & $\mathbf{T E C}_{\mathbf{v r s}}$ & $\mathbf{S C}$ \\
\hline Uganda & 42 & Low & 28 & 19.13 & 12.58 & 11.87 & -0.27 \\
& & Medium & 47 & 10.30 & -9.48 & 27.26 & -2.93 \\
& & High & 51 & 2.73 & -8.42 & 12.06 & -0.50 \\
Zambia & & & & & & & \\
& \multirow{2}{*}{27} & Low & 49 & 3.13 & -9.27 & 14.42 & -3.16 \\
& & Medium & 63 & 1.58 & -6.39 & 9.49 & -15.64 \\
& & High & 67 & 2.18 & -4.01 & 7.62 & -5.71 \\
\hline
\end{tabular}

Network density measured as the share of water connections per network length. The rest as earlier defined.

Annex 5.5: Urban water services coverage and productivity growth

\begin{tabular}{lccrrrr}
\hline Country & WUs & Unserved population (\%) & MPG $_{\mathbf{v r s}}$ & TC $_{\mathbf{v r s}}$ & TEC $_{\mathbf{v r s}}$ & $\mathbf{S C}$ \\
\hline Uganda & 42 & Low & 4.40 & -6.67 & 11.73 & -2.08 \\
& & Medium & 8.99 & -3.15 & 14.57 & -1.48 \\
& & High & 15.50 & -13.79 & 48.39 & -0.04 \\
\multirow{3}{*}{ Zambia } & \multirow{2}{*}{27} & Low & & & & \\
& & Medium & 0.31 & -9.09 & 11.18 & -12.57 \\
& & High & 2.64 & -1.63 & 4.46 & -6.98 \\
& & & 6.53 & -12.71 & 26.52 & -1.40 \\
\hline
\end{tabular}




\section{CHAPTER 6: Efficiency and effectiveness analysis ${ }^{144}$}

\subsection{Introduction}

Faced with limited inputs and increasing safe water coverage deficiency challenges, urban WUs in Africa need to operate both efficiently and effectively. Farrell (1957) defines overall WU's efficiency as a product of both allocative efficiency and technical efficiency. ${ }^{145}$ This chapter, similar to chapters 4 and 5 , focuses on the latter and defines (technical) efficiency as the equiproportionate physical output expansion with given inputs. Or the physical input minimization for a given (physical) output level - in the alternative case where policy makers aim to minimize WUs' inputs for a given output level. Utilities' effectiveness reflects the extent to which sector objectives are met within each WU's licensed jurisdiction. In other words, besides obtaining a maximal output with the given resources (i.e., efficiency), utility managers need to universally meet their customer demands for quality (i.e., non-contaminated) and reliable (constant daily flow) water supply services (i.e., effectiveness).

Effectiveness can loosely be defined as 'doing the right things'. The need for effectiveness is made clear by looking at service delivery levels. By 2006, African urban WUs only delivered water to about 65 percent of the population within their licensed jurisdiction (WSP-WB, 2009). This is low when compared to other developing regions that served on average 73 (East Asia and Pacific region), 85 (Central Asia region) and 85 (Latin America and the Caribbean region) percent of their urban populations with safe piped water services in 2006 (WSP-WB, 2009). This chapter examines whether utility managers in the different African countries (can) meet the demand for qualitative and reliable water supply.

\footnotetext{
${ }^{144}$ This chapter is available as: Mbuvi, D., De Witte, K., and Perelman, S. (2012). Urban water sector performance in Africa: A Stepwise bias-corrected efficiency and effectiveness analysis, Utilities Policy, 22: 31-40, doi:10.1016/j.jup.2012.02.004. We are grateful to the participants of the DEA2011 conference (DEA Applications parallel session) and two anonymous referees for insightful comments on a previous draft of this paper. We are indebted to Josses Mugabi (WSP World Bank) for his assistance in accessing the WOP dataset.

${ }^{145}$ For more information on how these components are decomposed when either output maximization or cost minimization objectives are considered, see also Fried et al. (2008)
} 
Efficiency can on the other hand, be delineated as 'doing things right'. The call for an efficient use of inputs is clear when one looks at WUs' costs and revenues. At the cost side and owing to the increasing multi-sectoral competition for the shrinking renewable water resources, production costs are increasing over time (UNESCO and Earthscan, 2009). At the revenue side, WUs often incur low cost-recovery levels as most user tariffs are centrally regulated (Madhoo, 2007). Even though increasing costs and decreasing revenues do not influence efficiency directly, they create pressure on utility managers to use their existing inputs in a better and, thus, more efficient way. This chapter explores to what extent utility managers are using their inputs to produce outputs. That is, if utilities would produce as efficiently as the best practice observation(s), how much more outputs would they produce with their given inputs?

We propose an approach to measure efficiency and effectiveness trends over time. We rely on productivity analysis techniques that enable us to identify utilities' efficiency and effectiveness. We further decompose utilities' ineffectiveness from inefficiency. This enables us to identify the highest (and lowest) performing WUs. Moreover, it allows us to identify specific performance improvement areas that can potentially inform and facilitate sector restructuring, reorganization and targeted decision making (on tariffs, quality standards) while limiting inevitable sector conflicts (Berg, 2007), adverse selection and moral hazard incentive problems (Bogetoft and Otto, 2011). To further explain WU's performance, the influence of different environmental factors on WUs' efficiency and effectiveness levels is explored. Here, we consider different national, sector and utility specific environmental factors that are beyond the control of WU managers but potentially influence managers' abilities to transform fixed inputs into controllable outputs.

We focus on the African urban water sector that has incurred increased organizational and institutional restructuring since the 1990s. Among other objectives, these reforms aim at improved utility efficiency and effectiveness (Estache and Kouassi, 2002; Kirkpatrick et al., 2006; Mwanza, 2010; see also Section 1.2.2). Subsequently, most African urban water sectors are governed by similarly orchestrated water legislations that define the 
respective key sector mission(s) and provide clear mandates (regarding service provision, regulation and policy making, among others) for the different sector stakeholders.

Across the African continent, urban piped water services are largely provided by public companies, either by the central government (e.g., in Eritrea), state owned agencies (Uganda and Ghana), full fledged water departments within local authorities (Namibia, South Africa and Zimbabwe) or public companies owned by municipalities (Kenya and Zambia; see WHO and UNICEF, 2000). A few African countries (including Cape Verde, Cote d'Ivoire, Gabon, Mozambique, Niger and Senegal) engage private actors through contractual arrangements other than service and management contracts (Mwanza, 2010). Following the commercialization reforms that were introduced across most of these countries, utilities are expected to operate efficiently - that is, expand outputs with given inputs. Moreover, utilities are required to work effectively: to reach their target in the form of complete coverage with quality and reliable water services for all customers within their licensed service areas.

Efficiency and effectiveness, and especially their interdependence in the context of the African urban water sector, have been explored only diminutively in previous literature. Exceptions are studies by Estache and Kouassi (2002) and Kirkpatrick et al. (2006). Using a Cobb-Douglas production function, Estache and Kouassi found the public owned African urban WUs less efficient than the privately-owned utilities. The latter (compared to the former) utilities were found less corrupt and well governed. They observed a total of 21 (18 public, 3 private) utilities between 1995 and 1997. Kirkpatrick et al. did not observe any efficiency differences between publicly and privately-owned African urban WUs. They compared results from both parametric (Cobb-Douglas cost function) and non-parametric (DEA) techniques on 14 utilities. Both studies quantified inefficiency between the publicly and privately-owned urban WUs in Africa.

For most public sectors (education, water supply, etc.), explicit market price information is missing or unreliable. In such cases, productivity analyses examine the extent to which utilities can technically increase their delivered outputs with given physical resources. 
Utilities' efficiency is then estimated against a frontier of best practice observations. In other words, with or without market price information, public utilities are supposed to operate efficiently and not waste scarce resources in such production process (Pestieau and Tulkens, 1993).

As for the African urban WUs, there might exist significant measurement errors in the data. To mitigate the influence of measurement errors in a nonparametric framework, we determine, similar to chapters 4 and 5, a frontier consisting of best practice utilities by the use of a double bootstrap technique that is based on the truncated maximum likelihood estimators (Simar and Wilson, 2007). In an alternative case, one could estimate a (semi)parametric frontier such as the Stochastic Frontier Analysis (see for e.g., Greene, 2008 for a discussion). As we do not have any a priori information on the specification of the production frontier, we rely only on non-parametric techniques. The double bootstrap approach permits the estimation of bias-corrected technical efficiency scores (with the bias arising from possible measurement errors) and allows for the examination of efficiency covariates. We distinguish various influences that characterize the observed WUs' operating environments. Identified inefficiency and ineffectiveness sources form the basis on which future performance improvement policies at the macro (country), meso (sector) and micro (utility) levels can be formulated.

We further disentangle WUs' ineffectiveness from inefficiency. We measure to what extent utilities are able to achieve their differently prioritized effectiveness goals for all customers within their licensed service areas. To do so, as noted in Lovell et al. (1995), it is necessary to aggregate all indicators into a single performance index. The latter helps us to summarize the multi-faceted WU's goals into a single performance measure that is easy to interpret and easily useful to sector regulators and utility managers among other interested stakeholders, in designing and enforcing appropriate performance improvement policy strategies (Saisana and Tarantola, 2002).

To examine utilities effectiveness, we use a 'Benefit of the Doubt' (hereafter BoD) analysis (Melyn and Moesen, 1991; Cherchye et al., 2007). This non-parametric 
technique aggregates observed effectiveness sub-indicators into utility-specific performance indexes (explained further in section 6.3.3). The chapter unfolds as follows. The next section discusses the analytical framework and the data used for the analysis. Section 6.3 provides the study's empirical model while section 6.4 describes and discusses the study findings. Section 6.5 concludes the chapter.

\subsection{Analytical framework and data}

\subsubsection{Analytical framework}

To estimate WU's technical efficiency in our first step, we rely on a DEA-VRS framework as defined earlier in section 1.4.3. The $B o D$ composite estimator (used in step 2) relies on an analogous optimization problem as the DEA indicator. The only difference between both indicators is that the $B o D$ composite (unlike the DEA) estimator, uses a vector with only ones as inputs rather than the observed WUs' input variables. It was first introduced by Melyn and Moesen (1991).

In estimating WU's effectiveness, the $B o D$ estimator is preferred as it exploits the attractive features of DEA - that is, it permits endogenous weight selection. $B o D$ values closer to (and far from) 1 signify better (and worst) performance in relation to the best practice (or benchmark) WUs. $B o D$ values of 1 indicate best performance of a given WU. For more information on the $B o D$ composite estimator, see for e.g., Cherchye et al. (2007).

Exogenous characteristics beyond WU managers' control influence the inputs use, output production and consequently, WUs' efficiency (and effectiveness). Their influence can be revealed by various approaches (see Coelli et al., 2005 for a discussion). This chapter uses the double bootstrap procedure as outlined earlier in section 1.4.

\subsubsection{Data}

We rely on the Water Operators Partnership (WOP) dataset. This rich dataset forms part of the WOP-Africa self assessment and benchmarking exercise facilitated by the Water 
and Sanitation Program (WSP) in 2006 across 134 African WUs (WSP-WB, 2009). WOP-Africa is part of the Global WOP Alliance provided by the Hashimoto Action Plan (UNSGAB, 2006). The latter was launched at the fourth World Water Forum (2005) and endorsed by the United National Secretary-General's Advisory Board on Water and Sanitation. Central to the WOP's initiative is the improvement of WUs' productivity (efficiency and effectiveness) mainly through peer-to-peer technical support partnerships.

Interestingly, the data collects homogenous information on the different production variables across African urban WUs. However, only quantity information on utilities water supply (distribution mains length, output levels, etc.) is consistently reported. Most observed utilities had some level of outsourcing through service contracts but detailed information on these contracts is unavailable. Nonetheless, such outsourcing is likely infinitesimal and homogenously spread-out across observed utilities. To further avoid data incompatibilities, only quantity vectors that are less prone to national fiscal (exchange rates) heterogeneities are used (see section 6.3)

\subsection{Empirical model specification}

\subsubsection{Input, output and quality variables}

The model specification relies on two output measures: water supply service coverage (measured in terms of the population served with piped water) and the volumetric water sold. The latter is highly correlated with utility revenues that are supposedly reinvested in advancing (to new costumers) and maintaining (for existing customers) service coverage. Output increases are expected to positively influence WUs' technical efficiency (and effectiveness). Table 6.1 presents some summary statistics. The data corresponds to 51 urban WUs from 21 African countries. The latter is equivalent to about 60 percent of all countries whose urban WU managers or administrators responded to the WOP-Africa self assessment and benchmarking questionnaires by 2006 .

On average, about 1,463,981 customers are served with piped water systems. The WU with the lowest customer coverage serves about one twenty one thousand customers 
while that with the highest coverage serves about nine million customers. The highest performing utility in this partial productivity dimension sells about 112 times more water than the lowest performing utility (see Table 6.1).

We consider two inputs: the total number of employees and the water distribution mains length (network length). The inputs capture WUs' labor and capital expenditure, respectively. However, since the WOP dataset does not provide disaggregated employee categories (full or part time, technical or administrative), we use the aggregated employee count that implicitly assumes uniform skill distribution across observed WUs. The average utility employs 748 persons. The utility with the most employees hires about 3,139 persons while that with the lowest employees engages 95 persons. Among other capital input measures, water distribution network length is less prone to country-specific measurement and exchange rate incompatibilities. The WU with the longest piped water system built a water distribution main that is about 300 times longer than the utility with the shortest piped water system.

Table 6.1: African urban water utilities summary statistics, 2006

\begin{tabular}{|c|c|c|c|c|c|}
\hline & WUs & Mean & StDev & Maximum & Minimum \\
\hline \multicolumn{6}{|l|}{ Input variables } \\
\hline Employees (numbers) & 51 & 748 & 736 & 3139 & 95 \\
\hline Network length (meters)*1000 & 51 & $2,113.748$ & $2,875.012$ & $12,575.000$ & 42.000 \\
\hline \multicolumn{6}{|l|}{ Output variables } \\
\hline Population served with piped water* 1000 & 51 & $1,463.981$ & $1,751.622$ & $9,361.760$ & 121.081 \\
\hline Water sold (cubic meters/year)*100000 & 51 & 374.12208 & 439.30290 & 2,000 & 17.88500 \\
\hline \multicolumn{6}{|l|}{ Quality variables } \\
\hline Total piped water connections $* 1000$ & 51 & 114.105 & 153.773 & 650.504 & 9.076 \\
\hline Daily water supply hours & 51 & 19 & 7 & 24 & 4 \\
\hline \multicolumn{6}{|l|}{ Sub-indicators } \\
\hline Population served/Target population & 51 & 0.695 & 0.229 & 1 & 0.249 \\
\hline Water sold/Target population & 51 & 26.26 & 23.95 & 97.30 & 1.51 \\
\hline Total water connections/Target population & 51 & 0.081 & 0.086 & 0.307 & 0.004 \\
\hline \multicolumn{6}{|l|}{ Environmental variables } \\
\hline Independent regulation (IR, dummy) & 51 & 0.294 & 0.460 & 1 & 0 \\
\hline Performance contract use (PC, dummy) & 51 & 0.628 & 0.488 & 1 & 0 \\
\hline GDP & 51 & 0.257 & 0.269 & 1 & 0.051 \\
\hline Network density & 51 & 0.065 & 0.049 & 0.286 & 0.015 \\
\hline
\end{tabular}


In addition to this basic model (hereafter referred to as Model 1), we consider different output quality variables. Previous literature (see Annex 6.1) considered the latter in the form of chemical treatment tests (Antonioli and Filippini, 2001; Corton, 2003; Lin, 2005; Lin and Berg, 2008), quality indexes (Saal and Parker, 2000: 2001; Woodbury and Dollery, 2004; Erbetta and Cave, 2007; Bottasso and Conti, 2009), service coverage (Lin, 2005), service continuity (Corton, 2003; Lin, 2005; Lin and Berg, 2008), accounted-for water ratio (Lin, 2005), unaccounted-for water (Antonioli and Filippini, 2001; Garcia and Thomas, 2001; Tupper and Resende, 2004; Picazo-Tadeo et al., 2008), annual mains breakage per observed output (Bhattacharyya et al., 1994), bathing water intensity (Saal et al., 2007) and household ratio (Mizutani and Urakami, 2001).

We capture WUs-output quality in terms of services connectivity and continuity. We use the total active piped water connections to proxy the former. Earlier WU efficiency studies have treated water connections variedly. Assuming a cost minimization objective, utilities' water connections have previously been used as a proxy for capital input (see Estache and Kouassi, 2002; Lin, 2005; Lin and Berg, 2008), utilities output (see Ashton, 2000a: 2000b; Estache and Rossi, 2002; García-Sánchez, 2006; Saal et al., 2007), operational scale (see for example Erbetta and Cave, 2007) and to capture the impact of utilities operational environment on cost efficiency (see for example Teeples and Glyer, 1987).

Holding inputs fixed we argue that to supply non-contaminated water, piped water distribution systems matter. This is importantly so for regions like Africa where universal urban water services coverage and increased mortality rates (owing especially to high water borne/water related diseases, see Gasana et al., 2002; Mutunga, 2007) are key developmental challenges. Using the case of India, Jalan and Ravallion (2003) found piped water delivery positively and significantly associated with reduced prevalence and duration of water borne diseases (e.g., diarrhea). As the safety of alternative urban nonpiped water distribution systems is not always guaranteed and can consequently accrue costs to affected customers, we use dissimilar to earlier studies, the number of active piped water connections as a proxy for utilities output quality. 
To capture services continuity, we use utilities daily hours of service provision. For connected customers, however, utilities can only provide water supply services for a maximum of 24 hours. As such, the variable is by construction restricted (between 0 and 24). To avoid imposing such a restriction to the DEA linear program, we adjust the output quality variable to take into account hours of daily water supply per connection. We therefore use the product of the daily hours of service provision and total piped water connections to capture utilities' service continuity. We consider service connectivity as a quality variable in Model 2. The smallest performing WU makes 9076 piped water connections (serving about 742,000 customers). This is 72 times less than the utility with the highest number of connections (650,504 but serving about 4,134,000 customers) within its licensed jurisdiction.

Model 3 includes service continuity. Constant service continuity for connected customers is associated with improved public health among other socio-economic advancements. The average observed utility provides daily piped water services over 19 hours (see Table $6.1)$.

\subsubsection{Environmental variables}

Often, urban WUs fail to reach their performance targets due to country specific (e.g., national income), sector specific (e.g., adopted regulatory structure) and/or utility specific (e.g., customer density) factors. In an attempt to explain this inability, we identify four environmental factors that potentially influence utilities' performance (technical efficiency and/or effectiveness). First, urban water supply is highly capital intensive. The lower the national per capita income, the lower the abilities to pay for public services, the less accrued returns are allocated for capital (re)investment and the more exclusive water service provision becomes. Wealthier economies are more likely to (i) subsidize water infrastructure investments and (ii) maintain strong regulatory institutions (Franceys and Gerlach, 2008). To capture these country-specific differences, we use the gross domestic product per capita purchasing power parity (hereafter, GDP) indicator (WDI and GDF, 
2010). Across observed countries, GDP is on average 3,431\$ (i.e., 25.7 percent $^{146}$, see Table 6.1). Gabon is the wealthiest country $(\mathrm{GDP}=13,349 \$)$ in the sample, while Malawi is the poorest with a GDP value of $681.37 \$$.

Second, regulation (largely economic regulation) is often adopted in the form of either formal (licenses) or informal (sector-specific commitments) rules. Strict regulatory systems (in the form of independent regulation) potentially results in increased regulatory risks (new expensive standards, tariffs) or sector credibility that respectively, augment sector uncertainty or/and investments (Kirkpatrick et al., 2006). Mwanza (2010) advocates for the creation of independent statutory regulatory agencies in Africa based on (i) clear legislative frameworks free from ministerial control, (ii) transparent procedures for appointing the board of directors, commissioners and key staff, (iii) secure tenure for elected oversight members remunerated based on private salary structures, (iv) sustainable finances through a regulatory fee charged on the regulated utilities, and (v) depolicized reporting mechanisms for the elected oversight members.

The WOP-Africa dataset distinguishes two main types of utilities: those regulated by an independent regulator and those regulated by the use of performance contracts (WSPWB, 2009). In Africa, independent regulatory structures are commonly established solely for the water sector (e.g., in Kenya, Mozambique and Zambia) or conjointly with other sectors including energy, telecommunications, waste removal and gas development sectors for example in Burundi, Gabon, Gambia, Ghana, Madagascar, Mali, Niger, Tanzania and Rwanda (see MWI, 2002; NWASCO, 2004b; Oelmann, 2007; Osumanu, 2008; URT, 2009; Mwanza, 2010). By 2006, about 29 percent of the observed urban water sectors in Africa had adopted independent regulatory institutions (see Table 6.1).

Regulation by contracts (e.g., in Burkina Faso, Ethiopia, Gabon and Senegal) is commonly organized within a ministerial department or an asset holding agency and overseen by an independent committee (MWR, 2001). About 63 percent of the observed urban water sectors had introduced regulation by performance contracts by 2006 (see

${ }^{146}$ Countries GDP values are normalized - as a share of the maximum GDP value across observed African countries in 2006. 
Table 6.1). We use two dummy variables (i) independent regulation and, (ii) performance contract use to capture these potential reverse causalities between utilities performance and regulatory strictness (at the sector level).

Thirdly, among other ways by which WUs can respond to customer demands for increased quality services provision is by augmenting the number of customers (population served) per mains length. Nonetheless, since all observed utilities provide services to urban populations that are more or less homogeneously populated (per square kilometer), we consider the influence of WUs' network densities (rather than customer densities) on their performance. To capture these network density economies at the utility level, we use the number of piped water connections per unit network length. On average, most observed WUs in Africa connect 6.5 percent of their population per unit network length. The smallest performing WU makes about 1.5 percent water connections per its established piped water distribution system (see Table 6.1).

\subsubsection{Stepwise model}

In assessing WUs' performance, we define a step-wise empirical model consisting of four steps. In step 1, we estimate utilities' technical efficiency (output expansion) under given resource constraints. Here, we rely on the input and output variables detailed in section 6.3.1 and the DEA-VRS model outlined in section 1.4.3.

Given unit input on one hand, utility managers seek to attain various effectiveness targets within their licensed service areas. They are supposed to serve as many customers with quality water systems, sell as much water, connect as many customers and provide reliable services for connected customers. Across observed WUs, 70 percent of the target population within utilities licensed jurisdictions are served with quality water supply systems (see Table 6.1). On average, observed utilities are able to sell about 26 cubic meters of water per customer per annum (though some water is often lost along the distribution system) and make about 81 connections by 1,000 inhabitants (see Table 6.1). 
To meet these effectiveness goals for all customers within their licensed jurisdictions, utility managers need not only to perform better in one of the targets, but in all of them.

To aggregate the different effectiveness targets, one can use the prices of the subindicators as weights. In addition (or alternatively), one could seek experts' opinion on the exact significance attached to all identified sub-indicators. Such price and/or subjective value information can then be used in defining the lower and upper bounds between which each of the identified sub-indicator can be allowed to vary. This kind of aggregation helps to enhance the resultant performance indexes' discriminatory power, credibility and acceptability among related sector stakeholders. Thanassoulis et al. (2004) and Nardo et al. (2005) provide an overview of diverse aggregation techniques.

For most public service sectors however, only sub-indicator's quantitative information is (consistently) available. In other cases, it is not a guarantee that a consensual point is attained regarding the exact sub-indicator's weights (Cherchye et al., 2007). To avoid such risks, we rely in a second step, on the BoD weighting approach (Cherchye et al., 2007). The $B o D$ framework allows each utility to freely (and endogenously) choose nonnegative weights for all selected sub-indicators that maximize its eventual effectiveness performance relative to other observed WUs.

As such, specific utilities' poor performance can only be blamed on the particular selfselected $B o D$ weights rather than on some a priori defined (often unfair or nonconsensual, etc) sub-indicator weighting system (Shwartz et al., 2010). By construction, resultant performance indexes (bounded between 0 and 1) only reflect utilities 'achievement' given unit input - that is, "without explicit reference to the inputs that are used in achieving such performance" (Cherchye et al., 2007). This is unlike normal DEA problems where existing input resources are taken into account. $B o D$ values of one imply 100 percent effectiveness while values near to (far from) one denote high (or low) effectiveness, relative to the benchmark utilities located on the best-practice effectiveness frontier. 
On the other hand and due to inefficiencies, utilities could fail to attain 100 percent effectiveness. Or vice versa, ineffective supply could foster a higher efficiency. To examine this relationship we use in a third step, the ratio of utilities' effectiveness (BoD) by technical efficiency (TE). We refer to this ratio as the utilities 'Potential Input Capacity' (PIC).

Consider in Figure 6.1 (i.e., Fig 6.1a to 6.1c) utilities 'A' and 'B'. Figure 6.1a presents the technical efficiency of the observations. It is presented in an output-oriented framework where we normalized the inputs. Observation ' $A$ ' is clearly more efficient than observation 'B', although not as efficient as its best practice. Therefore, observation ' $A$ ' and 'B' are located below the best practice frontier. Figure $6.1 \mathrm{~b}$ presents the effectiveness of the two observations. Here, the outputs are presented relatively to the unit input (i.e., the BoD framework). ${ }^{147}$ Both observations are as effective.

Figure 6.1c presents the PIC ratio. The ratio of effectiveness to technical efficiency equals to the distances $\mathrm{OA}_{\mathrm{BoD}} / \mathrm{OA}_{\mathrm{TE}}$ and $\mathrm{OB}_{\mathrm{BoD}} / \mathrm{OB}_{\mathrm{TE}}$, respectively for ' $\mathrm{A}$ ' and ' $\mathrm{B}$ '. This ratio is denoted, respectively, by the distances $\mathrm{OA}_{\mathrm{PIC}}$ (utility A) and $\mathrm{OB}_{\mathrm{PIC}}$ (utility B), see Fig 6.1c. Given a priori defined output target (to serve all the target population within each utilities' jurisdiction), the ratio indicates to what extent utilities potentially use available input resources (capital, labor, etc) to reach the target.

PIC values of less than one indicate resources deficiency. Affected utilities need more input resources to attain 100 percent effectiveness (reflected by the distance $\mathrm{S}$ for utility A in Fig 6.1c). For utilities with a PIC value $<1$, ineffectiveness is a more serious issue than inefficiency. PIC values larger than one denote utilities' excess use of resources. That is, if the specific utilities were technical efficient, they would reach their targets with less input resources (reflected by the distance $\mathrm{V}$ for utility B in Fig 6.1c). For these utilities with PIC > 1, inefficiency is a larger problem than ineffectiveness. PIC values

\footnotetext{
${ }^{147}$ While in reality both output variables are complementary, we assume that utilities can moreover substitute one output with the other (e.g., can increase their vvolumetric water sold without necessarily increasing their served population). This is for instance possible for utilities with high individual water connections rather than high shared connections.
} 
equal to one indicate exact resource allocation for observed utilities. That is, if observed utilities are technical efficient, then, they are also 100 percent effective.

\section{Figure 6.1: Step-wise model}

Fig 6.1a: Technical Efficiency

TE, $x$ is given

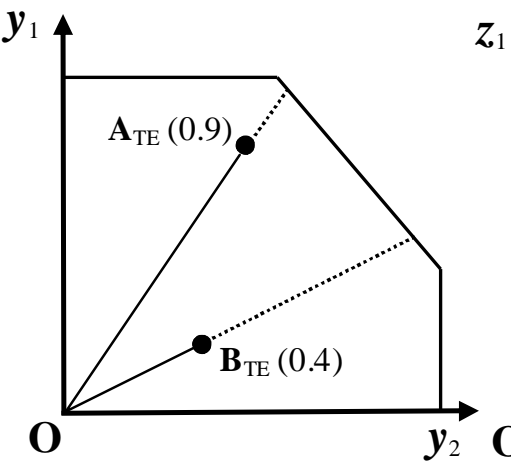

Fig 6.1b: Benefit of the Doubt

BoD, $x=1$
Fig 6.1c: Potential Input Capacity $\mathrm{PIC}=\mathrm{BoD} / \mathrm{TE}$

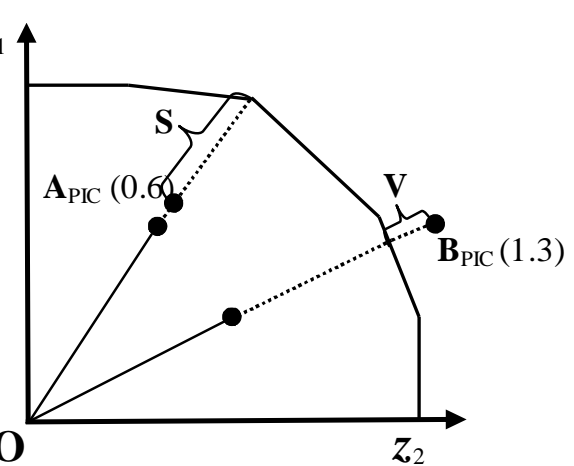

Abbreviations: TE, $x$, BoD, PIC and $y$ : as earlier defined, $z$ : Variable representing the ratio of population served and volumetric water sold over target population (see Section 6.3.3). Source: Authors illustration.

In a fourth and final step, we explore different inefficiency and ineffectiveness determinants. Unlike earlier studies that relied on the traditional two-step approach (where an environmental variable is regressed on the estimated efficiency scores), we use the double bootstrap procedure such that we correct for the measurement bias in the estimates (see Simar and Wilson, 2007: 2011 for an extensive discussion). Note that this fourth step allows us to indicate correlations between efficiency, effectiveness and environmental variables. Although not explicitly stated below, this does not allow us to draw causal interpretations. Figure 6.2 illustrates the four steps. 
Figure 6.2: Urban water utilities performance - stepwise analytical framework

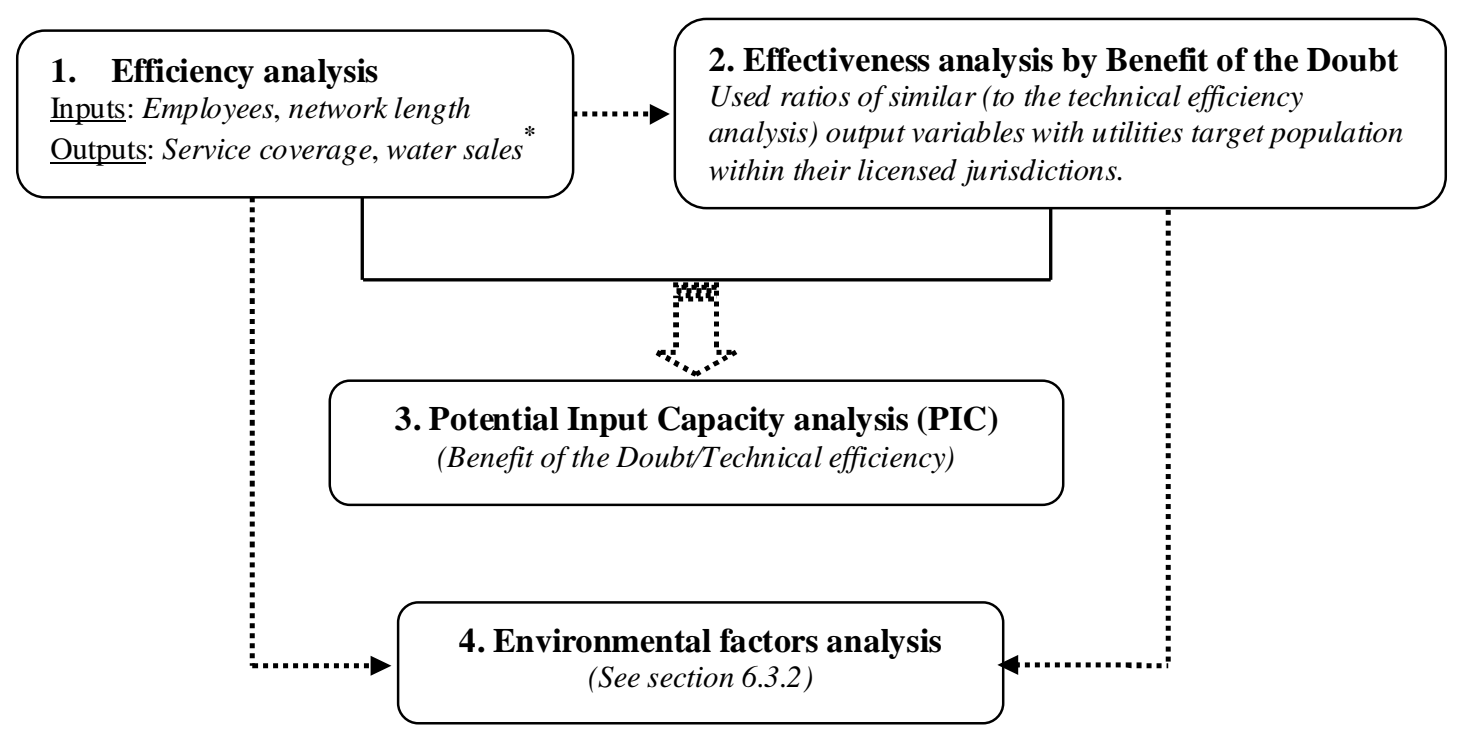

* Besides this basic model specification, two output quality (service connectivity and adjusted service continuity) variables are considered respectively, in Models 2 and 3 (see Section 6.3.1). Source: Authors illustration.

\subsection{Water utilities efficiency and effectiveness}

Table 6.2 presents the results of the analyses. Through the three model specifications (see section 6.3.1), utilities are observed to be more effective than efficient. On average, technical efficiency across the three model specifications amounts to $70 \%$ (when no output quality variables are considered), 63\% (when service connectivity variables are considered) and $68 \%$ (when service continuity variables are considered). Effectiveness amounts in the three specifications to $71 \%, 73 \%$ and $71 \%$, respectively. A quarter of the observed utilities have the possibility to increase their effectiveness by 44 percent and technical efficiency by 51 percent. The latter, through the three model specifications, is equivalent to about 56 (Model 1), 49.1 (Model 2) and 48.8 (Model 3) percent. This implies that, when a quarter of the observed utilities is considered, utilities are found to be less technical inefficient and ineffective only when service continuity quality variables are considered. 
As the average hides some information, we focus on the different quartiles of the efficiency distribution. In model 1, technical efficiency of the third quartile amounts to $80 \%$. This decreases to $71 \%$ in model 2 and to $76 \%$ in model 3 . However, effectiveness results do not show this pattern. Utilities effectiveness stays around $87 \%$ in all the three model specifications.

From the potential input capacity levels (PIC), we learn that the utilities (across the three model specifications) face more inefficiency than ineffectiveness problems. This implies that, if observed utilities would have been technical efficient, they would attain 100 percent effectiveness with less resources (inputs). As such, they do not need any additional resources to reach their effectiveness targets but a reduction of their existing inputs. The latter corresponds to about 2.4 percent (Model 1), 15.9 percent (Model 2) and 4.9 percent (Model 3). Note that, these PIC estimates are based on the underlying mean values thus, they do not necessarily correspond to the ratio of estimated TE and BoD means.

Across the three model specifications, technical efficiency is positively and significantly correlated with effectiveness only in the model without output quality variables (correlation of .29, p-value 0.0369 ) and if service continuity quality variables are considered (.44, p-value 0.0014$)$. While the relation is not very strong, an increase in technical efficiency is potentially allied with an increase in effectiveness. 
Table 6.2: Utilities technical efficiency, effectiveness and potential input capacity estimates

\begin{tabular}{lllll}
\hline \multirow{2}{*}{ Model 1* } & & TE & BoD & PIC \\
\cline { 3 - 4 } & Mean & 0.696 & 0.713 & 1.024 \\
& Quartile 1 & 0.576 & 0.682 & 1.155 \\
& Quartile 3 & 0.437 & 0.557 & 1.005 \\
Maximum & 0.796 & 0.868 & 5.023 \\
& Minimum & 0.896 & 0.971 & 0.254 \\
& & 0.156 & 0.228 & 1.159 \\
& Mean & & & 1.248 \\
Model 2 & Quartile 1 & 0.626 & 0.726 & 0.906 \\
& Quartile 3 & 0.619 & 0.681 & 1.399 \\
& Maximum & 0.509 & 0.547 & 20.413 \\
& Minimum & 0.706 & 0.885 & 0.263 \\
& & 0.871 & 0.968 & 1.049 \\
& Mean & 0.038 & 0.229 & 1.139 \\
& Median & & & 0.870 \\
& Quartile 1 & 0.677 & 0.676 & 1.319 \\
& Quartile 3 & 0.664 & 0.562 & 2.959 \\
& Maximum & 0.512 & 0.869 & 0.255 \\
\hline
\end{tabular}

TE: Technical efficiency, BoD: Effectiveness, PIC: Potential input capacity. All estimates are weighted by the population served. *For all models (1-3), similar 51 WUs are observed. Model 1 corresponds to network length and employees as inputs; and coverage and water sales as outputs. Models 2 and 3 add respectively, service connectivity and continuity as outputs to Model 1 .

\subsubsection{Regional performance}

To identify regional patterns, we explore in Table 6.3 regional utility-performance differences. Across the three model specifications, East African urban WUs (such as from Ethiopia, Kenya, Tanzania, Uganda) are more technical inefficient than ineffective. Given their existing resources, these utilities can expand their outputs by 45 percent, 39 percent and 38 percent along models 1 to 3 , respectively (see Table 6.3). Nonetheless, to entirely penetrate their licensed markets (i.e., completely attain their effectiveness targets for all population within their licensed jurisdictions) these utilities should increase their effectiveness (across the three model specifications) by 38 percent. Such performance improvement will demand no additional input usage (signaled respectively through the three models by PIC values of more than one).

Looking at both South African (including Malawi, Mauritius, Namibia, South Africa, Zambia) and West African (such as Benin, Cote d'Ivoire, Ghana, Mali, Mauritania, Nigeria) utilities, analogous conclusions are observed. Like their East African counterparts, these utilities seem less ineffective than technically inefficient. As indicated 
by their PIC values of more than one, observed utilities can indeed attain increased performance (100 percent effectiveness) with fewer resources than their present amounts. Input excess of about 35 and 16 percent across the three model specifications for the two regions respectively, is on average observed.

Through the three model specifications, South African utilities are the best performing both in terms of effectiveness and technical efficiency. They are followed by (when only models 2 and 3 results are considered) the East African and finally the West African utilities (see Table 6.3).

Table 6.3: Mean performance estimates per region

\begin{tabular}{|c|c|c|c|c|}
\hline & Region & TE & BoD & PIC \\
\hline \multirow[t]{4}{*}{ Model $1 *$} & East Africa & 0.556 & 0.623 & 1.456 \\
\hline & Central Africa** & 0.735 & 0.580 & 0.790 \\
\hline & South Africa & 0.586 & 0.805 & 1.520 \\
\hline & West Africa & 0.588 & 0.599 & 1.140 \\
\hline \multirow[t]{4}{*}{ Model 2} & East Africa & 0.607 & 0.625 & 2.564 \\
\hline & Central Africa** & 0.655 & 0.604 & 0.922 \\
\hline & South Africa & 0.644 & 0.810 & 1.300 \\
\hline & West Africa & 0.550 & 0.604 & 1.168 \\
\hline \multirow[t]{4}{*}{ Model 3} & East Africa & 0.617 & 0.629 & 1.068 \\
\hline & Central Africa** & 0.705 & 0.604 & 0.857 \\
\hline & South Africa & 0.669 & 0.794 & 1.233 \\
\hline & West Africa & 0.575 & 0.597 & 1.161 \\
\hline
\end{tabular}

* For all models (1-3), similar 51 WUs are observed. TE, BoD and PIC: As earlier defined.

** Only one utility is observed per model. All estimates are weighted by the population served.

\subsubsection{Explaining utility performance differences}

To explain efficiency and effectiveness differences, the following specification is estimated (in a similar vein as in Simar and Wilson, 2007):

$$
\text { WUperf }_{i}=\alpha_{i}+\beta_{1 i} I R+\beta_{2 i} P C+\beta_{3 i} G D P+\beta_{4 i} \text { Network density }+\varepsilon_{i}
$$

Where $W$ Uperf $_{i}$ denotes $\mathrm{WU}_{i}$ 's performance in terms of efficiency or effectiveness, and $\beta_{1,2,3,4}$ represent the estimated marginal effects on $\mathrm{WU}_{i}$ 's performance of the regulation 
(independent or not - IR), the use of performance contracts (PC), ${ }^{148}$ gross domestic product per capita purchasing power parity (GDP) and utilities network density. ${ }^{149}$

The results are presented in Tables 6.4 and 6.5. To examine the robustness of our results, we explored in different models the influences of additional country-specific (including political stability and corruption levels), sector-specific (such as, annual sector reports availability) and utility-specific (including utility ownership and scale economies) variables. While their influences are insignificant, estimated utility performance scores remain largely unchanged.

Only countries' GDP is found to positively and significantly correlate to technical efficiency especially when service connectivity and continuity variables are considered (see Table 6.4). An increase by US\$1,000 of a specific country's GDP (say from US\$ 2,420 to US\$ 3,420 ) is significantly associated with a technical efficiency increase of 9.75 and 11.2 (i.e., when Models 2 and 3 results are considered, respectively). These particular findings are consistent with De Witte and Marques (2009). Using nonparametric envelopment techniques, the authors explored 122 urban WUs in Australia, Belgium, Netherlands, Portugal, United Kingdom (England and Wales) and found a positive correlation between utilities technical efficiency and regional wealth per capita (measured in gross regional product per capita).

The use of stricter regulatory systems (independent regulation) correlates positively with WUs' technical efficiency. A sub-sample with either regulation or the use of performance contracts yields similar results. This is only significant when service connectivity variables are considered. Previous literature provides mixed results on the correlation between utilities' efficiency and the kind of adopted regulatory structure. Anwandter and Ozuna (2002) found an insignificant link between autonomous (independent) regulation and urban WUs efficiency. They observed a sample of 110 utilities in Mexico in 1995.

\footnotetext{
${ }^{148}$ We carefully examined the existence of any multicollinearity between regulation and the use of performance contracts, but found no evidence.

${ }^{149}$ It is likely that all four environmental aspects are correlated. We checked for these but found no significant results. Given our data and methodological-related constraints, we thus consider the four variables to offer sufficient variation for the analysis.
} 
Similar results were observed by Kirkpatrick et al. (2006) on a sample of 14 African urban WUs in $2000 .^{150}$

On the other hand, and based on 211 and 10 urban WUs in Wisconsin and, England and Wales respectively, Aubert and Reynaud (2005) and Fabrizio and Martin (2007) found analogous positive and significant correlation between regulation and efficiency. See also Erbetta and Cave (2007) and the references therein. In our case, a 1 percent increase in independent regulation is significantly associated with a 9.7 percent increase in technical efficiency (i.e., when Model 2 results are considered). Other control variables (use of performance contracts and network density) yield insignificant influences on utilities technical efficiency (see Table 6.4).

\section{Table 6.4: Technical efficiency determinants}

\begin{tabular}{llll}
\hline Variable & Model 1** & Model 2 & Model 3 \\
\hline Constant & $0.514(0.082) * * *$ & $0.439(0.063) * * *$ & $0.483(0.067)^{* * *}$ \\
Independent regulation (dummy) & $0.015(0.089)$ & $0.097(0.057) *$ & $0.008(0.070)$ \\
Performance contract use (dummy) & $-0.045(0.076)$ & $0.043(0.053)$ & $0.026(0.060)$ \\
GDP & $0.197(0.127)$ & $0.236(0.086)^{* * *}$ & $0.271(0.094)^{* * *}$ \\
Network density & $0.613(0.759)$ & $0.702(0.604)$ & $0.780(0.502)$ \\
\hline Note: Standard error between brackets; $*$ and $* * *$ denote respectively, statistical significance at 10 and 1 percent. \\
$* *$ For all models $(1-3)$, similar 51 WUs are observed. GDP and Network density as earlier defined.
\end{tabular}

Repeating the double bootstrap procedure on the effectiveness scores yields slightly different estimates. ${ }^{151}$ The results are presented in Table 6.5. A $1 \%$ increase in countries' GDP is positively and significantly linked to a more than 30 percent increase (on average across the model specifications) in utilities effectiveness. Interestingly, network density is found negatively correlated with utilities' effectiveness. This finding is, however, insignificant through the three model specifications. Though lower influences (compared to the estimated influence on utilities technical efficiency) are on average observed across the three specifications of about 4.4 percent, higher network densities are found to be

\footnotetext{
${ }^{150}$ See also Ferro et al. (2011) for Latin American WUs observed between 2003 and 2008.

${ }^{151}$ Alternatively, one could just relate the estimated effectiveness scores with the actual output compositions for specific WUs. While this is interesting, we preferred to examine the main effectiveness drivers in a second-stage analysis.
} 
good for technical efficiency improvement, but at the expense of reduced effectiveness. This can especially be the case when customers are sparsely located across specific WUs' licensed jurisdictions.

The remaining exogenous factors (independent regulation and use of performance contracts) are found to positively but insignificantly influence utilities' effectiveness (see Table 6.5).

Table 6.5: Effectiveness determinants

\begin{tabular}{llll}
\hline Variable & Model 1* & Model 2 & Model 3 \\
\hline Constant & $0.542(0.076)^{* * *}$ & $0.541(0.078) * * *$ & $0.539(0.076)^{* * *}$ \\
Independent regulation (dummy) & $0.008(0.070)$ & $0.018(0.069)$ & $0.023(0.070)$ \\
Performance contract use (dummy) & $0.092(0.064)$ & $0.089(0.063)$ & $0.080(0.060)$ \\
GDP & $0.326(0.122)^{* * *}$ & $0.340(0.121)^{* * *}$ & $0.319(0.119) * * *$ \\
Network density & $-0.066(0.909)$ & $-0.062(0.873)$ & $-0.004(0.884)$ \\
\hline
\end{tabular}

\subsection{Conclusion}

This chapter explored the use of benchmarking techniques in facilitating informed policy decisions across the African urban water sector. Using the double bootstrap procedure in a step-wise model approach, technical efficiency scores were first estimated and compared across different model specifications. The first (basic) specification ignored output quality variables. The second and third specification took into account both service connectivity (in terms of active piped water connections) and service continuity factors (measured in daily hours of water supply).

Second, utilities effectiveness levels were explored and unbundled from inefficiency in a third step. In the latter step, we used the ratio of WUs' effectiveness to technical efficiency to understand the key reasons behind utilities poor performance (due to either inefficiency or ineffectiveness) and the extent to which observed utilities utilize available resources to reach their effectiveness targets. We referred to this ratio as the "potential input capacity' (PIC). PIC values of less than, more than or equal to one denote WUs' resources deficiency, excess use of input resources (due to higher inefficiency than 
ineffectiveness problems) and, exact resource allocation. Finally, possible influences of country, sector and utility-specific environmental variables on utilities' technical efficiency (and effectiveness) levels were explored.

The results pointed out that most utilities faced more inefficiency than ineffectiveness problems (PIC values > 1). Consequently, if the utilities would have been performing as efficiently as the best practice observations, they would achieve their effectiveness targets with fewer resources. To provide water supply services to all the population within their licensed jurisdiction and attain 100 percent effectiveness, these utilities would not need any additional resources.

Across the African region, no major performance differences were observed. Utilities across the East, West and Southern African regions seemed less ineffective than technically inefficient. To fully penetrate their markets, these utilities would need to reduce their input use (as evident from their PIC values of more than one). Nonetheless, South African utilities were the most well performing (both effectively and efficiently) followed by (i.e., when both service connectivity and continuity variables were considered) the East African and the West African utilities.

Only countries' economic development (measured in terms of the gross domestic product per capita purchasing power parity) was found positively and significantly linked to utilities technical efficiency and effectiveness. Network density correlated positively to WUs' technical efficiency but negatively influenced utilities' effectiveness. This was, however, insignificant across the three model specifications. Independent regulation was found positively linked to WUs' technical efficiency and effectiveness. However, this was only significant when service connectivity variables were considered. 
Annex 6.1: Quality variables used in urban water distribution efficiency studies

\begin{tabular}{|c|c|c|c|c|}
\hline Author & Urban WUs (period, place) & Technique & Quality variable used & Quality variable influence on efficiency \\
\hline Bhattacharyya et al., 1994 & 257 (1992, North America) & TGV cost function & Mains breakdowns/output/year & Increased inputs requirement \\
\hline Saal and Parker, 2000 & 10 (1985-1999, England and Wales) & MO translog cost function & 9 water quality measures* & Quality-driven scope economies \\
\hline Antonioli \& Filippini, 2001 & 32 (1991-1995, Italy) & $\mathrm{CD}$ variable cost function & Water losses, WSCtreatment & Only WSCtreatment increases variable costs \\
\hline Garcia \& Thomas, 2001 & 55 (1995-1997, France) & GMM, translog cost function & Network losses & Increased input requirement \\
\hline Saal \& Parker, 2001 & 10 (1985-1999, England and Wales) & Tornqvist indexes & 9 water quality measures* & Lower productivity post-privatization \\
\hline Mizutani \& Urakami, 2001 & 112 (1994, Japan) & Log-linear, translog, hedonic function & Purifier level, household ratio & Better network and scale economies capture \\
\hline Corton, 2003 & 44 (1996-1998, Peru) & Regression techniques & CL tests, SCty, WSCtreatment & No significant impact on operation costs \\
\hline Tupper \& Resende, 2004 & 20 (1996-2000, Brazil) & DEA with tobit regression & Water loss index & Positive significant influence \\
\hline Woodbury \& Dollery, 2004 & 73 (1998-2000, Australia) & DEA with tobit regression & Water quality** \& service*** indexes & Minor variations in utilities efficiency \\
\hline Lin, 2005 & 198 (1996-2001, Peru) & Stochastic cost frontier & $\mathrm{AW}$ ratio, $\mathrm{CL}$ tests, $\mathrm{SCv}$, SCty & Positive significant influence \\
\hline Saal et al., 2007 & 10 (1985-2000, England and Wales) & GPP index & Bathing water intensity & Increased input requirement \\
\hline Erbetta \& Cave, 2007 & 10 (1993-2005, England and Wales) & DEA, Stochastic frontier & WU-specific DWQCI & Better output caputure \\
\hline Lin \& Berg, 2008 & 38 (1996-2001, Peru) & DEA, PSM and QMPI & CL tests \& SCty & Positive influence \\
\hline Picazo-Tadeo et al., 2008 & 38 (2001, Spain) & Translog cost function & Unaccounted-for water & Positive influence \\
\hline Bottasso and Conti, 2009 & 10 (1995-2004, England and Wales) & Translog cost function & Water quality & Lower productivity post-privatization \\
\hline
\end{tabular}




\section{CHAPTER 7: Conclusion}

\subsection{Main findings}

This thesis contributes to the existing literature on sector reforms and performance in urban water supply. Based on the study findings, we draw five key conclusions. First, urban WU restructuring is largely a political process among actors at different policy levels. While this finding is not unique (see for e.g., Larbi, 2001), we observe interesting trends in Chapter 2. The existence of multiple reform agendas and interests from different stakeholders at the global policy level provides sufficient opportunities for actors at the national policy level to (i) selectively adopt those reform strategies that suit best their national/sector/utility policy interests, and (ii) resist strategies that challenge their organizational autonomy. Besides, as power relations across actors (global to national) change over time, the respective bargaining positions and eventually the ensuant reform dynamics, change. This allows reform trajectories at particular points in time to weave in line with the prevailing interests of the most hegemonic actor(s) at both global and national policy levels.

In the case of Uganda (see Chapter 2), the change from complete urban water industry's privatization to sector commercialization began with NWSC's resistance of the privatization reforms as advanced by the World Bank. Learning from previously failed privatization attempts within and outside Uganda, NWSC managed to showcase improved performance without complete privatization. This gained the national bulk water utility international recognition and support from other global policy players. Forging strategic alliances with these latter players, NWSC managed to challenge and change the original neoliberalistic reforms' path - i.e., from complete sector privatization to commercialization.

Second, the intensity and nature of urban WU reform processes is contingent to the continuous association of four interdependent governance structures. Given the prevailing resources/infrastructure or technology, policies, institutions and organizations interact at different speeds and extents. These, as discussed in Chapter 3 translate in major and 
minor governance shifts in the urban water supply sector. Analyzing these governance structures at particular points in time, illuminate diverse shifts that subsequently characterize and explain reform trends and outcomes overtime.

Considering the case of the Zambian urban water sector since 1993 - the onset of the neoliberalistic reforms, two major governance shifts are evident. At the beginning of the reforms, private sector organizations were advanced with a high intensity, across the sector. These, similar to the privatization pressures across the Ugandan urban water sector (see chapter 2), were advanced by the World Bank. Over time however, these private sector organizations in urban water services provision were replaced by private sector institutions. These latter changes were built on the existing sector resources (technical, financial, human, etc) with the support of other bilateral stakeholders.

Third and since the late 1990s, public sector performance has particularly improved with the entrenchment of institutions traditionally predominant with private sector management. Chapter 4 examined two WU-groups under different managerial ownership arrangements. The public-public owned utility group rather than the public-private owned group was found more output-technical efficient. To operate on the best practice frontier, utilities in the latter group would need to increase their current outputs with the existing resources by 36 percent, compared to 22 percent by the public-public owned utilities.

Besides, the public-public owned utility group operated closer to the best-practice technology accessible to both utility groups, as defined by the metafrontier. Compared to the public-private owned group, the average public owned utility faced less restrictive operating environment. Compared to the former utilities, public-public owned utilities in Uganda are largely self-regulated besides regular oversights by the Ministry of Water and Environment. This creates and maintains within-utility pressures to operate on or near to the best practice frontier. Nonetheless, these utilities operated largely, under decreasing returns to scale regions. This was unlike the public-private owned utilities that enjoyed economies of scale. 
Besides technical efficiency increases given the reforms across the Ugandan urban water sector (as discussed in Chapter 4), utilities experienced fourthly, positive productivity growths. Using the case of both Zambian and Ugandan (public-public owned) urban WUs, productivity increases were attributed to positive technical efficiency changes more than technical change and/or scale changes, see Chapter 5. However, as utilities expanded piped water connections per network length, installed meters and maintained water mains, their productivity growth declined, at least in the short term.

Fifth, increased WUs' performance can either be as a result of efficiency or effectiveness advances. We explained and disentangled these performance components in Chapter 6. More so as unearthed in the chapter, countries' economic development is paramount for utilities' efficiency and effectiveness improvements.

\subsection{Policy ramifications and recommendations}

Rational decision makers' face, among other phenomena, bounded rationality challenges (Simon, 1957). They lack knowledge ex-ante, of what might become of newly-designed reform programs. Knowledge acquisition is constrained on one hand by their limited cognitive capabilities and on the other, by the environment (prevailing or future socialeconomic and political developments). With these uncertainties that relay in high transaction costs, reformers at all policy levels try to forge strategic alliances with specific actors. As evidenced in Chapter 2, these alliances between formerly weak national actors and hegemonic actors at the global policy level, result in the empowerment of the former weak actors. This changes the rules of the game for certain actors and at specific periods of time. The particular forms of these alliances and power shifts at specific times are however, dynamic and hardly predictable in the middle to long-run.

Besides inherent politics in urban water supply, a careful identification and analysis of the underlying governance shifts that epitomize reform processes at particular points in 
time provide additional insights. Such, as discussed in Chapter 3 unveil major and minor governance shifts that allow a better understanding of reform processes.

Turning to the African urban water sector's organization, universal qualitative services coverage is (still) possible under the new public management (see Chapter 4). Firstly, private sector investments into the water sector are unlikely in the foreseeable future given the unattractiveness of the industry. Secondly, both public and private monopolies face comparable principal-agent problems that motivate agents to take advantage of innate information asymmetries and extract economic rents at the expense of the principal (and subsequently, the customers). Thirdly, the entrenchment of private ethos (institutions) into the traditional public enterprises including the use of time-bound contracts has eased sector regulation. Competitive bidding for the urban water market and benchmarking based on mutually defined performance targets among other aspects have made it possible to regulate entry into, products produced in, and utilities operating within the market.

Fourthly, active public sector engagement in and subsidization of piped water provision in Africa, as is the case in most developed economies (Prasad, 2008; Checchi et al., 2009) is likely to persist (Bayliss and McKinley, 2007; Castro, 2008; Swyngedouw, 2009). Indeed, the public sector provides water services to more than 90 percent of the world's population (WHO and UNICEF, 2000; Prasad, 2006). Besides, when non-public owned water supply systems are abandoned or insolvent, it is the government that is expected to take-over and manage such systems. As such, public sector capacities in Africa, alike other less developed regions, need strengthening for inclusive, reliable and sustainable water services provision.

Whilst benchmarking exercises including the use of productivity growth analyses (see Chapter 5) help to discern utilities' performance, they do not necessarily result in direct performance improvements for observed firms. The process nonetheless allows decision makers to first, identify potential scopes for efficiency gains - i.e., for both inefficient and efficient utilities. To operate on the best practice frontier given prevailing inputs, 
inefficient utilities can benefit from increased technical efficiency in the subsequent periods $(t+n)$ relative to the base period $(t)$. Efficient utilities in the base period can on the other hand, increase their innovativeness in producing more outputs given the prevailing inputs, relative to the overall technology. Utilities can additionally opt to operate at technologically optimal scales given the available technology and benefit from scale economies.

Second, the exercise facilitates the identification of diverse productivity change drivers at, but not limited to the utility levels. Third, one can correlate estimated productivity changes with different efficiency (e.g., water losses) and effectiveness (e.g., services coverage) targets at the utility level. Such provides additional insights on whether productivity gains are matched with improved (in)efficiency or (in)effectiveness.

Last but not least, efficiency and effectiveness are not a trade-off. Urban WUs can improve their effectiveness by increasing their efficiency. This is confirmed in Chapter 6. To do so, poor performers should learn from best practices. To improve utilities' performance moreover; policy makers and international organizations such as the United Nations should examine and foster diverse efficiency and effectiveness enhancers such as, countries per capita wealth.

\subsection{Study limitations and avenues of further research}

First, since actors and operating environments differ from one policy level to another (i.e., in space and time), we are unable to generalize the nature and outcomes of the specific sector reforms in Uganda and Zambia to other urban water supply sectors in Africa. Further research could nonetheless, build on the analytical frameworks outlined in Chapters 2 and 3, while taking into account inherent structural disparities among utilities across the continent, to comparatively analyze and explain sector trends given specific reform programs. Second, it would be insightful to examine what these developments (in Uganda, Zambia, etc) mean to other actors such as, the water users. 
Third, the thesis findings are conditional on the specific datasets employed and more so, on the ensuing methodological choices. The availability of complete operational data (both quantity and cost data) would permit the extension of this study (refer to Chapters 4 to 6) to explore other kinds of efficiency (including cost and allocative efficiencies) and effectiveness measures. Long panel data would allow the control of unobserved heterogeneity that would otherwise make specific utilities to speciously appear better than others. Consistent data would assure the extension of, for example, the metafrontier framework (see Chapter 4) to explore in particular, potential peer and target-utilities from which inefficient utilities could learn from. Similarly, it would be insightful to apply the proposed step-wise model (see Chapter 6) to other sectors and continents.

Fourth, Chapters 4 to 6 provide some first steps in explaining efficiency and effectiveness drivers. Further research is needed to explore and explain the influence of other political economy variables, management indicators, quality and equity related factors. Fifth, a better understanding of the complex relationship between efficiency and effectiveness is needed. 


\section{References}

Abbott, M., and Cohen, B. (2009). Productivity and efficiency in the water industry. Utilities policy, 17 (3-4): 233-244.

Abbott, M., Wang, W., and Cohen, B. (2011). The long-term reform of the water and wastewater industry: The case of Melbourne in Australia. Utilities Policy, 19 (2): 115122.

ADB (Asian Development Bank). (2007). Delivering piped water on a small scale: Results of ADB's water supply service market survey in Manila (Water Briefs). Manila: Asian Development Bank.

AfDB (African Development Bank). (2010). Gender, poverty and environmental indicators on African countries 2010 (Vol. XI). Tunis, Tunisia: Economic and Social Statistics Division, African Development Bank.

AMCW, AfDB, AfDF, EUWI, WSP, and UNDP. (2006). Getting Africa on track to meet the MDGs on water and sanitation: A status review of sixteen African countries. African Ministers' Council on Water, African Development Bank, African Development Fund, European Water Initiative, Water and Sanitation Program and United Nations Development Programme.

Andrés, L., Guasch, J., Haven, T., and Foster, V. (2008). The impact of private sector participation in infrastructure: Lights, shadows and the road ahead. Washington DC: World Bank Publications.

Angelakis, A., Mays, L., Koutsoyiannis, D., and Mamassis, N. (2012). Evolution of water supply through the millennia. London, UK: IWA publishing.

Antonioli, B., and Filippini, M. (2001). The use of a variable cost function in the regulation of the Italian water industry. Utilities Policy, 10(3-4): 181-187. 
Anwandter, L., and Ozuna, T. (2002). Can public sector reforms improve the efficiency of public water utilities? Environment and Development Economics, 7(4): 687-700.

Aoki, M. (2001). Towards a comparactive institutional analysis. Massachusetts: The MIT Press.

Ashton, J. (2000a). Total factor productivity growth and technical change in the water and sewerage industry. The Service Industries Journal, 20 (4): 121 - 130.

Ashton, J. (2000b). Cost efficiency in the UK water and sewerage industry. Applied Economics Letters, 7 (7): 455-458.

Aubert, C., and Reynaud, A. (2005). The impact of regulation on cost efficiency: An empirical analysis of Wisconsin water utilities. Journal of Productivity Analysis, 23(3): 383-409.

Auriol, E., and Blanc, A. (2009). Capture and corruption in public utilities: The cases of water and electricity in Sub-Saharan Africa. Utilities Policy, 17(2): 203-216.

Baietti, A., Kingdom, W., and van Ginneken, M. (2006). Characteristics of well performing public water utilities (Water Supply \& Sanitation Working Note No. 9). Washington DC, USA: World Bank.

Bakker, K. (2002). From state to market?: Water mercantilización in Spain. Environment and Planning A, 34(5): 767 - 790.

Balk, B. (2001). Scale efficiency and productivity change. Journal of Productivity Analysis, 15 (3): 159-183.

Banker, D. (1984). Estimating most productive scale size using data envelopment analysis. European Journal of Operational Research, 17(1): 35-44. 
Banker, R., Charnes, A., Cooper, W., Swarts J., and Thomas, D. (1989). An introduction to Data Envelopment Analysis with some of its models and their uses. Research in Governmental and Nonprofit Accounting 5: 125-163.

Barry, F. (1990). The evolution of Zambia's macroeconomic crisis, 1970 - 90 (Policy Paper No. PP90/2). Centre for Economic Research. Dublin, Ireland: Department of Political Economy, University College Dublin.

Bayliss, K, and McKinley, T. (2007). Privatising basic utilities in Sub-Saharan Africa: The MDG impact (IPC Policy Research Brief No. 3). Brazil: International Poverty Centre.

Bel, G., Fageda, X., and Warner, M. (2010). Is private production of public services cheaper than public production? A meta-regression analysis of solid waste and water services. Journal of Policy Analysis and Management, 29 (3): 553-577.

Berg, S. (2007). Conflict resolution: benchmarking water utility performance. Public Administration and Development, 27(1): 1-11.

Bhattacharyya, A., Harris, T., Narayanan, R., and Raffiee, K. (1995). Specification and estimation of the effect of ownership on the economic efficiency of the water utilities. Regional Science and Urban Economics, 25(6): 759-784.

Bhattacharyya, A., Parker, E., and Raffiee, K. (1994). An examination of the effect of ownership on the relative efficiency of public and private water utilities. Land Economics, 70(2): 197-209.

Bitran, G., and Valenzuela, E. (2003). Water services in Chile. Comparing private and public performance (Public Policy for the Private Sector No. 255). Washington DC, USA: The World Bank. 
Blanc, D. (2008). A framework for analyzing tariffs and subsidies in water provision to urban households in developing countries (DESA Working Paper No. 63), United Nations.

Bogetoft, P., and Otto, L. (2011). Benchmarking with DEA, SFA, and R. USA: Springer Science+Business Media, LLC.

Borins, S. (1997). A survey of commonwealth experience. In: Jones, L., Schedler, K., and Wade, S. (eds.), International perspectives on the New Public Management, Greenwich, UK: JAI Press Inc.

Bottasso, A., and Conti, M. (2009). Price cap regulation and the ratchet effect: A generalized index approach. Journal of Productivity Analysis, 32(3): 191-201.

Boubakri, N., Cosset, J., and Guedhami, O. (2008). Privatisation in developing countries: Performance and ownership effects. Development Policy Review, 26 (3): 275-308.

Braadbaart, O. (2005). Privatizing water and wastewater in developing countries: Assessing the 1990s' experiments. Water Policy, 7(4): 329-344.

Braadbaart, O. (2007). Privatizing water: The Jakarta concession and the limits of contract. In: Boomgaard P (ed.), A World of Water: Rain, rivers and seas in Southeast Asian histories. Leiden, Netherlands: KITLV Press.

Braadbaart, O. (2009). North-South transfer of the paradigm of piped water: The role of the public sector in water and sanitation services. In Castro, J., and Heller, L. Water and sanitation services: Public policy and management. London: Earthscan Ltd. Pgs 38 - 55.

Brenner, N., and Theodore, N. (2002). Cities and the geographies of actually existing neoliberalism. Antipode, 34(3): 349-379. 
Burki, S. and Perry, G. (1998). Beyond the Washington consensus: Institutions matter. Washington D.C.: World Bank.

Byrnes, P. (1985). Ownership and efficiency in the water supply industry: An application of the nonparametric programming approach to efficiency measurement (Doctoral thesis). Carbondale: Southern Illinois University.

Byrnes, P., Grosskopf, S., and Hayes, K. (1986). Efficiency and ownership: Further evidence. The Review of Economics and Statistics, 68(2): 337-341.

Campbell, J. (2006). What's new? General patterns of planned macro-institutional change. In, Hage, J., and Meeus, M. Innovation, science and institutional change. New York: Oxford University Press. Pp 505 - 524.

Carvalho, P., Marques, R., and Berg, S. (2012). A meta-regression analysis of benchmarking studies on water utilities market structure. Utilities Policy, doi:10.1016/j.jup.2011.12.005

Castro, J. (2008). Neoliberal water and sanitation policies as a failed development strategy. Progress in Development Studies, 8(1): 63 -83.

Castro, J. (2009). Systemic conditions and public policy in the water and sanitation sector. In, Castro, J., and Heller, L. Water and sanitation services: Public policy and management. London: Earthscan Ltd.

Castro, J., and Heller, L. (2009). Water and sanitation services: Public policy and management. London: Earthscan Ltd.

Caves, D., Christensen, L., and Diewert, E. (1982). The economic theory of index numbers and the measurement of input, output and productivity. Econometrica, 50 (6): 1393-1414. 
Chalos, P., and Cherian, J. (1995). An application of data envelopment analysis to public sector performance measurement and accountability. Journal of Accounting and Public Policy, 14 (2): 143-160.

Chanda, O. (2000). Regulating the Water and Sanitation Sector in Zambia, Lusaka: National Water Supply and Sanitation Council.

Charnes, A., Cooper, W., and Rhodes, E. (1978). Measuring the efficiency of decision making units. European Journal of Operational Research, 2 (6): 429-444.

Checchi, D., Florio, M., and Carrera, J. (2009). Privatisation discontent and utility reform in Latin America. Journal of Development Studies, 45 (3): 333-350.

Cherchye, L., Moesen, W., Rogge, N and Puyenbroeck, T. (2007). An introduction to 'Benefit of the Doubt' composite indicators. Social Indicators Research, 82 (1): 111-145.

Cocq, K. (2005). "There is still no alternative": The beginnings of water privatization in Lusaka. In, Ruiters, G., and McDonald, D, The age of commodity: Water privatization in Southern Africa. United Kingdom: Earthscan.

Coelli, T., Estache, A., Perelman, S., and Trujillo, L. (2003). A primer on efficiency measurement for utilities and transport regulators. World Bank Publications.

Coelli, T., Rao, P., O’Donnell, C., and Battese, G. (2005). An introduction to efficiency and productivity analysis (2nd ed.). Springer.

Coelli, T., and Perelman, S. (1999). A comparison of parametric and non-parametric distance functions: With application to European railways. European Journal of Operational Research, 117(2): 326-339. 
Coelli, T., and Walding, S. (2005). Performance measurement in the Australian water supply industry (Centre for Efficiency and Productivity Analysis, WP01/2005), University of Queensland, Australia.

Conca, K. (2006). Governing water: Contentious transnational politics and global institution building (1st ed.). USA: MIT Press.

Cooper, W., Seiford, L., and Tone, K. (2007). Data Envelopment Analysis: A comprehensive text with models, applications, references and DEA-Solver software. New York: Springer Science+Business Media, LLC.

Cooper, W., Seiford, L., and Zhu, J. (2011). Handbook on Data Envelopment Analysis $\left(2^{\text {nd }}\right.$ Ed). New York, Springer.

Correia, T., and Marques, R. (2011). Performance of Portuguese water utilities: How do ownership, size, diversification and vertical integration relate to efficiency? Water Policy, $13(3), 343-361$.

Corton, M. (2003). Benchmarking in the Latin American water sector: the case of Peru. Utilities Policy, 11(3): 133-142.

Corton, M., and Berg, S. (2009). Benchmarking central American water utilities. Utilities Policy, 17 (3-4): 267 - 275.

Crain, W., and Zardkoohi, A. (1978). A test of the property-rights theory of the Firm: Water utilities in the United States. Journal of Law and Economics, 21(2): 395-408.

Crain, W., and Zardkoohi, A. (1980). Public sector expansion: Stagnant technology or attenuated property rights? Southern Economic Journal, 46(4): 1069-1082.

Dagdeviren, H. (2008). Waiting for miracles: The commercialization of urban water services in Zambia. Development and Change, 39(1): 101-121. 
Daraio, C., and Simar, L. (2007). Advanced robust and nonparametric methods in efficiency analysis: Methodology and applications. USA: Springer Science+Business Media, LLC.

Davis, J. (2005). Private-sector participation in the water and sanitation sector. Annual review of environment and resources, 30: 145-183.

De Witte, K., and Marques, R. (2009). Designing performance incentives, an international benchmark study in the water sector. Central European Journal of Operations Research, 18(2): 189-220.

De Witte, K., and Marques, R. (2011). Gaming in a benchmarking environment. A nonparametric analysis of benchmarking in the water sector. Water Policy, 14 (1): 45-66.

Durant, R. (2001). Politics, paradox and the ecology of public administration: Challenges, choices and opportunities for a new century. In, Liou, K. Handbook of public management practice and reform. New York: Marcel Dekker, Inc.

ECA (Economic Commission for Africa). (2005). Public-private partnerships for service delivery: Water and sanitation (No. E/ECA/CHDCS.3/4). Economic Commission for Africa. United Nations Economic and Social Council.

Economist. (1994). Of wets and water (water supplies in developing countries). The Economist March 26th, London.

Emrouznejad, A., and De Witte, K. (2010). COOPER-framework: A unified process for non-parametric projects. European Journal of Operational Research, 207 (3): 15731586.

England, K., and Ward, K. (2007). Neoliberalization: States, networks, people. Oxford: Blackwell Publishing Ltd. 
Erbetta, F., and Cave, M. (2007). Regulation and efficiency incentives: Evidence from the England and Wales water and sewerage industry. Review of Network Economics, 6 (4): $425-452$.

Estache, A. (2005). What do we know about Sub-Saharan Africa's infrastructure and the impacts of its 1990 reform? The World Bank and ECARES, Universiteit Libre de Bruxelles.

Estache, A., and Kouassi, E. (2002). Sector organization, governance, and the inefficiency of African water utilities (Policy Research Working Paper No. 2890), The World Bank.

Estache, A., and Rossi, M. (2002). How different is the efficiency of public and private water companies in Asia? The World Bank Economic Review, 16(1): 139 -148.

Estache, A., and Wren-Lewis, L. (2009). Toward a theory of regulation for developing countries: Following Jean-Jacques Laffont's lead. Journal of Economic Literature, 47 (3): 729-770.

Fabrizio, E., and Martin, C. (2007). Regulation and efficiency incentives: Evidence from the England and Wales water and sewerage industry. Review of Network Economics, 6(4): 425-452.

Färe, R., Grosskopf, S., and Margaritis, D. (2011). Mamlquist productivity indexes and DEA. In, Cooper, W., Seiford, L., and Zhu, J. Handbook on Data Envelopment Analysis (2nd Edition), Springer Science+Business Media, LLC, New York: USA.

Färe, R., Grosskopf, S., and Roos, P. (1998). Malmquist productivity indexes: A Survey of theory and practice. In, Färe, R., Grosskopf, S., and Russell, R. (Eds.), Index numbers essays in honour of Sten Malmquist. Boston, USA: Kluwer Academic Publishers. 
Färe, R., Grosskopf, S., Norris, M., and Zhang, Z. (1994). Productivity growth, technical progress, and efficiency change in industrialized countries. The American Economic Review, 84(1): 66-83.

Farrell, M. (1957). The measurement of productive efficiency. Journal of the Royal Statistical Society. Series A (General), 120 (3): 253-290.

Feigenbaum, S., and Teeples, R. (1983). Public versus private water delivery: A hedonic cost approach. The Review of Economics and Statistics, 65(4): 672-678.

Feldheim, M. (2001). Downsizing in the public sector: Implications for public administration. In, Liou, K. Handbook of public management practice and reform. New York: Marcel Dekker, Inc.

Ferlie, E., and Steane, P. (2002). Changing developments in NPM. International Journal of Public Administration, 25 (12): 1459 - 1469.

Ferro, G., Romero, C., and Covelli, M. (2011). Regulation and performance: A production frontier estimate for the Latin American water and sanitation sector. Utilities Policy, 19(4): 211-217.

Foster, V. (1996). Policy issues for the water and sanitation sectors (No. IFM96-101). Washington D.C, USA: Inter-American Development Bank.

Franceys, R. (2008). GATS, "privatization" and institutional development for urban water provision. Progress in Development Studies, 8(1): 45 -58.

Franceys, R., and Gerlach, E. (2008). Regulating water and sanitation for the poor: Economic regulation for public and private partnerships. United Kingdom: Earthscan Publications Ltd. 
Frant, H. (1998). Missing pieces in each other's puzzles: Integrating the new public management and the new political economy. International Public Management Journal, 1 (1): $19-35$

Fried, H., Lovell, K., and Schmidt, S. (2008). The measurement of productive efficiency and productivity growth. Oxford University Press, USA.

Furubotn, E., and Richter, R. (2005). Institutions and economic theory: The contribution of the New Institutional Economics (2nd Ed). Michigan: The University of Michigan Press.

García-Sánchez, I. (2006). Efficiency measurement in Spanish local government: The case of municipal water services. Review of Policy Research, 23 (2): 355-372.

Garcia, S., and Thomas, A. (2001). The structure of municipal water supply costs: Application to a panel of French local communities. Journal of Productivity Analysis, 16 (1): 5-29.

Gasana J., Morin J., Ndikuyeze A., and Kamoso P. (2002). Impact of water supply and sanitation on diarrheal morbidity among young children in the socioeconomic and cultural context of Rwanda (Africa). Environmental Research Section A, 90(2): 76-88.

Gassner, K., Popov, A., and Pushak, N. (2009). Does private sector participation improve performance in electricity and water distribution? Washington DC, USA: The International Bank for Reconstruction and Development /The World Bank.

Gleick, P. (2003). Global freshwater resources: Soft-path solutions for the 21st century. Science, 302 (5650): 1524-1528.

GoZ (Government of Zambia). (1991). Local Government Act Cap 281. Lusaka: Zambia. 
GoZ (Government of Zambia). (1997). The water supply and sanitation Act, No. 28. Lusaka: Zambia.

GoZ (Government of Zambia). (2006). Fifth national development plan 2006-2010. Lusaka, Zambia.

Greene, W. (2008). The econometric approach to efficiency analysis. In Fried, H., Lovell, C., and Schmidt., S, The measurement of productive efficiency and productivity growth (pp. 92 - 250). New York: Oxford University Press, Inc.

Grosskopf, S. (1993). Efficiency and productivity. In, Fried, H., Schmidt, S., and Lovell, $\mathrm{K}$. The measurement of productive efficiency: Techniques and applications ( $1^{\text {st }}$ edition). USA: Oxford University Press, 160-194.

Grifell-Tatjé, E., and Lovell, C. (1995). A note on the Malmquist productivity index. Economics Letters, 47 (2): 169-175.

Hage, J., and Meeus, M. (2006). Innovation, science and institutional change. New York: Oxford University Press.

Hall, D., and Lobina, E. (2005). The relative efficiency of public and private sector water. London, UK: Public Services International Research Unit (PSIRU).

Harvey, D. (2005). A brief history of neoliberalism. New York: Oxford University Press Inc.

Hausman, W., Kemme, D., and Neufeld, J. (1986). The relative economic efficiency of private versus municipal waterworks in the 1890s. Business and economic history, 15(2): $13-27$. 
Hood, C. (1991). A Public Management for All Seasons. Public Administration, 69 (1): 3-19.

Hood, C. (1995). The "New public management" in the 1980s: Variations on a theme. Accounting organizations and society, 20 (2): 93-109.

Hope, K., and Chikulo, B. (2000). Decentralization, the New Public Management, and the changing role of the public sector in Africa. Public Management: An International Journal of Research and Theory, 2(1): 25 - 42.

Idelovitch, E., and Ringskog, K. (1995). Private sector participation in water supply and sanitation in Latin America. Washington D.C, USA: International Bank for Reconstruction and Development/ The World Bank.

Jalan, J., and Ravallion, M. (2003). Does piped water reduce diarrhea for children in rural India? Journal of Econometrics, 112(1): 153-173.

Jensen, O. (2005). Troubled partnerships: Problems on coping strategies in Jakarta's water concessions. Presented at the 4th Conference on Applied Infrastructure Research, Berlin, Germany. Retrieved from: http://www.infraday.tuberlin.de/fileadmin/documents/infraday/2005/papers/jensen_Troubled_Partnerships_Prob lems.pdf (November, 2011).

Jimenez, A., and Perez-Foguet, A. (2009). International investments in the water sector. International Journal of Water Resources Development, 25 (1): 1-14.

Johnston, V., and Seidenstat, P. (2001). Privatization policy and public management. In, Liou, K. Handbook of public management practice and reform. New York: Marcel Dekker, Inc. 
Joskow, P. (2007). Regulation of natural monopolies. Handbook of Law and economics (1st ed.). North-Holland: Elsevier B.V.

Jreisat, J. (2001). The new public management and reform. In, Liou, K. Handbook of public management practice and reform. New York: Marcel Dekker, Inc.

Kernaghan, K. (2000). The post-bureaucratic organization and public service values. International Review of Administrative Sciences, 66 (1): 91-104.

Kessides, I. (2004). Reforming infrastructure: Privatization, regulation and competition. Washington DC: The World Bank and Oxford University Press.

Kirkpatrick, C., Parker, D., and Zhang, Y. (2006). An empirical analysis of state and private-sector provision of water services in Africa. The World Bank Economic Review, 20(1): $143-163$.

Kneip, A., Simar, L., and Wilson, P. (2003). Asymptotics for DEA estimators in nonparametric frontier models (Technical report No. 0323). IAP Statistics Network. Interuniversity Attraction Pole, Belgium.

Kneip, A., Simar, L., and Wilson, P. (2008). Asymptotics and consistent bootstraps for DEA estimators in nonparametric frontier models. Econometric Theory, 24(06): 16631697.

Krasachat, W. (2003). Technical efficiencies of rice farms in Thailand: A nonparametric approach. Presented at the Hawaii International Conference on Business, Honolulu.

Kun, O., Talib, S., and Redzwan, G. (2007). Establishment of performance indicators for water supply services industry in Malaysia. Malaysian Journal of Civil Engineering, 19(1): 73-83. 
Kuteesa, F., Tumusiime-Mutebile, E., and Whitworth, A. (2010). Uganda's economic reforms: Insider accounts. New York, USA: Oxford University Press.

Lambert, K., Dimo, D., and Kambiz, R. (1993). Ownership and sources of inefficiency in the provision of water services. Water Resources Research, 29(6): 1573-1578.

Lane, J. (1994). Public management vs. public administration. Asian Journal of Public Administration, 16 (2): 139-151.

Lane, J. (2000). New public management. London: Routledge.

Laking, R., and Norman, R. (2007). Imitation and inspiration in public sector reform: Lessons from Commonwealth experiences. International Review of Administrative Sciences, 73 (4): 517-530.

Larbi, G. (2001). Performance contracting in practice: Experience and lessons from the water sector in Ghana. Public Management Review, 3 (3): 305-324.

Larson, B., Minten, B., and Razafindralambo, R. (2006). Unravelling the linkages between the millennium development goals for poverty, education, access to water and household water use in developing countries: Evidence from Madagascar. Journal of Development Studies, 42(1): 22-40.

Legard, R., Keegan, J., and Ward, K. (2003). In-depth Interviews. In, Ritchie, J., and Lewis, J (eds), Qualitative research practice. A guide for social science students and researchers. London: Sage Publications. Pp $138-169$.

Lin, C. (2005). Service quality and prospects for benchmarking: Evidence from the Peru water sector. Utilities Policy, 13(3): 230-239. 
Lin, C., and Berg, S. (2008). Incorporating service quality into yardstick regulation: An application to the Peru water sector. Review of Industrial Organization, 32(1): 53-75.

Lin, C., Ma, Y., and Su, D. (2009). Corporate governance and firm efficiency: evidence from China's publicly listed firms. Managerial and Decision Economics, 30(3): 193-209.

Liou, K. (2001). Handbook of public management practice and reform. New York: Marcel Dekker, Inc.

Lobina, E., and Hall, D. (2003). Problems with private water concessions: A review of experience. London, UK: Public Services International Research Unit (PSIRU).

Lovell, K., Jesus, P., and Judi, T. (1995). Measuring macroeconomic performance in the OECD: A comparison of European and non-European countries. European Journal of Operational Research, 87 (3): 507-518.

Lynk, E. (1993). Privatisation, joint production and the comparative efficiencies of private and public ownership: The UK water industry case. Fiscal Studies, 14(2): 98-116.

Lynn, L. (1998). A critical analysis of the new public management. International Public Management Journal, 1(1): 107-123

Madhoo, Y. (2007). International trends in water utility regimes. Annals of Public and Cooperative Economics, 78(1): 87-135.

Malmquist, S. (1953). Index numbers and indifference surfaces. Trabajos de Estadística y de Investigación Operativa, 4 (2): 209-242.

Manning, N. (2001). The legacy of the New Public Management in developing countries. International Review of Administrative Sciences, 67 (2): 297 - 312. 
Marin, P. (2009). Public-Private Partnerships for urban water utilities: A review of experiences in developing countries (No. 8). Trends and Policy Options. Washington D.C, USA: The International Bank for Reconstruction and Development / The World Bank.

Marques, R. (2008a). Comparing private and public performance of Portuguese water services. Water policy, 10(1): 25 - 42.

Marques, R. (2008b). Measuring the total factor productivity of the Portuguese water and sewerage services. Economia Aplicada, 12(2): 251-237.

Mbuvi, D., De Witte, K., and Perelman, S. (2012). Urban water sector performance in Africa: A Stepwise bias-corrected efficiency and effectiveness analysis. Utilities Policy, 22: 31-40, doi:10.1016/j.jup.2012.02.004.

Melyn, W., and Moesen, W. 1991. Towards a synthetic indicator of macroeconomic performance: Unequal weighting when limited information is available. Public Economics Research Paper 17, K.U.Leuven Centrum voor Economische Studiën, Belgium.

Mizutani, F., and Urakami, T. (2001). Identifying network density and scale economies for Japanese water supply organizations. Papers in Regional Science, 80(2): 211-230.

Mollinga, P. (2008). Water, politics and development: Framing a political sociology of water resources management. Water Alternatives, 1(1): 7-23.

Moreira, T., Souza, G., and Faria, R. (2005). Public versus private water utilities: Empirical evidence for Brazilian companies. Economics Bulletin, 8(2): 1 - 7.

Mugisha, S. (2007). Effects of incentive applications on technical efficiencies: Empirical evidence from Ugandan water utilities. Utilities Policy, 15(4): 225-233. 
Mugisha, S. (2008). Infrastructure optimization and performance monitoring: empirical findings from the water sector in Uganda. African Journal of Business Management, 2(1): $13-25$.

Muhairwe, W. (2009). Making public enterprises work: From despair to promise - A turn around account. London, UK: IWA publishing.

Mutunga, C. (2007). Environmental determinants of child mortality in Kenya (Research Paper No. 2007/83), UNU-WIDER, Finland.

Mwanza, D. (2001). Reforming Africa's water and sanitation sector: Issues and challenges. Presented at the $27^{\text {th }}$ WEDC Conference, Lusaka, Zambia.

Mwanza, D. (2005). Promoting good governance through regulatory frameworks in African water utilities. Water Science and Technology: A Journal of the International Association on Water Pollution Research, 51(8): 71-79.

Mwanza, D. (2010). Roles and institutional arrangements for economic regulation of urban water services in Sub-Saharan Africa (Doctoral thesis). Loughborough University, United Kingdom.

MWI (Ministry of Water and Irrigation). (2002). Water Act, No 8. Republic of Kenya.

MWLE (Ministry of Water, Lands and Environment). (1999). A National Water Policy. The Republic of Uganda: Ministry of Water, Lands and Environment.

MWLE. (2001). The urban water supply and sanitation sub-sector: Sector reform paper. Kampala, Uganda: Ministry of Water, Lands and Environment. 
MWLE. (2006). Water and sanitation sector performance report. The Republic of Uganda: Ministry of Water, Lands and Environment.

MWLE. (2007). Water and sanitation sector performance report. The Republic of Uganda: Ministry of Water, Lands and Environment.

MWLE. (2008). Water and sanitation sector performance report. The Republic of Uganda: Ministry of Water, Lands and Environment.

MWR (Ministry of Water Resources). (2001). Ethiopian water sector policy. The Federal Democratic Republic of Ethiopia: Ministry of Water Resources.

Nabakiibi, W., and Schwartz, K. (2009). The management transfer policy in the Ugandan water services sector. In: Schouten, M., Hes, E., and Hoko, Z. Innovative practices in the African water supply and sanitation sector. Stellenbosch, South Africa: SUN MeDIA.

Nardo, M., Saisana,M., Saltelli, A., Tarantola, S., Hoffman, A., and Giovannini, E. (2005). Handbook on constructing composite indicators: Methodology and user guide. OECD Statistics Working Paper 2005/03, OECD Publishing.

Nauges, C., and van den Berg, C. (2007). How "natural" are natural monopolies in the water supply and sewerage sector? Case studies from developing and transition economies (Policy Research Working Paper No. 4137), The World Bank.

Nickson, A. (1997), The public-private mix in urban water supply. International Review of Administrative Sciences, 63 (2): 165-186.

Nickson, A. (1999). Does the NPM work in less developed countries? The case of the urban water supply sector. Journal of International Development, 11 (5): 777-783. 
Nilsson, D. (2006). A heritage of unsustainability? Reviewing the origin of the largescale water and sanitation system in Kampala, Uganda. Environment and Urbanization, 18(2): $369-385$.

NWASCO (National Water Supply and Sanitation Council). (2002). Urban Water and Sanitation Sector Report 2001/2002. Lusaka, Zambia: National Water Supply and Sanitation Council.

NWASCO. (2004a). Regulating water supply and sanitation: Regulatory tools and legislation. Lusaka, Zambia: National Water Supply and Sanitation Council.

NWASCO. (2004b). Water sector reform in Zambia. The Republic of Zambia: National Water Supply and Sanitation Council.

NWASCO. (2005). Urban and peri-urban water supply and sanitation sector report 2004/2005. Lusaka, Zambia: National Water Supply and Sanitation Council.

NWASCO. (2006). Urban and peri-urban water supply and sanitation sector report 2005/2006. Lusaka, Zambia: National Water Supply and Sanitation Council.

NWASCO. (2008). Annual report. National Water Supply and Sanitation Council, The Republic of Zambia.

NWASCO. (2009). Water watch groups: Involving consumers in monitoring water supply and sanitation services in Zambia. Lusaka, Zambia: National Water Supply and Sanitation Council.

NWASCO. (2010a). Urban and peri-urban water supply and sanitation sector report 2009/2010. Republic of Zambia: National Water Supply and Sanitation Council. 
NWASCO. (2010b). 2010 Annual report. Republic of Zambia: National Water Supply and Sanitation Council.

NWASCO. (2011). Urban and peri-urban water supply and sanitation sector report 2010/2011. Republic of Zambia: National Water Supply and Sanitation Council.

NWSC (National Water and Sewerage Corporation). (2001). Review of the technical provisions of the KRIP contract. The Republic of Uganda: National Water and Sewerage Corporation.

NWSC. (2003). Annual report 2002/3. The Republic of Uganda: National Water and Sewerage Corporation.

NWSC. (2004). Annual report 2003/4. The Republic of Uganda: National Water and Sewerage Corporation.

NWSC. (2008). Annual report 2007/2008. National Water and Sewerage Service Corporation, Uganda.

NWSC. (2009a). Annual report 2008/9. The Republic of Uganda: National Water and Sewerage Corporation.

NWSC (2009b). Corporate plan 2009 - 2012. National Water and Sewerage Service Corporation, Uganda.

NWSC. (2010). Annual report 2009/10. The Republic of Uganda: National Water and Sewerage Corporation.

NWSC management. (1999). The 100- Days Programme to improve NWSC services. NWSC corporate management document, The Republic of Uganda. 
Nyarko, K. (2007). Drinking water sector in Ghana: Drivers for performance (Doctoral thesis). Institute of Social Studies and UNESCO-IHE Institute for Water Education.

Nyumbu, I., Mphande, C., Pertz, K., Cummins, K., Helming, S., Mndege, N., Mutasa, E., Jareg, P., and Ravdal, E. (1997). Review of the water sector reforms programme in Zambia: Main report. Government of the Republic of Zambia: Programme Co-ordination Unit.

O'Donnell, C., Rao, D., and Battese, G. (2007). Metafrontier frameworks for the study of firm-level efficiencies and technology ratios. Empirical Economics, 34(2): 231-255.

OECD (Organization for Economic Cooperation and Development). 1995. Governance in transition: Public management reforms in OECD countries, Paris, France: OECD.

Oelmann, M. (2007). Assessment of the current regulatory practices of the Southern and East African water utilities regulators (Synthesis report of a meeting of African water utilities regulators). Lusaka, Zambia.

Opio-Lukone, V. (2003). Uganda's experience with public sector reform. Presented at the 8th Commonwealth Advanced Seminar, Wellington, New Zealand.

Osborne, D. and Gaebler, T. (1992). Reinventing government: How the entrepreneurial spirit is transforming the public sector, Reading, UK: Addison-Wesley.

Osumanu, I. (2008). Private sector participation in urban water and sanitation provision in Ghana: Experiences from the Tamale Metropolitan Area (TMA). Environmental Management, 42(1): 102-110.

Panayotou, T. (1997). The role of the private sector in sustainable infrastructure development. In: Gomez-Echeverri, L. (ed.). Bridges to sustainability: Business and 
government working together for a better environment, Yale School of Forestry and Environmental Studies Bulletin Series 101, New Haven: Yale University.

Paradi, J., Vela, S., and Yang, Z. (2004). Assessing bank and bank branch performance: Modeling considerations and approaches. In Cooper, W., Seiford, L., and Zhu, J. Handbook on Data Envelopment Analysis. New York: Kluwer Academic Publishers.

Parker, D., and Kirkpatrick, C. (2005). Privatisation in developing countries: A review of the evidence and the policy lessons. Journal of Development Studies, 41(4): 513-541.

Parker, D., and Saal, D. (2003). International handbook on privatization. Great Britain: Edward Elgar Publishing, Inc.

Pastor, J., Asmild, M., and Lovell, K. (2011). The biennial Malmquist productivity change index. Socio-Economic Planning Sciences, 45 (1): 10-15.

Pastor, J., and Lovell, C. (2005). A global malmquist productivity index. Economic letters, 88(2): 266-271.

Patashnik, E. (2008). Reforms at risk: What happens after major policy changes are enacted. Princeton, USA: Princeton University Press.

Peck, J. (2004). Geography and public policy: constructions of neoliberalism. Progress in Human Geography, 28(3): 392-405.

Perreault, T. (2006). From the Guerra Del Agua to the Guerra Del Gas: Resource governance, neoliberalism and popular protest in Bolivia. Antipode 38 (1): 150-172.

Pestieau, P., and Tulkens, H. (1993). Assessing and explaining the performance of public enterprises", FinanzArchiv/Public Finance Analysis, 50 (3): 293-323. 
Picazo-Tadeo, A., Sáez-Fernández, F., and González-Gómez, F. (2008). Does service quality matter in measuring the performance of water utilities? Utilities Policy, 16(1): 3038.

Picazo-Tadeo, A., Sáez-Fernández, F., and González-Gómez, F. (2009). The role of environmental factors in water utilities' technical efficiency. Empirical evidence from Spanish companies. Applied Economics, 41 (5): 615 - 628.

Pollitt, C. (2003). The essential public manager, Maidenhead, UK: Open University Press.

Pollitt, C., and Bouckaert, G. (2002). Public management reform: A comparative analysis. New York: Oxford University Press Inc.

Prasad, N. (2006). Privatisation results: Private sector participation in water services after 15 years. Development Policy Review, 24(6): 669-692.

Prasad, N. (2007). Social policy and water sector reform: Markets, business and regulation (Programme paper no. 3), UNRISD, Switzerland.

Prasad, N. 2008. Social policies and private sector participation in water supply: Beyond regulation. New York: Palgrave Macmillan.

Purcell, M. (2008). Recapturing democracy: Neoliberalization and the struggle for alternative urban futures. New York: Routledge.

Raffiee, K., Narayanan, R., Harris, T., Lambert, D., and Collins, J. (1993). Cost analysis of water utilities: A goodness-of-fit approach. Atlantic Economic Journal, 21(3): 18-29.

Rao, D., O'Donnell, C., and Battese, G. (2003). Metafrontier functions for the study of inter-regional productivity differences (No. 01/2003). CEPA Working Paper Series. Australia: School of Economics, University of Queensland. 
Rap, E. (2006). The success of a policy model: Irrigation management transfer in Mexico. Journal of Development Studies, 42(8): 1301-1324.

Ray, S., and Desli, E. (1997). Productivity growth, technical progress, and efficiency change in industrialized countries: Comment. The American Economic Review, 87 (5): 1033-1039.

Richards, T., Doering, E., D`Souza, A., Lang, H., Plumm, H., Schaefer, D., Werchota, R. (2008). Water supply and sanitation sector reforms in Kenya, Tanzania, Uganda and Zambia: Challenges and lessons. Frankfurt: Deutsche Gesellschaft fuer Technische Zusammenarbeit (GTZ) GmbH.

RoU (Republic of Uganda). (1997). The water Act, cap 152. The Republic of Uganda.

RoU. (2008). The local government Act, cap 243. The Republic of Uganda: The Uganda Law Reform Commission.

Ruester, S., and Zschille, M. (2010). The impact of governance structure on firm performance: An application to the German water distribution sector. Utilities Policy, 18(3): $154-162$.

Rusaw, A. (2001). Four models of public sector change. In, Liou, K. Handbook of public management practice and reform. New York: Marcel Dekker, Inc.

Saal, D., and Parker, D. (2000). The impact of privatization and regulation on the water and sewerage industry in England and Wales: A translog cost function model. Managerial and Decision Economics, 21(6): 253-268.

Saal, D., and Parker, D. (2001). Productivity and price performance in the privatized water and sewerage companies of England and Wales. Journal of Regulatory Economics, 20(1): $61-90$. 
Saal, D., and Parker, D. (2004). The comparative impact of privatization and regulation on productivity growth in the English and Welsh water and sewerage industry, 1985-99. International Journal of Regulation and Governance, 4(2): 139 - 170.

Saal, D., Parker, D., and Weyman-Jones, T. (2007). Determining the contribution of technical change, efficiency change and scale change to productivity growth in the privatized English and Welsh water and sewerage industry: 1985-2000. Journal of Productivity Analysis, 28(1): 127-139.

Saisana, M., and Tarantola, S. (2002). State-of-the-art report on current methodologies and practices for composite indicator development. Institute for the Protection and Security of the Citizen Technological and Economic Risk Management, EC Joint Research Centre, Italy.

Santhakumar, V. (1998). Inefficiency and institutional issues in the provision of merit goods: A case study of public water supply in rural Kerala. Centre for Development Studies, India.

SAPRIN (The Structural Adjustment Participatory Review International Network). (2004). Structural adjustment: The SAPRI report: The policy roots of economic crisis, poverty and inequality. London \& New York: Zed Books.

Savenije, H. (2002). Why water is not an ordinary economic good, or why the girl is special. Physics and Chemistry of the Earth, 27(11): 741-744.

Savoie, J. (1995). What is wrong with the New Public Management. Canadian Public Administration, 38 (1): 112 - 121.

Schaub-Jones, D. (2008). Harnessing entrepreneurship in the water sector: Expanding water services through independent network operators. Waterlines, 27(4): 270-288. 
Schouten, M. (2009). Strategy and performance of water supply and sanitation providers: Effects of two decades of neo-liberalism (Doctoral thesis). Erasmus Universiteit Rotterdam.

Schouten, M., and Buyi, T. (2010). 100-days rapid change initiatives in African public water utilities. International Journal of Public Sector Management, 23(5): 431 - 443.

Schwartz, K. (2006). Managing public water utilities: An assessment of bureaucratic and New Public Management models in the water supply and sanitation sectors in low- and middle-income countries (Doctoral thesis). Erasmus University Rotterdam.

Schwartz, K. (2008). The new public management: The future for reforms in the African water supply and sanitation sector? Utilities Policy, 16 (1): 49-58.

Scott, W. (2001). Institutions and organizations (2nd Ed). California: Sage Publication, Inc.

Seppala, O., Hukka, J., and Katko, T. (2001). Public-private partnerships in water and sewerage services: Privatization for profit or improvement of service and performance? Public Works Management and Policy, 6(1): 42-58.

Shaoul, J. (1997). A critical financial analysis of the performance of privatized industries: The case of the water industry in England and Wales. Critical Perspectives on Accounting, 8(5): 479-505.

Shephard, R. (1970). Theory of cost and production functions. Princeton: Princeton University Press.

Sherman, H., and Zhu, J. (2006). Service productivity management: Improving service performance using Data Envelopment Analysis (DEA).New York, USA: Springer Science+Business Media, LLC. 
Sheshinski, E., and Lòpez-Calva, L. (2003). Privatization and its benefits: Theory and evidence. CESifo Economic Studies, 49 (3): 429 - 459.

Shestalova, V. (2003). Sequential Malmquist indices of productivity growth: An application to OECD industrial activities. Journal of Productivity Analysis, 19 (2-3): 211 226.

Shwartz, M., Burgess, J., and Berlowitz, D. (2010). Benefit-of-the-doubt approaches for calculating a composite measure of quality. Health Services and Outcomes Research Methodology, 9(4): 234-251.

Simar, L., and Wilson, P. (1998). Sensitivity analysis of efficiency scores: How to bootstrap in nonparametric frontier models. Management Science, 44 (1): 49 - 61.

Simar, L., and Wilson, P. (1999). Estimating and bootstrapping Malmquist indices. European Journal of Operational Research, 115 (3): 459-471.

Simar, L., and Wilson, P. (2007). Estimation and inference in two-stage, semi-parametric models of production processes. Journal of Econometrics, 136(1): 31-64.

Simar, L., and Wilson, P. (2011). Performance of the bootstrap for DEA estimators and iterating the principle. In Cooper, W., Seiford, L., and Zhu, J. Handbook on Data Envelopment Analysis ( ${ }^{\text {nd }}$ Ed). New York, Springer.

Simon, H. (1957). Models of man: Social and rational; Mathematical essays on rational human behavior in a social setting. New York: Wiley.

Smith, L. (2004). The murky waters of the second wave of neoliberalism: corporatization as a service delivery model in Cape Town. Geoforum, 35(3): 375-393.

Smith, P (1990). Data envelopment analysis applied to financial statements, Omega, 18 (2): 131-138 
Solo, T. (2003). Independent water entrepreneurs in Latin America: The other private sector in water services. Washington D.C, USA: World Bank.

Souza, G., Faria, R., and Moreira, T. (2007). Estimating the relative efficiency of Brazilian publicly and privately owned water utilities: A stochastic cost frontier approach. Journal of the American Water Resources Association, 43(5): 1237-1244.

Souza, G., Faria, R., and Moreira, T. (2008). Efficiency of Brazilian public and private water utilities. Estudos Econômicos (São Paulo), 38 (4): 905-917.

Spiller, P., and Savedoff, W. (1999). Government opportunism and the provision of water. In, Savedoff, W., and Spiller, P. Spilled water: Institutional commitment in the provision of water services. Washington, D.C: Inter-American Development Bank.

Spronk, S. (2010). Water and sanitation utilities in the global south: Re-centering the debate on "Efficiency." Review of Radical Political Economics, 42(2): 156 -174.

SUEZ. (2003). SUEZ introduces its 2003-2004 Action Plan: Refocus, reduce debt, increase profitability. PR Newswire, Paris.

Swyngedouw, E. (2004). Social power and the urbanization of water: Flows of power. Oxford, UK: Oxford University Press.

Swyngedouw, E. (2009). Troubled waters: The political economy of essential public services. In Castro, J., and Heller, L. Water and sanitation services: Public policy and management. London: Earthscan Ltd. Pgs 38 - 55.

Talbot, J. 2002. Is the international water business really a business? Presented at the World Bank water and sanitation lecture series, 13th February. Retrieved from: http://info.worldbank.org/etools/docs/voddocs/96/189/SAUR.pdf (April, 2012). 
Teeples, R, and Glyer, D. (1987). Cost of water delivery systems: Specification and ownership effects. The Review of Economics and Statistics, 69(3): 399-408.

Thanassoulis, E., Portela, M., and Allen, R. (2004). Incorporating Value Judgments in DEA. In Cooper, W., Seiford, L., and Zhu, J, Handbook on Data Envelopment Analysis, Boston: Kluwer Academic Publishers.

Thynne, I. (2000). The state and governance: Issues and challenges in perspective. International Review of Administrative Sciences, 66(2): 227 -240.

Tisdell, C., and Hartley, K. (2008). Microeconomic policy: A new perspective. Great Britain: Edward Elgar Publishing Limited.

Tone, K (2004). Malmquist productivity index: Efficiency change over time. In Cooper, W., Seiford, L., and Zhu, J. Handbook on Data Envelopment Analysis, Boston: Kluwer Academic Publishers.

Tupper, H., and Resende, M. (2004). Efficiency and regulatory issues in the Brazilian water and sewage sector: An empirical study. Utilities Policy, 12(1):29-40.

Twort, A., Ratnayaka, D., and Brandt, M. (2000). Water supply (5th Ed). Elsevier Ltd, London.

Tynan, N., and Kingdom, B. (2002). A water scorecard: Setting performance targets for water utilities (Public Policy for the Private Sector Note No. 242), The World Bank.

UN-Water., and WWAP. (2006). National water development report: Uganda (A report prepared for the 2nd UN-World Water Development Report, Water, a shared responsibility). UN-Water and WWAP. 
UNDP (United Nations Development Programme). (2006). Beyond scarcity: Power, poverty and the global water crisis. Human Development Report 2006. New York: Palgrave Macmillan.

UNESCO., and Earthscan. (2009). Water in a changing world: The United Nations world water development report 3. Paris, France and London, United Kingdom: United Nations Educational Scientific and Cultural Organization and Earthscan publishing.

UNICEF (United Nations Children's Fund) and., WHO (World Health Organization). (2011). Drinking water: Equity, safety and sustainability. New York: UNICEF and WHO.

United Nations. (2010). The human right to water and sanitation (A/RES/64/292), United Nations.

UNSGAB (United Nations Secretary-General's Advisory Board). (2006). Hashimoto action plan: Compendium of actions. United Nations Secretary-General's Advisory Board on Water and Sanitation.

URT (United Republic of Tanzania). (2009). The water supply and sanitation Act, No. 12. Dar Es Salaam, The United Republic of Tanzania.

Van Dijk, M. (2006). Managing cities in developing countries: The theory and practice of urban management. Great Britain: Edward Elgar.

Van Donge, J. (2002). Agencification, In: Kirkpatrick, C., Clarke, R. and Polidano, C. (eds.), Handbook on development policy and management, Northampton: Edward Elgar Publishing. 
Vining, A., and Boardman, A. (1992). Ownership versus competition: Efficiency in public enterprise. Public Choice, 73(2): 205-239.

Walsh, K. (1995). Public services and market mechanisms: Competition, contracting and the new public management. United Kingdom: Macmillan Press Ltd.

Walter, M., Cullmann, A., Hirschhausen, C., Wand, R., and Zschille, M. (2009). Quo vadis efficiency analysis of water distribution? A comparative literature review. Utilities Policy, 17 (3-4): 225 - 232.

Wang, H., Wu, W., and Zheng, S. (2011). An econometric analysis of private sector participation in China's urban water supply. Utilities Policy, 19 (3): 134-141.

Waterson, M. (1988). Regulation of the firm and natural monopoly. United Kingdom: Basil Blackwell Ltd.

WDI (World Development Indicators)., and GDF (Global Development Finance). (2010). GDP per capita, PPP (current international \$). Retrieved from:

$\mathrm{http} / / /$ search.worldbank.org/quickview?name $=\mathrm{GDP}+$ per+capita\%2C $+\mathrm{PPP}+\% 28$ current $+\mathrm{i}$ nternational+\%24\%29\&id=NY.GDP.PCAP.PP.CD\&type=Indicators\&qterm=purchasing +power+parity (June 2010).

WHO (World health Organization)., and UNICEF (The United Nations Children's Fund). (2000). Global water supply and sanitation assessment 2000 report. USA: World Health Organization and United Nations Children's Fund.

Wilson, P. (2010). Package 'FEAR'. Retrieved from:

http://www.clemson.edu/economics/faculty/wilson/Software/FEAR/FEAR-1.13/FEARmanual.pdf [January, 2011]. 
Woodbury, K., and Dollery, B. (2004). Efficiency measurement in Australian local government: The case of New South Wales municipal water services. Review of Policy Research, 21(5): 615-636.

World Bank. (1994). World development report 1994: Infrastructure for development. Washington D.C, USA: Oxford University Press.

World Bank. (1997). Toolkits for private participation in water and sanitation. Washington D.C, USA: World Bank.

World Bank. (2005). Water supply and sanitation lending: Volume rises, quality remains high. Water Supply and Sanitation Feature Story.

World Bank. (2009). IDA at work: Uganda (No. 52007). Washington D.C, USA: World Bank.

WSP-WB (Water and Sanitation Program-Africa of the World Bank). (2009). Water operators partnership: Africa utility performance assessment. Nairobi, Kenya: The World Bank/UN Habitat/ESAR/AfWA.

WUP (Water Utility Partnership). (2001). Strengthening capacity of water utilities to provide water supply and sanitation services, environmental and hygiene education in a sustainable way to low income urban areas: Case study of Lusaka Water and Sewerage Company. Abidjan, WUP.

Yatchew, A. (1998), Nonparametric regression techniques in economics. Journal of Economic Literature 36 (2): 669-721.

ZWP (Zambia Water Partnership). (2008). Zambia water directory. Zambia: WASAZA, ZWP and Global Water Partnership Southern Africa. 
Zanetta, C. (2001). The evolution of the World Bank's urban lending in Latin America: from sites and services to municipal reform and beyond. Habitat International, 25 (4): $513-533$. 


\section{Appendixes}

\section{Appendix 1: Key informants interview guide}

\section{Section 1: Informant Background Information}

This introductory part seeks to understand the main roles (including the objectives and influence) of the different actors/stakeholders, in the operations and management of urban water and sanitation provision.

1. Which organization do you work for?

2. What is your current position?

3. How would you describe your organization in terms of ownership?
(i) Public
(ii) Private
(iii) NGO
(iv) Cooperating development partner
(v) Other (please state which)

4. How would you describe your organization in terms of Management?

(i) Public (ii) Private (iii) NGO (iv) Cooperating development partner

(v) Other (please state which)

5. What activities does your organization get involved in, in light of the Ugandan water supply and sanitation?
a)
b)
d)
e)
f)

6. For how long have you worked in your current position? years / months

\section{Section 2: Reforms Evolution within the Urban Water Sub-Sector}

This section investigates first; the evolution of sub-sector reforms (reform context) and secondly, the major differences (from the reforms design, implementation to present outcomes) based on the specific reform parameters, within (and across) the urban water sub-sectors.

7. In your opinion, has the Ugandan urban water sub-sector been restructured/reformed?
(i) Yes
(ii) $\mathrm{No}$
(iii) Not sure
(iv) I do not know

(If YES, please continue....)

8. When were the reforms (i) initiated (ii) implemented $?$

9. How can you grade the pre-reform urban water and sanitation sub-sector performance?
(i) Very poor
(ii) Poor
(iii) Medium
(iv) Good
(v) Very good 
10. Why do you think so? In other words, what were the characteristics/nature of the pre-reform sub-sector set-up and performance?

11. In your opinion, what were the main reform drivers at both sub-sector and/or utility level (and who made related decisions/drove the reforms)? 
12. In your opinion, what were the main reform objectives and expected outcomes (in order of priority - where 1 denotes of the highest priority and 10 denotes of the least priority)? Why were the decisions made or what drove the decisions? Who made the decisions? Who approved (or approves) the decisions? Are the decisions amended? How often? By whom?

\begin{tabular}{|c|c|c|c|c|c|}
\hline Reform objective & Expected outcome & Why decisions were made & Who made the decisions & Who approves decisions & Decision amendment \\
\hline & & & & & \\
\hline & & & & & \\
\hline & & & & & \\
\hline & & & & & \\
\hline & & & & & \\
\hline & & & & & \\
\hline & & & & & \\
\hline & & & & & \\
\hline & & & & & \\
\hline & & & & & \\
\hline & & & & & \\
\hline & & & & & \\
\hline
\end{tabular}




\section{Section 3: Reform Implementation}

13. In your opinion, how were the reform decisions (stated in 12) initiated and implemented at the sector and/or utility levels? Have the originally designed reform objectives been implemented as planned? Why?

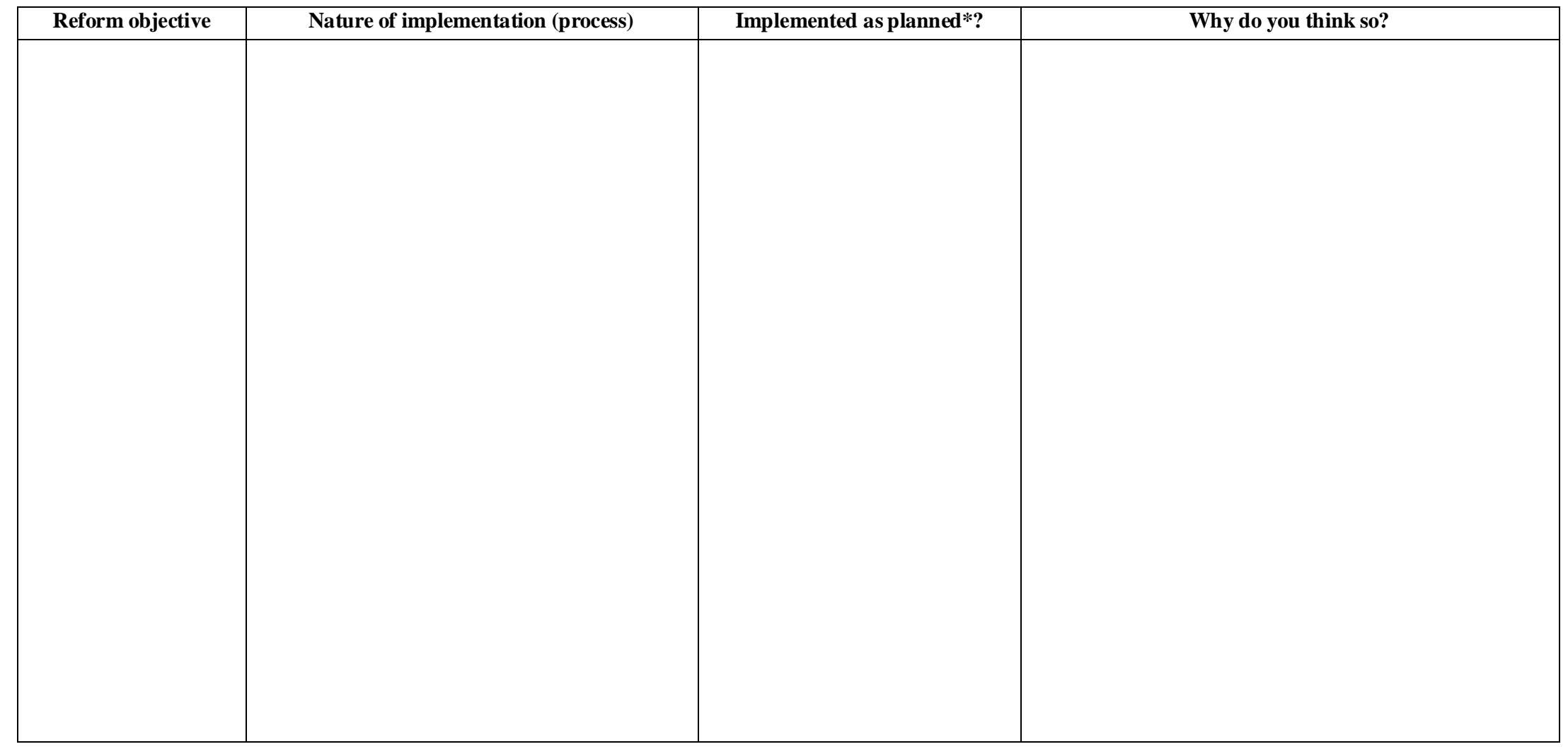

$\begin{array}{llll}* \text { (i) } \text { Yes } & \text { (ii) No } & \text { (iii) Not sure } & \text { (iv) I do not know }\end{array}$ 


\section{Section 4: Stakeholder(s) opinion on the Reform Process}

14. What do you think of the overall implemented reform programmes within the Ugandan urban water sector? Have they led to increased performance?
(i) Very slightly
(ii) Slightly
(iii) Medium
(iv) Much
(v) Very much

14.1. Why do you think so? (Please expound your answer)

15. Under whose management mandate is the service provision role in the Ugandan urban water sector?
(i) Public
(ii) Private
(iii) Non-governmental
(iv) Cooperating development partner
(v) Other (please state)

16. What do you think of the present service provision management model adopted for the urban water sector in Uganda? (large/small towns WSS management, etc)
(i) Very bad idea
(ii) Bad idea
(iii) Not bad \& not good idea
(iv) Good idea
(v) Very good idea

16.1. Why do you think so? (Please expound your answer)

17. Under whose ownership mandate are the assets in water service provision?
(i) Public
(ii) Private
(iii) Non-governmental
(iv) Cooperating development partner
(v) Other (please state)

18. What do you think of the present ownership (of assets) model adopted for the urban water sector in Uganda? (NWSC, DWD, etc)
(i) Very bad idea
(iv) Good idea
(ii) Bad idea (iii) Not bad \& not good idea
(v) Very good idea

18.1. Why do you think so? (Please expound your answer)

19. What do you think of involving the private sector in water provision in Uganda?
(i) Very bad idea (go to 19.2)
(ii) Bad idea (go to 19.2)
(iii) Not bad \& not good idea (go to 19.2)
(iv) Good idea (go to 19.1)

(v) Very good idea (go to 19.1) 
19.1. At what level or how should the private sector be involved in WSS delivery? (go to 19.2)

19.2. Why do you think so?

20. What is the process/procedure of the management transfer arrangement from small to large town management?

20.1. In your opinion, what problems or challenges does such management transfer arrangement face or what problems or challenges evolve as a result of such management transfer arrangement? $\rightarrow$ to the receiving provider (NWSC), sending/previous provider and the (iii) urban water sector?

21. Is the present sector financing sustainable/sufficient now \& in the future?
(i) Yes
(ii) $\mathrm{No}$
(iii) Not sure
(iv) I do not know

21.1. Why do you think so? (Please expound your answer)

22. Do you think the current global financial crisis have had any impact on the financial sustainability of the sector and/or utility operations?
(i) Yes (go to 22.1)
(ii) No (go to 22.2)
(iii) Not sure (go to 22.2)
(iv) I do not know (go to 23)

22.1. If YES, to what extent? (Go to 22.2)
(i) Very badly
(ii) Badly
(iii) Medium
(iv) Not badly
(v) Not very badly 
22.2. Why do you think so? In other words, since when and in what ways have the fiscal crisis impacted the sector or utilities operations' sustainability?

23. What do you think of the present regulatory arrangement within the Ugandan urban water sector?
(i) Very bad idea
(ii)
Bad idea
(iv) Good idea
(v) Very good idea
(iii) Not bad \& not good idea

23.1. Why do you think so? (Please expound your answer)

24. Does there exist any incentive programme to WSPs/customers for performance improvement?
(i) Yes
(ii) No
(iii) Not sure
(iv) I do not know

24.1. What is the nature of the incentive programme?

25. To what extent do the urban poor customers (low cost and peri urban customers) benefit from the reform programmes?
(i) Very low
(ii) Low
(iii) Medium
(iv) Highly
(v) Very highly

25.1. Why do you think so?

26. In your opinion, how are the water user charges to the urban poor customers?
(i) Very low
(ii) Low
(iii) Medium
(iv) High
(v) Very high

27. In your opinion, how is the quality of the water supplied by the water providers to the urban customers?
(i) Very poor
(iv) Good
(ii) Poor
(v) Very good
(iii) Medium 
28. In your opinion, do customers treat their water before drinking?

(i) Yes (which customer types? how? and why?)
(ii) No
(iii) Not sure
(iv) I do not know

29. Is there a difference in water quality between the urban rich and urban poor customers?
(i) Yes
(ii) No
(iii) Not sure
(iv) I do not know

29.1. Why do you think so?

30. Whom does your organization deal directly with? (i) Customers (ii) Service providers (iii) Others

30.1. At what level?

31. In what ways does your organization receive or/and communicate with water service providers and/or customers?

32. Does your organization keep customer complaints records?
(i) Yes
(ii) No
(iii) Not sure
(iv) I do not know

32.1. What are the main causes of complaints? 
33. In your opinion, what problems, limitations or challenges encounter the successful initiation and/or implementation of the reform programmes (stated in 12)?

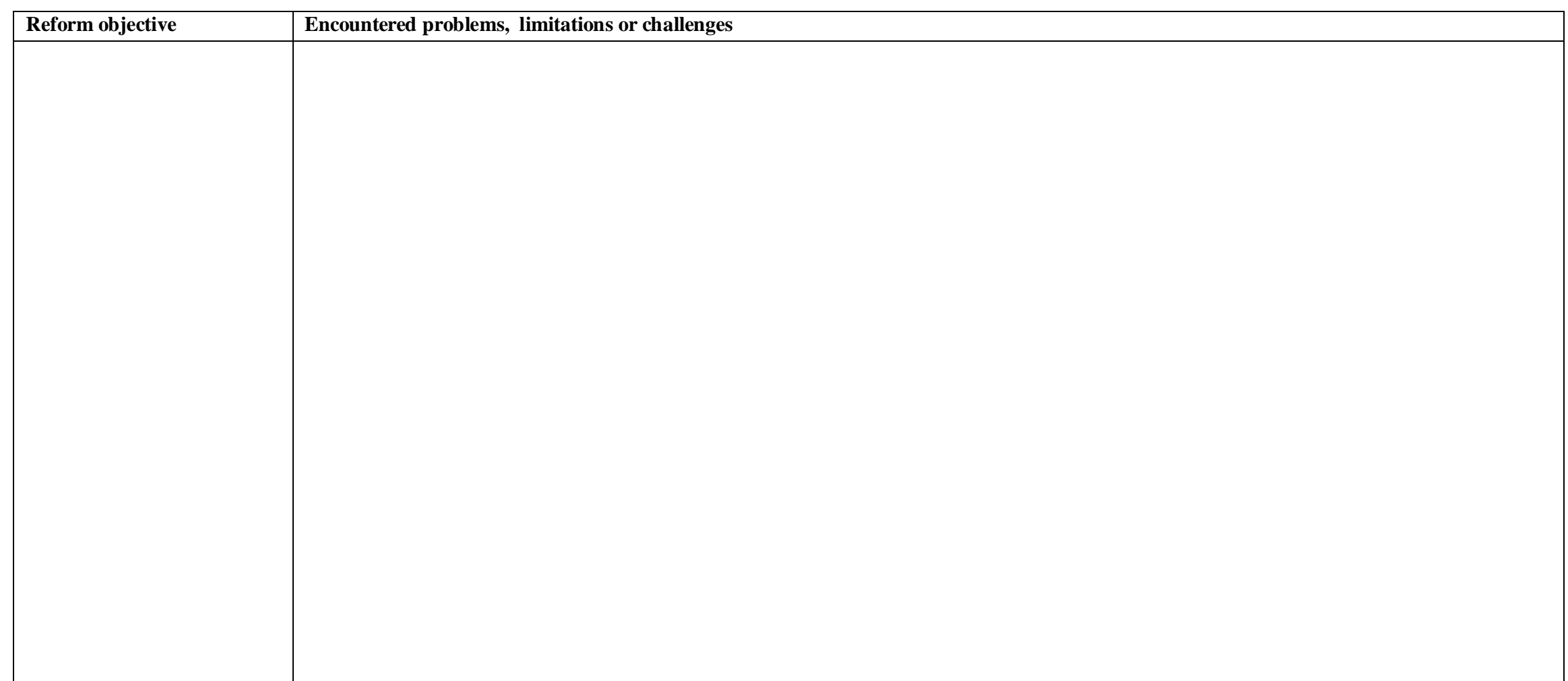

Thank you very much!! 


\section{Saamenvatting}

\section{[1] Voornaamste bevindingen}

De stedelijke watersectoren in de meeste ontwikkelingslanden, en met name in Afrika, zijn op verschillende manieren getransformeerd met de opkomst van de neoliberale ideologieën. Deze zijn sinds de jaren '90 voorgesteld en op uiteenlopende wijzen op het continent ingevoerd (zie Sectie 1.2.2). Beleidsvormers binnen de sector (en alle geïnteresseerde belanghebbenden) moeten de aard van deze transformaties begrijpen, alsook hun invloed op de huidige beheersstructuren en hun rol in de verbetering van de openbare voorzieningen (zie Sectie 1.3). Met deze thesis proberen we deze complexe zaken te vast te stellen en waardevolle inzichten te bieden. We gebruiken hierbij zowel kwalitatieve (interviews sleutelinformanten) als kwantitatieve (non-parametrische) benaderingen (zie Sectie 1.4).

Gebaseerd op de uitkomst van het onderzoek trekken we vijf hoofdconclusies. Ten eerste is de herstructurering van de stedelijke watervoorziening (hierna WU genoemd) voornamelijk een politiek proces tussen actoren op verschillende beleidsniveaus. Hoewel deze bevinding niet uniek is, zullen we in Hoofdstuk 2 interessante trends bespreken. Omdat verschillende belanghebbenden op het niveau van het wereldwijde beleid meerdere agenda's en belangen hebben wat betreft de hervormingen, zijn er voldoende mogelijkheden voor actoren op het nationaal beleidsniveau om (i) deze hervormingsstrategieën selectief toe te passen zoals het beste aansluit bij de beleidsbelangen van hun land/sector/voorziening, en (ii) die strategieën tegen te houden die de organisatorische autonomie bedreigen. Bovendien, terwijl machtsrelaties tussen actoren (zowel wereldwijd als landelijk) door de tijd heen veranderen, veranderen ook de respectievelijke onderhandelingsposities en uiteindelijk de daaruit volgende hervormingsdynamica. Zo ontstaat er op specifieke momenten de mogelijkheid om hervormingstrajecten te voegen naar de heersende belangen van de machtigste betrokkene(n) op zowel het wereldwijde als het nationale beleidsniveau. In Hoofdstuk 2 worden deze ontwikkelingen besproken aan de hand van de casus van de stedelijke watersector in Oeganda.

Ten tweede is de intensiteit en de aard van het WU-hervormingsproces afhankelijk van de aanhoudende samenwerking van vier onderling afhankelijke beheersstructuren. Gezien de gangbare middelen/infrastructuur of technologie, zal de interactie tussen het beleid, de instellingen en organisaties verschillen in snelheid en mate. Zoals in Hoofdstuk 3 wordt 
besproken, vertalen deze zich naar grote en kleine bestuursveranderingen binnen de stedelijke watervoorzieningssector. Dit wordt geillustreerd met een casus van de stedelijke watervoorziening in Zambia.

Ten derde zijn de prestaties van de openbare sector sinds eind jaren '90 voornamelijk verbeterd door de traditioneel gezien overheersende instellingen te versterken met privé-management. In Hoofdstuk 4 bestuderen we twee WU-groepen die beide een andere vorm van eigendom en management kennen. In plaats van de voorzieningsgroep die zowel in openbare als in private handen is, is juist de groep die geheel in openbaar bezit is efficiënter wat betreft de technische output. Om zo dicht mogelijk bij de best practice frontier te komen, zou de eerste groep de huidige output met de bestaande middelen moeten verhogen met 36 procent, vergeleken met de 22 procent binnen de voorzieningen die geheel in openbaar bezit zijn.

Daarbij komt de werkwijze van de voorzieningsgroep die geheel in openbaar bezit is dichter bij de zogenaamde best practice technologie, die voor beide voorzieningsgroepen voor handen is, zoals gedefinieerd door de metafrontier. Vergeleken met de groep die zowel in openbare als private handen is, heeft de gemiddelde voorziening in openbaar bezit minder te maken met beperkende werkomgevingen dan de gemiddelde voorziening die zowel in openbare als in private handen is. Vergeleken met deze laatste groep zijn de voorzieningen die geheel in openbaar bezit zijn in Oeganda desondanks grotendeels zelfregulerend, naast het regelmatige toezicht van het Ministerie van Water en Omgeving. Dit creëert en onderhoudt een druk binnen de voorziening om op of dicht bij de best practice frontier te werken. Aan de andere kant, echter, werken deze voorzieningen grotendeels verminderende regio's in schaalvoordelen.

Naast de toename in technische efficiëntie door de hervormingen binnen de Oegandese stedelijke watersector - zie Hoofdstuk 4 - ondervinden voorzieningen ten vierde een positieve groei in productiviteit. Aan de hand van de casussen van stedelijke WU's in zowel Zambia en Oeganda (geheel in openbaar bezit), wordt de toename in productiviteit meer toegeschreven aan positieve veranderingen binnen de technische efficiëntie dan aan technische veranderingen of schaalveranderingen. Zie Hoofdstuk 5. Maar wanneer voorzieningen de waterleidingen per 
netwerk verlengen, meters installeren en hoofdleidingen onderhouden, neemt de groei in productiviteit af, in ieder geval op korte termijn.

Ten vijfde kunnen toegenomen prestaties van WU's het resultaat zijn van toename in zowel efficiëntie als effectiviteit. In Hoofdstuk 6 worden deze prestatiecomponenten ontward en uitgelegd. Zoals ook in dit hoofdstuk naar voren komt, is de ontwikkeling van de landseconomie het belangrijkste voor de verbeteringen in efficiëntie en effectiviteit van de voorzieningen.

\section{[2] Onderverdelingen en aanbevelingen van het beleid}

Rationele beleidsvormers krijgen onder andere te maken met problemen op het gebied van beperkte rationaliteit (Simon, 1957). Ze hebben een gebrek aan voorkennis van wat het resultaat zou kunnen zijn van nieuw-bedachte hervormingsprojecten. De kennisvergaring is aan de ene kant begrensd door hun beperkte cognitieve vaardigheden en aan de andere kant door de omgeving (overheersende of toekomstige sociaal-economische en politieke ontwikkelingen). Met deze onzekerheden, die in hoge transactiekosten resulteren, proberen hervormers op alle beleidsniveaus strategische allianties te sluiten met specifieke actoren. Zoals bewezen in Hoofdstuk 2 hebben deze allianties, tussen voorheen zwakke nationale actoren en de machtigste actoren op het wereldwijde beleidsniveau, tot gevolg dat de voorheen zwakke actoren sterker worden. Dit verandert de spelregels voor bepaalde actoren en bepaalde periodes. De specifieke vormen van deze allianties en machtsverschuivingen op bepaalde momenten zijn echter dynamisch en op gemiddelde tot lange termijn nauwelijks te voorspellen.

Naast de inherente politiek wat betreft de stedelijke watervoorziening kunnen een zorgvuldige identificatie en analyse van de veranderingen in het onderliggende beheer, die op specifieke momenten hervormingsprocessen samenvatten, extra inzicht bieden. Dergelijke inzichten, zoals die in Hoofdstuk 3 worden besproken, laten grote en kleine verschuivingen in het beheer zien voor een beter begrip van het hervormingsproces.

Wat de organisatie van de stedelijke watersector in Afrika betreft, is een dekking van universeel kwalitatieve diensten (nog steeds) mogelijk onder het nieuwe openbare management (zie Hoofdstuk 4). Ten eerste is het onwaarschijnlijk dat er in de nabije toekomst vanuit de 
privésector wordt geïnvesteerd in de watersector, gezien het een onaantrekkelijke bedrijfstak is. Ten tweede hebben zowel openbare als private monopolies te maken met een vergelijkbare principaal-agentproblematiek die agenten motiveert om gebruik te maken van de natuurlijke informatie-symmetrie en winstgevende huur af te dwingen ten koste van de principaal (en vervolgens de klanten). Ten derde heeft de versterking van de privé-ethos (instellingen) binnen de traditionele openbare ondernemingen, waaronder het gebruik van tijdgebonden contracten, de regulering van de sector verminderd. Onder andere het competitief bieden voor de stedelijke watermarkt en benchmarking op basis van wederzijds gestelde prestatiedoelen hebben het mogelijk gemaakt om de toegang tot de markt te reguleren, als ook de producten die op de markt worden geproduceerd en de voorzieningen die daarbinnen actief zijn.

Ten vierde is het waarschijnlijk dat de betrokkenheid van de actieve openbare sector bij en de subsidiëring van de watervoorziening via leidingen in Afrika, zoals in de meeste ontwikkelde economieën (Prasad, 2008; Checchi et al., 2009) zal aanhouden (Bayliss and McKinley, 2007; Castro, 2008; Swyngedouw, 2009). Inderdaad, de openbare sector verschaft watervoorzieningen aan meer dan 90 procent van de wereldbevolking (WHO and UNICEF, 2000; Prasad, 2006). Daarnaast, als watervoorzieningssystemen die niet in openbaar bezit zijn worden verlaten of failliet gaan, dan wordt er van de overheid verwacht om dergelijke systemen over te nemen en te beheren. Daarom is het nodig dat de capaciteiten van de openbare sector in Afrika, alsook andere minder ontwikkelde regio's, worden versterkt voor de voorziening van inclusieve, betrouwbare en houdbare watervoorzieningen.

Hoewel benchmarking, waaronder het gebruik van analyses van de productiviteitstoename (zie Hoofdstuk 5), bijdraagt om de prestaties van voorzieningen te onderscheiden, heeft het niet automatisch tot gevolg dat de prestaties van de geanalyseerde bedrijven ook verbeteren. Desondanks geeft het proces beleidsmakers de mogelijkheid om eerst te ontdekken waar ze op efficiëntie kunnen winnen - voor zowel inefficiënte als efficiënte voorzieningen. Om op de best practice frontier te werken met de huidige input, kunnen inefficiënte voorzieningen gebruik maken van een toegenomen technische efficiëntie in de volgende periodes $(t+n)$ relatief aan de basisperiode $(\mathrm{t})$. Aan de andere kant kunnen efficiënte voorzieningen tijdens de basisperiode hun innovatie verbeteren om meer output te creëren met de huidige input, relatief aan de totale 
technologie. Daarbij kunnen voorzieningen ervoor kiezen om op de technologisch optimale schaal te werken met de beschikbare technologie en voordeel te halen van schaaleconomieën.

Ten tweede bevordert deze oefening de identificatie van diverse prikkels voor productiviteitsveranderingen op, maar niet beperkt tot, de voorzieningsniveaus. Ten derde kan men verbanden leggen tussen de geschatte productiviteitsveranderingen met verschillende doelen op het gebied van efficiëntie (bijvoorbeeld waterverlies) en effectiviteit (bijvoorbeeld de spreiding van de voorziening) op het niveau van de voorzieningen. Dit zorgt voor extra inzicht of de productiviteitstoename veroorzaakt is door een verbeterde (in)efficiëntie of (in)effectiviteit.

Ten slotte bestaat er geen compromis tussen efficiëntie en effectiviteit. Stedelijke WU's kunnen hun effectiviteit verbeteren door hun efficiëntie te verhogen. Dit wordt bevestigd in Hoofdstuk 6 . Om dit te bereiken zullen de uitvoerders van de best practices moeten leren. Om de prestatie van de voorzieningen te verbeteren, zouden beleidsmakers en internationale organisaties zoals de Verenigde Naties diverse efficiëntie- en effectiviteitsverbeteraars moeten onderzoeken en aanmoedigen, zoals de nationale welvaart per capita.

Deze thesis kent een aantal beperkingen. Deze worden in Sectie 7.3 genoemd. In deze sectie worden bovendien mogelijke benaderingen besproken voor verder onderzoek. 


\section{MGSoG Dissertation Series}

Lina Salanauskaitè

Distributional Impacts of Public Policies:

Essays in Ex-Ante and Ex-Post Evaluation

MGSoG Dissertation Series, nr 30 (2012)

Esther Schüring

To Condition or not - is that the Question?

An Analysis of the Effectiveness of ex-ante and ex-post Conditionality in Social Cash Transfer

Programs

MGSoG Dissertation Series, nr 29 (2012)

Joe Abah

Strong Organisations in Weak States

Atypical Public Sector Performance in Dysfunctional Environments

MGSoG Dissertation Series, nr 28 (2012)

Zina Samih Nimeh

Social Citizenship Rights: Inequality and Exclusion

MGSoG Dissertation Series, nr 27 (2012)

Lenka Eisenhamerová

Legitimacy of 'Humanitarian Military Intervention'

MGSoG Dissertation Series, nr 26 (2011)

Sonila Tomini

Informal Payments for Health Care Services in Albania

MGSoG Dissertation Series, nr 25 (2011)

Jinjing Li

Dynamic Microsimulation in Public Policy Evaluation

MGSoG Dissertation Series, nr 24 (2011)

Aziz Atamanov

Rural Nonfarm Employment and International Migration as Alternatives to Agricultural Employment: The Case of Kyrgyztan

MGSoG Dissertation Series, nr 23 (2011)

Frieda Vandeninden

Poverty Alleviation: Aid and Social Pensions

MGSoG Dissertation Series, nr 22 (2011)

Juliana Nyasha Tirivayi

The Welfare Effects of Integrating AIDS Treatment with Food Transfers:

Evidence from Zambia 
MGSoG Dissertation Series, nr 21 (2011)

Agnieska Ewa Sowa

Who's Left Behind? Social Dimensions of Health Transition and Utilization of Medical Care in Poland

MGSoG Dissertation Series, nr 20 (2011)

Emmanaouil Sfakianakis

The Role of Private Actors in the Provision of Public Goods with Applications to Infrastructure and Financial Stability

MGSoG Dissertation Series, nr 19 (2011)

Siu Hing Lo

White Collars Green Sleeves

An Interonganizational Compariso of Deteminants of Energie-Related Behaviors among Office Workers

MGSoG Dissertation Series, nr 18 (2011)

Treena $\mathrm{Wu}$

Constraints to Human Capital Investment in Developing Countries:

Using the Asian Financial Crisis in Indonesia as a Natural Experiment

MGSoG Dissertation Series, nr 17 (2011)

Henry Espinoza Peña

Impact Evaluation of a Job-Training Programme for Disadvantaged Youths:

The Case of Projoven

MGSoG Dissertation Series, nr 16 (2011)

Florian Tomini

Between Family and Friends

Understanding the Interdependency of Private Transfers

MGSoG Dissertation Series, nr 15 (2010)

Michał Polalowski

The Institutional Transformation of Social Policy in East Central Europe:

Poland and Hungary in comparative and historical perspective

MGSoG Dissertation Series, nr 14 (2010)

Maha Ahmed

Defining, Measuring and Adressing Vulnerability:

The Case of Post Conflict Environments

MGSoG Dissertation Series, nr 13 (2010)

Pascal Beckers

Local Space and Economic Success

The role of spatial segregation of migrants in the Netherlands 
MGSoG Dissertation Series, nr 12 (2010)

Victor Cebotari

Complicting Demands in Ethnically Diverse Societies

Ethnopolitical Contention and Identity Values in Europe

MGSoG Dissertation Series, nr 11 (2010)

Dennis Gyllensporre

Competing and Complementary Perspectives on the EU as a Crisis Management Actor:

An Examination of the Common Security and Defence Policy through the Lenses of Idealism and Realism

MGSoG Dissertation Series, nr 10 (2010)

Judit Vall Castello

Business Cycle and Policy Effects on Labour Market Transitions of Older and Disabled Workers in Spain

MGSoG Dissertation Series, nr. 9 (2010)

Keetie Roelen

False Positives or Hidden Dimentions: the definition and measurement of child poverty

MGSoG Dissertation Series, nr. 8 (2010)

Denisa Maria Sologon

Earning Dynamics in Europe

MGSoG Dissertation Series, nr. 7 (2010)

Melissa Siegel

Money and Mobility: Migration and Remittances

MGSoG Dissertation Series, nr. 6 (2010)

Jessica S. Hagen-Zanker

Modest Expectations: Causes and effects of migration on migrant households in source countries

MGSoG Dissertation Series, nr. 5 (2010)

Mirtha R. Muniz Castillo

Human Development and Autonomy in Project Aid: Experiences from four bilateral projects in Nigaragua and El Salvador

MGSoG Dissertation Series, nr. 4 (2009)

Christiane Arndt

Governance Indicators

MGSoG Dissertation Series, nr. 3 (2009)

Britta Augsburg

Microfinance - Greater Good or Lesser Evil? 
MGSoG Dissertation Series, nr. 2 (2009)

Geranda Notten

Measuring and Managing Poverty Risks

MGSoG Dissertation Series, nr. 1 (2008) 